\author{
A. S. Tonkoshkur, A. V. Ivanchenko, \\ L. V. Nakashydze, A. Yu. Lyashkov, I. V. Gomilko
}

\title{
APPLICATION OF POLYMER POSISTOR NANOCOMPOSITES IN SYSTEMS FOR PROTECTING PHOTOVOLTAIC COMPONENTS OF SOLAR ARRAYS FROM ELECTRICAL OVERLOADS
}

Monograph 
MINISTRY OF EDUCATION AND SCIENCE OF UKRAINE OLES HONCHAR DNIPRO NATIONAL UNIVERSITY

\author{
A. S. Tonkoshkur, A. V. Ivanchenko, \\ L. V. Nakashydze, A. Yu. Lyashkov, I. V. Gomilko
}

\begin{abstract}
APPLICATION OF POLYMER POSISTOR NANOCOMPOSITES IN SYSTEMS FOR PROTECTING PHOTOVOLTAIC COMPONENTS OF SOLAR ARRAYS FROM ELECTRICAL OVERLOADS
\end{abstract}

Monograph 


\title{
UDC 621.31
}

\author{
Author's: \\ A. S. Tonkoshkur, A. V. Ivanchenko, \\ L. V. Nakashydze, A. Yu. Lyashkov, I. V. Gomilko
}

Is published in accordance with the decision of the Academic Council of the Oles Honchar Dnipro National University (19.11.2020, protocol No. 4)

\section{Reviewers:}

M. M. Dron' - Doctor of Technical Sciences, Professor of the Department of Design and Construction of Oles Honchar Dnipro National University;

V. I. Havryliuk - Doctor of Physical and Mathematical Sciences, Professor, Head of the Department of Automatic and Telecommunication of Dnipro National University of Railway Transport named after Academician V. Lazaryan;

A. I. Nesterenko - Doctor of Physical and Mathematical Sciences, Professor of the Department of Power Engineering of the State Higher Educational Institution "Ukrainian State University of Chemical Technology".

Tonkoshkur A. S., Ivanchenko A. V., Nakashydze L. V., Lyashkov A. Yu., Gomilko I. V. Application of polymer posistor nanocomposites in systems for protecting photovoltaic components of solar arrays from electrical overloads. Monograph. - Primedia eLaunch, Boston, USA, 2021. - 172 p.

Library of Congress Cataloging-in-Publication Data

\section{ISBN - 978-1-63972-054-5}

\section{DOI: 10.46299/978-1-63972-054-5}

The concept of protection of photovoltaic components of solar cells from electric overloads by means of use of resettable fuses on the basis of polymeric nanocomposite materials with nanocarbon fillers is investigated and substantiated.

The suitability of the modern nomenclature of the known commercial specified fuses and the developed combined structures on their basis, in particular two-layer structure varistor-fuse, for the decision of problems of creation of electric protection of photovoltaic systems by circuit means is defined. The efficiency of development of photovoltaic cells with built-in posistor layer on the basis of polymer composites with nanocarbon fillers for prevention of overheating in photovoltaic modules is investigated and shown.

UDC 621:31

ISBN - 978-1-63972-054-5
(C) A. S. Tonkoshkur, A. V. Ivanchenko, L. V. Nakashydze, A. Yu. Lyashkov, I. V. Gomilko, 2021 


\begin{abstract}
ANNOTATION
\end{abstract}
The experience of operating solar arrays indicates the need to solve the problem of creating effective and reliable switching elements to block defective and damaged photovoltaic cells. Available methods of solving this problem (for example, the use of transistor switches, electronic systems, etc.) either do not completely solve it, or are expensive. The tasks of increasing the reliability and efficiency of switching elements, preventing the destruction of photovoltaic cells which occurs during heating by dark current ("hot spots" and fire hazardous situations) are relevant.

Recently, one of the promising solutions of this problem is the use of additional devices for isolating inactive (shaded or defective) areas of both separate photovoltaic cells and their modules. These devices are PPTC (polymeric positive temperature coefficient) resettable fuses of PolySwitch type, which are polymer composites with nanoscale carbon fillers. The basic functional property of PPTC fuse is an abrupt increase in electrical resistance by several orders of magnitude when a temperature is reached and a return to the initial high conductive state when the temperature drops.

The advantages of such structures based on polymer composites with nanocarbon fillers include:

- close to the metal resistance to the switching temperature and to the resistance of the insulator above the specified temperature;

- possibility of realization in the form of discrete elements and continuous filmtapes (that is important at the decision of problems of realization of isolation of defective local area of the separate photovoltaic cell);

- reaction in the form of temporary isolation of separate components of the solar array to increase their temperature.

The research results are presented and the concept of overload protection by using resettable fuses based on polymer nanocomposite materials with nanocarbon fillers is substantiated in this paper. 
In particular, the expediency of series connection of PolySwitch fuses to photovoltaic modules with parallel connection of their strings is shown to prevent an abnormal situation, namely, a complete loss of electrical energy generated by such a string, which can occur when one of its modules is short-circuited. The circuit solutions in the form of combined structure based on layers of a varistor ceramics and a posistor polymer nanocomposite with carbon filler being in thermal contact are investigated. The prospect of its use to protect photovoltaic cells with a high reverse resistance from overvoltage is established. The problem of protection against local overheating in photovoltaic cells (or their parallel connections) by physical and technological methods, in particular, by creating photovoltaic cells with a built-in layer based on a posistor composite being in thermal contact with it, is analyzed.

In general, the described results represent a new direction in the field of improving photovoltaic systems, in particular, in terms of increasing their efficiency, operating time and reliability by using solid-state devices based on polymer posistor nanocomposites and varistor ceramics as means of their protection from electrical and thermal overloads.

Keywords: SOLAR ARRAY, PHOTOVOLTAIC MODULE, PHOTOVOLTAIC CELL, ELECTRIC OVERLOAD, POLYMER POSISTOR NANOCOMPOSITE, HOT SPOT, VARISTOR CERAMICS 


\section{CONTENT}

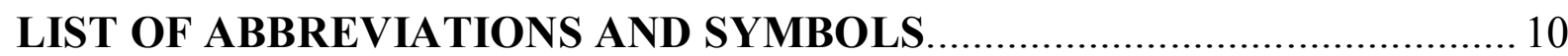

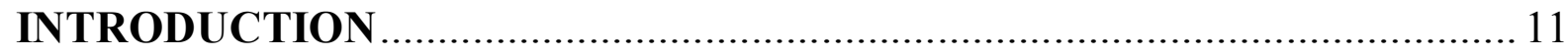

\section{Chapter 1 RELIABILITY PROBLEMS OF SOLAR-BASED}

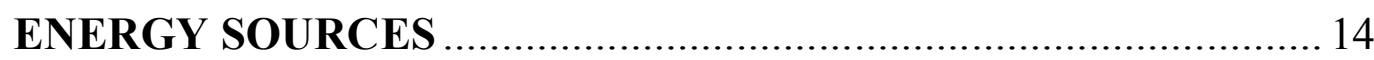

1.1 Brief information about the construction and sources of unreliability

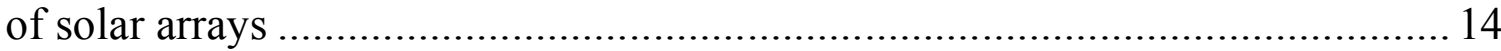

1.1.1 Generalized structure of a solar battery and the main sources

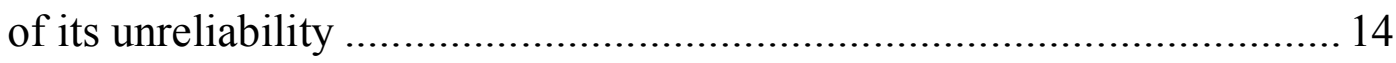

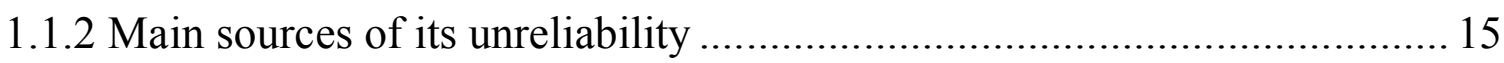

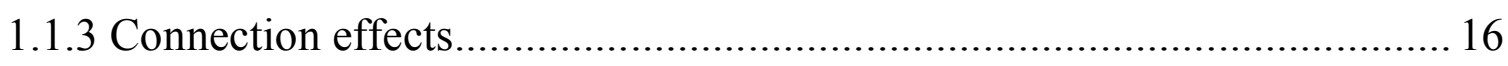

1.1.3.1 Inconsistency of series-connected elements ................................ 17

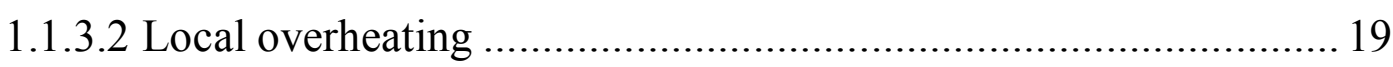

1.1.3.3 Inconsistency of parallel connected elements............................... 21

1.2 Methods and means of minimizing the influence of regime factors

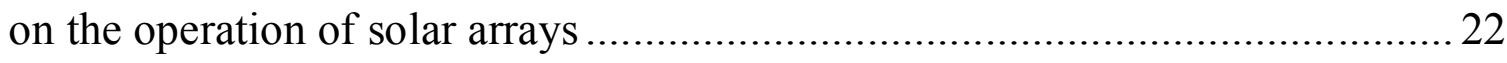

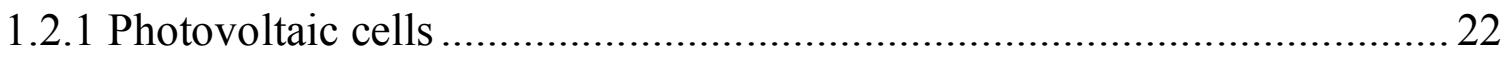

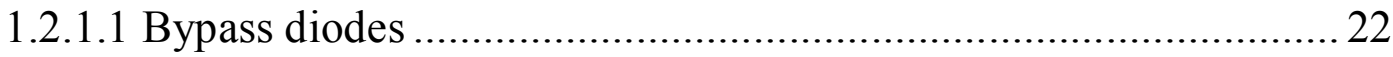

1.2.1.2 Mechanism of formation of "hot spots"....................................... 24

1.2.1.3 Circuitry methods to prevent the appearance of "hot spots" .......... 26

1.2.1.4 Physical and technological methods to prevent

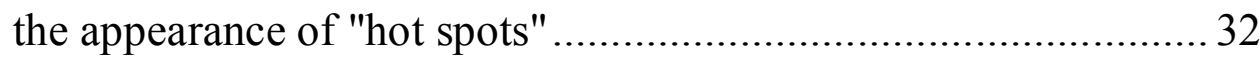

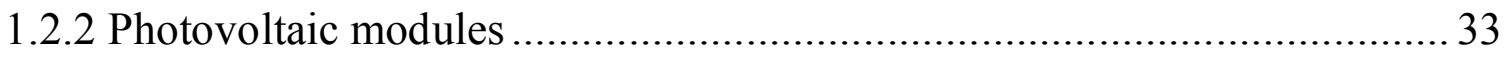

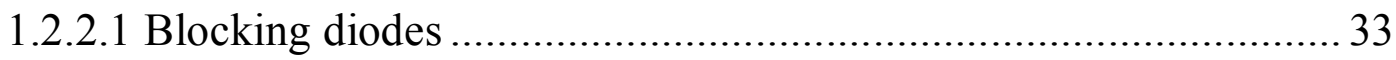

1.2.2.2 Means of protection against electrical overloads

of solar power plants................................................................ 34

1.3 Prospects for improving the efficiency of circuitry methods of protection against electrical overloads...... 


\section{Chapter 2 STRUCTURES BASED ON POLYMER NANOCOMPOSITES}

\section{WITH CARBON FILLER AS ELEMENTS OF ELECTRICAL}

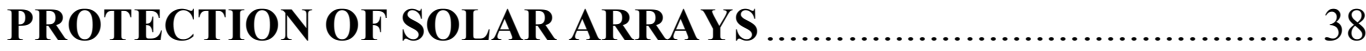

2.1 Solid-state PolySwitch elements for protection against electric overloads.... 38

2.1.1 Principle of operation of elements based on nanocomposites

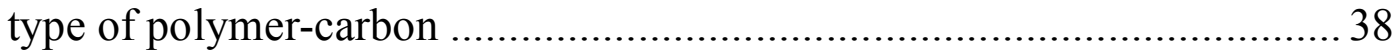

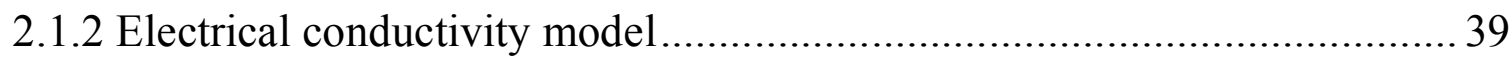

2.1.3 Main characteristics and technical parameters ....................................... 41

2.2 Model structure of a solar array with resettable fuses and measurement methods

2.3 Experimental photovoltaic characteristics of solar array model

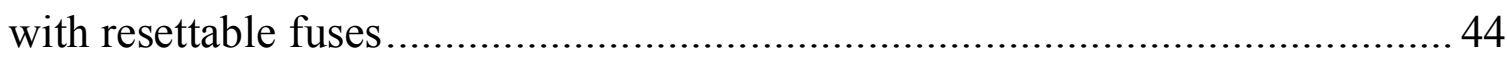

2.3.1 Influence of resettable fuses on photovoltaic characteristics.................... 44

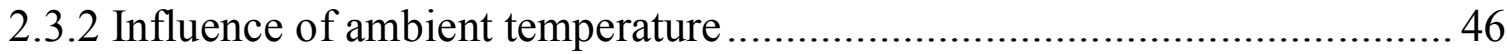

2.3.3 Influence of resettable fuses on the stability of photovoltaic

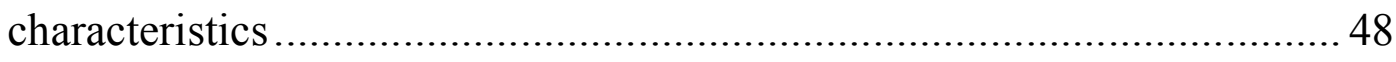

\section{Chapter 3 CURRENT LIMITATION IN THE COMPONENTS} OF SOLAR POWER PLANTS USING POLYSWITCH

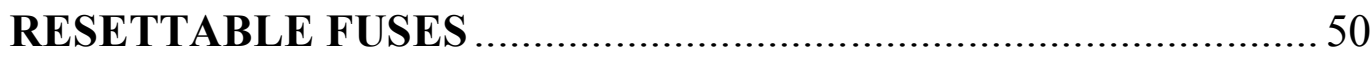

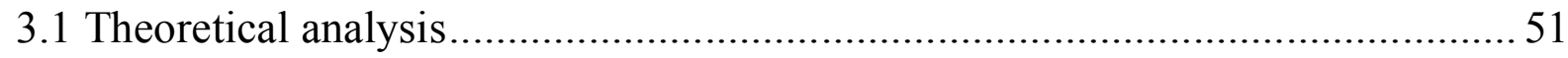

3.1.1 Simplified structure of photovoltaic system with current limitation ..........51

3.1.2 Current-voltage characteristics of photovoltaic components.....................52

3.1.3 Approximation of electrical characteristics of PolySwitch

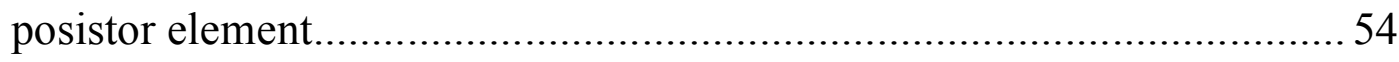

3.1.4 Equation for the current-voltage characteristics of

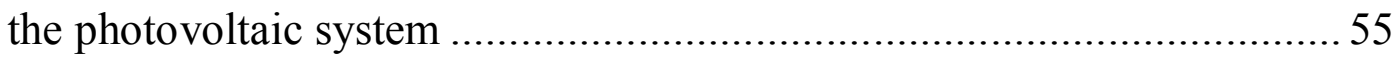

3.1.5 Electrical characteristics of photovoltaic system with current

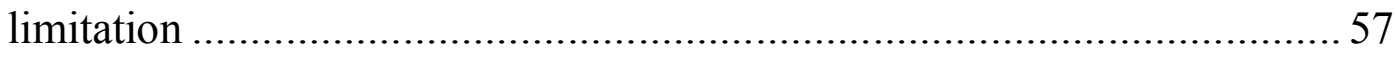

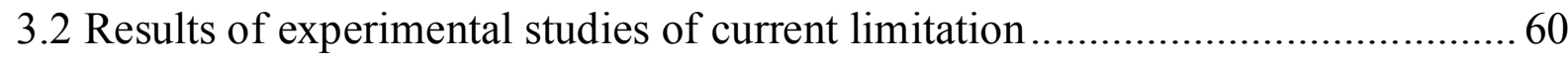




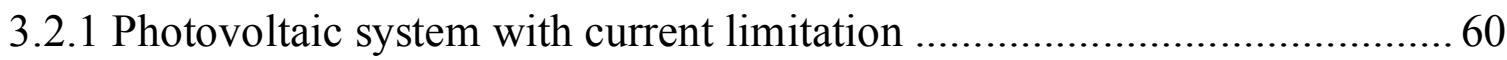

3.2.2 Experimental photovoltaic characteristics and their discussion ................. 62

\section{Chapter 4 VOLTAGE LIMITATION USING VARISTOR-POSISTOR}

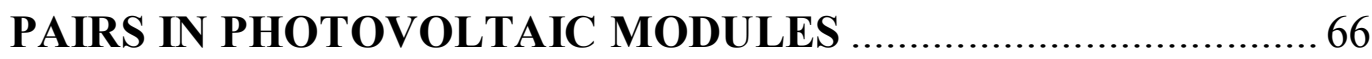

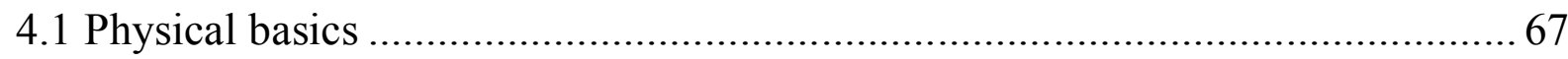

4.2 Modeling of voltage limitation in photovoltaic systems ................................... 72

4.2.1 Voltage limiting device for a separate photovoltaic cell .......................... 72

4.2.1.1 Basic equations of the model ................................................... 72

4.2.1.2 Functional characteristics of the limiting device .......................... 73

4.2.2 Voltage limiting device for a group of series-connected

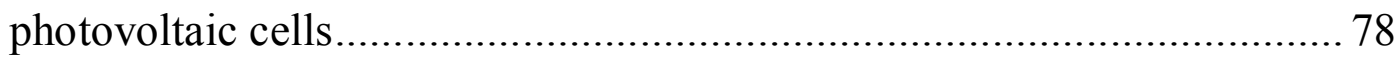

4.2.2.1 Circuit and its mathematical description ....................................... 78

4.2.2.2 Dependence of voltage limitation on the size of groups ................ 81

4.2.3 Analysis of relaxation of voltage limiting devices in

photovoltaic modules during lighting restoration.................................... 84

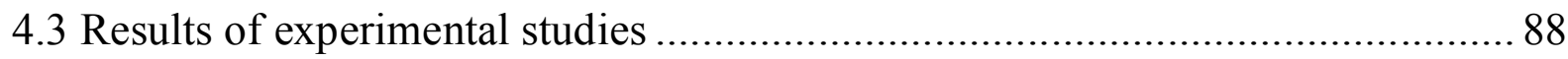

4.3.1 Voltage limiting device based on zinc oxide varistor and PPTC fuse ........ 88

4.3.2 Application of voltage limiting device for overvoltage protection

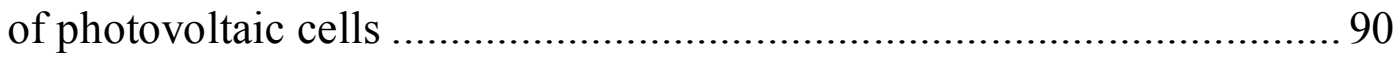

4.3.2.1 Photovoltaic module with overvoltage protection ........................ 90

4.3.2.2 Voltage limiting device for a separate photovoltaic cell ................ 93

4.3.2.3 Voltage limitation for a group of series-connected

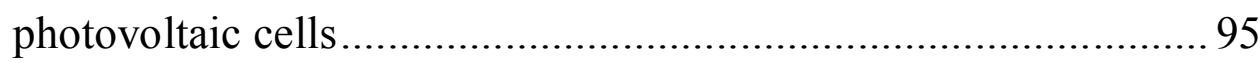

\section{Chapter 5 PHYSICAL AND TECHNOLOGICAL APPROACHES TO}

SOLVING THE PROBLEM OF PROTECTION AGAINST

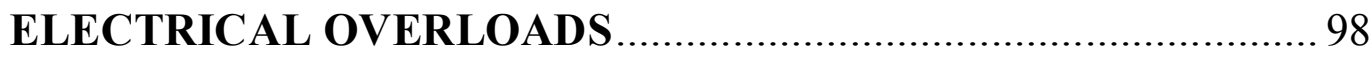

5.1 Changes in the characteristics of silicon photovoltaic cells during

overheating

5.1.1 Samples and methods of research 
5.1.2 Influence of heat treatment temperature on the characteristics of photovoltaic cells

5.1.3 Changes in the characteristics of the photovoltaic cell from the duration of heat treatment

5.2 Changes in the characteristics of silicon photovoltaic cells after current overloads

5.2.1 Research methodology 108

5.2.2 Influence of current overloads on the characteristics of photovoltaic cells

5.3 Electrical properties of a photovoltaic cell with a built-in posistor layer based on a polymer nanocomposite with a carbon filler 115

5.3.1 Studied structure and its circuitry representation 116

5.3.2 Kinetics of the voltage limiting process of a photovoltaic cell with a posistor layer.

5.3.3 Influence of overvoltage amplitude and internal resistance of voltage source

5.3.4 Dependence on the parameters of thermal contact between photovoltaic and posistor elements

\section{Chapter 6 PROSPECTS FOR THE CREATION OF SPECIALIZED} RESETTABLE FUSES FOR SYSTEMS OF PROTECTION OF PHOTOVOLTAIC CELLS OF SOLAR ARRAYS FROM ELECTRICAL OVERLOADS

6.1 Commercial resettable fuses based on polymer composites with nanocarbon fillers

6.1.1 Basic electrical characteristics of resettable fuses based on polymer composites with carbon fillers

6.1.2 Correlation between the resistance in the conducting state and the tripping current

6.2 Posistor elements based on ceresin-nanocarbon composites 
6.2.1 Manufacturing technology and features of research methods 130

6.2.2 Structure and physical properties....................................................... 131

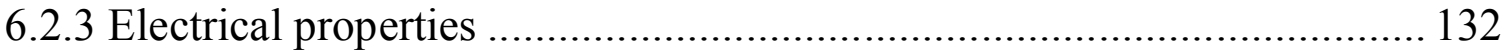

6.2.3.1 Temperature dependences of electrical conductivity .................. 132

6.2.3.2 Current-voltage characteristics................................................ 135

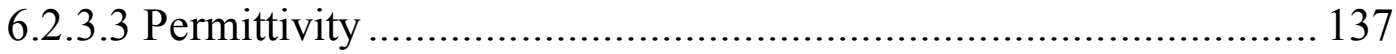

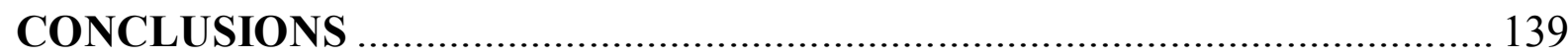

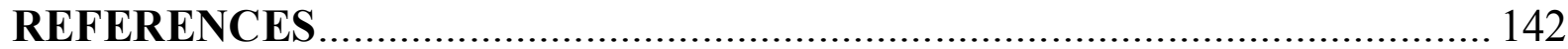

Appendix A MEASUREMENT OF THE MAIN FUNCTIONAL

CHARACTERISTICS AND PARAMETERS OF PHOTOVOLTAIC

CELLS AND THEIR CONNECTIONS .......................................... 159

A.1 Methods for determining the electrical parameters of photovoltaic cells.......... 159

A.1.1 Equivalent circuit of a photovoltaic cell ............................................. 159

A.1.2 Parameters of light current-voltage and power-voltage characteristics..... 160

A.1.3 Methods for determining the parameters of photovoltaic cell

from its light characteristics and their comparison ................................. 161

A.1.4 Method using the angles of inclination of the current-voltage

characteristic of the cell to the coordinate axes ........................................ 163

A.1.5 Semi-empirical method using the parameters of current-voltage

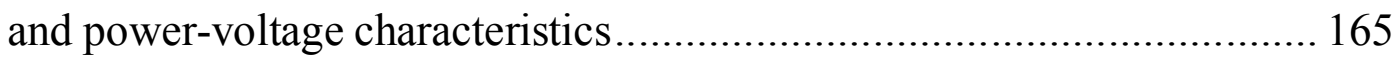

A.2 Specialized equipment for measurements ................................................... 166

A.3 Program for calculating the parameters of the equivalent electrical

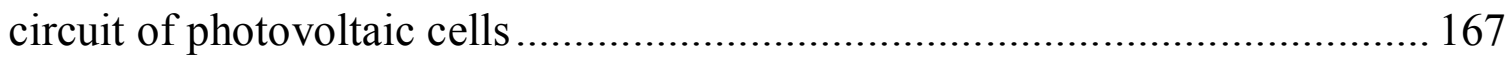

A.3.1 Block diagram of the program ........................................................... 167

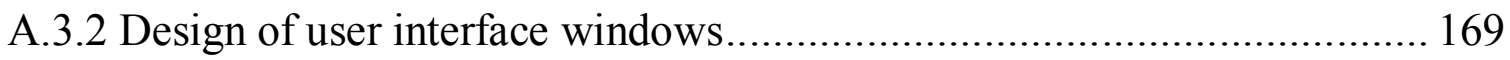

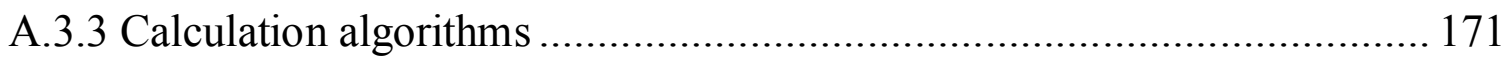




\section{LIST OF ABBREVIATIONS AND SYMBOLS}

CVC - Current-Voltage Characteristic;

HT $\quad-$ Heat Treatment;

MPPT - Maximum Power Point Tracking;

PEC - Personal Electronic Computer;

PPTC - Polymeric Positive Temperature Coefficient;

PV - PhotoVoltaic;

PVC - Power-Voltage Characteristic;

PVM - PhotoVoltaic Module;

PVS - PhotoVoltaic System;

$\mathrm{RFu} \quad-$ Resettable Fuse;

D $\quad$ - bypass diode;

Ff - factor of filling the light current-voltage characteristic of the photovoltaic cell;

$I$ (or $i) \quad-$ magnitude of the electric current;

$i_{0} \quad-$ magnitude of the saturation current of the diode;

$I_{p h}\left(\right.$ or $\left.i_{p h}\right)$ - generated photocurrent of photovoltaic cells;

$P_{M} \quad-$ maximum output power of the photovoltaic cell;

$R_{1 \max } \quad-$ maximum resistance of PPTC-fuse at $23{ }^{\circ} \mathrm{C}, 1$ hour after tripping;

$R_{s h}\left(\right.$ or $\left.r_{s h}\right)$ - shunt resistance of the photovoltaic cell;

U - electrical voltage;

$U_{D} \quad-$ voltage drop across the bypass diode;

$U_{F} \quad-$ voltage drop across the forward biased $p-n$ junction of the illuminated photovoltaic cell;

$U_{O C} \quad$ - open-circuit voltage;

$U_{R} \quad-$ voltage drop across the reverse biased $p$-n junction of the shaded photovoltaic cell. 


\section{INTRODUCTION}

The world experience of operation of solar power generation systems shows the need to solve the problem of stability and reliability of switching elements and blocking of defective solar elements. Their presence in the electrical circuit leads to a significant reduction in the functionality of the entire power generation system or to its complete failure. One of the urgent tasks in this direction is the searching and development of technologies for the protection components of solar arrays from electrical and thermal overloads in order to increase the service life and prevent abnormal (including fire hazardous) situations [1].

It is known, that solar arrays are one of the most promising renewable energy sources. They consist of tens and hundreds of thousands of individual photovoltaic cells connected in parallel and in series to provide the required current and voltage values. The identity of their electrical characteristics is one of the determining factors in ensuring the optimal mode of operation and reliability of such multicomponent systems.

However, the manifestation and creation of various defects during operation in photovoltaic cells and their connections, as well as their operation in the mode of variable inhomogeneous illumination, lead to so-called sequential and parallel discrepancies (differences) between individual elements and their groups [2-4].

It should be noted that currently the development of methods and means to prevent electrical and thermal overloads (including the manifestation of "hot spots") in the photovoltaic components of solar arrays is given considerable attention. Particularly, approaches are being developed based on the use of photovoltaic cells with low reverse breakdown voltages, circuit solutions with bypass diodes and active switches, based on automated systems for monitoring electrical parameters during their operation. However, these approaches are not universal. They are not always efficient enough, usually require complex circuit solutions and significant costs. 
The approach adopted in these studies is based on the use of inexpensive solidstate electronics elements made of composite materials such as nanocarbon filler in a polymer matrix made by the technology of PolySwitch resettable fuse. The basic functional property of resettable fuse is an abrupt increase in electrical resistance when reaching a certain temperature limit by several orders of magnitude and return to the original high-conductivity state when the temperature decreases. Such elements of electrical and thermal protection have already found application in batteries and galvanic power supplies. However, the results of the study of the relevant literature and the patent search indicate the lack of research in the direction of their application in the means of electrical protection of solar power generation systems.

The subjects of this work were switching elements using polymer nanocomposites with carbon fillers, and the objects of study were the protection structures of solar photovoltaic cells and their physical and technological properties.

The aim of the project is to create and apply for solar cells reliable and competitive switching and protection elements based on polymer composites with nanocarbon fillers.

According to the above-stated purpose of the project the following tasks were defined as the main tasks:

- review of modern circuit approaches and ways to increase the reliability of the photovoltaic system of solar arrays by protection against current overloads and overvoltages;

- analysis of prospects and formulation of the concept of protection against these overloads within the framework of the approach based on the use for these purposes of resettable fuses based on polymeric nanocomposite materials with nanocarbon fillers (PolySwitch technology);

- study of the suitability of modern nomenclature of commercial fuses of PolySwitch technology and combined structures based on it for solving problems of electrical protection of photovoltaic systems; 
- determination of requirements to the electrical parameters of these devices, which follow from the tasks of their use in solar arrays to limit current and voltage in the components of solar power plants, their theoretical justification and experimental verification;

- analysis of prospects of physical and technological approaches to the development of systems for protection of photovoltaic cells from overheating of electrical origin by creating thermosensor fuses that respond to changes in temperature.

The performed researches on the problems of application of solid-state electronics elements as means of protection of photovoltaic components of solar power plants correspond to the world level of developments in the field of energy. They present another direction in the field of improving photovoltaic systems, in particular in terms of improving their efficiency, service lifetime and reliability.

These results can be used in solving other scientific and technical problems, which require the creation of protection against electrical and thermal overloads. They also deserve to be familiar with the specialists involved in the design, manufacture and operation of solar energy sources. Accordingly, the obtained results are presented as a basis for solving scientific and methodological problems in the preparation of undergraduates (students), graduate students and doctoral students.

The Introduction was written by A. S. Tonkoshkur.

The Chapter 1 was written by A. S. Tonkoshkur, L. V. Nakashydze.

The Chapter 2 was written by A. S. Tonkoshkur, A. V. Ivanchenko.

The Chapter 3 was written by A. V. Ivanchenko, L. V. Nakashydze.

The Chapter 4 was written by A. S. Tonkoshkur, A. V. Ivanchenko.

The Chapter 5 was written by A. V. Ivanchenko.

The Chapter 6 was written by A. Yu. Lyashkov.

The Conclusions was written by A. S. Tonkoshkur.

The Appendix A was written by L. V. Nakashydze, I. V. Gomilko. 


\title{
Chapter 1
}

\section{RELIABILITY PROBLEMS OF SOLAR-BASED ENERGY SOURCES}

\author{
1.1 Brief information about the construction and \\ sources of unreliability of solar arrays
}

\subsubsection{Generalized structure of a solar battery and the main sources of its unreliability}

As is known, the basis of a solar array is a photovoltaic cell, which is a semiconductor $p$ - $n$ junction designed to convert electromagnetic solar radiation into electrical energy [5]. When sunlight enters the boundary zone between $n$ - and $p$-type layers, an electromotive force occurs, which creates an electric current in a closed external circuit connected to the contacts of photovoltaic cells. The charge carriers arising in the cell create a so-called photocurrent, which is determined by the level of solar radiation.

Silicon (monocrystalline, polycrystalline, amorphous), cadmium telluride and copper (indium) gallium (di)selenide, gallium arsenide, polymers and organics based on carbon fullerenes, copper phthalocyanine, polyphenylene etc. are used for the maufacturing of photovoltaic cells $[6,7]$.

By design, photovoltaic cell is a plate, the size of which according to the technological features of production can not exceed a certain value.

When series, parallel or combined connection of these elements are assembled photovoltaic modules (PVM), which are also called solar panels. Accordingly, a photovoltaic system known as a solar array consists of such PVMs [5, 7, 8].

The modules of the most common crystalline solar elements (Fig. 1.1) consist of a transparent front surface layer (1), an encapsulator (2), between two layers of which are placed photovoltaic cells electrically interconnected by metal busbars (3), lower (rear) layer (4), which are enclosed in a frame of aluminum profile. 


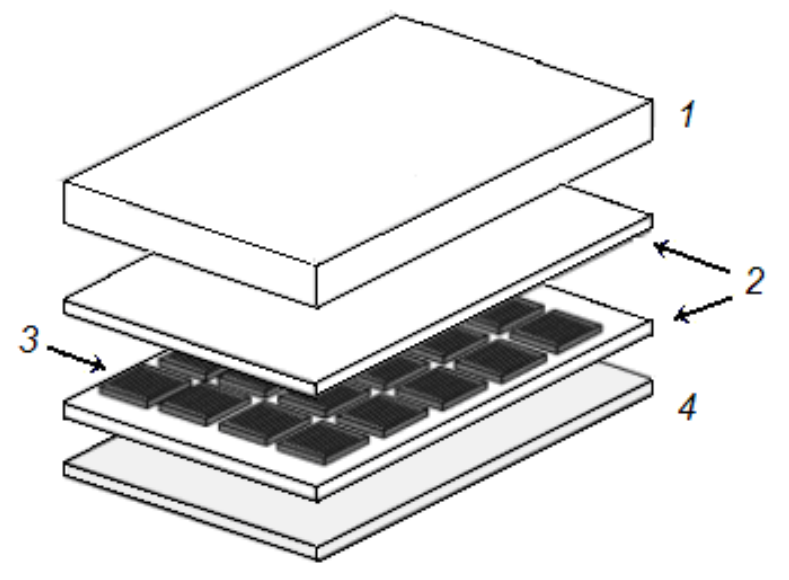

Figure 1.1. Structure of the photovoltaic module.

1 - transparent front surface layer; 2 - encapsulator between two layers of which are placed photovoltaic cells; 3 - metal busbars; 4 - lower layer.

In most modules, the top layer is made of glass with a low iron content. It has high strength, stability, transparency, impermeability to water and gases, has good self-cleaning properties and low cost.

The encapsulator is needed to create an intermediate layer between the solar elements, the front and rear surfaces of the PVM. It is made of ethyl vinyl acetate (EVA). It is optically transparent and has low thermal resistance. Polyvinyl fluoride (PVF or Tedlar) is used for the back layer. The main requirement for it is low thermal resistance, water resistance and transparency (in bilateral modules). The aluminum frame must not protrude beyond the surface of the module so that water, dust and dirt do not accumulate on it. The module protects the photovoltaic cell from weather conditions, and users from electric shock.

\subsubsection{Main sources of its unreliability}

According to the ideas about the reliability of electronic and microelectronic devices to the first group of sources of unreliability of components, unreliability should include [2,9]: 
- degradation of photovoltaic cells (reduction of output power or failure) due to deterioration of contacts or corrosion, migration of metal through $p-n$ junction, deterioration of anti-reflective coating;

- short-circuits between the connecting contacts and photovoltaic cells, if they are damaged by corrosion, and in the module ("hidden" manufacturing defects or the result of insulation degradation under the influence of the environment, which leads to delamination, cracking and electrochemical corrosion);

- rupture of the electrical circuit of photovoltaic cells due to its cracking caused by thermal stress, hail or damage during production, which creates "hidden cracks" that cannot be identified during the inspection at the enterprise, but which appear later;

- breaks in the connection diagram or in the modules (in the busbar or junction box) due to fatigue as a result of cyclic thermal stress and wind;

- mechanical damage of the glass and the encapsulator due to leaching and diffusion (there is a slow depletion, and when the concentration becomes below the critical level, there is a rapid degradation of the encapsulator material).

Elimination or minimization of the impact of these factors on the operation of the solar array can be achieved by improving the design and technology of their manufacture, as well as the use of methods of structural (hardware) redundancy in particularly important cases $[10,11]$. The sources of unreliability of the second group are factors directly related to the features of the mode of variable non-uniform lighting and local overheatings arising in photocells due to the so-called connection effects. The currently available circuit methods and means of minimizing the influence of these factors and increasing the reliability components of solar array are discussed below.

\subsubsection{Connection effects}

The effect of connections is defined as inconsistencies (mismatches) of electrical circuits in one module, caused by the use of elements with different properties or 
operating in different conditions. The mismatch is a serious problem in photovoltaic modules and arrays under certain conditions, because the output parameters of the module in these conditions are determined by the characteristics of the photovoltaic cell with the lowest output of useful electrical power. For example, when a shadow falls on one of the module elements, the power produced by the other elements may dissipate on the "bad" element and not reach the payload. This can dissipate a large amount of electrical power over a small area, resulting in a significant increase in temperature and the likelihood of irreversible damage.

\subsubsection{Inconsistency of series-connected elements}

Serial connection of photovoltaic cells (or PVM) with different parameters can lead to discrepancies between their short-circuit currents and open-circuit voltages, which significantly affect the efficiency of such electrical circuits. The currents flowing through two series-connected elements are equal $\left(I_{1}=I_{2}=I_{S}\right)$. The resulting voltage is equal to the sum of the voltages on each element $\left(U_{1}+U_{2}=U_{S}\right)$. Because the current must be the same, a current mismatch means that the total current from the two elements will be equal to the lesser of the currents.

Of the two simplest types of mismatch (mismatch of short-circuit current and open-circuit voltage mismatch), short-circuit current mismatch is more common because it can occur due to shading of part of the module. This type of mismatch is also the most significant.

In the event of a mismatch of the open-circuit voltage in the case of a series connection at the short-circuit point, the total current of the module remains unchanged. However, the power of the module at the point of maximum power decreases due to lower performance of the "bad" photovoltaic cell [2], because the two elements are connected in series, the same current flows through them, and 
the resulting voltage can be found by adding voltages on each of the two elements (Fig. 1.2a).
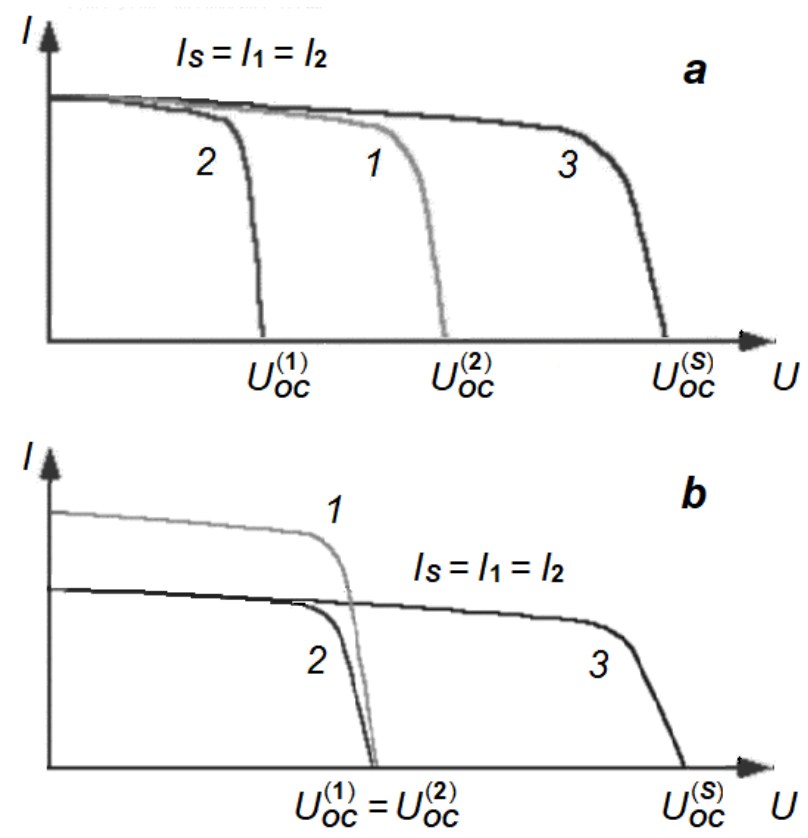

Figure 1.2. Current-voltage characteristics of the series connection of photovoltaic cells (3) at mismatch of open-circuit voltages $(a)$ and short-circuit currents $(b)$. 1 - "good" and 2 - "bad" PV-cell, $U_{O C}$ - open-circuit voltage.

Inconsistency short-circuit current with series connection depending on the operating point can negatively affect the photovoltaic device.

At the open-circuit voltage point, the effect of reducing the short-circuit current is relatively small. The open-circuit voltage decreases only slightly, because it logarithmically depends on the short-circuit current.

However, because the current flowing through the two photovoltaic cells must be the same, the total current cannot exceed the current from the "bad" element.

Therefore, the current from the two elements cannot be greater than the shortcircuit current of a "bad" photovoltaic cell. At low voltage, when this condition is met, the additionally generated current of a "good" photovoltaic cell will not be 
dissipated on each element of their series connection, but only in the "bad" element. High energy dissipation in a "bad" photovoltaic cell can cause irreversible damage.

\subsubsection{Local overheating}

Overheating in the active section of the series connection of photovoltaic cells (or photovoltaic modules) occurs when one of them with a low short-circuit current ("bad", for example, a shaded element) is connected in series with several photovoltaic cells with a high short-circuit current (Fig. 1.3).

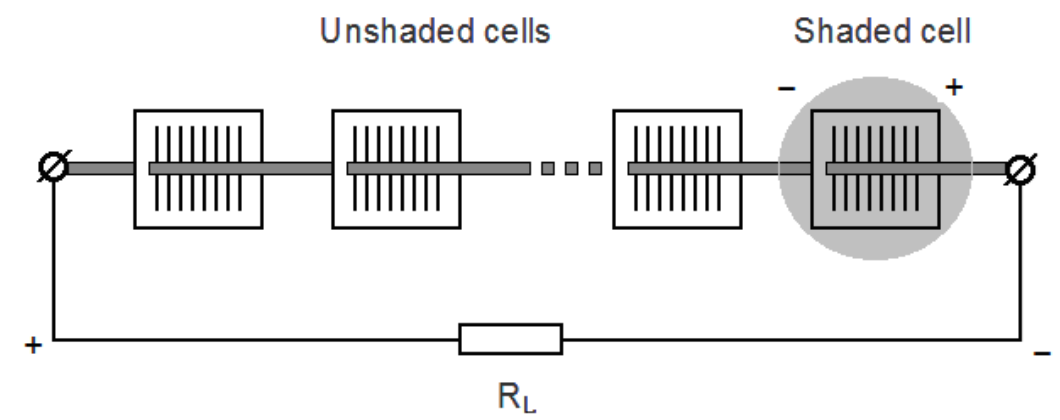

Figure 1.3. Circuitry representation of the electrical circuit in the presence of a shaded photovoltaic cell.

One shaded photovoltaic cell in the circuit reduces the current through the illuminated photovoltaic cells (unshaded cells), as a result of which they create a higher voltage, which can biases the "bad" element in the reverse direction at low load resistances $R_{L}$.

If the resulting current of the electrical circuit is close to the short-circuit current of the "bad" photovoltaic cell, it is limited by this current.

The additional current generated by "good" photovoltaic cells biases their in the forward direction. If the circuit is closed, then the forward bias on the "good" photovoltaic cells biases the "bad" element in the reverse direction, and it works as a load, not as a generator. 
The energy dissipation on such loads leads to inhomogeneous heating of the photovoltaic cell (or PVM), in particular to the appearance of areas of local heating, which are called "hot spots".

Heterogeneities of PVM heating are detected and investigated by visual inspection, infrared thermography, electroluminescent methods [13-16], etc. Fig. 1.4 shows the thermogram of the PVM section presented in [2], which illustrates the inhomogeneity of the temperature distribution in photovoltaic modules.

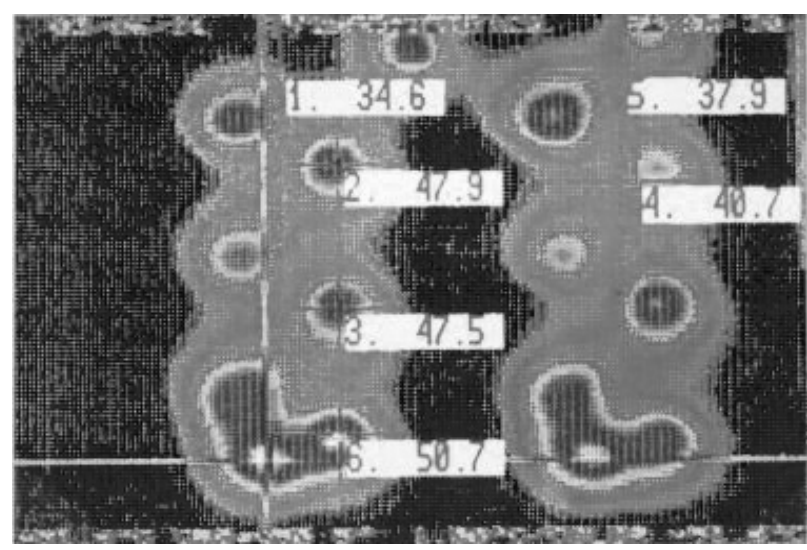

Figure 1.4. Thermographic image of a photovoltaic module of 16 photovoltaic cells with one bypass diode at reverse bias.

The numbers indicate the temperatures of the respective local areas.

The appearance of "hot spots" and an increase of the PVM temperature leads to a number of undesirable effects [16]. Particularly:

- reducing its voltage and, consequently, the output power;

- increase in mechanical stress associated with thermal expansion, and various damage (cracking of glass, solder melting, damage to photovoltaic cells, etc.);

- increasing the rate of degradation.

It should be noted that other potential causes of "hot spots" are defects in the module, such as a crack, poor soldering of two terminals of busbars inside the modules, punctures in the lower fluoroplastic sheet, polarization or dent $[13,14,17]$. 
This defect becomes a load, so the current flowing in this area gives significant power dissipation on it.

The consequences of the appearance of "hot spots" in most cases lead to accelerated aging of PVM. A "hot spot" caused by a short-circuit between the front and rear area of the PVM can cause its lower layer to "melt" and cause fires.

\subsubsection{Inconsistency of parallel connected elements}

In this case, the voltage in the circuit is always the same, and the resulting current is equal to the sum of the currents from each photovoltaic cell (Fig. 1.5).
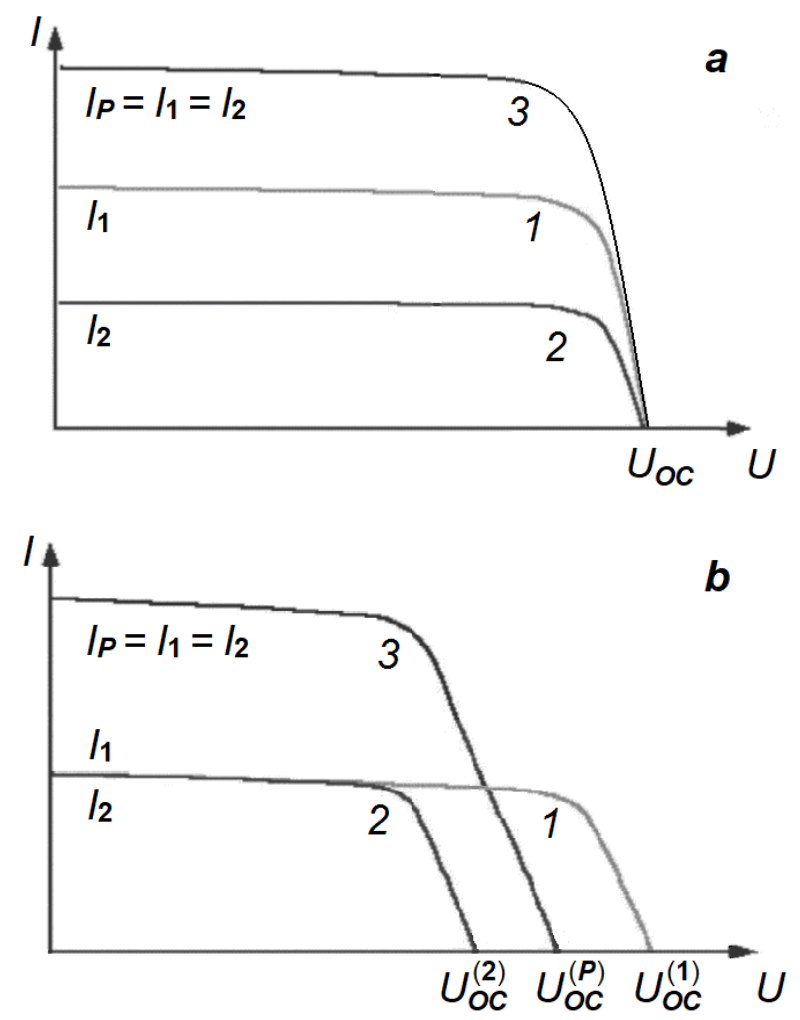

Figure 1.5. Current-voltage characteristics of the parallel connection of photovoltaic cells (3) in the mismatch of short-circuit currents $(a)$ and open-circuit voltages $(b)$. 1 - "good" photovoltaic cell, 2 - "bad" photovoltaic cell. 
In Fig. $1.5 a$ the output current of the second ("bad") photovoltaic cell is lower than the first.

In case of mismatch of currents, no problems arise: the total current is always higher than the current of each element.

In the case of mismatch of voltages of two elements connected in parallel, the "bad" photovoltaic cell reduces the open-circuit voltage of the "good" photovoltaic cell (Fig. 1.5b).

\subsection{Methods and means of minimizing the influence of regime factors on the operation of solar arrays}

\subsubsection{Photovoltaic cells}

\subsubsection{Bypass diodes}

The destructive effect of local overheating can be offset by a bypass diode. The bypass diode is connected in parallel with the photovoltaic cell so that their polarities are opposite.

Under conditions of short-circuit $\left(R_{L} \rightarrow 0\right)$ and open-circuit $\left(R_{L} \rightarrow \infty\right)$ at matched currents, each photovoltaic cell from their series connection will be biased in the forward direction, and the bypass diode - in the reverse.

However, when a "bad" photovoltaic cell biases in the reverse direction due to a mismatch of short-circuit currents between several series-connected elements, the bypass diode becomes conductive, allowing current from "good" elements to flow in the outer circuit without changing the voltage on each "good" element. 
The maximum reverse voltage across the "bad" element is reduced to the voltage across its bypass diode, while reducing the current and preventing overheating of the "bad" element.

The operation of the bypass diode during a short-circuit with mismatched currents is shown in Fig. 1.6.

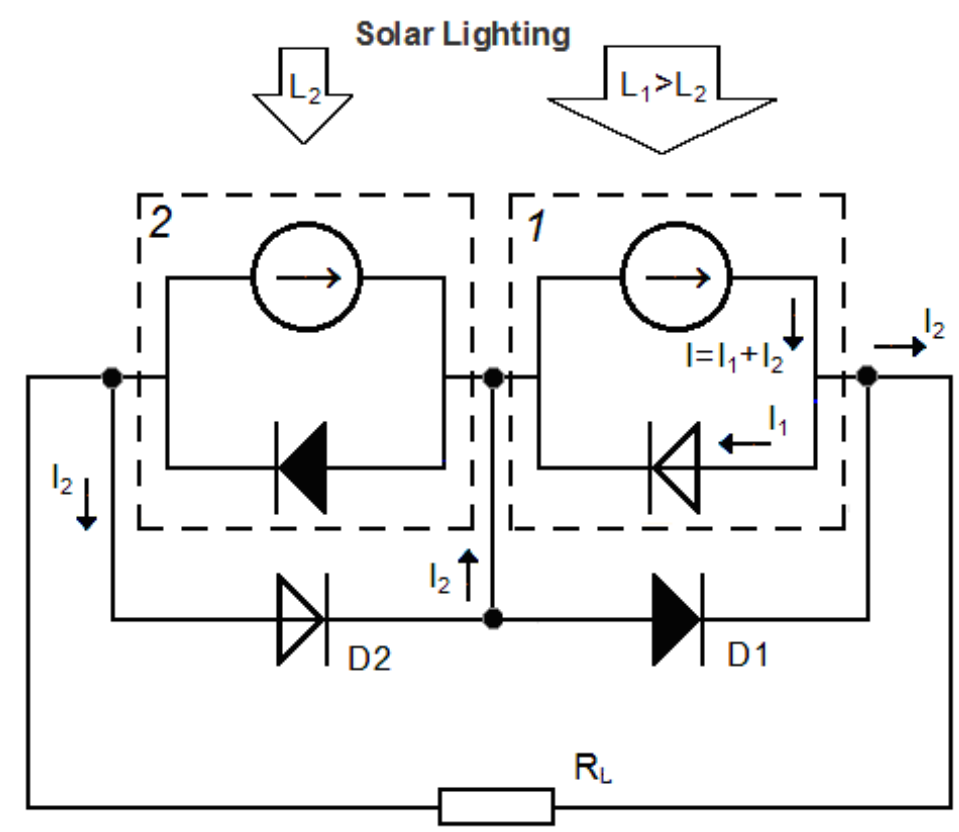

Figure 1.6. The principle of operation of the bypass diodes in series-connected photovoltaic cells in the case of mismatched currents at short-circuit. It is accepted that the photovoltaic cells of the circuit contained in the dotted lines simulate unshaded (1) and partially shaded (2) photovoltaic cells. The current source is the current $I$, that is generated by light (solar lighting). Diodes $D 1$ and $D 2$ outside the dotted line are bypass.

The bypass diode of the "good" module $D 1$ is reverse biased and gives no effect. The bypass diode of shaded cell $D 2$ is forward biased from the voltage of the "good" photovoltaic cell and conducts current. The shaded cell has a reverse bias. 
In an open-circuit with mismatched currents, the shaded solar element has a reduced open-circuit voltage $U_{O C}$. Bypass diodes are reverse biased and do not give any effect.

Due to the fact that in practice it is too expensive to use a bypass diode for each photovoltaic cell, they are connected at once to a series connection from several PV-cells (subpanels) or to the whole PVM (panel). The voltage on the shaded element or any other element that generates a low current is equal to the voltage of the forward bias on all other series-connected photovoltaic cells plus the voltage on the bypass diode.

\subsubsection{Mechanism of formation of "hot spots"}

As it is known, photovoltaic modules or panels of solar array consist of seriesconnected photovoltaic cells. Usually, they are organized in a subpanel of 20 pieces. Each subpanel is equipped with a bypass diode [18]. If one or more photovoltaic cells are shaded or faulty, they reduce the generated photocurrent and thus go into reverse bias mode, and the bypass diode guarantees an alternative current path, thereby ensuring the operation of other subpanels [4] (Fig. 1.7).

If the current generated by the photovoltaic cell (cell 1) is less than the other (in Fig. 1.7 it is assumed to be zero), the excess current coming from other subpanels $I_{\text {string }}$ is forced to pass through the bypass diode $D$ (in the first approximation the current component through $R_{s h 1}$ can not taken into account, i.e. can be accepted $\left.R_{s h 1}=\infty\right)$. As a result, the voltage across the subpanel coincides with the voltage drop $U_{D}$ on the directly offset bypass diode $D$.

The remaining photovoltaic cells (cell $i$, where $i=2,3, \ldots, N$ ) inside the subpanel can not give their generated photocurrents to the external electrical circuit, because their series connection is disconnected by the element cell 1 . These currents are 
forced to pass through the corresponding internal directly offset diodes $D_{i}$, forming a voltage drop on each of them $U_{F}$.

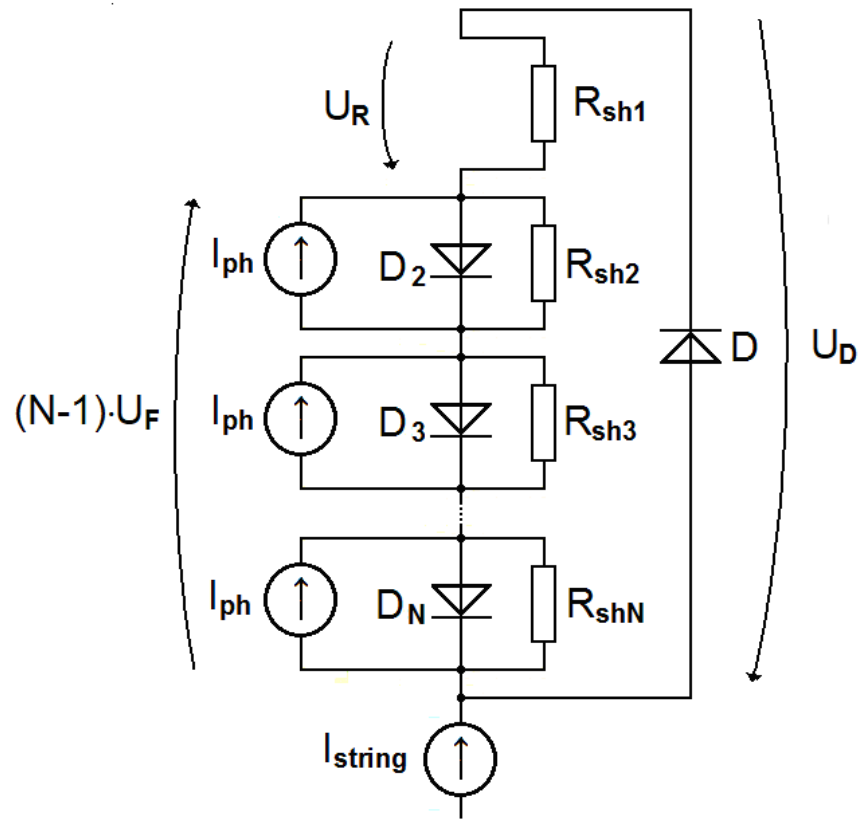

$\boldsymbol{a}$

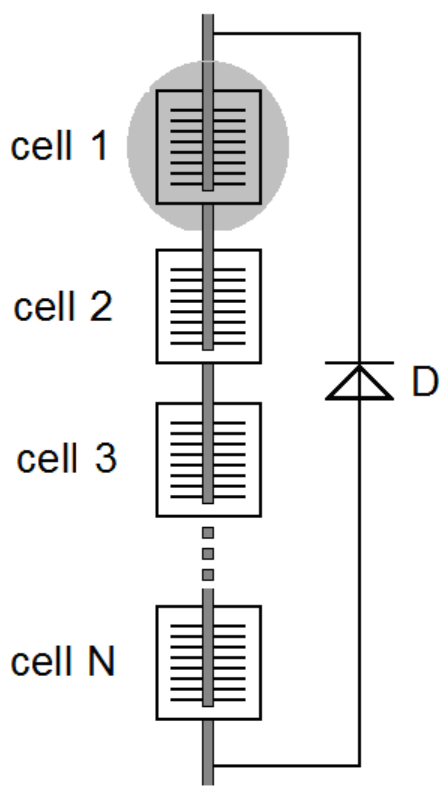

$b$

Figure 1.7. Equivalent circuit $(a)$ and simplified representations $(b)$ of a separate subpanel. The cell 1 is accepted completely shaded. $D$ - bypass diode; $D_{2} \ldots D_{N}-$ forward biased $p$ - $n$ junctions of illuminated photovoltaic cells; $U_{F}, U_{R}$ and $U_{D}-$ voltage drop across the forward biased $p$ - $n$ junction of the illuminated photovoltaic cell, the reverse biased $p$ - $n$ junction of the shaded photovoltaic cell (cell 1$)$ and the

forward biased bypass diode $D ; I_{p h}$ and $R_{s h}$ - generated photocurrent and shunt resistances of photovoltaic cells; $I_{\text {string }}$ - excess current coming from other subpanels.

As a result of the voltage drop across the series connection of the illuminated photovoltaic cells is equal to $(N-1) \cdot U_{F}$. According to Kirchhoff's law, the reverse voltage on a shaded photovoltaic cell is defined as $U_{R}=(N-1) \cdot U_{F}+U_{D}$.

For a reliable design, the number $N$ must be chosen small enough to prevent the $U_{R}$ from exceeding the breakdown voltage of the reverse biased $p-n$ junction of the shaded photovoltaic cell. 
If this is not done, the photovoltaic cell will heat up due to the resulting power dissipation. High temperatures in local areas of photovoltaic cells can lead to "hot spots". Thus, with increasing cell temperature, a thermal breakdown of the $p$ - $n$ junction may occur, when the magnitude of the reverse voltage decreases with increasing current and there is a local thermal drift in time. This forms one-dimensional current channels, which can lead to internal temperatures in the PVM that significantly exceed $400{ }^{\circ} \mathrm{C}$ [19]. "Hot spots" with or without thermal breakdown can lead to degradation and destruction of photovoltaic cells.

\subsubsection{Circuitry methods to prevent the appearance of "hot spots"}

Today the main directions of development of methods and means of prevention of emergence of "hot spots" are the following:

- improvement of known circuit technologies based on bypass diodes, which include active bypass switches,

- the use of photovoltaic cells that have the characteristics of the reverse breakdown with a small voltage amplitude or protection against open-circuit,

- application of detection and active protection which are based on technologies of tracking of a point of the maximum power of components of solar arrays.

Below is a brief overview of the main results in these areas recently achieved.

Active bypass switches. Bypass diodes help limit the maximum power dissipation of the reverse biased PV cell, but this level of power limiting depends on the number of PV cells in the sub-panel row. Series strings with more cells will dissipate more heat than strings with fewer cells $[19,20]$.

Thus, bypass diodes are more effective in mitigating "hot spots" for short line lengths of photovoltaic cells. For example, placing a bypass diode on every two photovoltaic cells in a module ensures that one photovoltaic cell never dissipates 
more than the rated power of two such cells. This is a power level that is unlikely to damage a single photovoltaic cell.

Previously, the concept of adding bypass diodes in each cell of photovoltaic cells and embedding a bypass diode in the element was proposed. However, the addition of discrete or built-in bypass diodes at the level of individual photovoltaic cells significantly increases the cost of the system. In the terrestrial photovoltaic industry, this added cost is too high, so individual bypass diodes have generally not been implemented and are unlikely to be adopted in the near future. Thus, other inexpensive and practical methods of preventing "hot spots" are needed [19].

In $[21,22]$ active switching solutions are proposed, which also reduce the substring (subpanel) of photovoltaic cells when bypassing it. The approach of the active bypass switch reduces the voltage and power loss in the line of photovoltaic cells in the situation of the current circuit and thus reduces the likelihood of "hot spots".

Fig. 1.8 shows a variant of such an active bypass system, proposed in [22]. The circuit includes:

- bipolar transistor $M_{b i p}$, which acts as a bypass component, offering an alternative path for the current $I_{\text {bypass }}$, when the subpanel is partially shaded;

- two $n$-channel MOS transistors, marked $M_{A}$ and $M_{B}$, which are designed to automatically turn on the bipolar transistor $M_{b i p}$ in case of shading, as well as for its inactivity when the subpanel is exposed to sunlight;

- additional diode to partially support the bipolar transistor or fully withstand the bypass current if the subpanel is broken or subjected to perfectly shadow conditions (current $I_{\text {shadow }}=0$ ).

The main behavior of the proposed circuit can be explained as follows. From Fig. 1.8 it follows that the voltage generated by the subpanel is $U_{\text {subpanel }}=U_{G S A}$ and the voltage drop caused by its current $\left(I_{\text {subpanel }}\right)$ is $U_{D S A}=U_{G S B}$. 


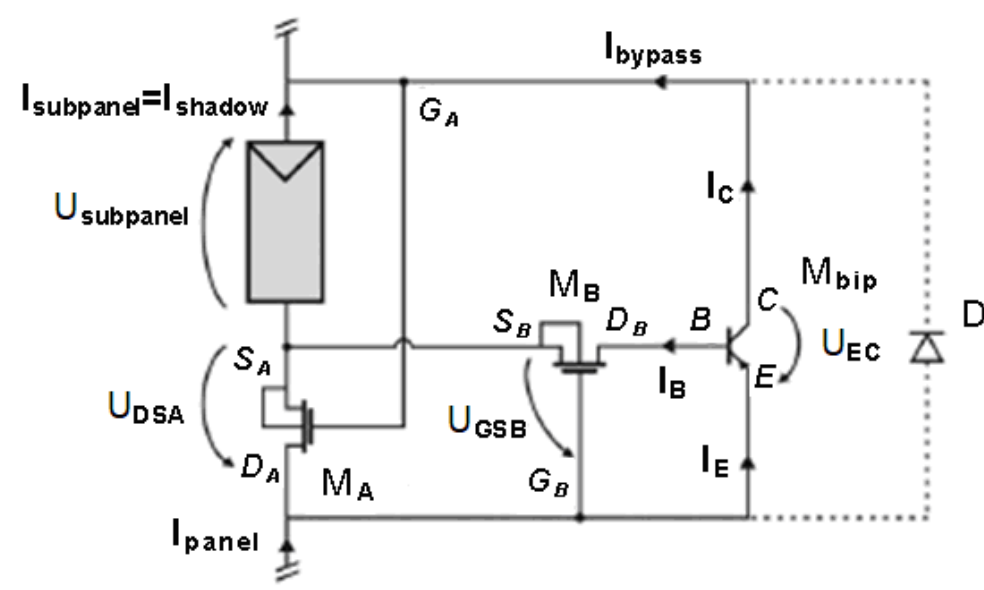

Figure 1.8. Circuit of the active bypass switch based on transistors.

If the subpanel is illuminated, the high (positive) voltage $U_{\text {subpanel }}$ brings the field-effect transistor $M_{A}$ to linear mode (charge-enriched channel). Therefore, the voltage between its drain and the $U_{D S A}$ source is much lower than the threshold voltage $U_{T H B}$ of the transistor $M_{B}$. The latter is in cut-off mode (depleted channel) and virtually shuts off the base current $I_{B}$ of the bipolar transistor $M_{b i p}$, ensuring its closed state. When the subpanel is partially shaded, the voltage $U_{\text {subpanel }}$ decreases. The transistor $M_{A}$ partially overlaps the channel, and the voltage $U_{D S A}$ (equal to $U_{G S B}$ ) increases. When $U_{D S A}>U_{T H B}$, transistor $M_{B}$ goes into linear mode (opens the channel) and provides a base current $I_{B}=I_{D B}$ of bipolar transistor $M_{b i p}$, which goes into saturation (when the voltage drop between the emitter and the collector $U_{E C}$ is low), forming a bypass channel for current $I_{\text {bypass. }}$. In this case, the subpanel continues to generate electrical energy, which is dissipated by the field-effect transistor $M_{A}$, which reduces the likelihood of local damage due to the appearance of "hot spots" and avalanche destruction of the elements inside the subpanel.

With more complete shading of the subpanel, it acts as a load (or part of it) relative to other unshaded subpanels (connected in series in the corresponding panel) and the voltage applied to it is inverse relative to the voltage $U_{\text {subpanel }}$ during lighting. As a result, $I_{\text {shadow }}=0$, both field-effect transistors are closed (since if $I_{\text {shadow }}=0$, then $I_{D A}=I_{D B}=0$ ) and an additional bypass diode $D$ works, which will fully conduct the current of $I_{\text {panel }}$ photovoltaic cells belonging to other subpanels. 
Methods of detection and active protection. Today, there are two areas in the development of protection against "hot spots" at the level of a separate photovoltaic module (solar panel), which are based on the use of methods for the maximum power point tracking (MPPT).

The first of them reduces the task of protection to the optimization of the modes of operation of individual parts of solar arrays. An example of such an approach is the results of simulation and field tests of "hot spot" behavior in photovoltaic systems with central and distributed MPPT [23]. The latter is considered more effective because it avoids "hot spots" in the shading of a larger surface of one cell than when using a central MPPT.

Another direction is to prevent the occurrence of "hot spots" by monitoring the serial connection of solar panels during operation. This should allow timely detection and active protection of their string when a state of "hot spot" is detected in it [19].

To detect "hot spots", a concept was proposed based on the use of changes in the impedance parameters [24] or the current-voltage characteristics [25] of the PVM string with partial shading of its individual modules. "Hot spot" detection algorithms can work in tandem with MPPT control, periodically interrupting MPPT to measure the impedance or other electrical parameters of a string of photovoltaic modules (panels).

When a substring containing an uncoordinated area (for example, a separate solar panel) is detected, the guaranteed method of preventing a "hot spot" is to turn it off, because in this case the current does not pass through its cells. In this regard, the concept of protection of panels strings of photovoltaic cell from "hot spots" by disconnecting them is promising [19, 26, 27].

The block diagram of one of the variants of such protection, where there is a system of diagnostics and monitoring of a separate solar panel and means to exclude it from the line, if it is inconsistent (for example, shaded) [26], is presented in Fig. 1.9 and 1.10 . 


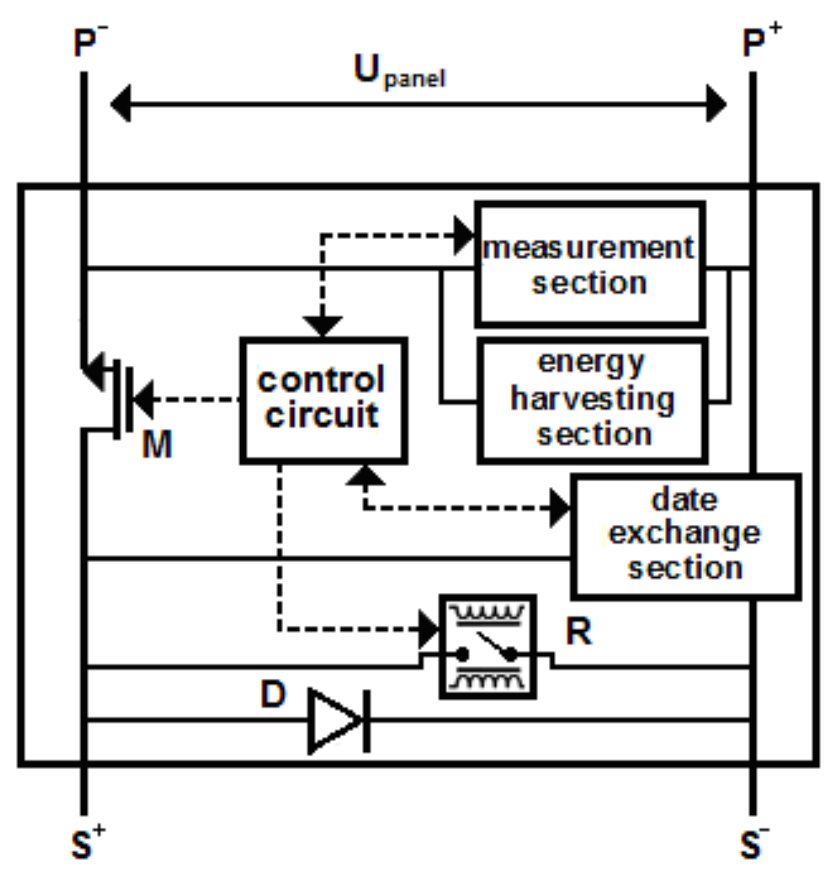

Figure 1.9. Circuit of inclusion of protection devices of photovoltaic modules (solar panels) in their string.

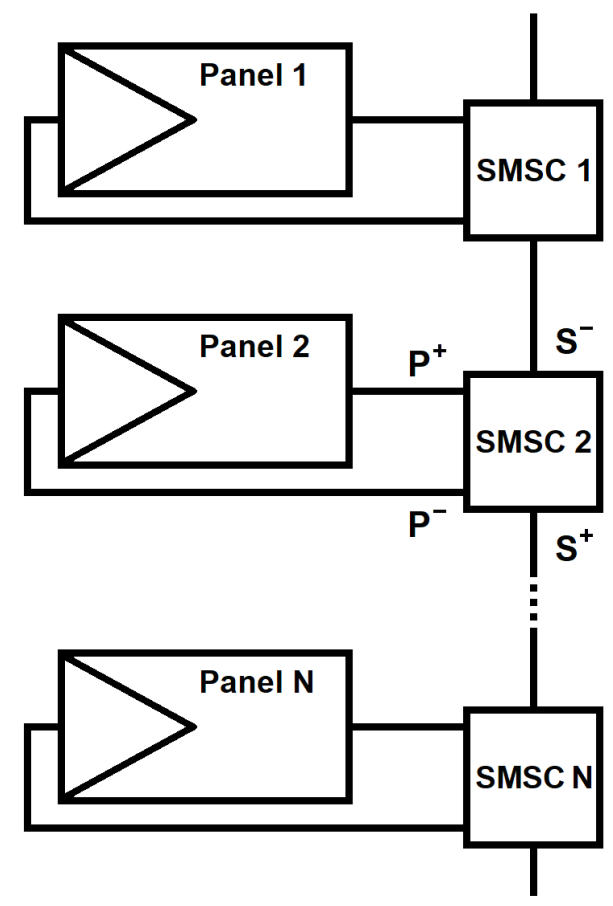

Figure 1.10. Block diagram of inclusion of protection devices of photovoltaic modules (solar panels) in their string. 
As can see, this single module safety circuit (SMSC) consists of the following sections: measurement section, energy harvesting section and date exchange section. The device also includes a bypass diode $D$ that disconnects the panel, a field-effect transistor $M$, a bipolar electromechanical relay for shorting the external terminals of the panel in abnormal situations, and a control circuit that uses a microcontroller to provide general synchronization and switching on.

The solar panel terminals $P^{+}$and $P^{-}$are physically separated from the output terminals $\left(S^{+}\right.$and $S$ ), which are used to connect the solar panels to each other in series.

When the field-effect transistor $M$ is in the off state, it operates as an opencircuit, i.e. "disconnects" the $P^{-}$leads from the $S^{+}$leads. The device is in the active state, as its energy harvesting section is directly connected to the "internal" terminals $P^{+}$and $P^{-}$. This allows to provide a positive voltage $U_{\text {panel }}$, which is equal to the voltage of the open-circuit $U_{O C}$ of the disconnected solar panel.

Otherwise, it is equal to its operating voltage. As a result, the circuit is always controlled, and the panel of solar array can eventually be connected by opening a relay and controlling the transistor $M$ in the on state.

The bypass diode $D$ allows a continuous current of the line from the panels, regardless of the state of the transistor $M$, i.e. the continuous power supplied from the line is guaranteed, even when a separate solar panel is turned off.

When transistor $M$ is switched off, the measuring section operates on an isolated separate panel. The measured values (open-circuit voltage and short-circuit current) do not depend on the operating point of the other panels of the string and can thus be used to individually characterize the state of an individual panel. When transistor $M$ is turned on, the actual electricity production is registered (according to the control point).

The data exchange section during normal operation monitors their traffic for configuration or diagnostic purposes. In the event of an abnormal situation, it 
recognizes a specific codified word and starts the safety procedure, which means closing of relay $R$.

Data transmission can be implemented on the same principles as the known units for monitoring purposes $[25,28]$, where the measured data (operating voltages and currents) were transmitted to the Central unit using wireless protocols [28] or based on the power lines communications (PLC) technology [25, 29]. In this embodiment, a special communication PLC circuit is used, which uses a DC busbar to connect the solar panels. Problems of elimination of distortions of the data signals arising at their movement on solar arrays are solved by use of the bypass highfrequency filters connected in parallel to each panel of solar arrays [26, 30].

\subsubsection{Physical and technological methods to prevent the appearance of "hot spots"}

One of the ways to solve the problem of preventing the appearance of hot spots is the use of photovoltaic cells with low resistance to breakdown. Such photovoltaic cells detect the maximum power dissipation at full shading. It is known that the power dissipation is proportional to the breakdown voltage. Thus, reducing the value of the breakdown voltage also reduces the maximum possible power dissipated in the area of the photovoltaic cell. However, photovoltaic cells with low reverse breakdown characteristics also become reverse biased and dissipate heat. This approach is effective only when the photovoltaic cell dissipates heat without causing damage.

Previous studies in [19] indicate that the dissipation losses are 3 times greater than at the point of maximum power of the photovoltaic cell, potentially can damage it. Thus, further research is needed in this direction on photovoltaic cells with small breakdown voltages to determine their susceptibility to "hot spots". 


\subsubsection{Photovoltaic modules}

\subsubsection{Blocking diodes}

In large photovoltaic systems, the modules are connected both in series and in parallel. Set of elements or modules connected in series is called a "string". Combining series and parallel connections can lead to some problems in solar arrays.

For example, if one string of a parallel connection (often referred to as a "block") is open-circuited, the current through the remaining strings will be less than the current through the other blocks in the array. Eventually this leads to loss of generated power.

Series connection of PVMs blocks in combination with the effect of mismatch in one of them requires that bypass diodes connected in parallel to its modules can withstand the current of all series-connected other serviceable blocks. This discrepancy will cause current to flow through the bypass diode, heating it up, which will lead to a decrease in its effective resistance and a further increase in the flowing current. As a result, such bypass diodes become even hotter, their resistances decrease even more, increasing the current, etc. If the bypass diodes are not designed for such a large enough current, they can burn out, which will damage the photovoltaic modules.

In addition to the bypass diodes, an additional diode, called a blocking diode, is used to reduce the losses caused by the mismatch [2]. It is also used in stand-alone systems so that current from electric batteries does not flow through the solar battery at night. When the PVMs are connected in parallel, each string of modules must have a blocking diode. This not only reduces the load on a single diode, but also prevents the current from one parallel string to flow into a string with less current produced, which reduces the losses caused by the mismatch when connecting strings in parallel in the array (Fig. 1.11). 


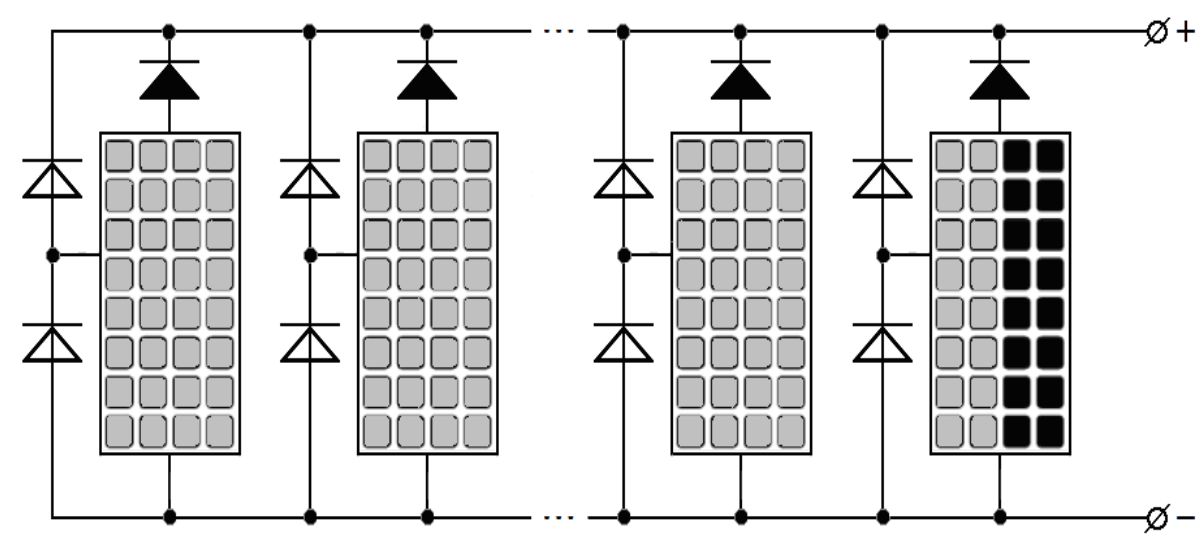

Figure 1.11. Blocking diodes (blackened) in parallel connection of photovoltaic modules.

The blocking diode on the shaded module does not allow current to flow into it from "good" parallel connected modules.

\subsubsection{Means of protection against electrical overloads of solar power plants}

Solar power plant is a system of photovoltaic modules, cables, fuses, surge arresters and energy converters [31]. Fig. 1.12 shows a simplified diagram of the power plant. Solar arrays use the energy of sunlight to convert photons into PV current. Electricity generated by solar arrays enters the current converter, where it is converted from direct current to alternating current.

Fuses protect against overload currents (Fig. 1.12). If the PV system consists of three or more strings that are connected in parallel, then each of them must be protected by fuses separately. If there are less than three strings in the system, the generated emergency current will not be able to damage the conductors and the solar array. 


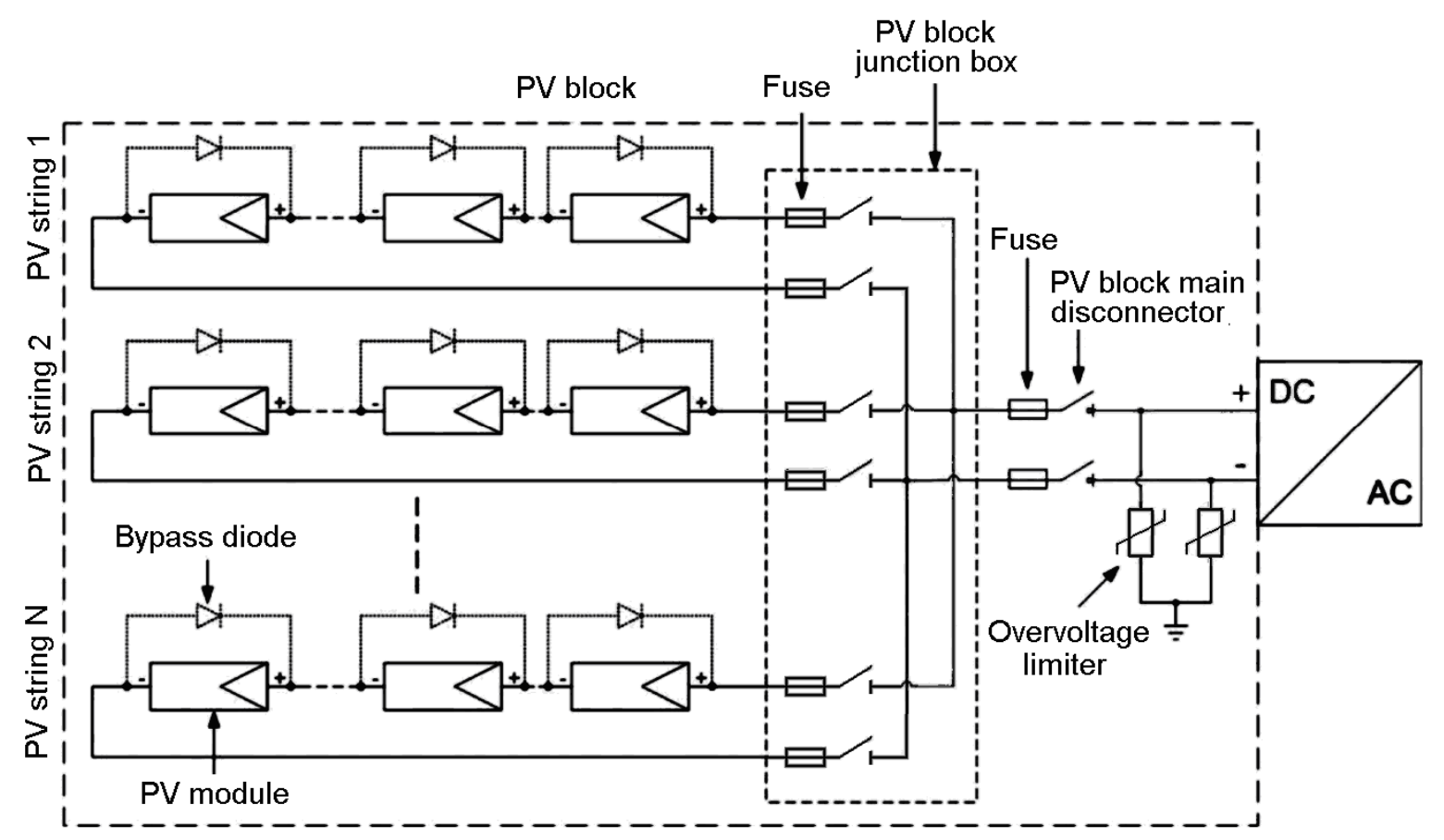

Figure 1.12. Simplified diagram of a solar power plant.

Typically, two fuses (on the "+" and "-" poles) are connected to each string, which protect the conductors and solar panels from damage and ensure safety. Fuses insulate emergency sections. The remainder of the PV system can continue to generate electricity.

Voltage limiting devices (ET1TEC B, C-PV series) were designed to protect against direct and indirect lightning strikes and can be used to protect solar systems. The circuit consists of two groups of varistors, each of which is protected by a thermal shut-off device.

\subsection{Prospects for improving the efficiency of circuitry methods of protection against electrical overloads}

There are two ways to prevent "hot spots": make sure that the solar cell can completely dissipate the power of the worst case without damaging the cell, or open 
the electrical circuit of photovoltaic elements. A "hot spot" can lead to secondary destruction or damage to the encapsulator elements and permanent degradation of the solar panels or to safety problems.

Physico-technological approaches, in particular the use of photovoltaic cells with low reverse breakdown voltages, which limit the power dissipated during heating of local areas of the PV-cell during the formation of "hot spots", can be an effective way to prevent it, if the value of this dissipation power is insufficient to damage the photovoltaic cell.

The results of modeling and experimental data available today show that the known circuit methods, in particular the use of bypass diodes in the subpanel strings of photovoltaic cells, do not completely protect against the appearance of "hot spots". Bypass diodes are more effective in preventing "hot spots" at very short strings lengths of photovoltaic cells, but this is not usually used in modern panel design.

Active bypass switches are an improvement over the bypass diode, but require more complex circuit solutions and significant costs.

Methods of "hot spots" detecting based on measurements of electrical parameters of solar panels in combination with active protection by the method of open electrical circuit more effectively protects against their occurrence. However, such technologies require complex special equipment and are developed only at the level of photovoltaic modules.

One of the promising solutions of this problem is the use of an additional device for isolating inactive (shaded or defective) areas of both individual photovoltaic cells and their modules, namely, PPTC (polymeric positive temperature coefficient) resettable fuses of PolySwitch type, which are polymer composites with nanoscale carbon fillers. The basic functional property of PPTC-fuse is an abrupt increase in electrical resistance by several orders of magnitude when reaching a certain temperature limit and return to the original high-conductivity state when the temperature decreases $[32,33]$. 
PPTC-fuses effectively protect power supplies in case of a short-circuit or overload. In particular, such elements are used as devices for electrical and thermal protection in batteries and galvanic power supplies [35-39]. For example, PolySwitch tape cells are designed to protect nickel-cadmium, nickel-hydrodometallic, and lithium-ion batteries used in cellular telephones, laptop computers, and other portable electronic equipment. Super-flat components can be welded directly to the battery cells to protect them from overheating caused by a short-circuit or overcurrent. When the fault is rectified, the resistance of the device is reduced to its original lowresistance value, and the battery can be used again. Such protection can be performed many times, preventing irreversible degradation processes in the protected elements, without causing the destruction of the protection element itself.

The advantages of such structures based on polymer composites with nanocarbon fillers include:

- resistance close to the metal resistance up to the tripping temperature and to the resistance of the insulator above the specified temperature [32, 33];

- possibility of realization in the form of discrete elements and continuous filmtapes [36-37] (that is important at the decision of problems of realization of isolation of defective local area of the separate photovoltaic cell);

- reaction to an increase in temperature of separate components of the solar array in the form of their temporary isolation $[32,33]$.

This paper investigates the possibilities of using PPTC-fuses based on polymer composites with nanocarbon fillers for insulation of "overheated" photovoltaic cells. The main attention is paid to the study of the influence of these fuses on the solar array operation in the operating temperature range and the functionality of their suitability in emergency situations associated with overheating. 


\section{Chapter 2}

\section{STRUCTURES BASED ON POLYMER NANOCOMPOSITES WITH CARBON FILLER AS ELEMENTS OF ELECTRICAL PROTECTION OF SOLAR ARRAYS}

\subsection{Solid-state PolySwitch elements for protection against electric overloads}

\subsubsection{Principle of operation of elements based on nanocomposites type of polymer-carbon}

Heterogeneous structures such as carbon dispersed in the polymer, including polyethylene, are conductive materials with a positive temperature coefficient (PTC) resistance $[32,33,40]$. Such inhomogeneous polymers can have a gradual increase in resistance with a linear dependence on temperature (linear characteristic of PTC) or a sharp increase in a narrow temperature range of the phase transition type (nonlinear characteristic of PTC). Accordingly, posistors are created on the basis of structures with a linear characteristic of PTC, and resettable fuses of the PolySwitch type are created on the basis of structures with a nonlinear characteristic of PTC.

There are various physical explanations for the posistor effect in polymer-carbon type structures.

In the first of these, the polymer material from PTC is a crystal lattice of an organic polymer, which contains scattered conductive particles (e.g., soot). The sharp increase of resistance is due to the phase transformation, namely the transition of the polymer from crystalline to amorphous. In the cold state, the material is mainly crystalline. Its conductive particles are "squeezed" into amorphous regions between small crystals. With a sufficiently high percentage of conductive particles, they collide or almost collide with each other, creating a three-dimensional electrically conductive structure. In areas of incomplete collision of current-conductive particles, the charge is transferred due to the tunneling effect. When the element is heated to 
the phase transition point in the polymer, the small crystals turn into an amorphous state. This increases the volume of the amorphous phase and destroys the structure of the conductive circuits. As the crystal structure is destroyed, the resistance of the element increases. After cooling the polymeric material, it is recrystallized, and the electrically conductive structure is gradually restored.

However, such ideas do not take into account a number of factors, in particular, the low probability of the presence of long-range order and the construction of a crystal lattice of polymers, which are giant chains of the same type of organic molecules; "ease" of repolymerization, with which the polymeric material returns to its original "crystalline" state after the phase transition (decay of polymer molecules into smaller molecular chains, etc.).

In another, more consistent, explanation, it is believed that the polymer has a large positive temperature coefficient of linear (volume) expansion and when heated simply breaks the conductive circuits between the carbon particles. The local area of the material overheats under the action of current, the polymer expands, pushing the carbon particles, the resistance increases. While the conductive circuit is not yet destroyed, the flowing current heats the polymer even more, which leads to even greater expansion and rupture of the chain of the conductive carbon matrix. After cooling of the polymer material, it is compressed and the current-carrying circuits are restored.

\subsubsection{Electrical conductivity model}

Recent ideas have made it possible to create a mathematical model of the electrical conductivity of the polyethylene-carbon posistor composite [40, 41].

When creating the model, it was taken into account that the thickness of the barrier formed by the polyethylene dielectric layer between carbon grains, which must be overcome by an electron, is quite large and therefore the most probable is the 
tunneling mechanism taking into account tunnel transitions between local centres. The probability of the transition of electrons from one carbon particle to another is most probable in the direction of the applied electric field.

The difference between the counter fluxes of charge carriers between adjacent (donor) levels located in the planes of a unit area cut parallel to the electrodes determines the steady-state current density through the considered structure. In the dielectric layer between two carbon particles there are several such centres, the distance between which should be no more than $10^{-7} \mathrm{~m}$ for the values of electrical conductivity observed in the experiment.

In [41] it was assumed that there are only 2 such local centres and they are at the same energy level (Fig. 2.1). When constructing a mathematical model, it was necessary to take into account both transitions from carbon to the centre and inverse transitions.

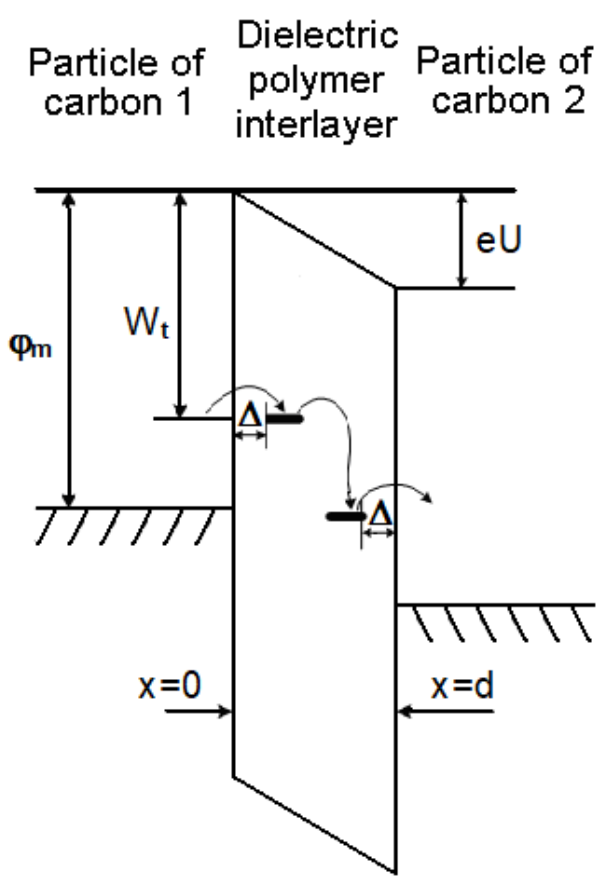

Figure 2.1. Zone diagram of the structure carbon particle - polyethylene layer - carbon particle.

The results of the calculation of the current-voltage characteristic (CVC) of the structure and comparison with the experiment are shown in Fig. 2.2. 


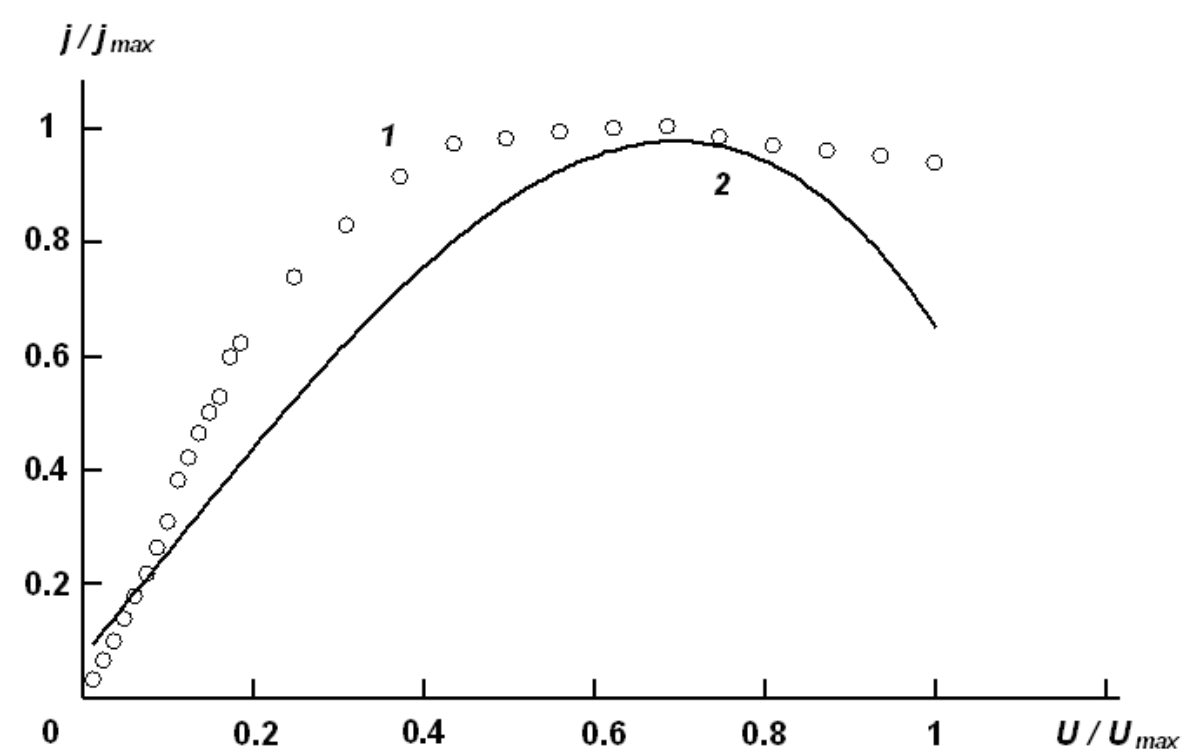

Figure 2.2. Static CVC of the composite (points are experiment) and structure carbon particle - polyethylene layer - carbon particle (solid is theoretical dependence).

As can be seen, the calculated $\mathrm{CVC}$ has a posistor section, which coincides in nature with the experimental one and is known in the literature [42], which can be considered as a confirmation of the model considered here. The observed expansion of the experimental curve in comparison with the calculated one may be related to the structural inhomogeneity of the studied posistor material.

\subsubsection{Main characteristics and technical parameters}

A typical temperature dependence of the PPTC-fuse is presented in Fig. 2.3 [33]. It corresponds to the physical mechanism described above, i.e. is determined by the structural features of the main functional material of the PPTC-fuse, which is a non-conductive polymer matrix (e.g., polyethylene) with a highly conductive filler (usually technical carbon). Due to the unheated carbon channels (region 1), the PPTC structure is a conductor with low intrinsic resistance. 


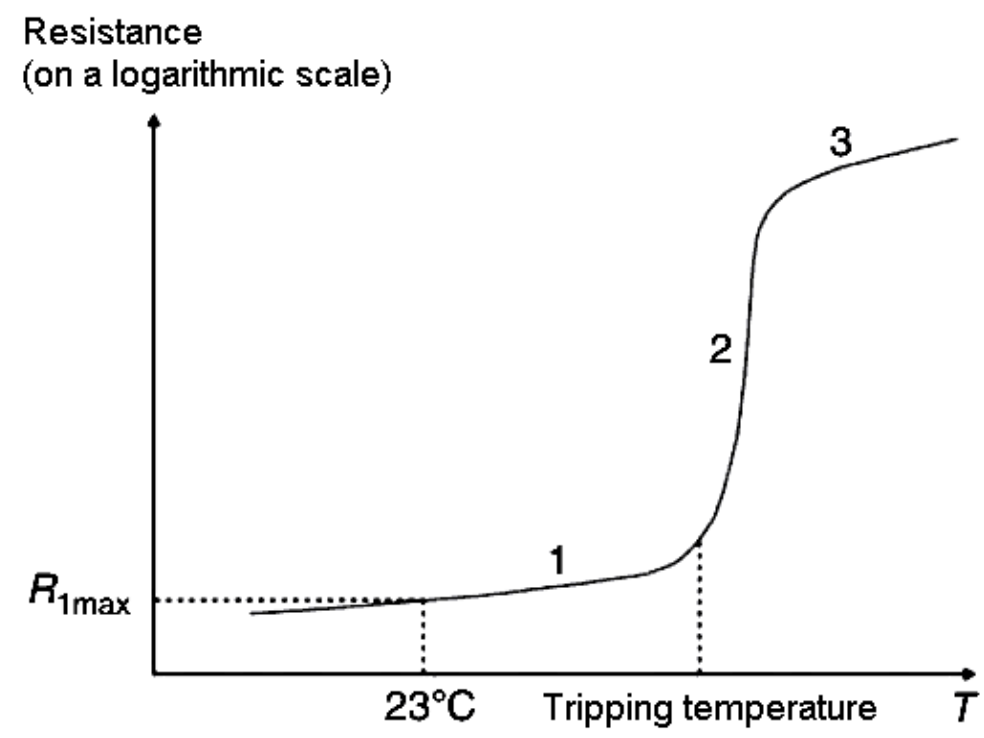

Figure 2.3. Dependence of resistance of PPTC-fuse on temperature.

$R_{1 \max }-$ maximum device resistance at $23{ }^{\circ} \mathrm{C}, 1$ hour after tripping.

When heating the above temperature (transition temperature) channels of carbon particles are broken due to the volumetric expansion of the polymer matrix and/or the transformation of the crystal structure of the matrix into an amorphous and electrical resistance of the structure increases sharply (region 2) [33, 39, 40]. In region 3 , the structure of the conductive channels is completely destroyed and the resistance of the PPTC-fuse reaches maximum value.

The operating temperature range, where low-conductivity is guaranteed, for commercial PPTC-fuses is from $-40{ }^{\circ} \mathrm{C}$ to $85^{\circ} \mathrm{C}$ or $125^{\circ} \mathrm{C}$. Their lower temperature types with the maximum temperature $60{ }^{\circ} \mathrm{C}$ are also known $[43,44]$. According to Fig. 2.1 the transition temperature has a value that slightly exceeds the specified values of the maximum temperature of the operating range.

In conclusion, the following general advantages of PPTC structures based on polymer composites with nanocarbon fillers should be noted:

- relatively low production costs and miniature size;

- resistance close to the resistance of metals at temperatures below the tripping temperature and close to the resistance of the insulator at temperatures above it; 
- the possibility of implementation in the form of discrete elements and continuous films;

- the possibility of temporary disconnection (isolation) of individual components of the electrical circuit.

\subsection{Model structure of a solar array with resettable fuses and measurement methods}

To experimental study the capabilities of resettable fuses of this type to protect against overheating or short-circuits of components of solar arrays, their model structure was investigated, which is a parallel connection of several series-connected photovoltaic cells and PPTC. The load of such a power supply is a variable resistor.

The expediency of choosing this model structure was determined by the following circumstances:

- first, it corresponds to the parallel connection of photovoltaic modules with series-connected photovoltaic cells in solar panels and arrays;

- second, it can be considered as a discrete representation of the individual photovoltaic cell, where the elements of the model correspond to a set of local areas of a single solar "cage" (comparable in area of local heating or short-circuit).

During the research, samples of photovoltaic cells based on single-crystal silicon SHB-10 with a translucent coating, based on ITO-film and PPTC-fuses of the type were used FRX375-60F.

The main characteristics that were measured were current-voltage and power-voltage (power curve) characteristics of the above-described model of solar array. The experiments used a known measuring circuit voltmeter-ammeter [45].

As a light source, a solar radiation simulator was used, which simulates the conditions of AM 1.5. Measurements at increased temperatures were performed by placing in a preheated thermostat. After each measurement at increased temperatures, the samples of model solar array were cooled in free mode to room temperature. 


\subsection{Experimental photovoltaic characteristics of solar array model with resettable fuses}

\subsubsection{Influence of resettable fuses on photovoltaic characteristics}

Fig. 2.4 and 2.5 show the results of the study of current-voltage characteristics $I(U)$ and power curves $P(U)$ of the solar array model from six included in parallel samples of photovoltaic cells without and using resettable fuses for electrical insulation when overheating some of them [46].
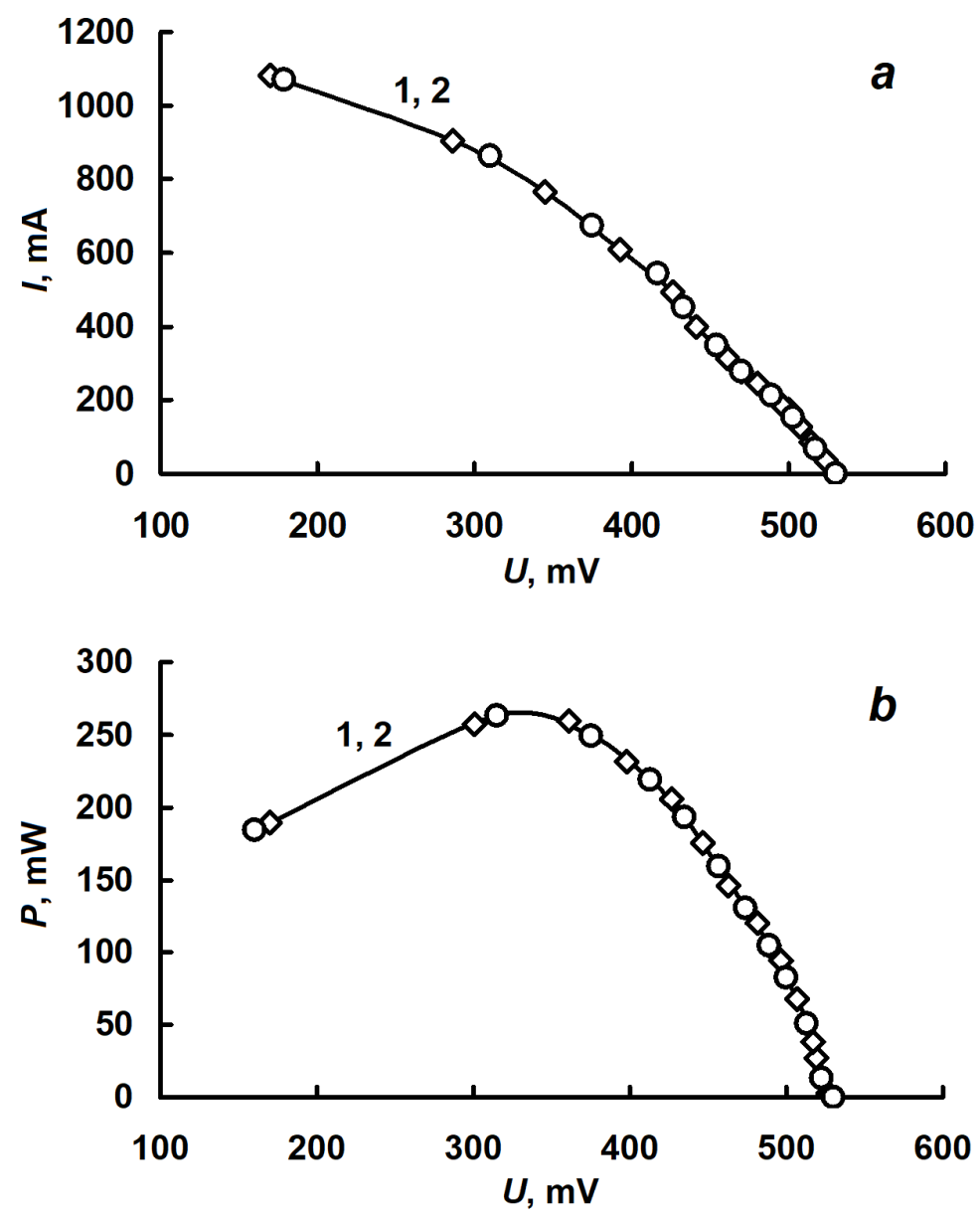

Figure 2.4. Current-voltage characteristics $(a)$ and power curves $(b)$ of the solar array model without (1) and with blocking PPTC fuses (2) at room temperature.

All photovoltaic cells are active. 


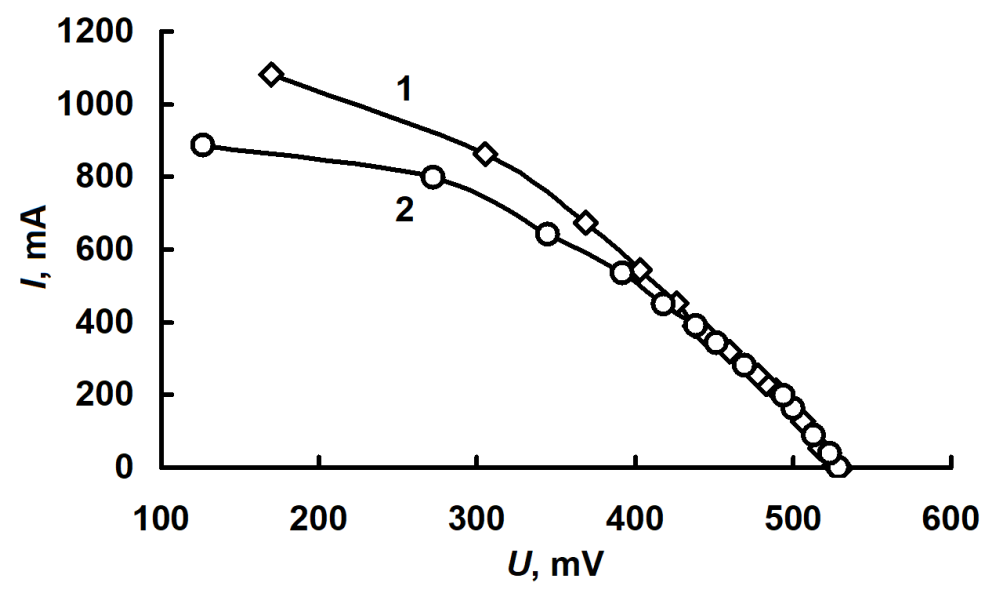

Figure 2.5. Current-voltage characteristics of a solar array model with blocking PPTC-fuses. All photovoltaic cells have room temperature (1) and one (2) is overheated, i.e. has a temperature above the limit for the fuse.

The sequence of studies was as follows. The dependences $I(U)$ and $P(U)$ of the solar array model were measured at room temperature without the connection of fuses and with the connection of fuses, which are in a highly conductive state at room temperature (Fig. 2.4).

Next, one of the circuits of photovoltaic cell - PPTC-fuse was heated to a temperature above the tripping temperature of the fuse. It was then cooled to room temperature, and the current-voltage characteristics and power curves of array were measured again.

As can be seen from Fig. 2.5, the introduction of resettable fuses in the electrical circuit of the solar array model does not affect its functional photovoltaic characteristics in the case of serviceability of all its photovoltaic cells.

Fig. 2.5 and 2.6 show the characteristics of the studied model of the solar array, in the presence of failure, i.e. when one of the circuits of the photovoltaic cell PPTC-fuse has a temperature above the transition point of the blocking fuse in the low-conductivity (insulating) state. This state can be reached both at the expense of increase in temperature of the specified block and at the expense of its heating by an electric current. 


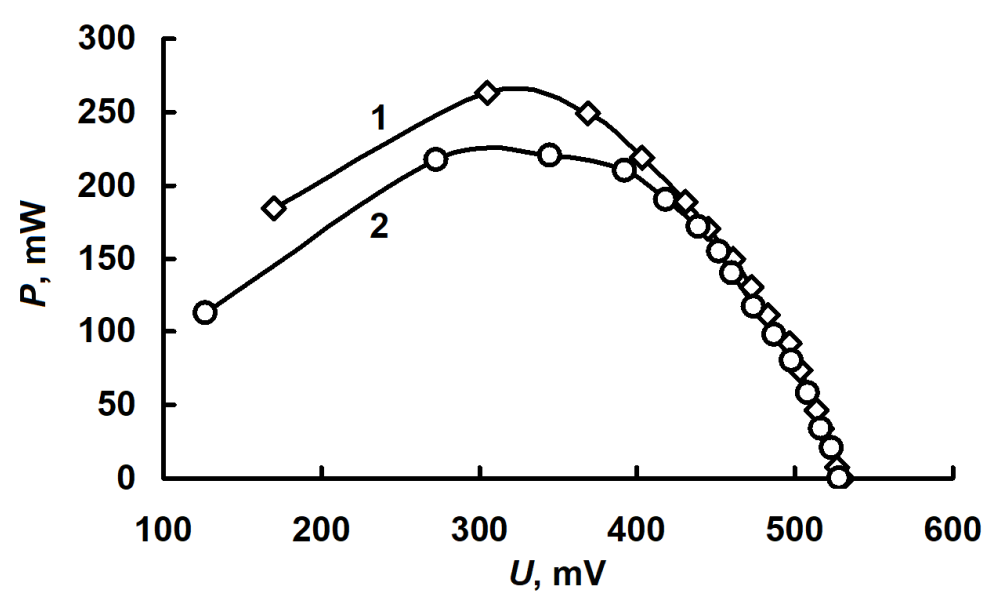

Figure 2.6. Power curves of a solar array model with blocking PPTC-fuses. All photovoltaic cells have room temperature (1) and one (2) is overheated, i.e. has a temperature above the limit for the fuse.

As can be seen, such a failure (overheating) of individual elements leads to similar results, which are obtained when using mechanical shutdown or blocking using diodes.

\subsubsection{Influence of ambient temperature}

The electrical characteristics of PPTC fuses are strongly dependent on the ambient temperature, which follows from the principle of its operation. As already mentioned, due to carbon channels in the unheated state, such a fuse is a conductor with low internal resistance, and when heated above a certain temperature, the conductive carbon channels are broken due to bulk expansion of the polymer matrix and / or transformation of the crystal matrix structure into amorphous.

In terms of implementation of protection against overheating of individual elements and components of solar arrays, a strong temperature dependence of the resistance of PPTC elements is quite functionally efficient. It is important to determine the influence of this factor on the functional properties of solar arrays. 
Fig. 2.7 shows that when the ambient temperature changes in the temperature range below the tripping point of the PPTC-fuse, the current-voltage characteristics and power curves of the solar array model studied here are independent of the presence of resettable fuses in series with photovoltaic cells.
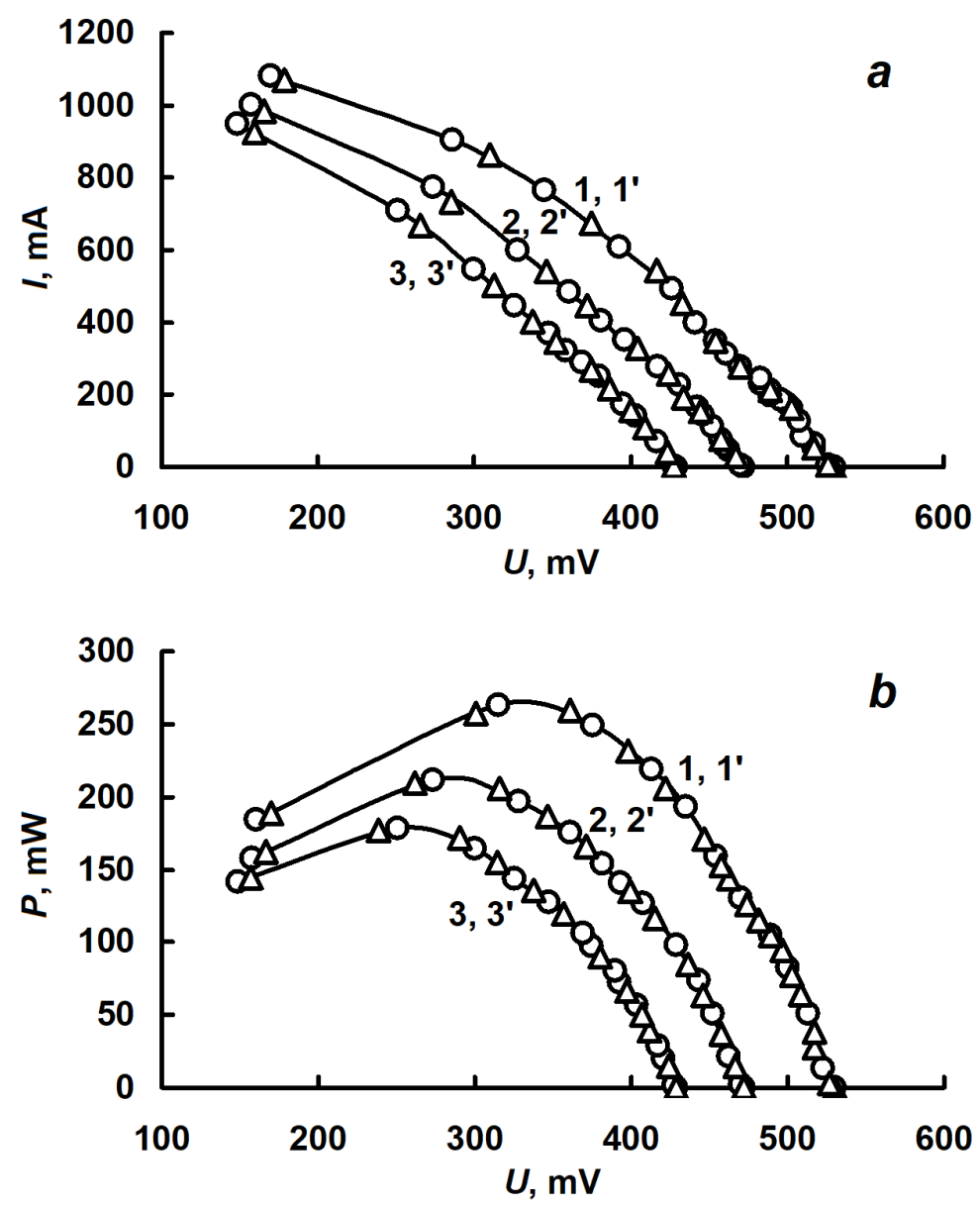

Figure 2.7. Current-voltage characteristics $(a)$ and power curves $(b)$ of the solar array model without $(1,2,3)$ and with blocking PPTC-fuses $\left(1^{\prime}, 2^{\prime}, 3^{\prime}\right)$ at different ambient temperatures, ${ }^{\circ} \mathrm{C}: 1,1^{\prime}-25 ; 2,2^{\prime}-40 ; 3,3^{\prime}-55$.

When using PPTC structures as protection against large currents, the temperature factor causes specific effects in their behavior. In particular, when the ambient temperature rises, there is some reduction in the current and time of tripping of the fuses. The higher the specified temperature, the lower the electrical power 
required to reach the temperature point of transition of the PPTC structure to the lowconductivity state. Also, it heats up faster. The range of tripping time starts from units of milliseconds to several seconds $[32,33]$.

\subsubsection{Influence of resettable fuses on the stability of photovoltaic characteristics}

The specificity of the tripping of PPTC-fuses, which is caused by thermal switching, is a long recovery process (can take several days or more, and is not complete in the real time of operation of the devices at real ambient temperatures $\left.\sim 20^{\circ} \mathrm{C}\right)[47,48]$. In this regard, to characterize the kinetics of the recovery process, the resistance parameter of the fuse after one hour of recovery at a given ambient temperature $R_{1 \max }$ is used. After each tripping, the resistance of the PPTC-fuse in the conductive state may drift and, as a rule, may increase slightly.

However, the range of the specified drift of resistance $R_{1 \max }$ in the operating (high-conductivity) state for the investigated PPTC-fuses was insignificant, which was checked by direct connecting of their samples, which were subjected to different numbers of cyclic trippings, in the solar array circuit.

This result can be considered as evidence of the absence of the influence of the considered kinetic thermal effects on the stability of the photovoltaic characteristics of the considered objects. The obtained pattern corresponds to the well-known idea that, firstly, the number of transitions from the conductive state to the non-conductive state and back, guaranteed by manufacturers, is of the order of several thousand, i.e. their number is almost unlimited. Secondly, in the high-conductivity state, PPTC-fuses, as a rule, have rather low resistance, which is either virtually unchanged [47], or its changes are small [48], and does not affect the performance and protection characteristics of the photovoltaic cell and other electronic devices. 
Thus, PolySwitch polymer elements function as reusable (resettable) fuses that do not need to be replaced and at the same time prevent current (thermal) overload of the object.

The discrepancy between the operating temperature range for photovoltaic modules (maximum temperature $\sim 80^{\circ} \mathrm{C}$ ) and the most common types of commercial PPTC-fuses, for which the beginning of the phase transition region (tripping) is estimated to be close to the specified temperature (Fig. 2.3). A significant change in resistance is observed at higher temperatures. This situation to some extent limits their widespread use as elements of protection against overheating, especially if the cause of overheating is temporary. 


\section{Chapter 3}

\section{CURRENT LIMITATION IN THE COMPONENTS OF SOLAR POWER PLANTS USING POLYSWITCH RESETTABLE FUSES}

One of the most undesirable sources of unreliability of photovoltaic components of solar arrays is current overloads and the occurrence of losses, including shortcircuits in them, as well as short-circuits between their connecting contacts [49, 51], Chapter 1. Here as photovoltaic (photogenerating) components are meant photovoltaic cells and photovoltaic modules. The physical causes of such situations may be corrosion damage during operation of their components, "hidden" manufacturing defects, faulty blocking and bypass diodes or the results of insulation degradation under the influence of the environment [49].

This is especially important for PVM based on thin-film silicon, where there is the formation of shunts as "hidden" defects in production, and due to the reverse displacement of cells caused by shading of modules or individual PV-cells of solar arrays during its operation. It is intensified by the fact that for thin-film modules, preventive measures using bypass diodes may not be possible to limit the reverse voltage on inactive PV-cells [1, 19].

The most unfavorable consequences of mentioned short-circuits occur in parallel connections of photovoltaic components (Chapter 1). In this case, they lead to the failure of the entire connection and the occurrence of significant overheating due to significant currents created by summing the currents of individual such elements. As a result, it can lead to abnormal (fire hazardous) situations. Elimination or minimization of the influence of this factor on the operation of solar arrays is the most necessary condition for the wider use of parallel connections in the formation of modules and panels of solar arrays.

The use of resettable fuses of PolySwitch type $[46,50]$ instead of the currently used fuses to isolate such defective short-circuited photovoltaic components is one of the promising areas for this task. A necessary step here is the development and modeling of circuit solutions for photovoltaic systems using these fuses. 
This section proposes a circuit solution and analyses the possibilities of using resettable fuses of PolySwitch type to prevent and minimize current overloads in parallel connections of photovoltaic cells and their modules.

\subsection{Theoretical analysis}

\subsubsection{Simplified structure of photovoltaic system with current limitation}

As already mentioned, short-circuits are the most undesirable in parallel connections of both PV-cells and PVMs. Fig. 3.1 shows that a short-circuit of one component $P V_{i}$ in the absence of $\mathrm{RFu}$ leads to the loss of the entire parallel circuit containing other serviceable components.

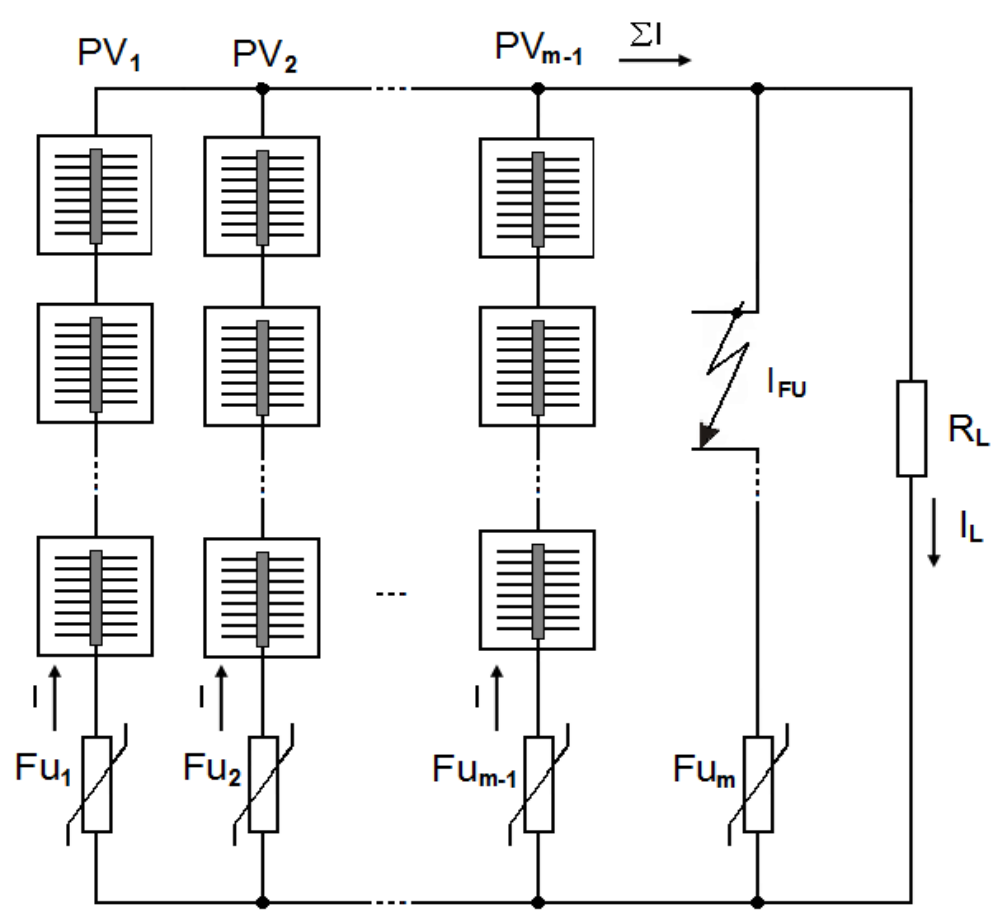

Figure 3.1. Simplified diagram illustrating short-circuit protection in parallel connection of photovoltaic components $P V_{i}(i=1,2, \ldots, m-1)$ using resettable fuses $F u_{i}(i=1,2, \ldots, m) . I_{L}, I_{F u}$ and $I$ - load resistor current $R_{L}$, short-circuit current and currents generated by $P V_{i}$. 
The presence of resettable fuses $F u_{i}$, connected in series with each photovoltaic component $P V_{i}$, allows to save and operate serviceable components in the presence of a short-circuit in one of them.

Mathematical model allows to analyze the considered effect of current limitation in case of short-circuit and to determine the most effective modes of such protection. It includes solving the problem of choosing equivalent circuits describing PV-cell and PVM, approximating the field dependence of the electrical resistance of $\mathrm{RFu}$, as well as formulating and solving the basic equations of this model to determine their current-voltage and power-voltage characteristics (PVC).

\subsubsection{Current-voltage characteristics of photovoltaic components}

PV-cells have nonlinear current-voltage characteristics that depend on the level of solar radiation, ambient temperature and the characteristics of the area. Currently, there are several basic circuits for the replacement of PV-cell, the mathematical description of which is used in modern modeling $[8,54,55]$. The best known of them contains a photocurrent source $\left(i_{p h}\right)$, a parallel-connected diode $(D)$ that simulates the $p$ - $n$ junction, a shunt resistance $\left(r_{s h}\right)$ that simulates leakage currents, and a series resistance $\left(r_{s}\right)$ that characterizes the internal resistance of the element and contacts (Fig. 3.2). In the operating mode of PV-cells (forward biased photodiode) the leakage current is neglected, i.e. it is assumed that $r_{s h}$ tends to infinity.

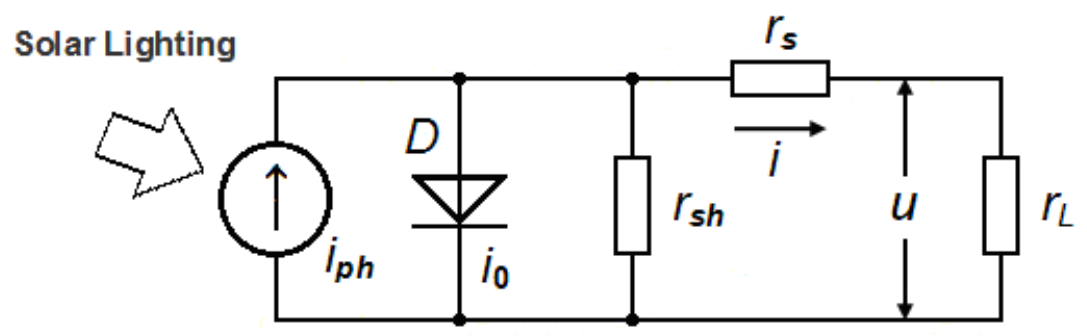

Figure 3.2. Equivalent circuit of PV-cell replacement. 
According to this substitution circuit, the output current of the PV-cell $i$ can be determined $[8,54]$ from the expression

$$
i=i_{p h}-i_{0}\left\{\exp \left[\frac{q\left(u+i r_{s}\right)}{A k T}\right]-1\right\},
$$

where $A$ - coefficient that depends on the physical properties of materials and parameters of the $p-n$ junction (for silicon is taken equal to $1.2-1.8$ accordingly [8, 56]); $k$ - Boltzmann constant; $T$ - absolute temperature of PV-cell; $q$ - electron charge; $u$ - the output voltage of the PV-cell; $i_{0}$ - reverse current of the $p-n$ junction of the diode; $r_{L}$ - load resistance.

PVMs are formed at serial, parallel or combined connection of photovoltaic cells. Various forms of their representation are used to determine the equivalent current-voltage characteristics of such connections $[2,8,57-60]$. For the model under consideration (Fig. 3.1), which corresponds to the parallel connection of $m$ PVMs (each of which is a series connection of $n \mathrm{PV}$-cells), the most suitable is expression, directly based on the formula $(3.1)[8,56,58-59]$

$$
I=I_{S C}\left\{1-\exp \left[\frac{U-U_{O C}+I R_{S}}{U_{T}}\right]\right\},
$$

where $I_{S C}=m \cdot i_{S C}-$ short-circuit current of the photovoltaic module;

$i_{S C}=i(u=0)=i_{p h}-$ short-circuit current of the PV-cell (the greatest current made by PV-cell under condition of closing of its contacts);

$U_{T}=(A k T / q) n-$ equivalent thermal voltage of the module;

$U_{O C}=n u_{O C}-$ open-circuit voltage of the module;

$u_{O C}=u(i=0)=(A k T / q) \ln \left[\left(i_{p h}+i_{0}\right) / i_{0}\right]-$ open-circuit voltage of the PV-cell (voltage drop at the $p-n$ junction, which creates a photocurrent $i_{p h}$, if the current in the external circuit $i$ is zero;

$R_{s}=r_{s} n / m-$ equivalent series resistance of the module. 


\subsubsection{Approximation of electrical characteristics of PolySwitch posistor element}

As is known, PolySwitch resettable fuses have a temperature dependence of RFu resistance, increasing with increasing temperature, which has three characteristic regions (Chapter 2). At relatively small values temperature (region 1 ) there is a gradual increase in their resistance to temperature. In the narrow temperature range of about $125^{\circ} \mathrm{C}$ there is a sharp increase (by several orders of magnitude) in the $\mathrm{RFu}$ resistance (region 2). With a further temperature increase, the dependence of the resistance of these devices on temperature also has a smooth increasing character (region 3) [33].

Regions 1 (high-conductivity state) and 2 (abrupt transition to low-conductivity state) have technical application. As the main parameters important for their application in the circuit of Fig. 3.1, should be adopted:

$R_{F u 0}$ - resettable fuse resistance in the conductive state (determined by the passport values of $R_{\min }-$ minimum device resistance at $T_{0}\left(T_{0} \sim 23{ }^{\circ} \mathrm{C}\right)$ or $R_{1 \max }-$ maximum device resistance at a given ambient temperature $T_{0}$, after one hour tripping).

$I_{\text {trip }}$ - resettable fuse tripping current, i.e. the minimum current through RFu at which there is a transition from the conducting state to the non-conductive.

Protection of parallel connection of photovoltaic components of solar arrays (Fig. 3.1) can be realized at performance of the following conditions [61]

$$
R_{F u 0}=R_{\min }\left(\text { or } R_{1 \max }\right)<<n R_{s}^{*},
$$

where $R_{S}{ }^{*}=r_{S}$ or $R_{S}{ }^{*}=R_{S}$ in series connection of $n$ cells or modules, respectively.

That is, the presence of such fuses in the electrical circuit should not affect the normal operation of photovoltaic components.

Second condition

$$
(n-1) \cdot I^{*}>I_{t r i p}>I_{S C}{ }^{*}
$$


where $I^{*}=i, I_{S C} *=i_{S C}$ and $I^{*}=I, I_{S C} *=I_{S C}$ in series connection of $n$ cells or modules, respectively.

That is, the tripping current of the PolySwitch fuse must be greater than the short-circuit current of a single component (individual photovoltaic module or photovoltaic cell) and less than the current of their parallel connection in the operating mode $(m-1) \cdot I^{*}$, where $(m-1)$ is the number of serviceable photovoltaic components.

Given the characteristic of $\mathrm{RFu}$ tripping current decrease with increasing temperature, it should be noted that the first of these requirements must be met at the maximum possible operating temperature of the $\mathrm{PV}$-cell $\left(\sim 60-80^{\circ} \mathrm{C}[46]\right)$.

\subsubsection{Equation for the current-voltage characteristics of the photovoltaic system}

Determination of the analytical expression for the CVC of the system on Fig. 3.1 can be made on the basis of equation (3.2). In particular, the presence of RFu can be accounted for by replacing in the corresponding equivalent circuit and formula of the series resistance $r_{s}$ by its sum with the part of the resistance RFu attributable to each PV-cell in their series connection, i.e. $\left(R_{S}{ }^{*}+R_{F u}\right)$. It should be noted that in accordance with the basic principle of using RFu [26], their resistance before tripping with increasing temperature is negligibly small compared to the sequential resistance of a single PVM, and thus in the normal mode can be taken $R_{F u 0}<<R_{S}{ }^{*}$.

The presence of a short-circuit of one photovoltaic component in accordance with the circuit on Fig. 3.1 can be considered as a parallel connection of the load resistance $R_{L}$ and the fuse resistance $R_{F u}\left(I_{F u}\right)$, which depends on the amount of current $I_{F u}$ flowing through it. It should be noted that the load resistance $R_{L}$ to simplify the calculations was taken as active, although it can be reactive (e.g., capacitive) or complex in the general case. 
Let's take into account that:

$$
U=U\left(I_{F u}, R_{L}\right)=I\left(I_{F u}, R_{L}\right) \frac{R_{F u}\left(I_{F u}\right) R_{L}}{R_{F u}\left(I_{F u}\right)+R_{L)}},
$$

where $I\left(I_{F u}, R_{L}\right)=I_{F u}+I_{L}$ is the value of the total current through the short-circuited circuit element and the load resistance.

Taking into account (3.5) the equation for calculating the CVC of the considered photovoltaic system (in the presence of a short-circuited one of its modules) can be obtained on the basis of (3.2), which after transformation (solution with respect to $U$ ) will look like this:

$$
U\left(I_{F u}, R_{L}\right)=U_{T} \ln \left[\frac{I_{S C}-I\left(I_{F u}, R_{L}\right)}{I_{S C}}\right]-U_{O C}+I\left(I_{F u}, R_{S}\right) R_{S},
$$

where $I\left(I_{F u}, R_{L}\right)=I_{F u}\left[1+\frac{R_{F u}\left(I_{F u}\right)}{R_{L}}\right]$.

When determining the parameters $U_{T}, I_{S C}, U_{O C}$, and $R_{S}$ it is necessary to replace the value of $m$ (the number of PVMs connected in parallel in the diagram of Fig. 3.1) with $(m-1)$.

The CVC of resettable fuse, like any posistor element, is represented by an $\mathrm{N}$-shaped dependence and can be determined in parametric form, where the heating temperature is used as such a parameter $[62,63]$. However, the use of such representations significantly complicates the problem. To simplify it, which allows to obtain a clear adequate result, it is possible to use ideas about the abrupt change in the resistance of the RFu in the field of currents close to the tripping current $I_{\text {trip }}$. Thus, it can be assumed that the dependence $R_{F u}\left(I_{F u}\right)$ takes the form of the switching function, which can be approximated in the form of the function

$$
R_{F u}\left(I_{F u}\right)=\left\{\begin{array}{l}
R_{F u}, \text { if } I_{F u}<I_{F u} ; \\
R_{F u 0}\left(\frac{I_{F u}}{I_{F u} 0}\right)^{\alpha}, \text { if } I_{F u} \geq I,
\end{array}\right.
$$

where $R_{F u 0}=R_{\min }\left(\right.$ or $\left.R_{1 \max }\right) ; I_{F u}=I_{\text {trip }}$. 


\subsubsection{Electrical characteristics of photovoltaic system with current limitation}

As already mentioned, the parameters that determine the effectiveness of the $\mathrm{RFu}$ use to protect photovoltaic systems from short-circuits are the resistance of the fuse in the conductive state $R_{F u}$ and its tripping current $I_{F u 0}$.

To study the functioning of the considered technical means of protection, numerical experiments were performed on the basis of the photovoltaic system (Fig. 3.1) with components based on elements with typical parameters given in Table 3.1.

Table 3.1

Parameters of the elements of the model of the photovoltaic system

\begin{tabular}{|c|c|c|}
\hline \multirow{2}{*}{ Component } & Parameters & Accepted values \\
\hline \multirow{2}{*}{ PV-cell [57] } & $i_{0}$ & $1 \mu \mathrm{A}$ \\
\cline { 2 - 3 } & $i_{p h}$ & $0.039 \mathrm{~A}$ \\
\cline { 2 - 3 } & $r_{s}$ & $2 \mathrm{Ohm}$ \\
\cline { 2 - 3 } RFu (RXEF series) [64] & $A$ & 1.8 \\
\cline { 2 - 3 } & $R_{F u 0}$ & $0.1-1 \mathrm{Ohm}$ \\
\hline $\begin{array}{c}\text { Number of series-connected } \\
\text { PV-cells }\end{array}$ & $I_{F u 0}$ & $0.3-1 \mathrm{~A}$ \\
\hline $\begin{array}{c}\text { Number of parallel connected } \\
\text { PVMs }\end{array}$ & $n$ & 36 \\
\hline
\end{tabular}

The parameter $\alpha$ in formula (3.7) was taken equal to 25 .

The influence of the resistance $R_{F u 0}$ on current-voltage and power-voltage characteristics of the studied photovoltaic system is shown in Fig. 3.3 and 3.4.

The influence of the value of the tripping current $\mathrm{RFu}$ on the similar characteristics of this photovoltaic system are shown in Fig. 3.5. 


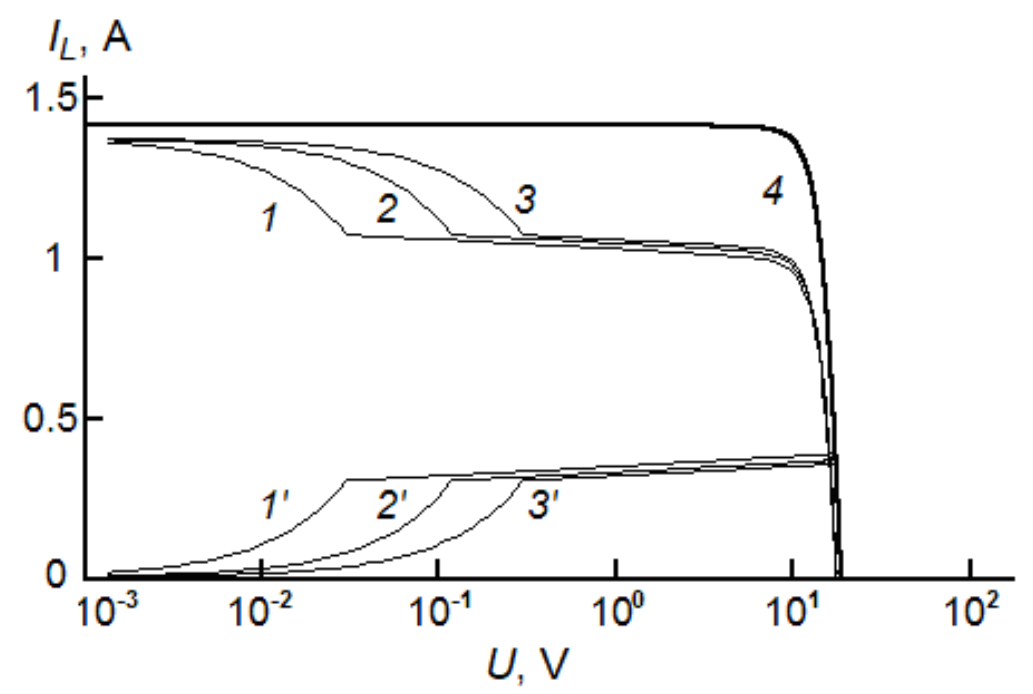

Figure 3.3. Current-voltage characteristics $I_{L}(U)$ (curves $\left.1-4\right)$ and current dependence through the $m$-th $\mathrm{RFu} I_{F u}(U)\left(I^{\prime}-3^{\prime}\right)$ of the simulated photovoltaic system in the presence of a short-circuit of the $n$-th component. RFu parameters $I_{F u 0}=0.3 \mathrm{~A}$ and $R_{F u 0}$, Ohm: $1-0.1 ; 2-0.4 ; 3-1$. Curves 4 corresponds to the absence of short-circuit.

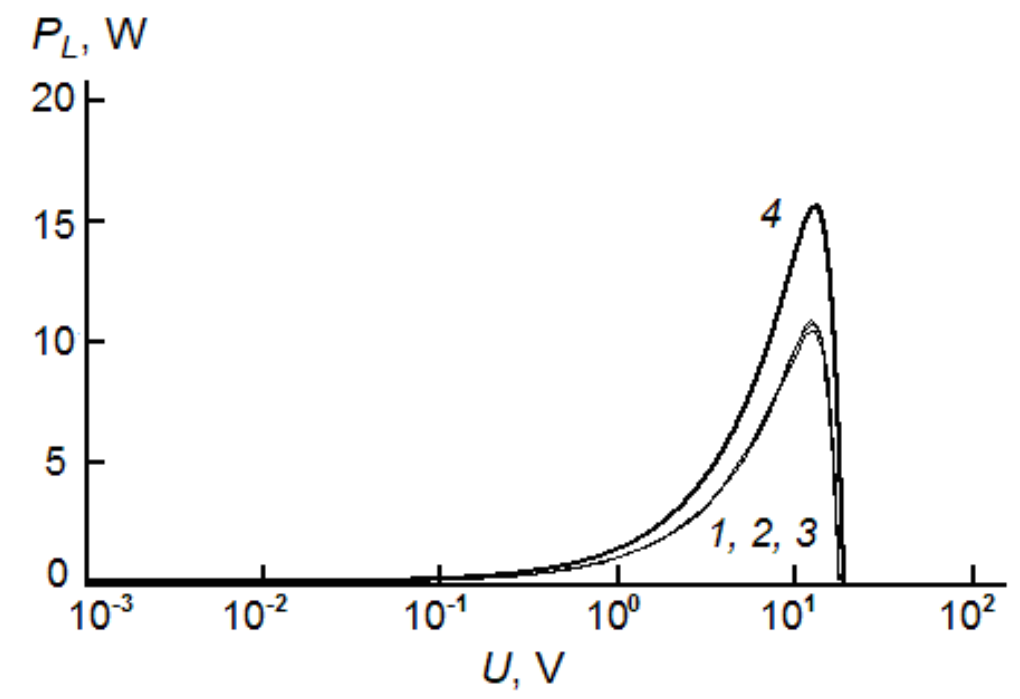

Figure 3.4. Power-voltage characteristics $P_{L}(U)$ of the simulated photovoltaic system in the presence of a short-circuit of one of its components. Parameters and designations correspond to those adopted in Fig. 3.3. 

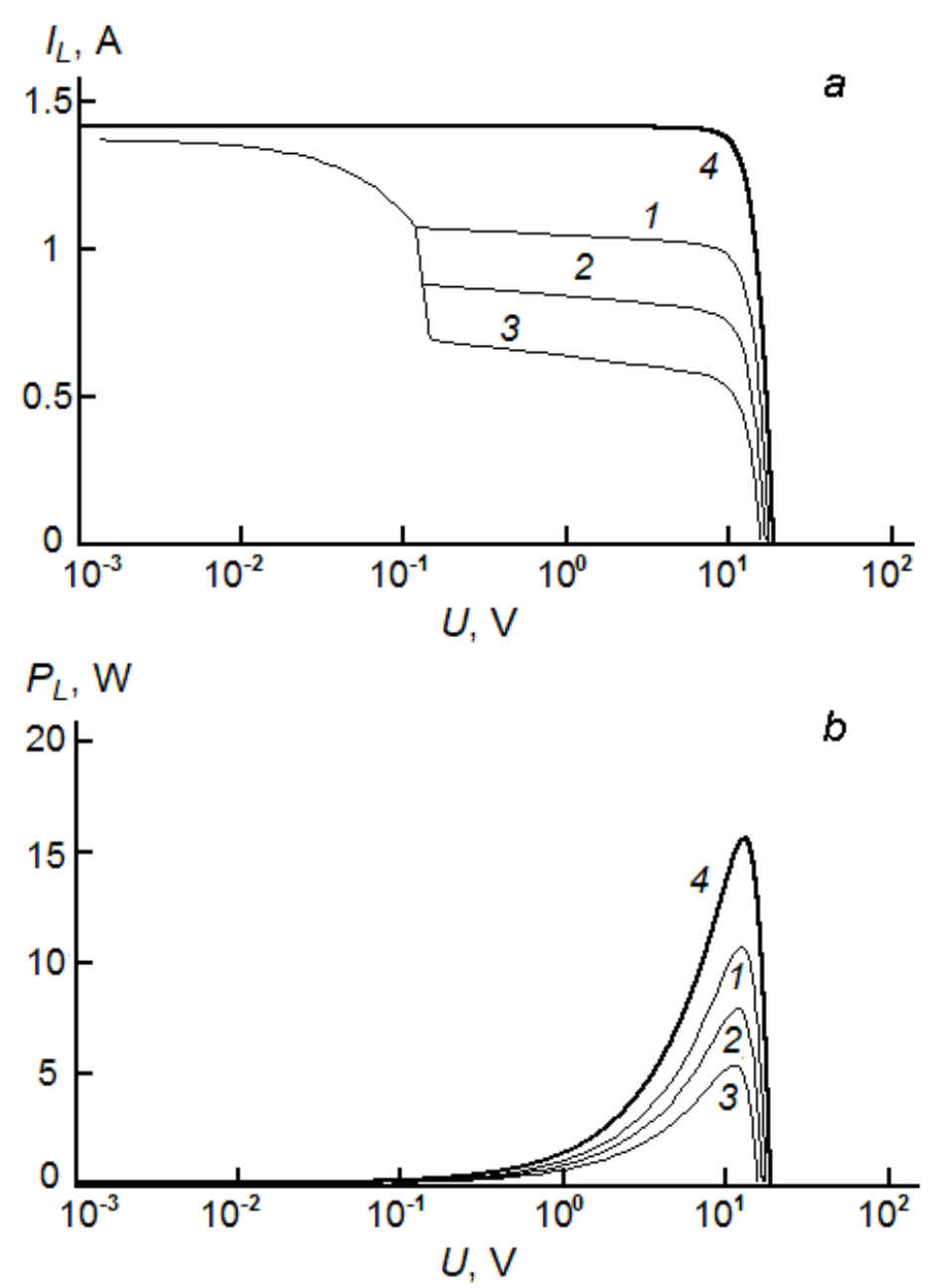

Figure 3.5. Current-voltage $(a)$ and power-voltage $(b)$ characteristics of the simulated photovoltaic system with a short-circuit of one of its components. RFu parameters $R_{F u 0}=0.4 \mathrm{Ohm}$ and $I_{F u 0}, \mathrm{~A}: 1-0.3 ; 2-0.5 ; 3-0.7$. Curves 4 corresponds to the absence of short-circuit.

As can be seen from Fig. 3.3, the effect of RFu resistance in the conductive state $R_{F u 0}$ occurs in the range of very low voltage $U$. It limits the initial section of the considered dependence, where the load resistance $R_{L}$ is less than $R_{F u 0}$ and there is almost no selection of current from the load on the fuse. As the $R_{F u 0}$ resistance decreases, this section decreases.

At higher $R_{L}$ values, the current through the RFu increases, which leads to the tripping of the latter. The result is a typical for photovoltaic systems dependence $I_{L}(U)$, but with the value of short-circuit current, reduced by a value that is the sum of 
currents disconnected (short-circuited) from the series connection of PV-cells $(\mathrm{PVm})$ and tripping current of fuse $F u_{m}$.

$\mathrm{RFu}$ presence leads only to a certain decrease in the electric power generation by the photovoltaic system, and not its complete failure (Fig. 3.4). Changing the resistance of the fuse in the conductive state has little effect on PVC.

According to data on Fig. 3.5a and $b$, variations in the tripping current of the fuse determine changes in the maximum current and electric power generation in the operating range, where short-circuit protection is implemented, i.e. where RFu is in a state with a high resistance value. Reducing the value of $I_{F u 0}$ reduces the energy cost of maintaining the fuse in a low-conducting state when the fuse blocks the shortcircuit of the component in a parallel circuit. As a result, this leads to an increase in the load current $I_{L}$ and the power $P_{L}$, i.e. to increase the efficiency of the entire photovoltaic system. The main limitation from the bottom in determining the tripping current of $\mathrm{RFu}$ is the requirement of the absence of any effect of the fuse on the normally functioning (in the absence of its short-circuits of this type) photovoltaic component, i.e. $I_{F u 0}>I_{S C}$.

Losses of the generated electric energy on operating the fuse in a situation of short-circuit of one of parallel connected photovoltaic components can be smaller, than received within the limits of this model. The latter is based on the approximation of the characteristics of the RFu switching function, which does not take into account that with increasing voltage drop across the fuse, its current may decrease.

\subsection{Results of experimental studies of current limitation}

\subsubsection{Photovoltaic system with current limitation}

To experimentally study the capabilities of fuses of this type for protection against current overloads and short-circuits in photovoltaic systems of solar arrays, a 
model structure was investigated, which is a parallel connection of several seriesconnected photovoltaic modules $\left(P V_{\mathrm{i}}\right)$ and $\mathrm{RFu}\left(F u_{i}\right)[65,66]$. The load of such power supply was a resistance box (Fig. 3.6).

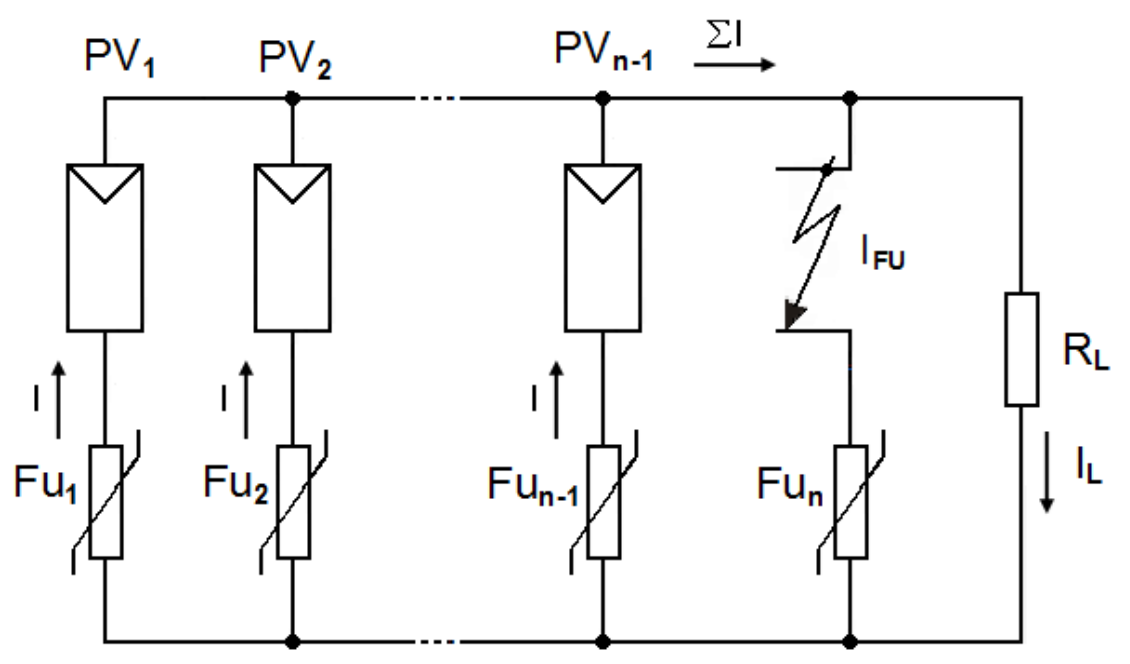

Figure 3.6. Electric diagram illustrating short-circuit protection in parallel connection of photovoltaic components $P V_{i}(i=1,2, \ldots, n-1)$ using resettable fuses $F u_{i}(i=1,2, \ldots, n) . I_{L}, I_{F u}$ and $I$ - load resistor current $R_{L}$, short-circuit current, and currents generated by module $P V_{i}$.

As already mentioned (subsection 3.1), a short-circuit of one photovoltaic module $P V_{n}$ such photovoltaic system (PVS) in the absence of RFu leads to a loss of power generated by the entire parallel circuit containing other serviceable components.

The presence of resettable fuses $F u_{i}$, connected in series with each photogenerating component $P V_{i}$, allows to save and operate a working part of the parallel circuit of the PVS in the event of a short-circuit in one of them.

RFus were selected so that two conditions were met (3.3 and 3.4). For the specific circuit considered here, they have the following form.

The first thing that follows from the fact that the presence of such fuses in the electrical circuit should not affect the PVM normal operation: 


$$
R_{\min }\left(\text { or } R_{1 \max }\right)<<R_{S},
$$

where $R_{\min }$ (or $R_{1 \max }$ ) - RFu resistance in the conductive state (determined by the passport values of $R_{\min }-$ minimum device resistance at $T_{0}\left(T_{0} \sim 23{ }^{\circ} \mathrm{C}\right)$ or $R_{1 \max }$ - maximum device resistance at a given ambient temperature $T_{0}$, after one hour tripping); $R_{S}$ - equivalent series resistance of the module.

The second condition that determines the moment of RFu tripping: the tripping current of the RFu (i.e. the minimum current through the RFu at which the transition from the conductive state to the non-conductive) must be greater than the shortcircuit current of one (separate) PVM and less than the operating current of the parallel connection of the PVM in the operating mode:

$$
(n-1) \cdot I>I_{\text {trip }}>I_{S C} \text {. }
$$

The main measured characteristics were current-voltage and power-voltage (power curve) characteristics of the described above model. The experiments used PVS consisting of three PVMs, one of which is shorted. A special experimental automated measuring complex described in $[51,67]$ was used to register light CVC. The stand allowed to use natural solar radiation as a light source.

Experimental studies used PVM samples developed on the basis of industrial silicon wafers SEF-4.5 [68], and PPTC of FRX375-60F type [69]. The evaluation of the effective series resistance of the used PVMs carried out according to the method $[70,71]$ was $\sim 1 \mathrm{Ohm}$. Passport values of the $\mathrm{RFu}$ parameters were $R_{\min }=0.03 \mathrm{Ohm}$ (or $R_{1 \max }=0.08 \mathrm{Ohm}$ ) and $\approx 3.5 \mathrm{~A}$ at a temperature of $\sim 50{ }^{\circ} \mathrm{C}$.

\subsubsection{Experimental photovoltaic characteristics and their discussion}

The sequence of calculations was as follows. The dependences of the current of the described photovoltaic system $I_{L}$ on the value of the resistance of the load resistor $R_{L}$ corresponding to the situations (modes) were measured:

- without connecting resettable fuses (mode I); 
- with the connection of fuses in series with each photovoltaic module (mode II);

- without fuses with one short-circuited module (mode III);

- with the connection of fuses in series with each photovoltaic module, one of which is short-circuited (mode IV).

Fixation of $I_{L}\left(R_{L}\right)$ dependence points corresponding to the specified modes was practically simultaneous, which was achieved by using appropriate switches.

The obtained experimental dependences $I_{L}\left(R_{L}\right)$ are presented in Fig. 3.7.

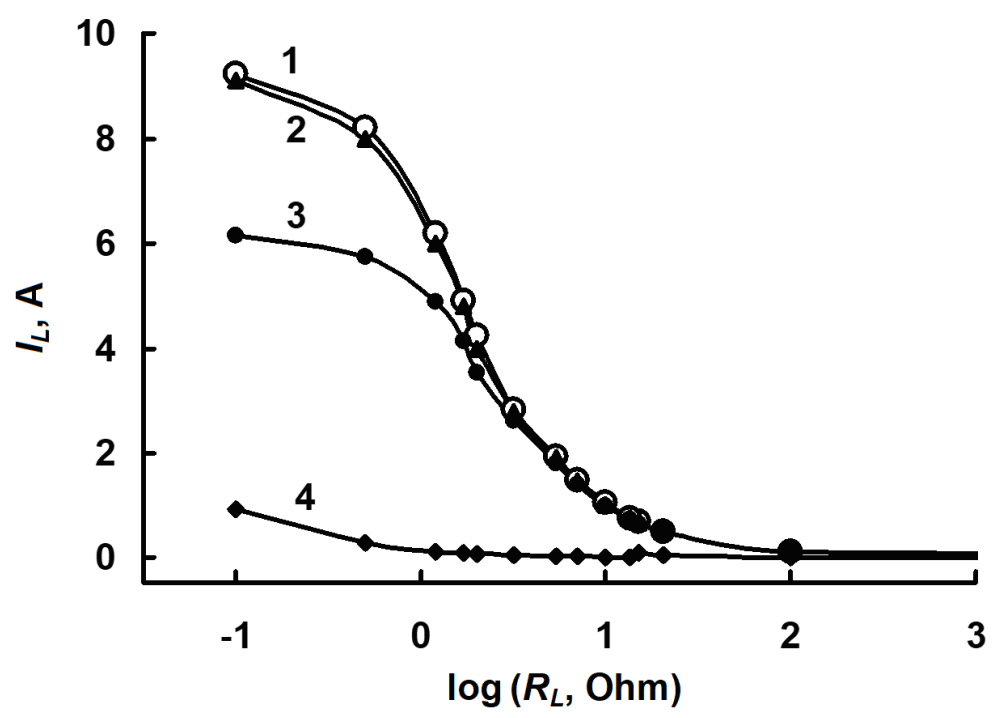

Figure 3.7. Dependences of current of parallel connection of photovoltaic modules, in a circuit of each of which the resettable fuse is consistently in series, on the value of the resistance of the load resistor $I_{L}\left(R_{L}\right)$ corresponding to modes:

$$
\text { I - curve } 1 \text {; II - 2; III - 4; IV - } 3 \text {. }
$$

Current-voltage and power-voltage characteristics that correspond to the modes described above, except for mode III, when these characteristics degenerate almost to the point $\left(I_{L}=0 ; U=0\right)$ are presented in Fig. 3.8.

Comparing, almost identical dependences $I_{L}\left(R_{L}\right), I_{L}(U)$ and $P(U)$, measured in modes I and II, we can unequivocally conclude that in this experiment, condition (3.8) is fulfilled: the inclusion of the selected RFu in series with each PVM has little effect on the electrical properties of the considered photovoltaic system. 

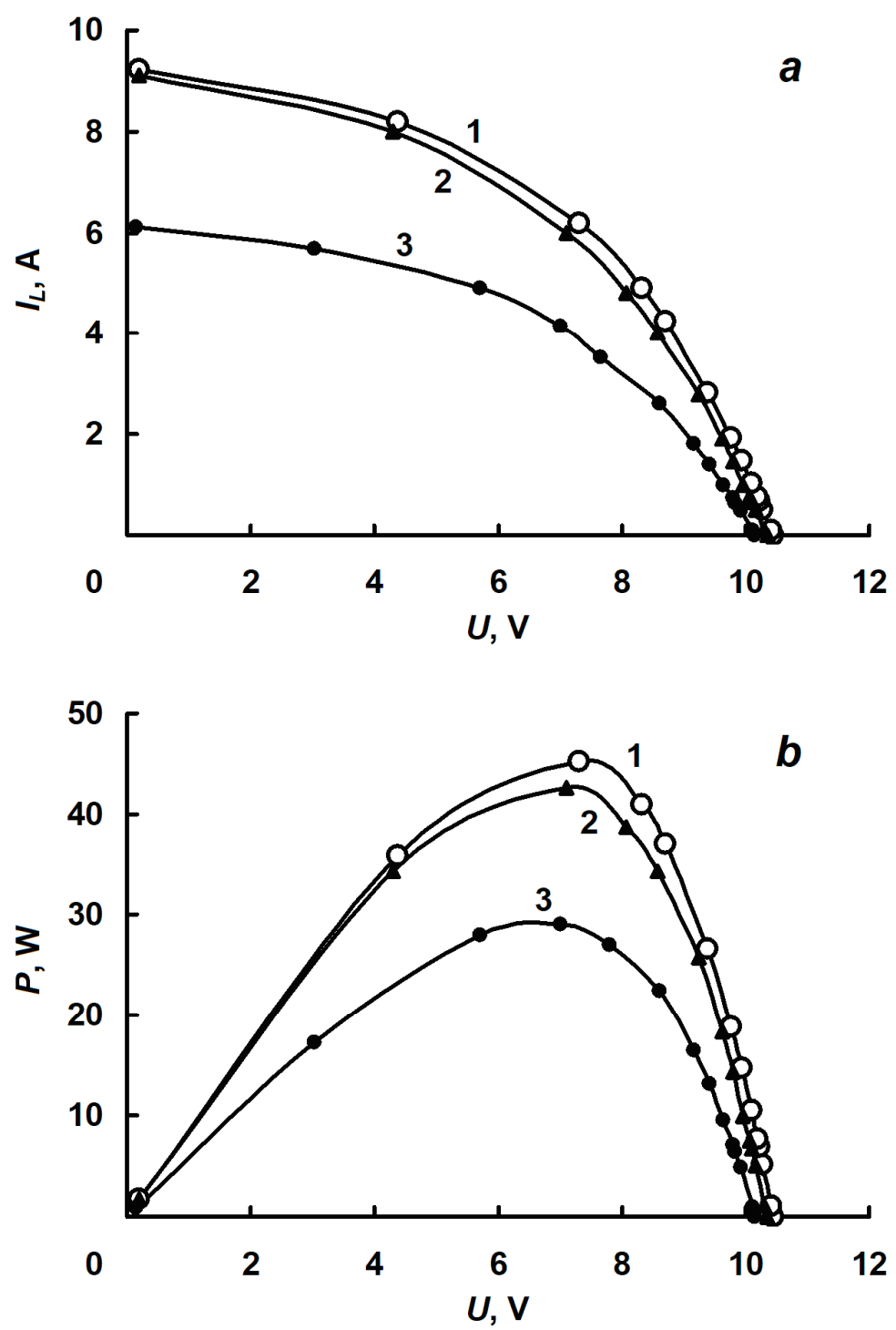

Figure 3.8. Current-voltage (a) and power-voltage (b) characteristics of the parallel connection of photovoltaic modules in modes I (curve 1), II (2), IV (3).

In case of a short-circuit of one of the PVMs without resettable fuses connected in series (mode III), the total load resistance of the PVS is a parallel connection of the short-circuited PVM resistance and the load resistance $R_{L}$. In the range of small resistances $R_{L}$, close to the resistance of the short-circuited PVM, there is a division of the total current of the PVS into the components of the current of the load resistor $I_{L}$ and the current of the short-circuited module $I_{F u}$ as observed in Fig. 3.7. When the 
resistance $R_{L}$ exceeds the resistance of the shorted PVM, the transmission of electrical energy in the load circuit is virtually absent (PVS is inoperable).

In the case of series-connected resettable fuses (mode IV) is the tripping of the $\mathrm{RFu}$ and there is only a slight decrease in the load current of the PVS (Fig. 3.7 and 3.8a), caused by the shutdown of the short-circuited PVM. In general, the PVS can be considered operational, because it is able to give electricity to the load, although less (Fig. 3.8b, curve 3). 


\section{Chapter 4}

\section{VOLTAGE LIMITATION USING VARISTOR-POSISTOR PAIRS IN PHOTOVOLTAIC MODULES}

The formation of "hot spots" is associated with the internal structure of photovoltaic modules. As is known, they consist of tens of series-connected individual semiconductor photovoltaic cells, each of which behaves as an independent current source. The identity of their electrical characteristics is one of the determining factors in ensuring the optimal mode of operation and reliability of such multicomponent systems. If, for some reason (in particular, due to a fault and/or shading), the current generated by one PV-cell is lower than the others, then it operates in the reverse bias mode and dissipates power. The level of danger of this mode is determined by such parameters of the volt-ampere characteristic of the internal $p$-n junction of the PV-cell [14] as the breakdown voltage $U_{b}$, the achievement of which leads to a significant increase in reverse current and, ultimately, to the destruction of the cell. The flow of current through the shunt resistance $r_{s h}$ leads to power dissipation and heating of the cell.

It should be noted that the maximum reverse voltage that can be applied to one $\mathrm{PV}$-cell depends on the number of cells connected in series, and to limit it, bypass diodes are used, which are antiparallel to two or more units of the module (submodules). With an average voltage drop across the forward biased of the PV-cell $\sim 0.6 \mathrm{~V}$ and the standard number of PV-cells in the submodule (up to 20), the reverse voltage on one of them is $11.4 \mathrm{~V}$. To ensure safe operation of the cell with its reverse bias, this value should be below its breakdown voltage [72-73]. However, according to the information given in $[1,65,73]$, the failure in the "hot spot" is one of the most commonly known phenomena that limit the service lifetime of the module. This is mainly due to the scatter of breakdown voltages (up to $10 \mathrm{~V}$ ) [19], and shunt resistance (up to $20 \mathrm{Ohm}$ ) [74]. 
As already mentioned in Chapter 1, one of the ways to solve this problem of isolation of "bad" (i.e., those that generate reduced photocurrent) individual PV-cells or their groups is the use of less expensive elements of solid-state electronics, particularly, resettable fuses of PolySwitch type [33, 35, 37, 46, 75, 76] and low-voltage varistors $[18,77,78]$. Of particular interest is the use to limit overvoltages of the circuit solution in the form of a combined two-layer structure of varistor and posistor layers, which are in thermal contact [80]. When applying the input overvoltage to such a structure, the heat released by the varistor layer, heats the series-connected layer of the posistor and causes an increase of its resistance. As a result, there is a redistribution of the input overvoltage between the layers, which can provide a limit at a given level of the output voltage of the varistor layer and, of course, on the parallel load.

A necessary step in the justification and application of electrical surge protection, which is based on the above principle, is the modeling and analysis of the operation of specific circuit solutions for PVM and other photovoltaic systems. This section analyses the possibilities of using varistor-posistor structures based on metal oxide varistor and $\mathrm{RFu}$ of PolySwitch type being in thermal contact to prevent overvoltage in series connections of PV-cells.

\subsection{Physical basics}

The photovoltaic module (solar panel) consists of series-connected PV-cells, which are divided into several submodules [80]. Each such submodule is equipped with a bypass diode, which is connected in parallel to it.

As was discussed earlier (1.2.1.2), the presence of shading or destruction of one or more cells leads to a decrease in the photocurrent generated by them. In this case, the bypass diode $D$ guarantees an alternative current path from other submodules (Fig. 4.1). The voltage across the submodule coincides with a low voltage drop across 
the forward biased diode (about $0.8-1 \mathrm{~V}$ for silicon diodes or $0.3-0.5 \mathrm{~V}$ for Schottky diodes depending on the excess current [73]), which corresponds to almost shortcircuit of the considered submodule.

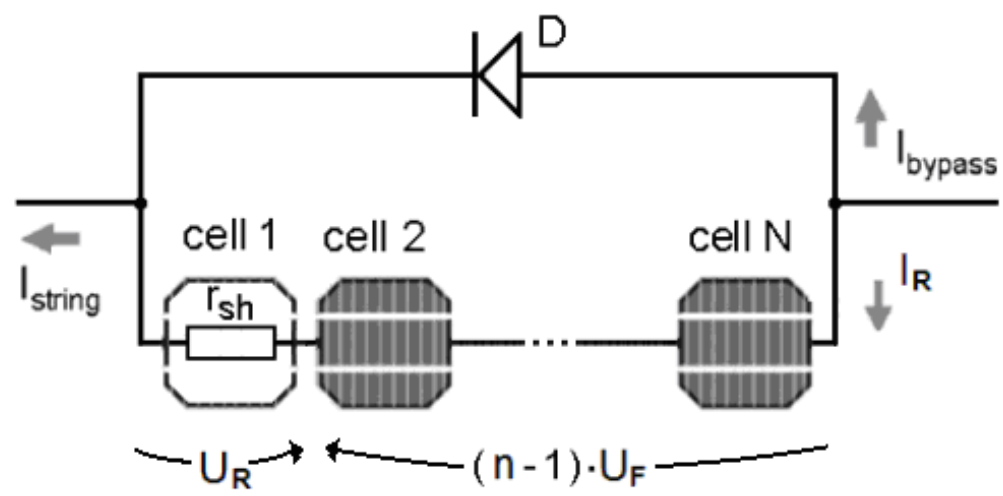

Figure 4.1. Simplified representations of a separate PVM submodule. PV-cell cell 1 is "bad". $D$ - bypass diode; $U_{F}$, and $U_{R}-$ voltage drop across the forward biased $p-n$ junction of the illuminated PV-cell and the reverse biased $p-n$ junction of the "bad" PV-cell; $r_{s h}$ - shunt resistance of PV-cell; $I_{\text {string }}, I_{\text {bypass }}$ and $I_{R}$ excess current coming from other submodules, current through the bypass diode $\left(I_{\text {bypass }} \approx I_{\text {string }}\right)$ and leakage current through $r_{s h}$ shaded PV-cell.

Illuminated cells inside the submodule can not give their generated photocurrents to the external electrical circuit, because the series connection is broken by "bad" cell. Forward bias on these PV-cells biases the "bad" element in the reverse direction, and it works as a load with resistance $r_{s h}$, not as a generator. The energy dissipation at such loads leads to inhomogeneous heating of the module, in particular to the appearance of areas of local heating ("hot spots") [73]. To prevent the voltage on the "bad" cell $U_{R}$ over the breakdown voltage of its reverse biased $p$ - $n$ junction $U_{b}$, the number of PV-cells in the submodule should be small. If this is not done, the PV-cell will heat up. High temperature in local areas of PV-cells can lead to "hot spots". Thus, with increasing cell temperature, a thermal breakdown of 
the $p$ - $n$ junction may occur, when the magnitude of the reverse voltage decreases with increasing current and there is a local thermal drift in time. This forms onedimensional current channels, which can lead to internal temperatures significantly exceeding $400{ }^{\circ} \mathrm{C}$ and damage to the PV-cell [19]. "Hot spots" with or without thermal breakdown can lead to degradation and complete destruction of PV-cells.

One of the means to prevent the concentration of high voltage on a separate PV-cell is to install a voltage limiting device parallel to it, as shown in Fig. 4.2.

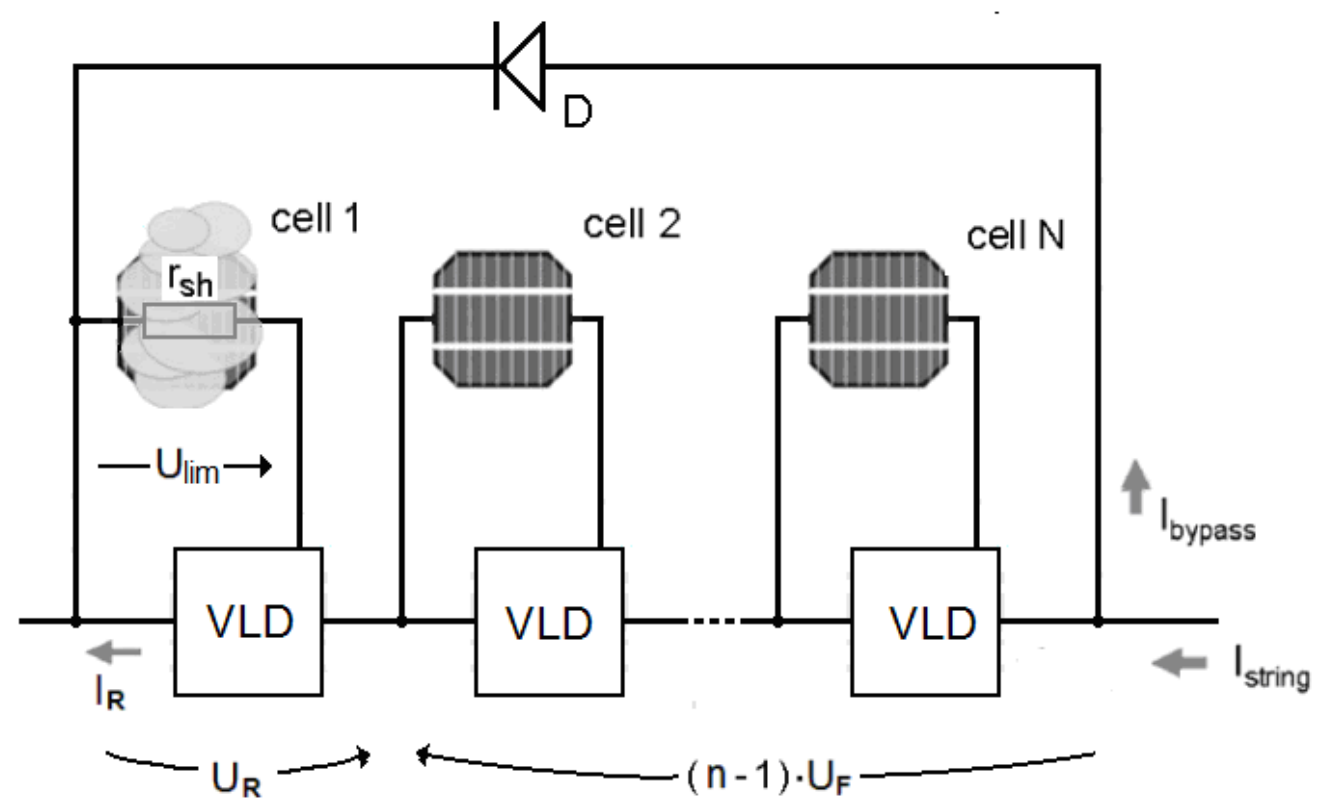

Figure 4.2. Circuit diagram of the voltage limiting device for individual protection of the photovoltaic cell. PV-cell cell 1 is accepted completely shaded. $U_{\text {lim }}$ - voltage on the "bad" PV-cell after the VLD. Other designations correspond to those adopted in Fig. 4.1.

Such a microminiature solid-state voltage limiting device (VLD) can be implemented on the basis of a structure consisting of series-connected with direct thermal contact layers of varistor ceramics (with electrical resistance $R_{U}$ ) and used in 
$\mathrm{RFu}$ posistor polymer nanocomposite (with $R_{F u}$ resistance) $[80,81]$, can be represented in Fig. 4.3 by an equivalent circuit.

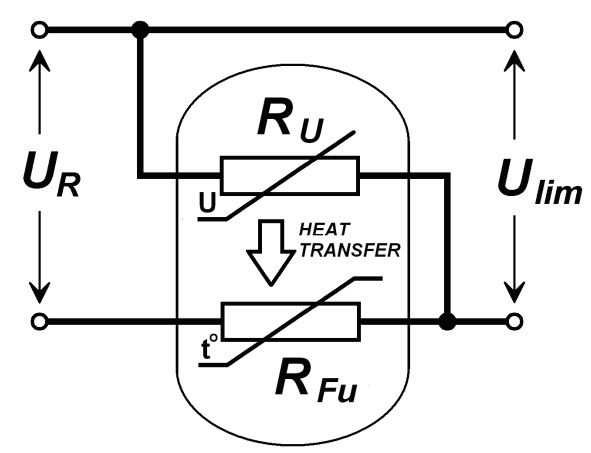

Figure 4.3. Equivalent electrical circuit of the voltage limiting device based on the two-layer structure of varistor ceramics - posistor nanocomposite.

At a voltage $U_{R}$, which is much less than the classification voltage of the varistor $U_{C}$, the electrical resistance of the varistor $R_{U}$ is large and almost all the voltage $U_{R}$ falls on it, as at temperatures below the tripping temperature $T_{\text {trip }} \approx 398 \mathrm{~K}$ $\left(125^{\circ} \mathrm{C}\right)[33,35,46]$ the posistor nanocomposite layer has low, close to metal, resistance $R_{F u}$. With $U_{R} \approx U_{C}$, the resistance of the varistor layer decreases, the $I_{R}$ current increases and heats this layer. Due to the thermal contact with the varistor layer, the layer of the posistor nanocomposite is also heated. As its temperature $T$ approaches the threshold $T_{\text {trip }}$, its resistance increases, reducing the current $I_{R}$ and the temperature of the structure $T$. This leads to a new redistribution of the voltage $U_{R}$ applied to the structure. As a result, the voltage on the varistor layer is stabilized. In the steady state, part of the overvoltage will be applied to the layer of the posistor nanocomposite, and on the varistor layer will remain its part $U_{\text {lim }}$, necessary for the current to maintain the temperature of the posistor layer.

As can be seen, the voltage limiting device, which operates according to this algorithm, is able to provide protection against prolonged overvoltage on devices connected in parallel to its varistor layer. As follows from this Fig. 4.2 and 4.3, each 
PV-cell is connected to the output circuit of a separate VLD. The series connection of the input circuits of VLD form a submodule of PVM with a parallel-connected bypass diode. Thus, resettable fuse is switched on between the individual PV-cells, and a varistor is connected in parallel to each PV-cell.

When the entire submodule is illuminated and serviceable, all PV-cells are forward biased and have low resistance. The current $I_{\text {string }}=I_{\text {subpanel }}$ flows through the submodule, and the bypass diode $D$ is turned off. The voltage generated by a separate PV-cell $U_{F}$ and applied to the varistor is less than the classification voltage of the varistor, i.e.

$$
U_{F}<<U_{C},
$$

and the latter is in a state of high resistance, and thus does not affect the operation of the PV-cell.

Also when the condition is met

$$
I_{S C}<I_{\text {trip }}
$$

connected in series to the photovoltaic cell $\mathrm{RFu}\left(I_{\text {trip }}\right.$ - its tripping current) has a resistance many times less than the series resistance of the PV-cell, i.e. $R_{F u}<<r_{s}$, and the fuse, as shown in [26], practically does not affect the operation of the PVM.

In the presence of at least one "bad" PV-cell, its resistance increases. The $I_{\text {string }}$ current begins to flow through the bypass diode $D$, which in the on state shorts the submodule. As a result, a situation is realized when all the voltage generated by the illuminated PV-cells will bias "bad" PV-cell in the reverse direction. If to choose a $U_{C}$ of varistor less than the total voltage generated illuminated PV-cells, i.e.

$$
U_{C}<U_{R}
$$

then the varistor will heat up, transferring heat to the fuse. As the VLD temperature rises to $T_{\text {trip }}$, the fuse will abruptly and much increase its resistance, which is equivalent to opening the circuit of this submodule. 


\subsection{Modeling of voltage limitation in photovoltaic systems}

\subsubsection{Voltage limiting device for a separate photovoltaic cell}

\subsubsection{Basic equations of the model}

"Bad", reverse biased photodiode of PV-cell, as a rule, is a shunt resistance (Fig. 4.1) [73]. To determine the equivalent CVC of PVM presented in Fig. 4.2, expression (3.2) can be used, where $m=1$ should be taken. According to (3.2) $I_{R}$ and $U_{R}$ are the current and voltage drop across the load resistor $R_{\text {sum }}$, which are generated by the series connection of the illuminated PV-cells of submodule.

Given the presence of VLD, this load resistance can be represented as follows:

$$
R_{\text {sum }}\left(U_{\text {lim }}, T\right)=R_{F u}(T)+r_{\text {sh }} \cdot R_{U}\left(U_{\text {lim }}\right) /\left[r_{\text {sh }}+R_{U}\left(U_{\text {lim }}\right)\right],
$$

where $R_{U}\left(U_{\text {lim }}\right)=U_{\text {lim }} / I_{R}\left(U_{\text {lim }}\right)$ - electrical resistance of the varistor depending on the applied voltage $U_{L} ; I_{R}\left(U_{L}\right)=U_{\text {lim }} / R_{U 0}+I_{0} \cdot\left(U_{\text {lim }} / U_{C}\right)^{\beta}$ - typical approximation of the CVC of varistor; $R_{U 0}$ - electrical resistance of the varistor in the low voltage range (linear section of CVC), $V_{C}, I_{0}$ and $\beta$ - passport classification voltage, varistor current and nonlinearity coefficient of its $\mathrm{CVC}$ in the varistor section; $R_{F u}(T)=C /\left(T_{\text {trip }}-T\right)-$ approximation of the dependence of the electrical resistance of $\mathrm{RFu}$ on the temperature $T[80] ; C=R_{F u 0}\left(T_{\text {trip }}-298\right) \quad\left(R_{F u 0}\right.$ corresponds to the value of the resistance of the fuse in the conductive state before its tripping).

It should be noted that the $\mathrm{RFu}$ resistance before tripping with increasing temperature is very small in comparison with the series resistance of a single PV-cell, i.e. $R_{F u}<<r_{s}$, and thus, in the normal mode can be taken $R_{F u}=0$.

The model for the analysis of the influence of the voltage value on the shaded individual PV-cell of submodule with VLD, included in accordance with Fig. 4.3, is based on the use of equation (3.2), where $n=n-1$ should be taken, and the heat balance equation. The system of equations can be written as follows 


$$
\begin{gathered}
U_{R}\left(U_{l i m}, T\right)-U_{T} \ln \left[\frac{I_{S C}-\frac{U_{R}\left(U_{l i m}, T\right)}{R_{S u}\left(U_{l i m}, T\right)}}{I_{S C}}\right]-U_{O C}+\frac{U_{R}\left(U_{l i m}, T\right)}{R_{S u}\left(U_{l i m}, T\right)} R_{S}=0 \\
I_{R}\left(U_{l i m}\right) \cdot U_{R}\left(U_{l i m}, T\right)-\frac{T-T_{0}}{R T}=0
\end{gathered}
$$

where, as follows from Fig. 4.2 and 4.3, $U_{R}\left(U_{l i m}, T\right)=U_{l i m}+\left[I_{R}\left(U_{l i m}\right)+\frac{U_{l i m}}{r_{s h}}\right] R_{F u}(T)$; $R T$ - value of thermal resistance of VLD; $T$ and $T_{0}-$ VLD and environment temperatures.

\subsubsection{Functional characteristics of the limiting device}

To study the features of VLD functioning in the PVM submodule, numerical experiments were performed based on the model described above (Fig. 4.2). The dependences of the VLD output voltage $U_{\text {lim }}$, which is applied directly to the "bad" PV-cell, the leakage current $I_{R}$ and the VLD temperature $T$ on the number of series-connected PV-cells in the submodule $z$ were investigated. This value determines the voltage drop on the "bad" PV-cell $U_{R}$. Under the real condition $z \cdot U_{F}>>U_{D}$, all the voltage generated by the indicated PV-cells is supplied to the VLD input $U_{R} \approx(z-1) \cdot U_{F}$. The calculations used the typical parameters of circuit elements shown in Table 4.1 .

As follows from the above principle of protection against high voltage on a shaded PV-cell using the analysed VLD, in the photovoltaic submodule the main determining parameters are the classification voltage of the varistor element $U_{C}$ and the current of the posistor element $I_{\text {trip }}$. Accordingly, Fig. 4.4 shows the voltage dependences on the "bad" PV-cell $U_{\text {lim }}$ from the number of illuminated serviceable PV-cell of submodule at different values of the classification voltage of the varistor element. 
Table 4.1

Parameters of model elements of photovoltaic system with voltage protection

\begin{tabular}{|l|c|c|}
\hline Component & Parameters & Accepted values \\
\hline \multirow{4}{*}{ PV-cell [56] } & $i_{0}$ & $1 \mu \mathrm{A}$ \\
\cline { 2 - 3 } & $r_{s h}$ & $1.210^{3} \mathrm{Ohm}$ \\
\cline { 2 - 3 } & $i_{S C}$ & $1.4 \mathrm{~A}$ \\
\cline { 2 - 3 } & $r_{s}$ & $1.7 \mathrm{Ohm}$ \\
\hline \multirow{3}{*}{ RFu (from RXEF series) [64] } & $A$ & 1.9 \\
\hline \multirow{3}{*}{ Varistor [81] } & $R_{F u 0}$ & $0.01 \mathrm{Ohm}$ \\
\cline { 2 - 3 } & $T_{\text {trip }}$ & $125^{\circ} \mathrm{C}$ \\
\hline & $U_{C}$ & $4-9 \mathrm{~V}$ \\
\cline { 2 - 3 } & $R_{U 0}$ & $10^{4} \mathrm{Ohm}$ \\
\cline { 2 - 3 } & $\beta$ & 50 \\
\hline
\end{tabular}

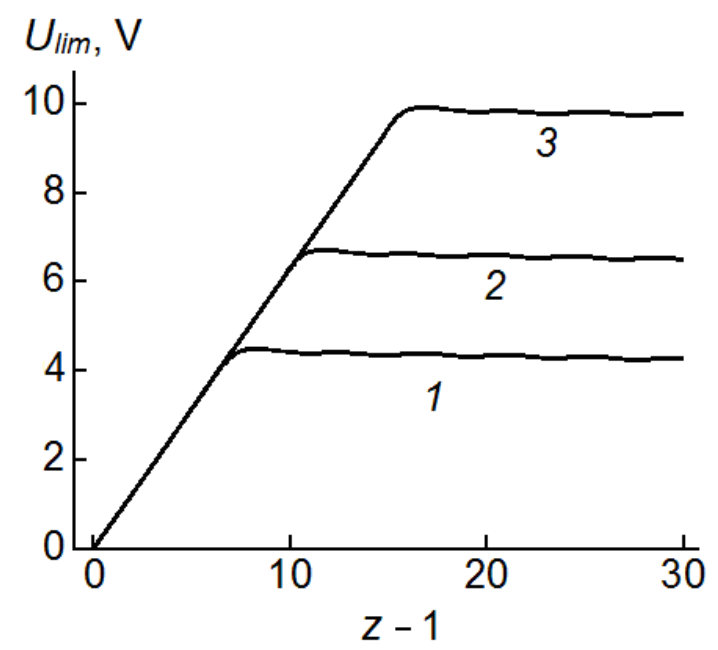

Figure 4.4. Dependences of voltage on "bad" PV-cell $U_{\text {lim }}$ on the number of illuminated serviceable PV-cell inside the submodule $(z-1)$, which create the voltage $U_{R}$, when using VLD with classification voltages $U_{C}, \mathrm{~V}: 1-5 ; 2-10 ; 3-20 ; 4-40$.

Other parameters correspond to those given in Table 4.1.

Similar dependences for the current $I_{R}$ flowing through the posistor layer are given in Fig. 4.5. Taking into account that the electrical resistance of the varistor 
element in the voltage limiting mode is much less than the shunt resistance of the protected "bad" PV-cell, the value of $I_{R}$ can be interpreted as the VLD leakage current.

Fig. 4.6 illustrates the dependence of the VLD temperature on the specified voltage and the influence of parameter $U_{C}$ on this dependence.

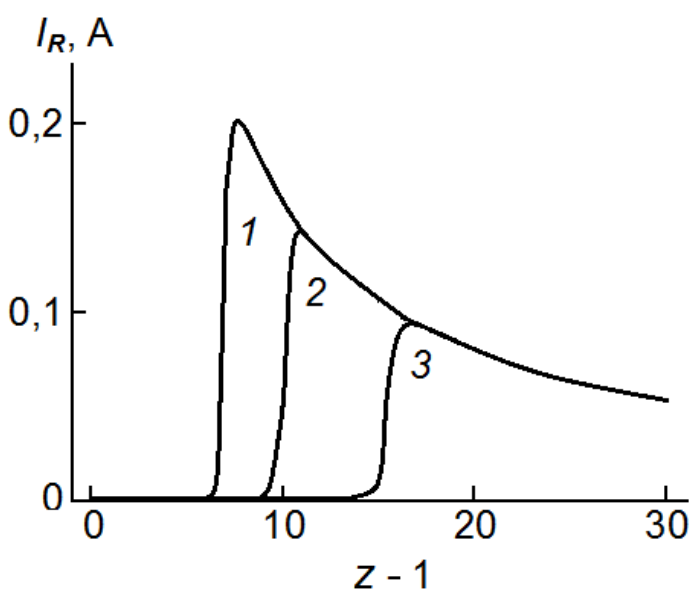

Figure 4.5. Dependences of current $I_{R}$ through the voltage limiting device on the number of illuminated PV-cells inside the submodule $(z-1)$, creating voltage $U_{R}$.

Designations correspond to those adopted in Fig. 4.4.

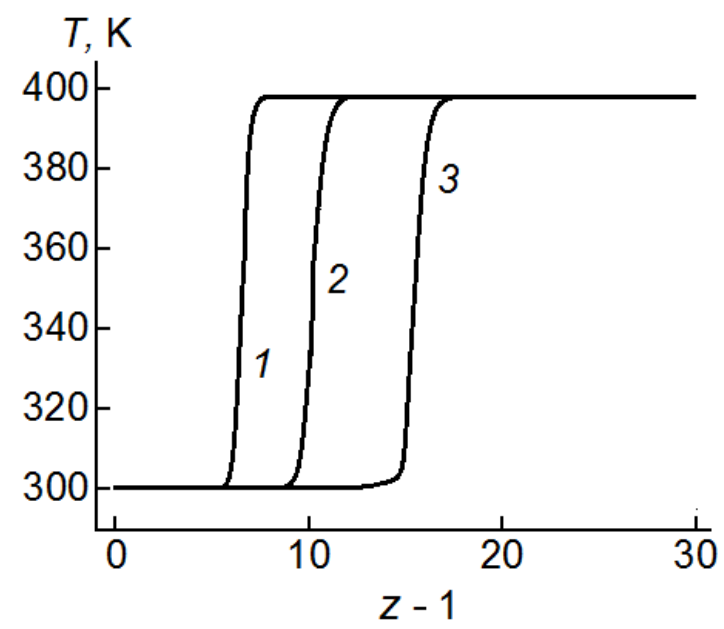

Figure 4.6. Dependences of temperature $T$ of voltage limiting device on the number of illuminated PV-cells inside the submodule $(z-1)$, creating voltage $U_{R}$.

Designations correspond to those adopted in Fig. 4.4. 
The data presented in Fig. 4.4 indicate that the voltage drop on the "bad" PV-cell $U_{\text {lim }}$ (output voltage for VLD) at any number of illuminated serviceable PV-cells, connected in series in the submodule with bypass diode, does not exceed a certain value of $U_{l i m 1}$, close to the classification voltage of the varistor element $U_{C}$ and, thus, is insufficient for its breakdown (or rapid degradation) [82]. By selecting a varistor element with different classification voltages, the value of $U_{\text {lim } 1}$ can be adjusted in a fairly wide range.

With increasing $U_{C}$ at fixed parameters of the posistor element based on $\mathrm{RFu}$ there is a decrease in the current of such VLD (Fig. 4.5), as the power required for the tripping of such a posistor element does not change, and the heating and phase transition is shifted towards high voltages. The data of Fig. 4.6 shows that the maximum possible temperature does not exceed the tripping temperature of the $\mathrm{RFu}$, which for commercial products is equal to $398 \mathrm{~K}\left(125^{\circ} \mathrm{C}\right)$. It is known that external heating to such a temperature for single-crystal silicon PV-cells does not lead to their significant degradation [83].

With increasing voltage generated by the illuminated PV-cells of submodule, there is a redistribution of dissipation power (which is almost independent of the voltage limitation $\left.(z-1) U_{F}\right)$ emitted by the structure, in the direction of reducing its varistor component after VLD tripping (Fig. 4.7).

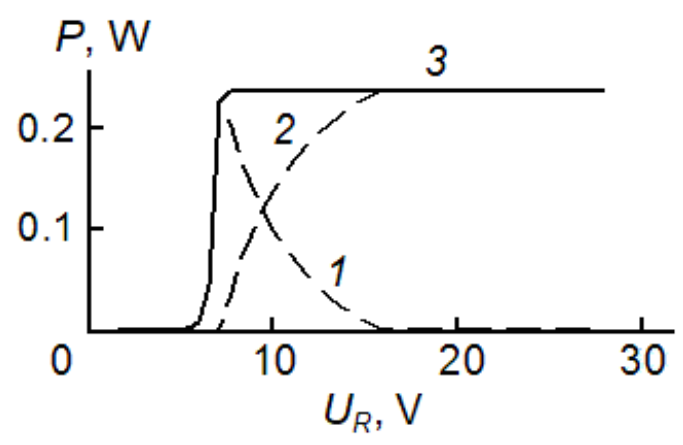

Fig. 4.7. Dependences of dissipation powers allocated on varistor (1), posistor (2) and total (3) on voltage $U_{R}\left(U_{C}=6 \mathrm{~V}\right)$ created by the illuminated PV-cells inside the submodule. 
Initially, the posistor element is in heating mode due to heat transfer from the heated varistor element. With a further increase in the input voltage $U_{R}$ and, accordingly, the VLD temperature, the resistance of the RFu increases, and the resistance of the PV-cell diode $r_{s h}$ naturally decreases. As a result, part of the voltage at $R_{F u}(T)$ becomes sufficient to maintain the RFu in a high-resistance "hot" mode by self-heating.

At lower $R_{s h}$ this is done at lower input VLD voltages (Fig. 4.8). It should be noted that at very low resistances of the reverse biased $p$ - $n$ junction of the PV-cell ( $R_{s h}$ value) there may be a situation when the reverse current flowing through the PV-cell can cause it to overheat and thermal breakdown, and the considered voltage protection will not be effective.

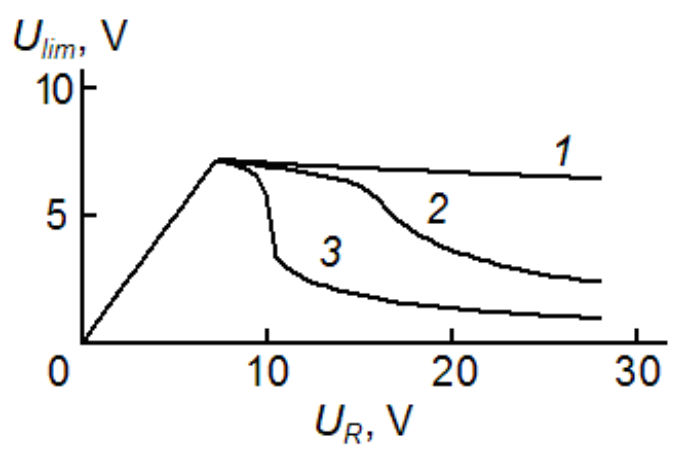

Figure 4.8. Dependences of voltage drop on the shaded PV-cell $U_{\text {lim }}$ on generated by the illuminated PV-cells of submodule $U_{R}$ at values $r_{s h}, \mathrm{Ohm}$ :

$$
1-10^{3} ; 2-2.510^{2} ; 3-10^{2}\left(U_{C}=6 \mathrm{~V}\right) \text {. }
$$

These data indicate that the structure has the functional properties of a DC or slowly varying voltage limiting device and, thus, allows to solve the problem formulated in this section of individual protection of the PV-cell from overvoltage on direct current.

Given the finiteness of the time of setting the low-conductivity state of the RFu (from a few seconds to several minutes $[84,85]$ ), the overvoltage that occurs in the presence of "bad" PV-cells will be short (pulse) and, thus, the degradation processes associated with thermal breakdown, will be manifested to a much lesser extent and at higher absolute values of overvoltage, which exceed the accepted value of breakdown voltage $U_{b}=12 \mathrm{~V}[4,86]$. 


\subsubsection{Voltage limiting device for a group of series-connected photovoltaic} cells

\subsubsection{Circuit and its mathematical description}

Based on the results of the analysis of individual protection of a single PV-cell, you can implement a similar circuit, which allows to use one VLD to protect against overvoltage of a group of several $(K)$ series-connected PV-cells (Fig. 4.9).

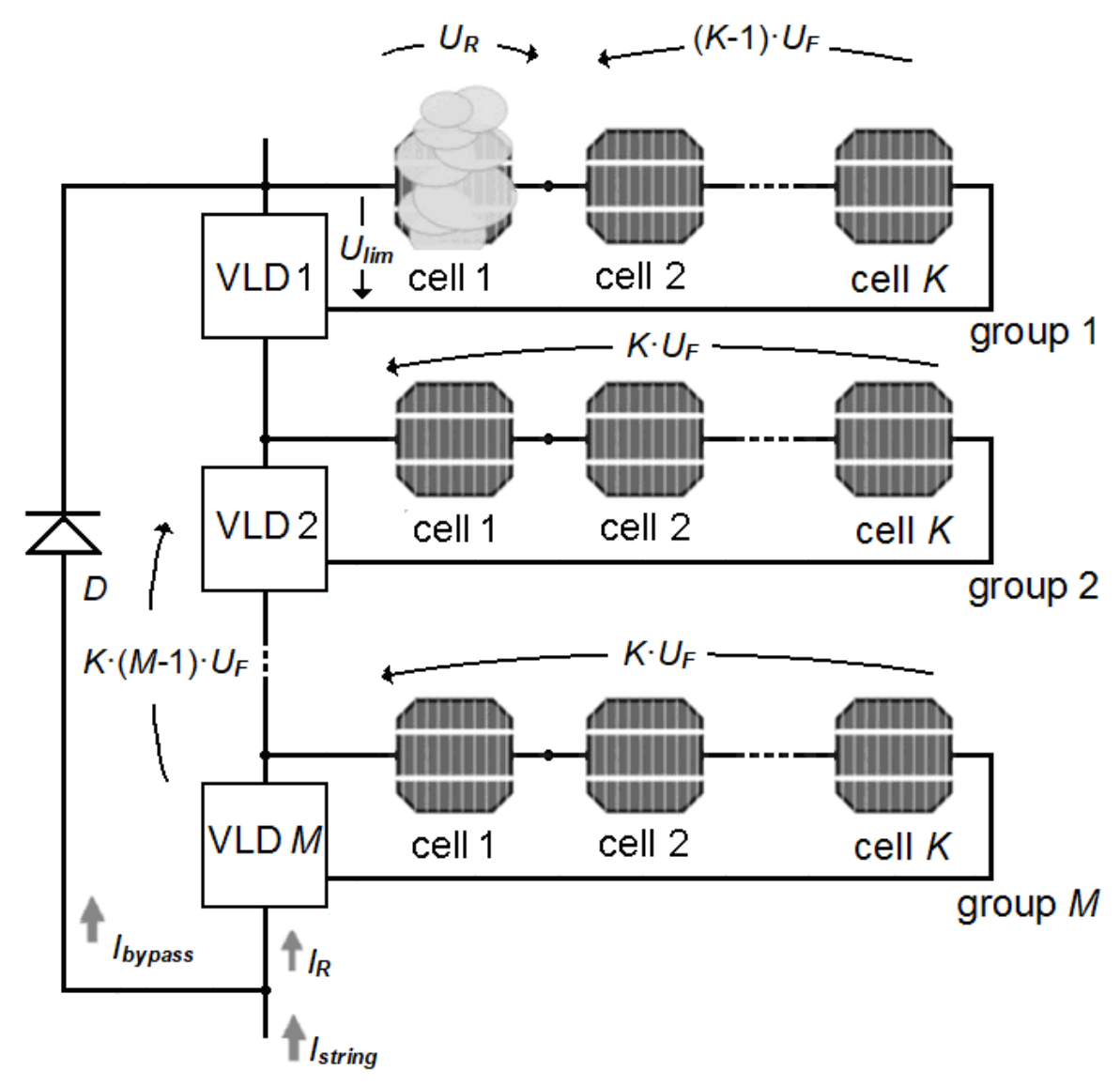

Figure 4.9. VLD connection diagram to protect a group of series-connected PV-cells. $M$ - the number of series-connected PV-cell groups, to each of which VLD is connected; $K$ - the total number of series-connected PV-cells in the group. Other designations correspond to those adopted in Fig. 4.2. 
As can be seen from this figure, this PV-cell group is connected to the output circuit of a separate VLD. The series connection of the input circuits of these VLD form a submodule of PVM with a bypass diode connected to it in parallel. Thus, resettable fuse is switched on between the PV-cells groups, and a varistor is connected in parallel to each PV-cell group.

As in the case shown in Fig. 4.2, when the entire submodule is illuminated, all PV-cells are offset in the forward biased and have low resistance. The current $I_{\text {bypass }} \approx I_{\text {string }}$ flows through the submodule, and the bypass diode $D$ is turned off. Voltage generated by the PV-cell group

$$
K \cdot U_{F}<<U_{C}<U_{b}
$$

and vatistor is in a state of high resistance, and does not affect the operation of the PV-cells.

If the condition

$$
I_{\text {string }}<I_{\text {trip }},
$$

is met (where $I_{\text {trip }}$ is the tripping current), the fuse has a resistance many times less, the series resistance of the PV-cells, and as shown in [46], has little effect on the operation of the PVM.

In the presence of at least one "bad" PV-cell, its resistance increases. The current $I_{\text {string }}$ begins to flow through the bypass diode $D$, which in the on state will shortcircuit the submodule. As a result, a situation is realized when all the voltage generated by the illuminated serviceable PV-cells will bias $p$ - $n$ junction of "bad" PV-cell in the reverse direction. If to choose $U_{C}$ of varistor less than the total voltage generated by illuminated PV-cells groups, except for one where there are "bad" cells (group 1 in Fig. 4.9), that is, if

$$
U_{C}<K \cdot(M-1) \cdot U_{F},
$$

then the varistor will heat up, transferring heat to the fuse. As the temperature rises to $T_{\text {trip }}$, the fuse will sharply and much increase its resistance, which is equivalent to opening the circuit of this submodule. 
To analyse the functioning of the circuit Fig. 4.9, the expression for its CVC (3.2) can be used, where $m=1$ should be taken. As already mentioned, in the lighting mode of all PV-cells submodules, the influence of VLD is almost absent. In the presence of some "bad" PV-cells CVC of the submodule on Fig. 4.9 can also be described by expression (3.2), where instead of the parameter $n$ we should take the values corresponding to the specific numbers of PV-cells which are connected in series. In this case, the load resistance of all series-connected illuminated PV-cells of submodule is the shunt resistance of the "bad" PV-cell(s) $r_{s h}\left(R_{s h}=r_{s h}\right)$, which is quite large (up to $10^{4} \mathrm{Ohms}[56]$ ) and, therefore, real correlation

$$
I_{S C}>>I_{R}
$$

Taking into acoount (4.10) and that $R_{s}<<R_{s h}$, based on expression (3.2) we can conclude that $U_{R} \approx U_{O C}$ and, thus, convert the electrical circuit of Fig. 4.9 to the form shown in Fig. 4.10.

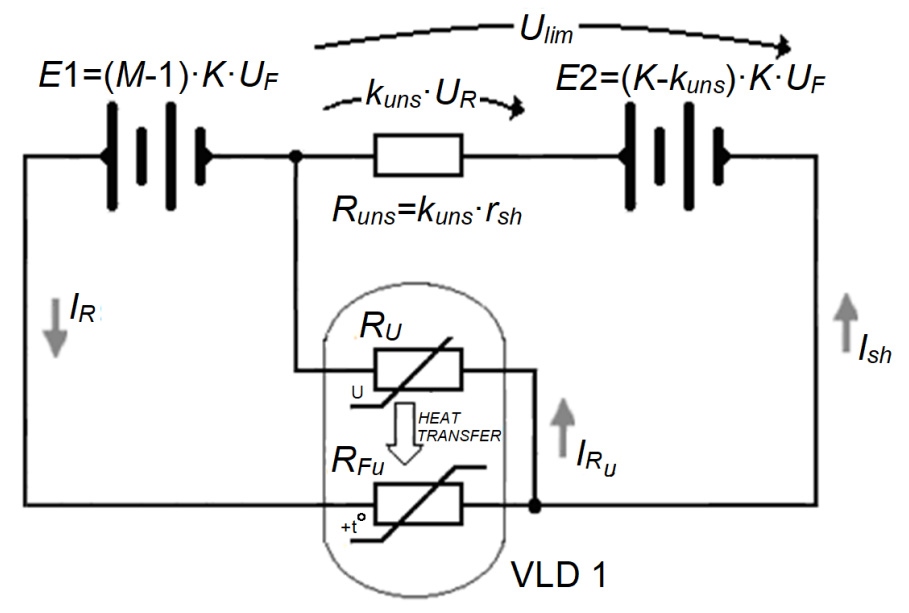

Figure 4.10. The diagram illustrates the operation of VLD in the presence of several "bad" PV-cells of PVM submodule. $k_{\text {uns }}$ - the number of "bad" PV-cells in one (first) group; $R_{u n s}=k_{u n s} \cdot r_{s h}-$ equivalent shunt resistance of all "bad" PV-cells; $I_{R U}$ and $I_{s h}-$ currents through the varistor element and "bad" PV-cell(s).

The equations for determining the magnitude of the voltage drop on the "bad" PV-cells of submodule in accordance with Fig. 4.10 and approximations (4.10) are 
based on the use of Kirchhoff's laws and the equation of heat balance. The system of Kirchhoff's equations can be written as following

$$
\begin{gathered}
I_{R}=I_{R U}+I_{s h} ; \\
E 1=I_{R}\left(R_{F u}(T)+I_{R U}\left(R_{U}\left(U_{\text {lim }}\right) ;\right.\right. \\
E 2=I_{\text {sh }} R_{u n s}-I_{R U} \cdot R_{U}\left(U_{\text {lim }}\right),
\end{gathered}
$$

where $E 1=(M-1) \cdot K \cdot U_{F}$ - total voltage generated by all PV-cells groups, except for the "bad" (the first in Fig. 4.9); $E 2=\left(K-k_{\text {uns }}\right) \cdot U_{F}$ - total voltage generated by all unshaded PV-cells of the first group; $U_{\text {lim }}=k_{\text {uns }} \cdot U_{R}-E 2$.

Taking into account that $U_{\text {lim }}=I_{R U} R_{U}\left(U_{\text {lim }}\right)$ and $I_{s h}=k_{\text {uns }} U_{R} / R_{\text {uns }}$ system (4.11) can be transformed to a nonlinear equation with unknown $U_{R}$ and $T$

$$
\left[\frac{U_{R}}{r_{u n s}}+I_{R U}\left(k_{u n s} \cdot U_{R}-E 2\right)\right] \cdot R_{F u}(T)+k_{u n s} \cdot U_{R}-E 1-E 2=0 .
$$

The equation for the VLD heat balance, also dependent on these unknowns, can be written as follows

$$
P_{\mathrm{var}}\left(U_{R}\right)+P_{P T T C}\left(U_{R}, T\right)-\frac{T-T_{0}}{R T}=0,
$$

where $R T-$ value of thermal resistance of the structure; $P_{\text {var }}\left(U_{R}\right)=I_{R U}\left(k_{\text {uns }} \cdot U_{R}-E 2\right) \cdot\left(k_{\text {uns }} \cdot U_{R}-E 2\right)$;

$P_{P P T C}\left(U_{R}, T\right)=\left[\frac{U_{R}}{r_{s h}}+I_{R U}\left(k_{u n s} \cdot U_{R}-E 2\right]^{2} \cdot R_{F u}(T)-\right.$ electrical powers released at the varistor and posistor, respectively.

\subsubsection{Dependence of voltage limitation on the size of groups}

It should be noted that the solutions of the system of nonlinear equations (4.12)-(4.13) must meet such physical constraints.

1. The voltage on a separate protected "bad" PV-cell in their series connection should not exceed the voltage of its breakdown 


$$
k_{\text {uns }} \cdot U_{R}=U_{C}+E 2<k_{\text {uns }} U_{b} .
$$

2. The voltage applied to the varistor element in the absence of "bad" PV-cell should be operating, i.e. less than its classification voltage

$$
E 2=K_{\max } \cdot U_{F}<U_{C} .
$$

From these constraints for the maximum number of series-connected PV-cells in the group $K_{\max }$ (Fig. 4.9) we can obtain the following expression

$$
K_{\max }=\min \left[U_{C} / U_{F},\left(U_{b}-U_{C}\right) / U_{F}\right] .
$$

Taking into account that the voltage is generated by one PV-cell $U_{F} \approx 0.56 \mathrm{~V}$ [56] it can be obtained from (4.16) that when using varistor elements with classification voltages $U_{C}$ equal to 4, 6 and $8 \mathrm{~V}$, the maximum number of PV-cells in the group protected by one VLD is 6,9 and 7, respectively. The biggest value of voltage on a separate PV-cell takes place in a situation when it is "bad", and all other PV-cells of group are illuminated and serviceable (Fig. 4.11 and 4.12).

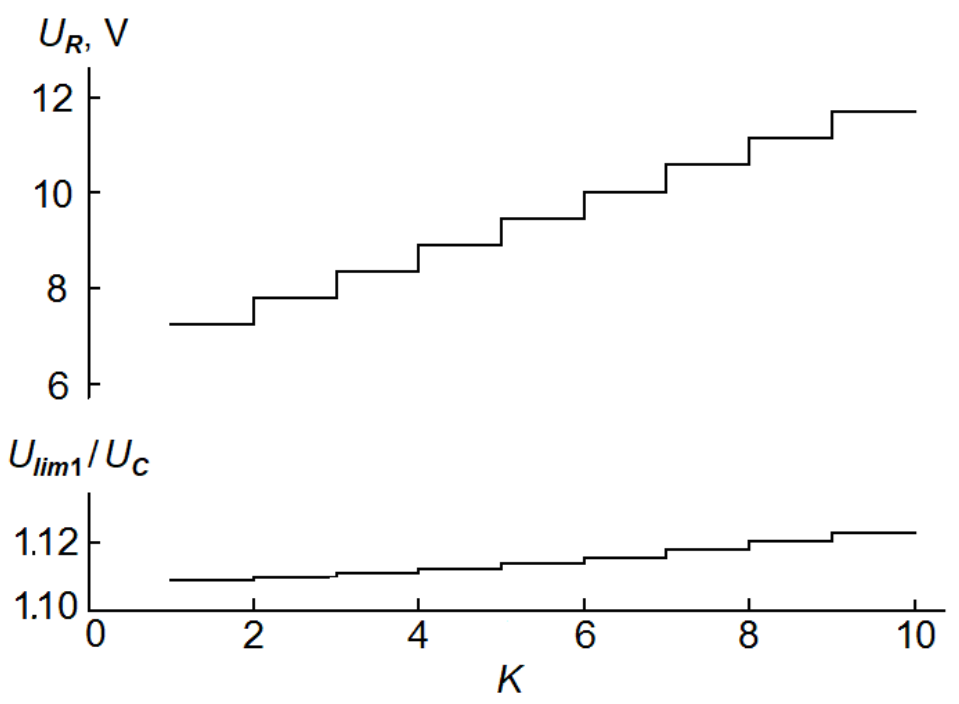

Figure 4.11. The dependence of the voltage on a separate $\left(k_{\text {uns }}=1\right)$ shaded PV-cell $U_{R}$ and on VLD varistor element $U_{\text {lim } 1}$ on their number in group $K$. The mode corresponds to the situation when one PV-cell is shaded and the others are illuminated. Classification voltage of the VLD varistor element $U_{C}=6 \mathrm{~V}$.

As can be seen from Fig. 4.12 voltage across the "bad" PV-cell is $U_{R}<U_{b}$ to value $K=9$ when using a varistor with $U_{C}=6 \mathrm{~V}$. The voltage on the varistor changes 
slightly. When using varistors with other $U_{C}$ values, the permissible number of PV-cells in one group is less, i.e. the use of a varistor with $U_{C}=6 \mathrm{~V}$ can be considered optimal.

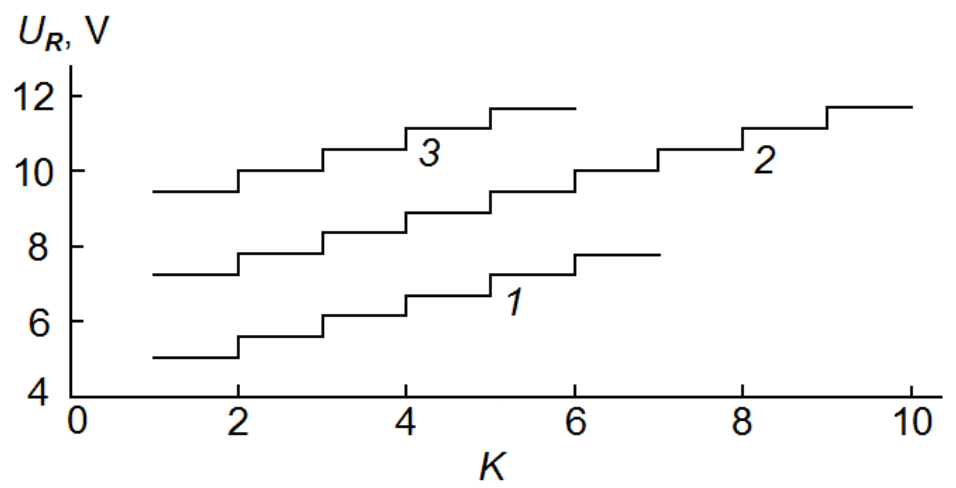

Figure 4.12. Dependence of voltage on a separate $\left(k_{\text {uns }}=1\right)$ "bad" PV-cell $U_{R}$ on number of PV-cells in group K when using VLD based on varistor elements with $U_{C}, \mathrm{~V}: 1-4 ; 2-6 ; 3-8$. The mode corresponds to the situation when one "bad" PV-cell and the others are illuminated and serviceable.

The change in voltage applied to a separate PV-cell in a situation where several PV-cells are "bad" tends to decrease (Fig. 4.13).

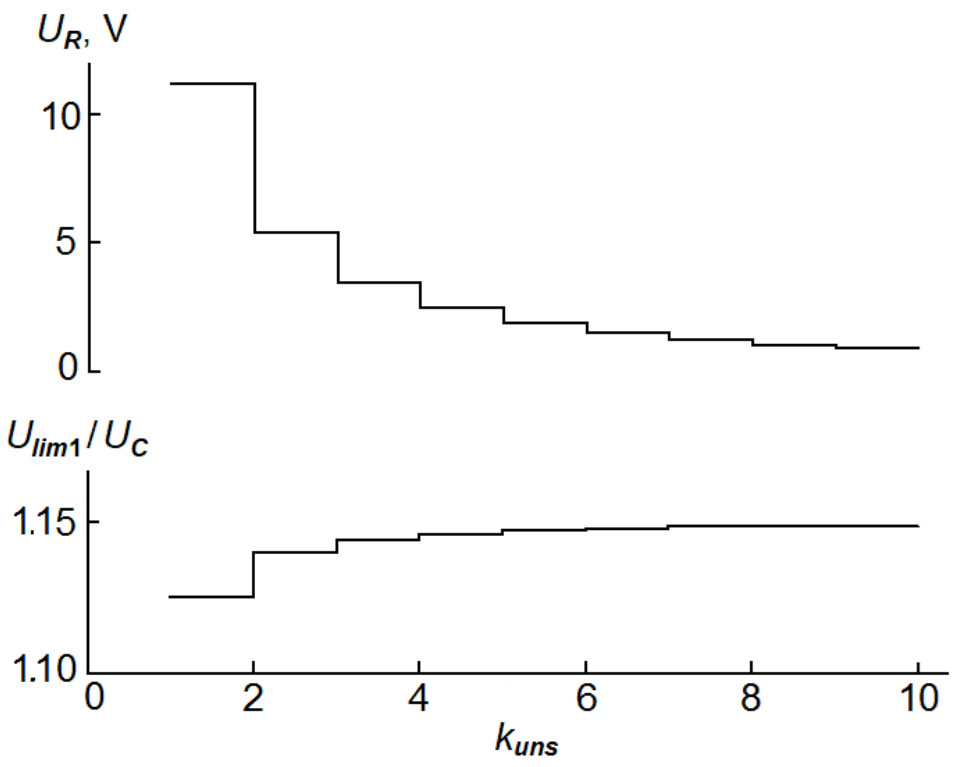

Figure 4.13. Dependence of voltage on a separate "bad" PV-cell $U_{R}$ and on VLD varistor element $U_{l i m 1}$ on number of "bad" PV-cells $k_{\text {uns }}$ (classification voltage of varistor element of VLD $U_{C}=6 \mathrm{~V}, K=9$ ). 


\subsubsection{Analysis of relaxation of voltage limiting devices in photovoltaic modules during lighting restoration}

It should be noted the peculiarities of the considered VLD in a situation where the overvoltage is due to the shading of individual PV-cells. The reverse transition of $\mathrm{RFu}$ to a highly conductive ("cold") state can occur only when its temperature decreases, and hence the input of electrical energy decreases. In the analyzed situation, this corresponds to the voltages at which the current through the VLD must be less than the tripping current $I_{\text {trip }}$ of RFu element. When choosing the parameters of the VLD mode, it should be taken into account that in this case this effect can be achieved by stopping the transfer of thermal power from the varistor, which can be provided by reducing the input voltage of VLD. This decrease may be the result of a significant reduction in the electrical resistance of the protected PV-cell, which goes from shaded to illuminated state.

Also, the RFu transition from low-conductivity to high-conductivity can be realized either by natural shading or a corresponding change in the mode of operation (e.g., disconnection) of the protected submodule for sufficient time to cool the $\mathrm{RFu}$, which, of course, is a limitation on the widespread use of such overvoltage protection.

To assess the prospects for the implementation of this device to protect the PV-cell from overvoltage, which occurs when shading individual PV-cell, one of the most important modes of its operation is its behaviour when returning the PVM submodule from a partially shaded state to illuminated. This section presents the results of a study of the functioning of varistor-posistor VLD in a state of relaxation during the restoration of lighting, obtained using mathematical modeling.

Thus, in the already mentioned case, when returning the PVM submodule from a partially shaded to a fully illuminated state, the RFu transition to a highly conductive ("cold") state can occur only when its temperature is reduced by reducing the electric power. The initial stage of this process is illustrated in Fig. 4.14. 


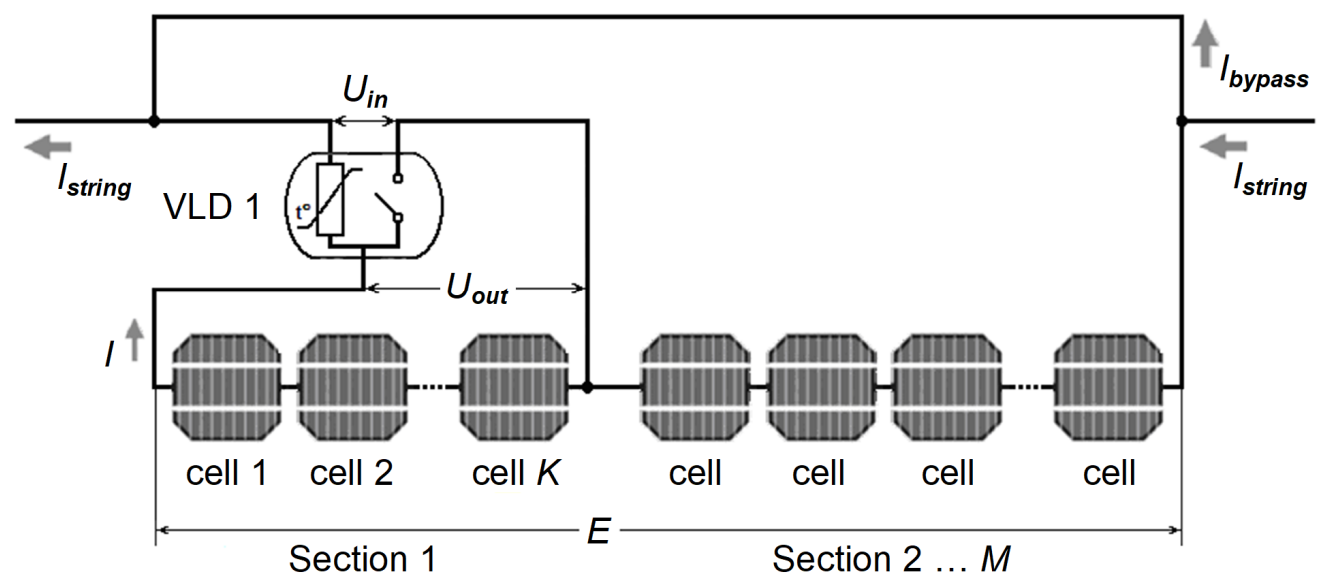

Figure 4.14. Equivalent diagram illustrating the state of the voltage limiter (VLD 1) at the initial moment of relaxation after the restoration of the state of illumination. $I_{\text {string }}, I_{\text {bypass }}$ and $I$ - current coming from other submodules, current through the bypass diode and leakage current through the (heated) VLD posistor layer; $E$ - the electric voltage generated by a section (group) of the photovoltaic submodule with a relaxing VLD; $K$ and $M$ - number of PV-cells in the section and the number of sections in the submodule.

The resistance of the varistor becomes large (shown by the open switch) due to the fact that low voltage is applied to it when the PVM submodule are fully illuminated. It is generated by one (or one group) PV-cell and is less than the classification voltage of the varistor. The thermal power dissipated by the varistor becomes insufficient to support the $\mathrm{RFu}$ at temperatures higher than $T_{\text {trip }}$. As a result, the temperature of RFu decreases and the resistance decreases. In the analysed situation, the current through VLD I must be less than the value of the tripping current of the RFu element $I_{\text {trip }}$ at the current temperature of the posistor layer. The equation of heat balance for the posistor layer, which describes this process of VLD relaxation, can be written as

$$
\begin{gathered}
C \frac{d T(t)}{d t}=P_{P P T C}[E, T(t)]-\frac{T(t)-T_{0}}{R T} ; \\
T(t=0)=T_{\text {trip }} .
\end{gathered}
$$

where $P_{P P T C}[E, T]=\frac{R_{F u}(T)}{R_{F u}(T)+R_{S}} \frac{E}{R_{F u}(T)+R_{s}} \cdot E ; T=T(t)$ and $T_{0}-$ the temperature of the PPTC element and the environment; $R_{F u}(T)=$ const $/\left(T_{\text {trip }}-T\right)$ - approximation of 
the temperature dependence of the PPTC fuse; const $=R_{F u 0}\left(T_{\text {trip }}-T_{0}\right)$, at $T_{0}=298 \mathrm{~K}$; $t$ - time; $R_{F u 0}$ - the value of the resistance of the fuse in the conductive state [87]; $E=K \cdot M \cdot U_{F}$ and $R_{S}=K \cdot M ; U_{F}$ and $r_{s}$ - the voltage generated by a separate PV-cell and its equivalent series electrical resistance; $C$ and $R T$ - VLD heat capacity and thermal resistance. In numerical experiments, typical values of PV-cell parameters with a generation current of $2 \mathrm{~A}$ based on monocrystalline silicon $U_{F}=0.56 \mathrm{~V}$; $r_{s}=0.04 \mathrm{Ohm}$ were used and $K=1 ; M=60$ were taken.

As follows from equation (4.17) for this mode of relaxation of varistor-posistor VLD, the main parameters that can be selected are its thermal resistance $R T$ and electrical resistance in the conductive ("cold") state of the posistor element $R_{F u 0}$.

Typical relaxation dependences of the temperature VLD $T(t)$ and the electrical resistance of VLD posistor element $R_{F u}(t)$ are presented in Fig. 4.15 and 4.16.

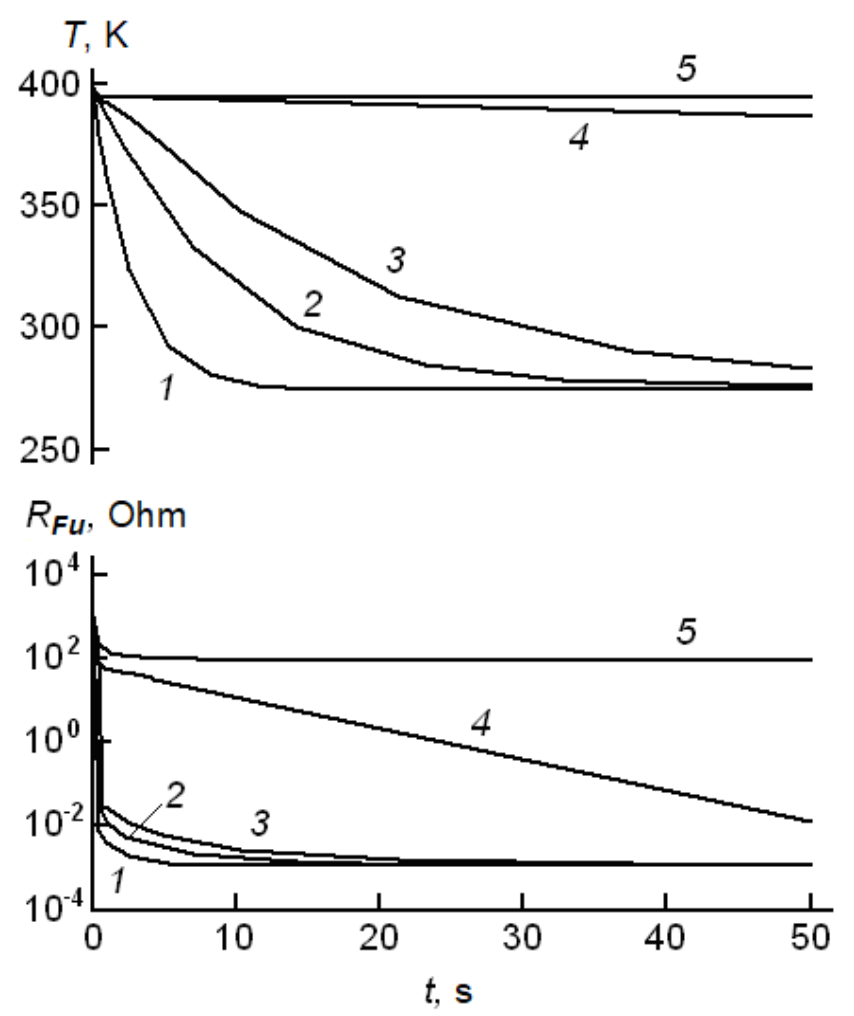

Figure 4.15. Dependences of temperature $T$ and electrical resistance of the layer of PPTC-fuse of VLD $R_{F U}$ on the relaxation time $t$ after returning the previously shaded $\mathrm{PV}$-cell to the illuminated state for $R_{F u 0}=0.001 \mathrm{Ohm}, R T, \mathrm{~K} / \mathrm{W}$ :

$$
1-5 ; 2-15 ; 3-27 ; 4-40 ; 5-60 \text {. }
$$




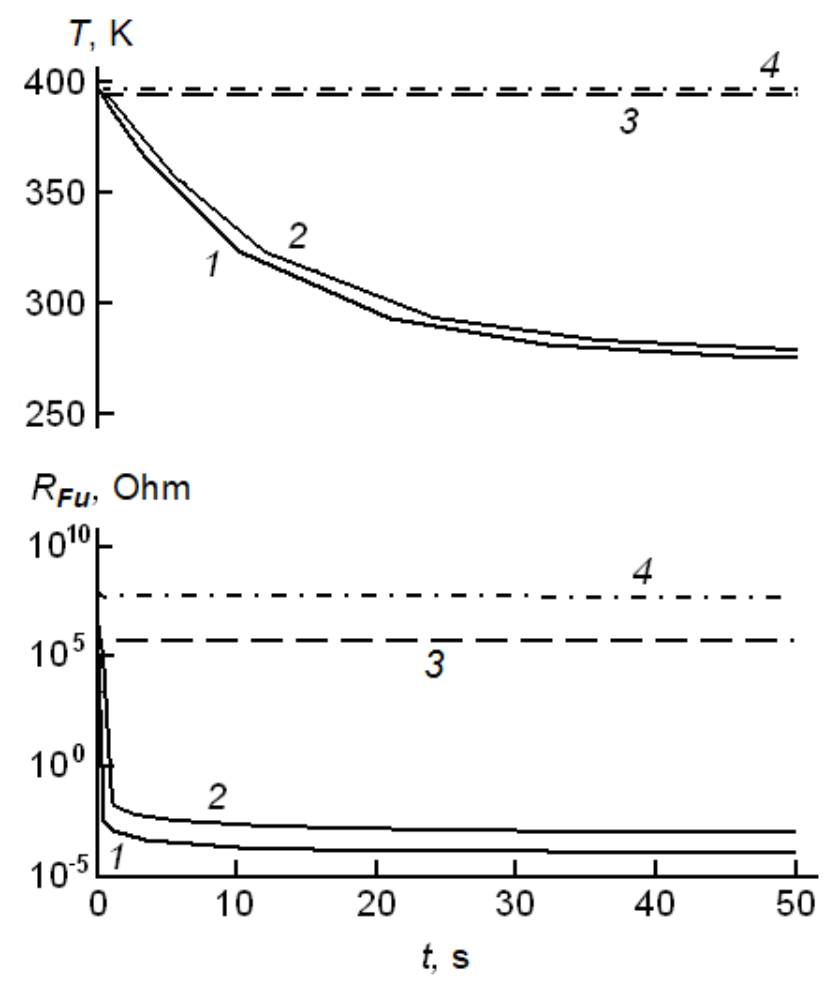

Figure 4.16. Dependences of temperature $T$ and electrical resistance of the layer of PPTC-fuse of VLD $R_{F U}$ on the relaxation time $t$ after returning the previously shaded $\mathrm{PV}$-cell to the illuminated state at $R T=20 \mathrm{~K} / \mathrm{W}, R_{F u 0}, \mathrm{Ohm}$ :

$$
1-0.0001 ; 2-0.001 ; 3-0.01 ; 4-0.1 \text {. }
$$

As can be seen, the previously mentioned VLD parameters also have a significant impact on these dependencies.

Relaxation of temperature and electrical resistance to its initial values (corresponding to the "cold" high-conductivity state of the posistor) is possible only for VLD, which have small values of VLD thermal resistance RT (Fig. 4.15, curves $1,2,3)$.

At large values of this parameter, relaxation is not observed. The duration of the relaxation time does not exceed a few seconds and decreases with decreasing VLD thermal resistance.

Similar patterns were found in the study of the influence of the parameter of the posistor element $R_{F u 0}$ on the form of the analysed relaxation dependences (Fig. 4.16). 
Relaxation of temperature and electrical resistance to its initial values is observed only for VLD, which have small values of electrical resistance of the posistor layer in the conductive state $R_{F u 0}$, (curves 1 and 2). Relaxation time is $1-3 \mathrm{~s}$. At large values of $R_{F u}$ it is in a stationary low-conductivity state (curves 3 and 4 ). In this case (as in the presence of large VLD thermal resistance $R T$ ), the transition of $\mathrm{RFu}$ from low-conductivity to high-conductivity can occur when shading the entire PVM submodule, which corresponds to the termination of the process of photogeneration of electricity or de-energization.

\subsection{Results of experimental studies}

\subsubsection{Voltage limiting device based on zinc oxide varistor and PPTC fuse}

The experiments used samples of the voltage limiting device based on a two-layer structure of varistor ceramics and a polymer nanocomposite with a carbon filler (Fig. 4.17).

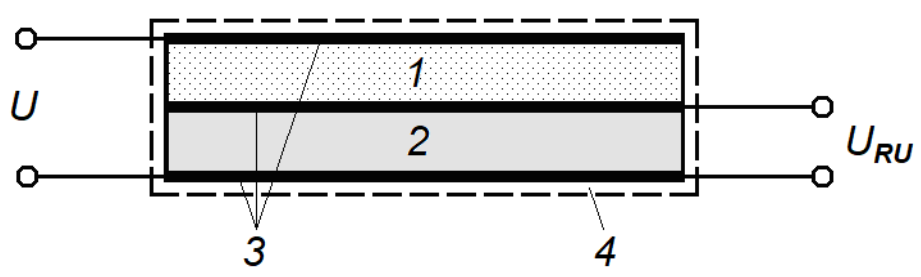

Figure 4.17. Layered structure of varistor ceramics - PPTC-nanocomposite.

1 - layer of polymer nanocomposite with a positive temperature coefficient of resistance; 2 - layer of metal oxide varistor ceramics; 3 - electrode layers; 4 - heat-insulating covering.

As one of the layers was used the working element (layer with a diameter of $14.3 \mathrm{~mm}$ and a thickness of $1.5 \mathrm{~mm}$ ) of the commercial varistor VCR-14D220K 
$\left(U_{C}=24 \mathrm{~V}, \beta \geq 50\right)$ [90], and the other was a layer of PPTC fuse type RXEF050 (diameter $6.8 \mathrm{~mm}$, thickness $2 \mathrm{~mm}$, the resistance of the element in the conductive state $1.17 \mathrm{Ohm} ; T_{\text {trip }}=125 \mathrm{C}$ ) [91]. Thermal contact between the layers was provided by gluing using silicone heat-conducting paste KPT-8 [92].

The main characteristic of VLD under consideration is the input-output transfer VLD characteristic $U_{l i m}=f(U)$, that is shown in Fig. 4.18.

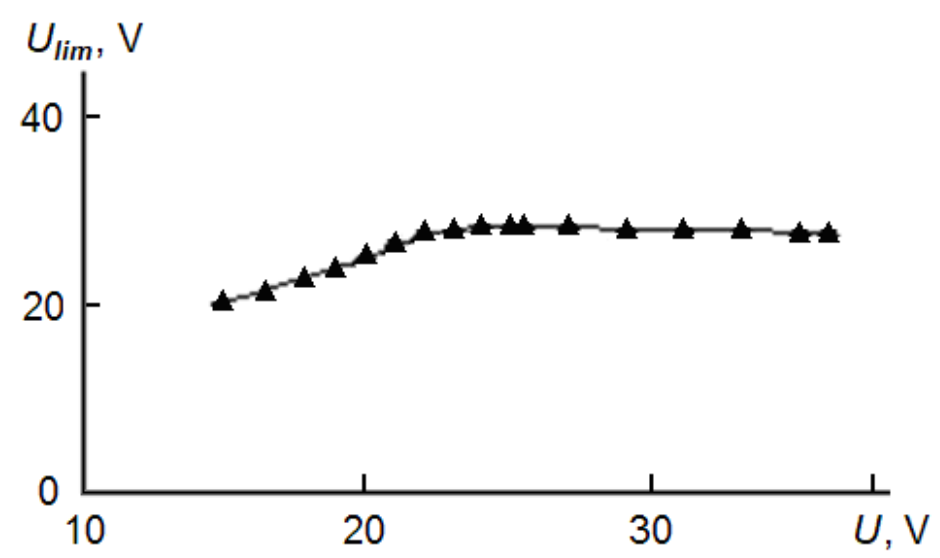

Figure 4.18. Dependence of the output voltage $U_{\text {lim }}$ of the studied two-layer VLD structure based on varistor ceramics and polymer nanocomposites with carbon filler on the applied input voltage $U$.

As can be seen with increasing input voltage $U$, the output voltage $U_{\text {lim }}$ of the studied structure tends to be limited. This effect is accompanied by an increase in the temperature of the VLD structure to a value close to the temperature of the phase transition conductor-insulator $T_{\text {trip }}$, which is observed in nanocomposites with a positive temperature coefficient of resistance [39, 33].

To interpret the dependence of Fig. 4.18, it should be taken into account that the series-connected layers of varistor ceramics (with the electrical resistance $R_{U}(U)$ ) and the mentioned nanocomposite $\left(R_{F u}(T)\right)$ are in direct thermal contact.

When the voltage applied to the considered layered structure above the allowable (overvoltage), it is first applied to the varistor layer with resistance $R_{U}(U)$, 
as at temperatures $T$ below the tripping temperature $T_{\text {trip }} \approx 398 \mathrm{~K}\left(125^{\circ} \mathrm{C}\right)[74,91,93]$ PPTC-layer has a low, close to metal, resistance $R_{F u}(T)$. Because of this, the varistor layer begins to heat up by increasing the current flowing, and its temperature rises. Due to thermal contact with it, the PPTC layer also heats up and as it approaches the threshold temperature $T_{\text {trip }}$, its resistance increases. The current flowing through the structure, and, consequently, through the layer of varistor ceramics, decreases slightly and the temperature of the structure decreases. As a result, the voltage on the varistor layer is limited for a long time. In the steady state, the main part of the voltage is applied to the PPTC layer, and the part of the voltage required for the support current of the PPTC layer to the low-conducting ohmic state is applied to the varistor layer. The VLD transition to the initial highly conductive state is possible only with cooling of the posistor element.

As can be seen, an electronic device operating according to this algorithm is able to provide protection in emergency situations associated with the presence of prolonged overvoltages on devices connected in parallel to its varistor layer. The operation of such VLD at overvoltages which arise on the shaded PV-cells in the PVM submodule in parallel to which the bypass diode is included is investigated below.

\subsubsection{Application of voltage limiting device for overvoltage protection of photovoltaic cells}

\subsubsection{Photovoltaic module with overvoltage protection}

A study of VLD functioning in PVM submodule was carried out using the model structure (Fig. 4.19), which is formed on the basis of the ideas set forth earlier in the theoretical part of this section. 


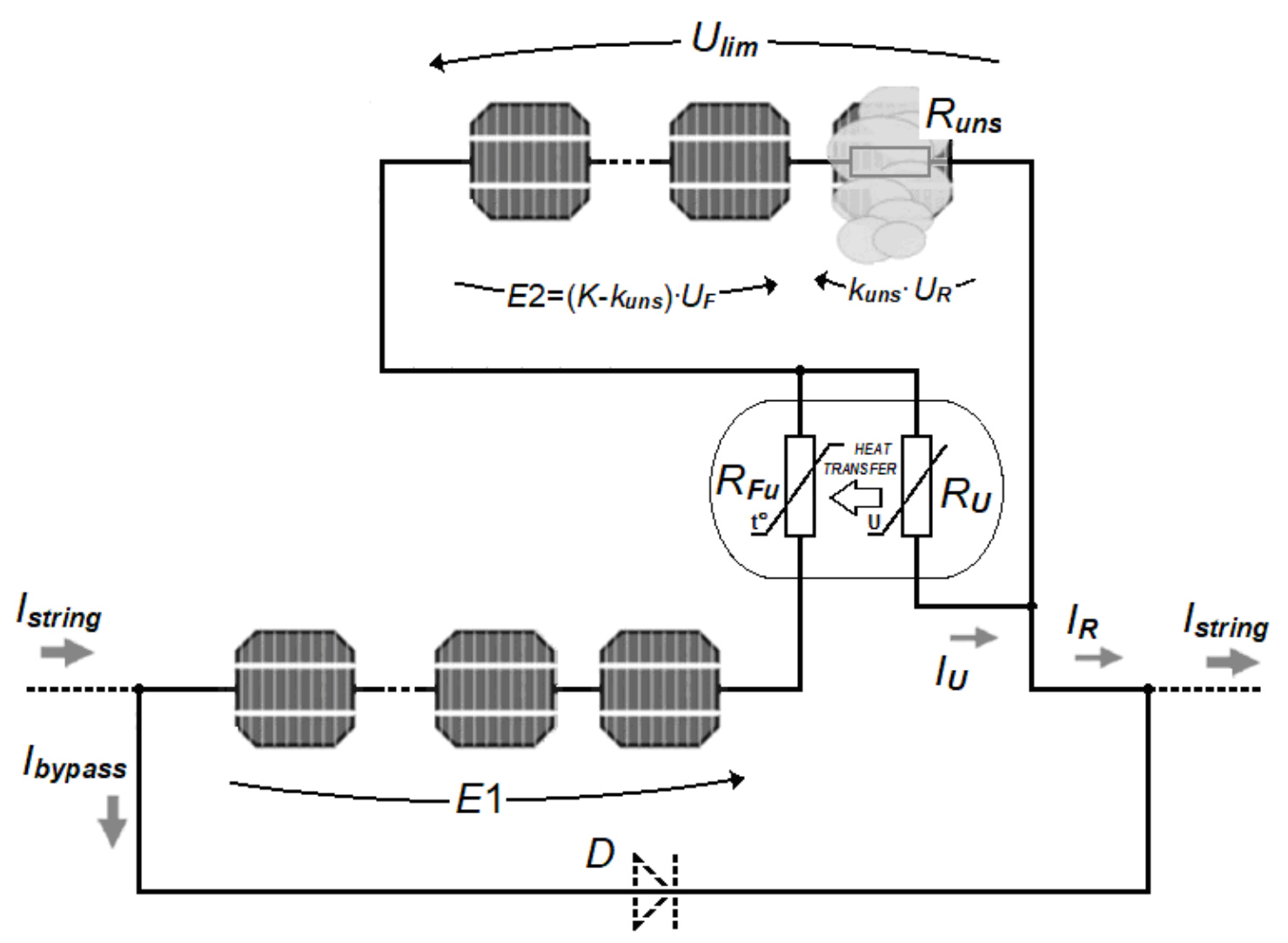

Figure 4.19. Model structure corresponding to the shading mode of one PV-cell in a photovoltaic submodule, which is short-circuited by a bypass diode in the presence of VLD. $R_{U}$ - varistor resistance; $R_{F u}-\mathrm{RFu}$ resistance; $K$ - number of PV-cell in the group protected from overvoltage by one VLD; $k_{\text {uns }}-$ number of shaded PV-cells in this group; $E 2=\left(K-k_{\text {uns }}\right) \cdot U_{F}-$ electrical voltage generated by the illuminated PV-cells of the protected group ( $U_{F}-$ voltage generated by one PV-cell); $E 1-$ electric voltage generated by the illuminated serviceable PV-cells of the submodule

which are not included in the specified group; $U_{\text {lim }}$ - voltage on the protected PV-cells group (VLD output); $I_{U}$ - current through varistor; $I_{R}-$ VLD current (flowing through $\mathrm{RFu}$ ); $R_{u n s}=k_{u n s} \cdot r_{s h}$ - the total shunt electrical resistance of the series connection of shaded (reverse biased) PV-cells $\left(r_{s h}-\right.$ shunt resistance of one PV-cell). $I_{\text {string }}$ and $I_{\text {bypass }}=I_{\text {string }}+I_{R}$ - excess current coming from other submodules, and current through the bypass diode. The dashed line shows the connection lines of the submodule in the PVM and the bypass diode included in the forward direction (the resistance of which was neglected). 
When the entire submodule is illuminated, all $p$ - $n$ junctions of the PV-cells are forward biased and have low resistance. The current $I_{\text {bypass }} \approx I_{\text {string }}$ flows through the submodule, and the bypass diode $D$ is turned off. VLD does not affect the work of the PVM under the following conditions:

- the voltage $K \cdot U_{F}$ generated by the group of $K$ series-connected PV-cells, much less than the classification voltage of the varistor $U_{C}$ and the breakdown voltage of the PV-cell $U_{b}$, i.e. $K \cdot U_{F}<<U_{C}<U_{b}$ (while the varistor is in a state with high resistance);

- the current through the PVM is less than the tripping current of the RFu $I_{\text {trip }}$ (i.e. $I_{\text {string }}<I_{\text {trip }}$ ) and the fuse has a resistance many times less than the series resistance of the PV-cells.

When shading of at least one PV-cell, its resistance increases. The current $I_{\text {string }}$ begins to flow through the bypass diode $D$, which in the on state will short the submodule. As a result, a situation is realized when all the voltage generated by the illuminated serviceable PV-cells will bias the $p$ - $n$ junction of the shaded PV-cell in the reverse direction. If to choose $U_{C}$ of varistor less than the total voltage generated by the illuminated PV-cells of submodule, located outside the group where there is shading, i.e. if $U_{C}<E 1$, then the varistor will heat up, transferring heat to the fuse. As the temperature rises to $T_{\text {trip }}$, the fuse will sharply and much increase its resistance, which is equivalent to opening the circuit of this submodule.

The main parameters that were measured were the voltage drop at the VLD output $U_{\text {lim }}$ and the shaded PV-cell(s) $U_{R}$, currents flowing through the varistor $I_{U}$ and posistor $I_{R}$ VLD elements, as well as their dependence on the voltage generated by the photovoltaic submodule with a short-circuited bypass diode.

When implementing the above model structure in the experiment as an input limited voltage $E 1$ used a DC voltage source TEC14.

VLD varistor elements were disk varistors of VCR-14D180L type [90], and posistor elements were disk PPTC fuses of FRX375-60F type [69]. 
Passport values of the RFu parameters are $R_{\min }=0.03 \mathrm{Ohm}$ (or $R_{1 \max }=0.08 \mathrm{Ohm}$ ) and $I_{\text {trip }}=7.5 \mathrm{~A}$ at a temperature of $23{ }^{\circ} \mathrm{C}$.

Considering that commercial disk varistors for low classification voltages from 4 to $8 \mathrm{~V}$ (the most suitable for this situation) are not currently produced, varistors VCR-14D180L with $U_{C}=18 \mathrm{~V}$ were used to determine the fundamental possibility of implementing the proposed circuit solution. It was taken into account that the breakdown voltage for the used silicon PV-cells is $12 \mathrm{~V}$ [94], and a series connection of 4 indicated PV-cells was used as a component shaded cell.

Before the start of all experimental studies, CVC of the submodule without and with connected VLD were measured in order to control the absence of VLD influence on the photovoltaic characteristics of the submodule in the mode of power generation.

\subsubsection{Voltage limiting device for a separate photovoltaic cell}

In the situation under consideration, the composite photovoltaic cell (four PV-cells) is shaded and it is included in the submodule through a separate VLD (i.e. $K=k_{\text {uns }}=4, E 2=0, U_{\text {lim }}=4 \cdot U_{R}$ and $\left.R_{u n s}=4 \cdot r_{\text {sh }}\right)$. The dependence of the VLD output voltage $U_{\text {lim }}$, which is applied directly to the shaded PV-cells, the leakage current $I_{R}$ and VLD temperature $T$ on the applied voltage $E 1$ generated by other illuminated PV-cells of submodule are investigated (Fig. 4.20).

The obtained dependences reveal the following patterns.

1. The voltage drop across the shaded PV-cells $4 \times U_{R}$, corresponding to the VLD output voltage in this case $\left(U_{\text {lim }}=4 \times U_{R}\right)$, for any $E 1$ (i.e. the number of illuminated PV-cells connected in series in the submodule with the bypass diode), does not exceed a certain value of $U_{\lim 1}$, relatively close to the classification voltage of the varistor element $U_{C}$ and, thus, $4 \times U_{R}$ is insufficient for breakdown (or rapid degradation) of the shaded PV-cells [95]. 

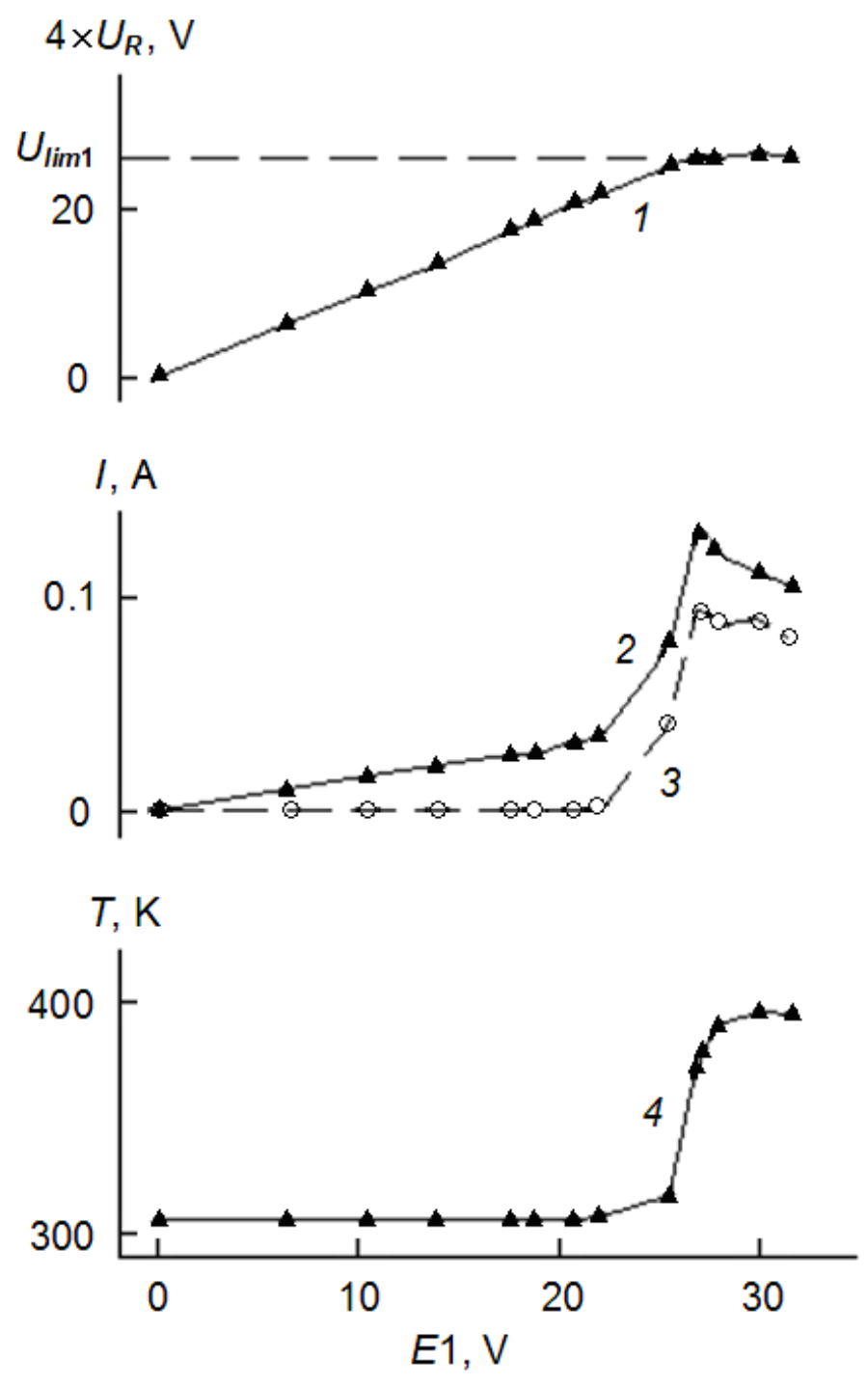

Figure 4.20. Dependences of voltage drop on four shaded PV-cells $4 \times U_{R}(1)$, currents through posistor $I_{R}(2)$ and varistor $I_{U}(3)$ elements and temperature $T$ of VLD on the applied limited input voltage $E 1$.

2. The currents through the posistor $I_{R}$ and varistor $I_{U}$ elements after reaching the maximum value corresponding to the tripping temperature of the posistor decreases, i.e. the dependences $I_{R}(E 1)$ and $I_{U}(E 1)$ have an $N$-shaped shape characteristic of the posistor elements.

3. The maximum possible temperature is close to the tripping temperature of $\mathrm{RFu}$, which is equal to $398 \mathrm{~K}\left(125^{\circ} \mathrm{C}\right)$. 
With increasing voltage generated by the illuminated PV-cells of submodule, there is a redistribution of the dissipation power (almost independent of the limited voltage $E 1$ ), which is released by the structure, in the direction of reducing its varistor part (Fig. 4.21) after VLD tripping. However, the total power released to maintain the VLD temperature, which provides a "heated" insulating resistance for the $\mathrm{RFu}$, is almost constant.

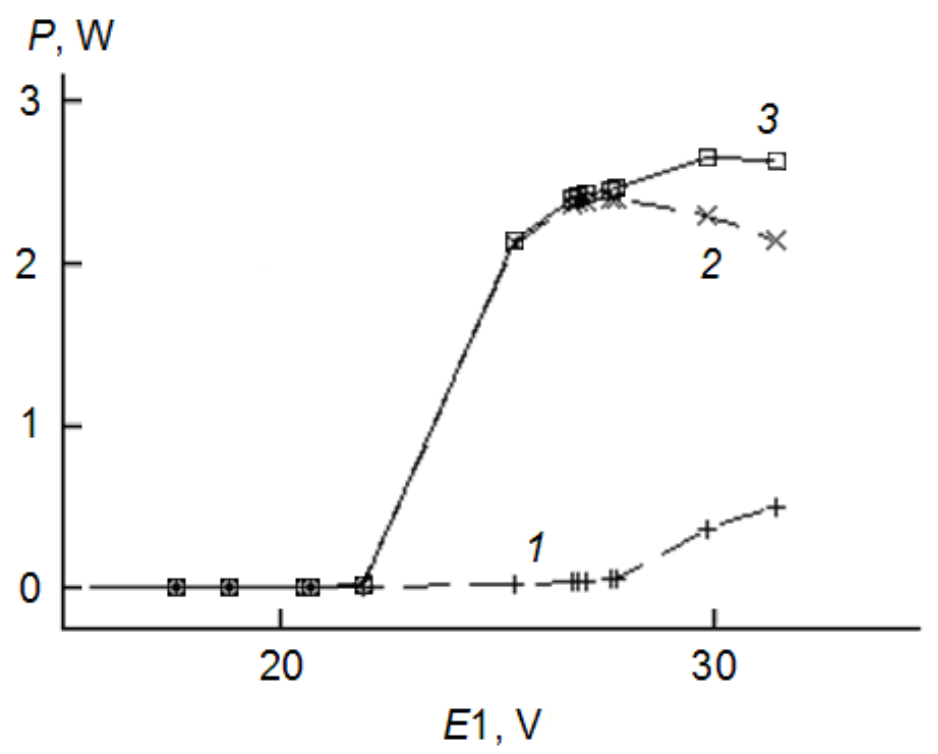

Figure 4.21. Dependences of the power dissipated on the posistor (1), varistor (2) elements and the total power dissipated (3) on VLD on the applied limited input voltage $E 1$.

\subsubsection{Voltage limitation for a group of series-connected photovoltaic cells}

According to the general circuit (Fig. 4.19) at use of one VLD for PV-cells group the maximum overvoltage on separate PV-cell arises in case it is the only shaded. In the analysed situation, in the presence of a component shaded photovoltaic cell (four PV-cells), this corresponds to the conditions $K>4, k_{u n s}=4, E 2=(K-4) \cdot U_{F}$, $U_{\text {lim }}=4 U_{R}-E 2$ and $R_{\text {uns }}=4 r_{\text {sh }}$. 
Fig. 4.22 shows the dependences of the voltage drop on the composite shaded photovoltaic cell $4 \times U_{R}$ and the output voltage of the limiter $U_{\text {lim } 1}$ on the number of illuminated PV-cells $(K-4)$ in the group with one common VLD. These data indicate that in the presence of illuminated PV-cells voltage drop across the reverse connected (shaded or faulty) diode of PV-cell increases by an amount equal to the voltage generated by these PV-cells. The value of the VLD output voltage $U_{\lim 1}$ is almost unchanged and is determined by the parameters of the VLD varistor element.

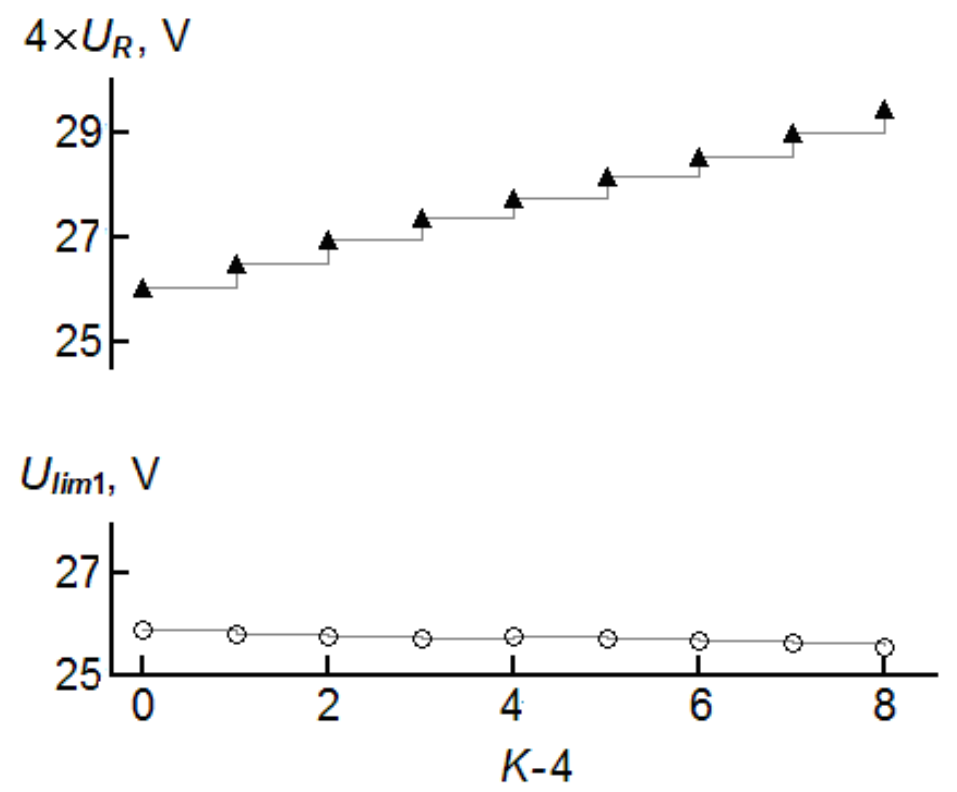

Figure 4.22. Dependence of the maximum voltage on the four shaded PV-cells $4 \times U_{R}$ and on the VLD varistor element $U_{\lim 1}$ on the number of illuminated serviceable PV-cells in the group. The mode corresponds to the situation when the indicated four PV-cells are shaded and the others $(K-4)$ are illuminated. $K$ - total number of elements in the group. Classification voltage of the VLD varistor element $U_{C}=18 \mathrm{~V}$.

As can be seen, the obtained experimental data are in accordance with the previously presented simulation results.

In conclusion, we note that similar patterns were obtained by us [96] and when using a working varistor element (layer with a diameter of $13 \mathrm{~mm}$ and a thickness of 
$\sim 1 \mathrm{~mm}$ ), assembled from 18 commercial low-voltage chip varistors V3.5MLA0603NH $\left(U_{C}=3.7-7 \mathrm{~V}, \beta=30-50\right)$ [97] connected in parallel, and posistor PPTC element of FRX110-60F type (diameter $13 \mathrm{~mm}$, thickness $\sim 1 \mathrm{~mm}$, the resistance of the element in the conductive state of $0.38 \mathrm{Ohm} ; T_{\text {trip }}=125^{\circ} \mathrm{C}$ ) [98].

The results of the study of the electrical characteristics of the structure based on the varistor ceramic layer and the posistor layer, which uses a polymer PPTC-nanocomposite, give reason to believe that such a device has certain unique functionality that makes it possible to implement DC overvoltage protection. Particularly, such device allows to limit the long-term DC overvoltages that occur in photovoltaic systems at the level of PV-cells in the event of their malfunction or shading, which can lead to increase in electrical resistance and loss of ability to generate electrical power.

However, there are some difficulties in implementing such a solution in photovoltaic systems. One of them is related to the lack of commercial production of disk-type varistor elements with low classification voltage (4-8 V), suitable for use as a "heater" of such a voltage limiting device. Another is due to the fact that when restoring the initial high-conductivity state of the VLD posistor element, when the illumination resumes, it is necessary to ensure its cooling by reducing the electric power, which requires appropriate experimental studies when choosing the parameters of the components of the protection device (subsection 4.3.2). 


\section{Chapter 5}

\section{PHYSICAL AND TECHNOLOGICAL APPROACHES TO SOLVING THE PROBLEM OF PROTECTION AGAINST ELECTRICAL OVERLOADS}

In the development of methods and means to prevent the occurrence of local overheating in the photovoltaic components of solar arrays, the main currently is the circuit direction, in particular, the use of bypass diodes and switches $[19,50]$. Much less attention is paid to physical and technological means. The most famous achievement in this direction was the creation of photovoltaic cells with low reverse breakdown voltages [19].

New perspectives in the development of such means of overvoltage prevention appeared in connection with the creation and widespread use of a new class of semiconductor materials, namely posistor polymer composites with nanocarbon filler, which are a basic element of PPTC (polymeric positive temperature coefficient) resettable fuses.

A special feature of such fuses is a sharp increase in resistance when heated to temperatures close to the phase transition temperature in polyethylene $\left(\sim 125^{\circ} \mathrm{C}\right)$, which is called the tripping temperature $T_{\text {trip }}$ [33]. This indicates another way to solve the problem of preventing local overheating in solar photovoltaic components, which is based on the tripping of the resettable fuse, which directly contact the surface of the photovoltaic cell, when increasing the temperature.

Accordingly, the urgent tasks for progress in this direction are the study of the impact on the main characteristics of PV-cell increased temperatures and significant reverse currents and direct justification and testing of the above method of preventing local overheating. 


\subsection{Changes in the characteristics of silicon photovoltaic cells during overheating}

It is known that solar arrays have recently become one of the most desirable renewable sources of electricity. In this regard, the requirements for such systems are put forward in the foreground, in particular, the stability of the main functional properties after being at increased temperatures.

It is known that structurally solar arrays consist of many photovoltaic cells connected in series and in parallel. The main part of the PV-cell is often a silicon $p$ - $n$ junction. According to the data presented in $[99,100]$, a number of other devices that use silicon junctions (diodes, transistors), retain their performance to temperatures of $150^{\circ} \mathrm{C}$ and above. However, for similar silicon devices used as $\mathrm{PV}$-cells in solar energy, the maximum operating temperature is limited $60-80{ }^{\circ} \mathrm{C}$ [101]. The reason for this is a sharp decrease of generated power [102-104].

However, the question of the level of degradation and preservation of PV-cell after exposure to high temperatures for a limited period of time is not sufficiently studied. Among the known works in this direction should be noted articles [104, 105], where the reduction of open-circuit voltage and short-circuit current of silicon PV-cells after exposure to heat treatment in atmospheric conditions and reaching a temperature of about $300{ }^{\circ} \mathrm{C}$ at different durations was established.

Such research is needed in connection with the prospect of solving the problem of improving the reliability of solar arrays by using resettable fuses of PolySwitch type as additional devices to insulate inactive (shaded or defective) areas as individual PV-cells and their modules $[46,106]$.

One of the problems of their application in solar arrays is the mismatch of the operating temperature range for photovoltaic modules (maximum allowable temperature $\sim 80^{\circ} \mathrm{C}[101]$ ) and the most common types of commercial PPTC fuses, for which the phase transition (tripping) region is estimated by values of $125{ }^{\circ} \mathrm{C}[33$, $39,46]$. 
In this subsection, the effect of the stay of photovoltaic cells of solar arrays at high temperatures on their current-voltage characteristics is studied. Particular attention is paid to lighting modes and states (open, short-circuited) of PV-cells, which were used in heat treatment (HT). They correspond to real situations of overheating during operation of PV-cells and are important at development of circuits of devices for their protection against electric and thermal overloads.

\subsubsection{Samples and methods of research}

The studies used PV-cell samples produced by PC "Gamma" based on single-crystal silicon SHB-10 with a coating based on ITO-film, which were used in $[45,46,107]$.

An automated measuring system described in the previous section was used to measure the current-voltage and power-voltage characteristics (power curve).

The role of the light source was performed by a simulator of solar radiation, which simulates the conditions AM1.5. For studies at increased temperature, the PV-cell was placed in a heated thermostat, and after each such measurement was cooled to room temperature in free mode.

Experimental studies were performed in the following order. To determine the effect of the stay of PV-cell at increased temperatures (temperature treatment) on their performance, their CVC were measured in shaded and light modes, in each of which the studies were performed in the open and short-circuited state of the cell. Based on the obtained $\mathrm{CVC}$, the corresponding power-voltage characteristics were calculated.

As a result, the values of the main parameters of the CVC and PVC of photovoltaic cells were recorded: the open-circuit voltage $U_{O C}$, the short-circuit current $I_{S C}$ and the maximum power $P_{M}$, which is released into the external electrical circuit. 
The obtained results were presented in the form of correlation fields, where the values of temperature and duration of heat treatment were taken as an independent factor $x$, and the values of the above parameters of CVC and PVC of the investigated PV-cells were taken as a random variable. These data were also represented by approximate linear functions obtained using the least squares method.

For their analysis, a method, similar to assess the stability of varistor products, was used and based on the fixation of deviations of their functional parameters from the nominal values due to ageing or exposure to various heat treatments $[108,109]$.

The controlled value, called the waste of the corresponding parameter, was determined by the general formula

$$
\Delta y(x)=\frac{y(x)-y^{*}(0)}{y^{*}(0)} \cdot 100 \%,
$$

where $y(x)$ and $y(0)$ - the value of the parameter $y$ at the value of the factor level (temperature or duration of heat treatment) $x$ and its initial (nominal) value.

\subsubsection{Influence of heat treatment temperature on the characteristics of photovoltaic cells}

Fig. 5.1 shows the results of measurements of current-voltage and power-viltage characteristics of PV-cells, which were subjected to heat treatment at different temperatures in the open state and shaded mode. As can be seen, HT leads to some "drift" of these characteristics, which has the character of a random scatter. Particularly, there may be deterioration and improvement of PV-cell parameters, which corresponds to the known processes of their degradation and regeneration $[110,111]$. 

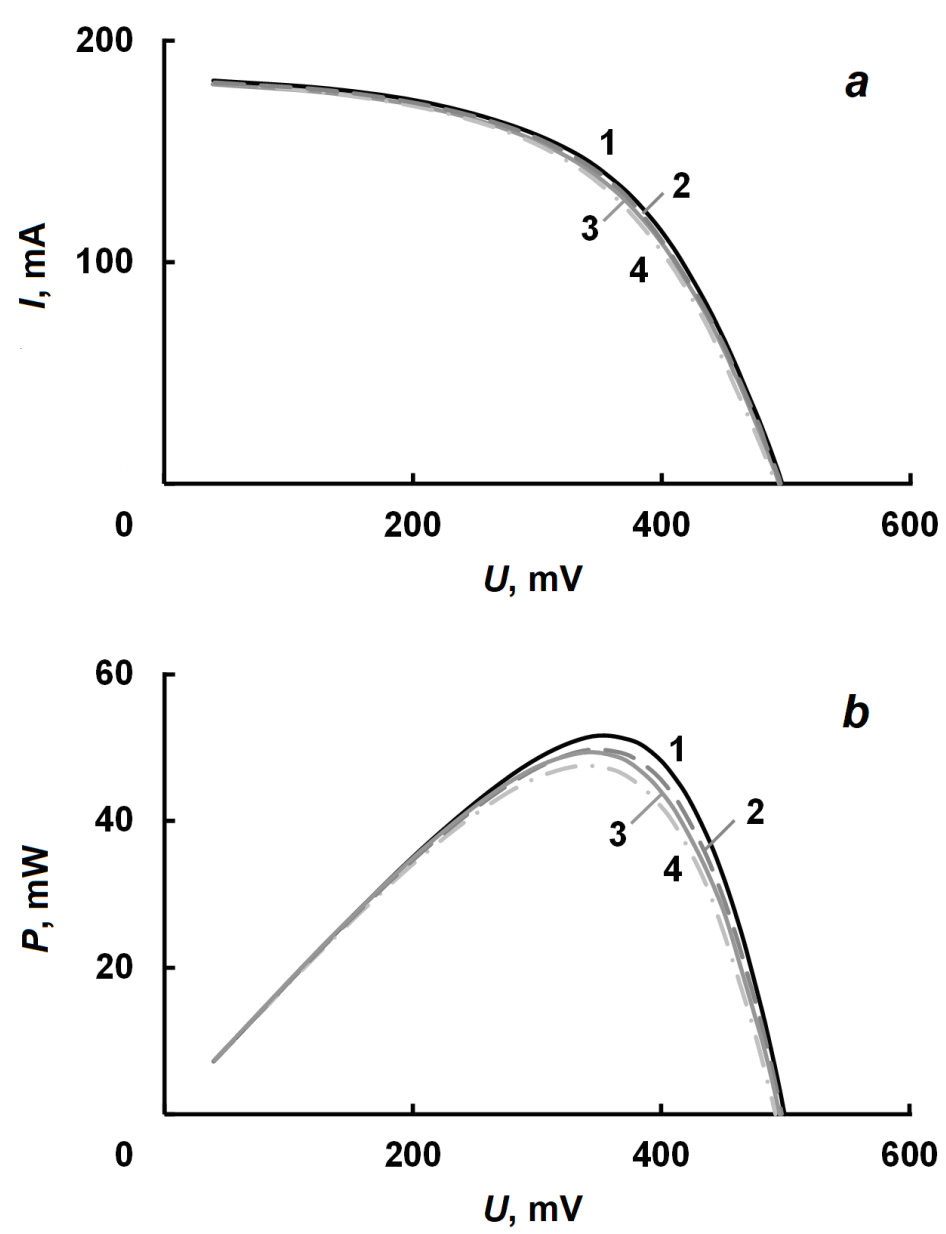

Figure 5.1. Typical CVC $(a)$ and PVC $(b)$ of the samples of the investigated PV-cells (illuminated mode, short-circuited terminals), which were subjected to HT lasting 10 minutes and temperature, ${ }^{\circ} \mathrm{C}: 1-25 ; 2-75 ; 3-120 ; 4-165$.

For the analysis in Fig. 5.2 the values of such CVC parameters as open-circuit voltage and short-circuit current at different temperatures corresponding to HT with different lighting modes and PV-cells states are given.

In Fig. 5.2 points are experiment. "Painted" light dots correspond to HT in lighted mode, "unpainted" - in shaded mode; the circles correspond to the heat treatment of the PV-cell in the open-circuited state, and the triangles - in the short-circuited state. The line is the resulting averaged using the least squares method (solid corresponds to the heat treatment of PV-cell in the open-circuited state, dotted - in the short-circuited state). 

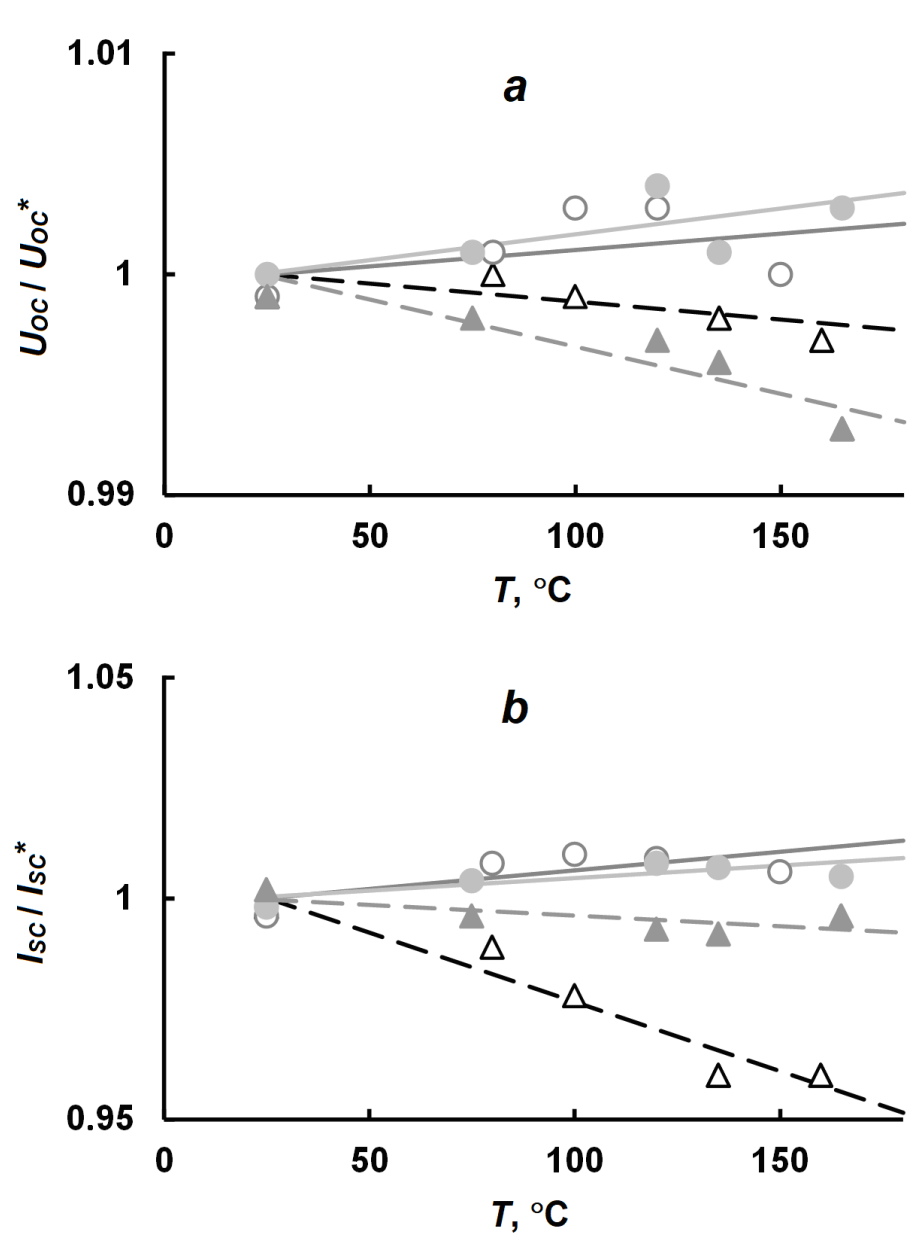

Figure 5.2. Dependence of open-circuit voltage $(a)$ and short-circuit current $(b)$ on the heat treatment temperature $T_{H T}$ for a time $t_{H T}=10 \mathrm{~min}$.

As can be seen, the value of $U_{O C}$ is almost independent of the HT influence with temperatures ranging from 25 to $\sim 160{ }^{\circ} \mathrm{C}$ in all used modes and states of the PV-cells. This is evidenced by the values of waste at a temperature of $150{ }^{\circ} \mathrm{C} \Delta U_{O C}$ are given in Table 5.1.

The magnitude of the short-circuit current (as well as the values of currents at any fixed voltage, see Fig. 5.1) is characterized by some variation of values, especially if the heat treatment was carried out in the shaded mode. However, the value of deviation $\Delta I_{S C}\left(150^{\circ} \mathrm{C}\right)$ does not exceed $\sim 10 \%$. It is worth noting that the deviation in the shaded mode is greater than in the lighted. This agrees with the data on the effect of regeneration of photovoltaic properties of the studied silicon PV-cells 
during heat treatment (thermal annealing) on lighting $[110,111]$. Since the values of the maximum power of the PV-cell are directly related to the values of its current, similar patterns are manifested depending on $P_{M}\left(T_{H T}\right)$ (Fig. 5.3, Table 5.1).

Table 5.1

Estimation of influence of factors of temperature and duration of heat treatment on the basic functional parameters of the investigated PV-cells

\begin{tabular}{|c|c|c|c|c|c|}
\hline \multirow{3}{*}{ Influence factor } & \multirow{2}{*}{ Mode } & \multirow{2}{*}{$\begin{array}{c}\text { PV-cell state } \\
\text { at HT }\end{array}$} & \multicolumn{4}{|c|}{$\begin{array}{c}\text { Maximum deviation of the } \\
\text { parameter, \% }\end{array}$} \\
\cline { 4 - 6 } & & & $U_{O C}$ & $I_{S C}$ & $P_{\max }$ \\
\hline \multirow{2}{*}{$\begin{array}{c}\text { Temperature } \\
\text { (duration of HT }- \\
10 \text { min) }\end{array}$} & shaded & open-circuit & 0.23 & 1.052 & 2.148 \\
\cline { 4 - 6 } & lighted & open-circuit & 0.301 & 0.709 & 1.613 \\
\cline { 2 - 6 } & shaded & short-circuit & -0.204 & -3.921 & -4.264 \\
\cline { 2 - 6 } & lighted & short-circuit & -0.534 & -0.604 & -6.145 \\
\hline \multirow{2}{*}{$\begin{array}{c}\text { Duration of HT } \\
\text { (temperature }- \\
\left.150{ }^{\circ} \mathrm{C}\right)\end{array}$} & shaded & open-circuit & -0.791 & 3.377 & 3.279 \\
\cline { 2 - 6 } & lighted & open-circuit & -0.16 & 3.937 & -1.116 \\
\cline { 2 - 6 } & shaded & short-circuit & -0.626 & -4.753 & -3.823 \\
\cline { 2 - 6 } & lighted & short-circuit & 0.032 & 2.534 & -1.329 \\
\hline
\end{tabular}

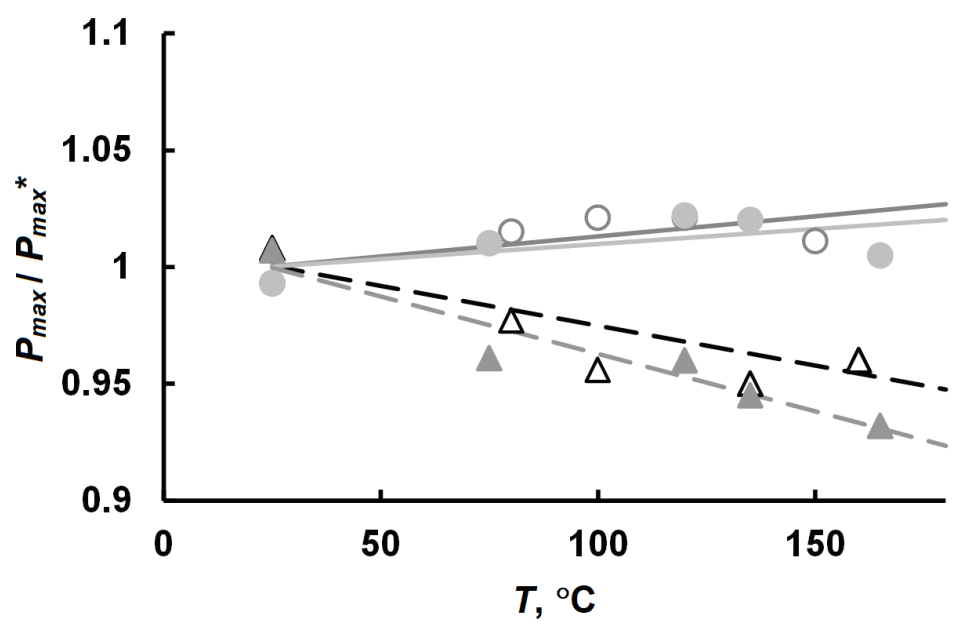

Figure 5.3. Dependence of the maximum power given to the PV-cell on the heat treatment temperature of $T_{H T}$ for a time $t_{H T}=10 \mathrm{~min}$. Designations correspond to those adopted for Fig. 5.2. 


\subsubsection{Changes in the characteristics of the photovoltaic cell from the duration of heat treatment}

The results of measurements of CVC and PVC of PV-cells, which were subjected to heat treatment, are shown in Fig. 5.4.
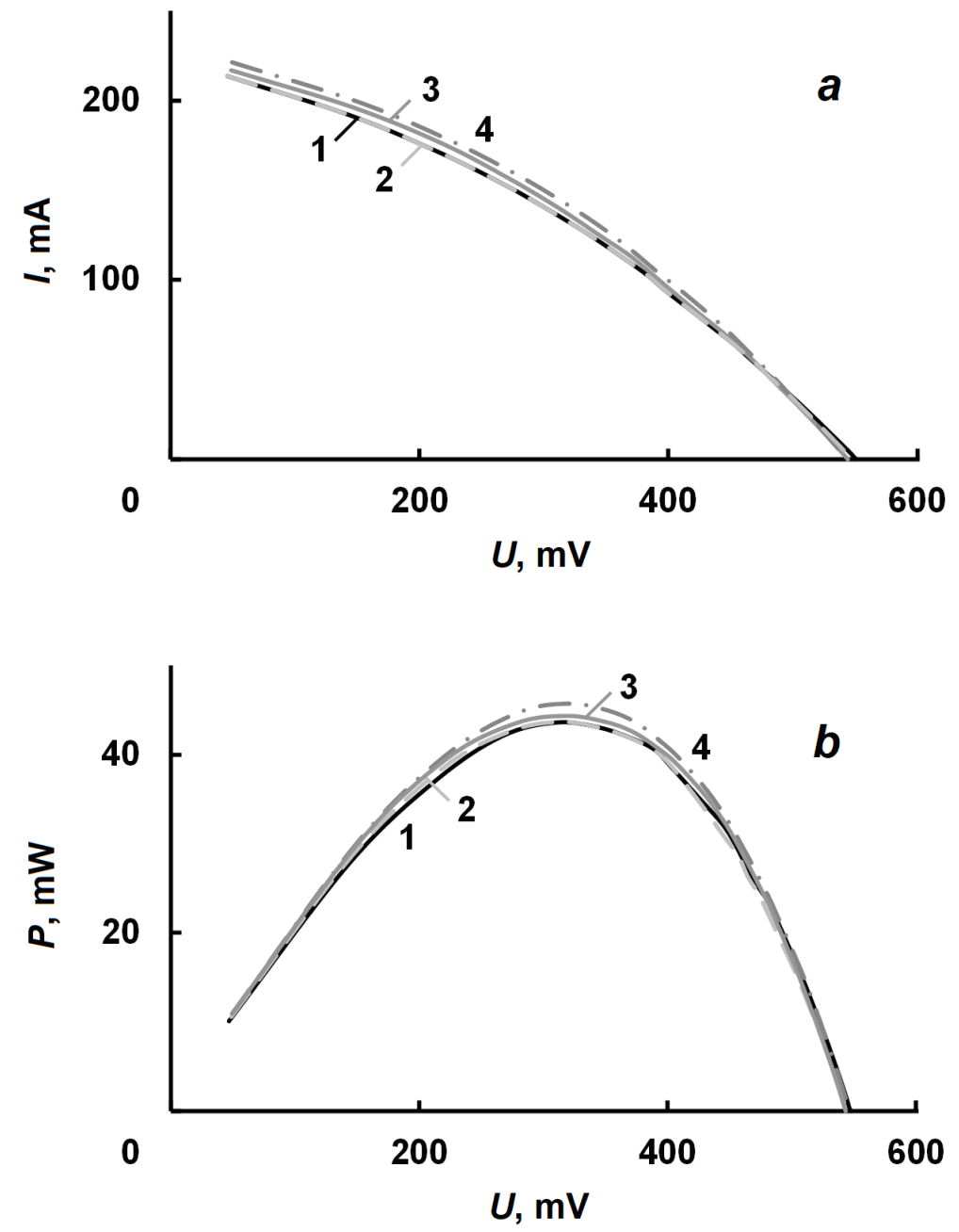

Figure 5.4. CVC (a) and PVC (b) of samples of the investigated PV-cells (shaded mode, open-circuit), which were subjected to maintenance with a temperature of $150{ }^{\circ} \mathrm{C}$ for a time interval, min: $1-0 ; 2-60 ; 3-180 ; 4-360$.

As can be seen, heat treatment, as in the case described in the previous section, leads to an accidental "drift" of these characteristics (Fig. 5.5 and 5.6). 

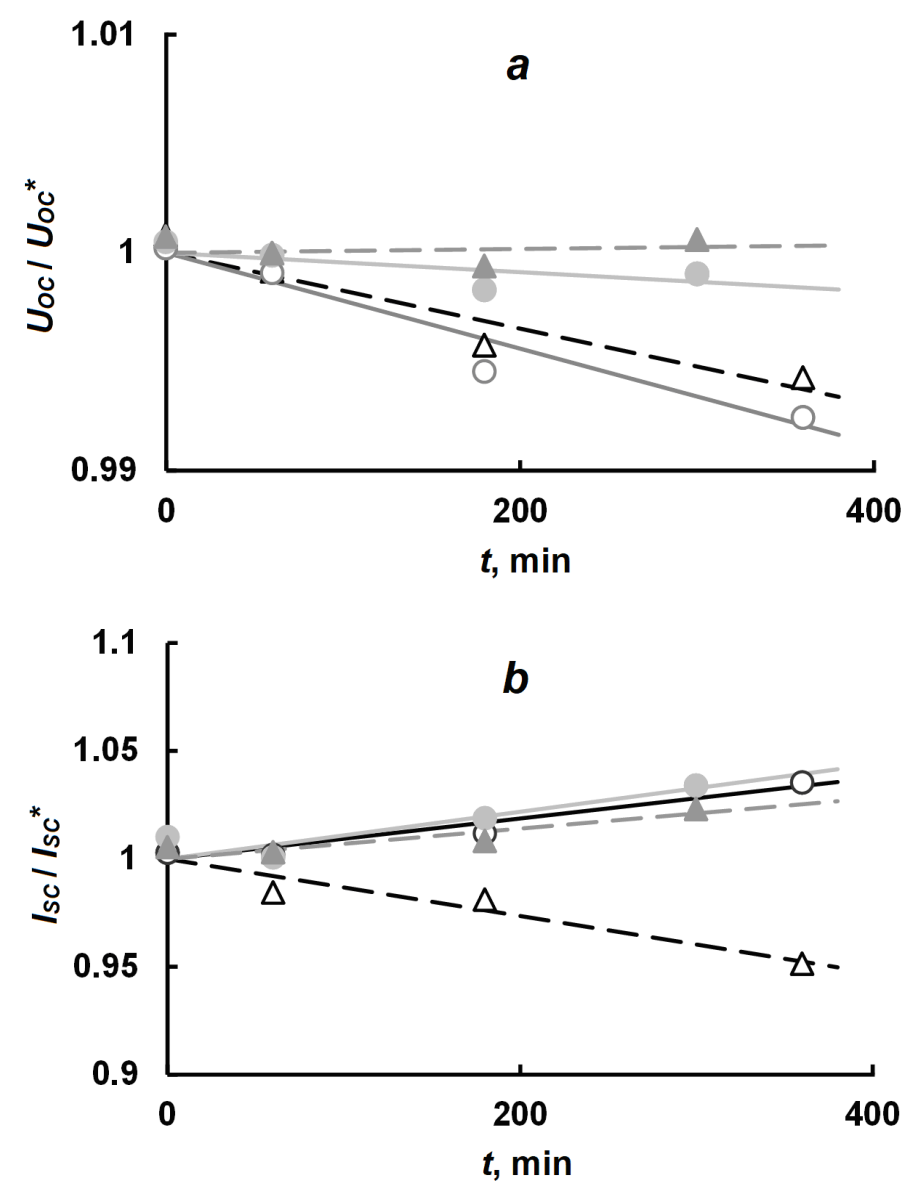

Figure 5.5. Dependence of open-circuit voltage (a), short-circuit current $(b)$ on the duration of heat treatment $t_{H T}$ at temperature $T_{H T}=150^{\circ} \mathrm{C}$. Designations correspond to those adopted for Fig. 5.2.

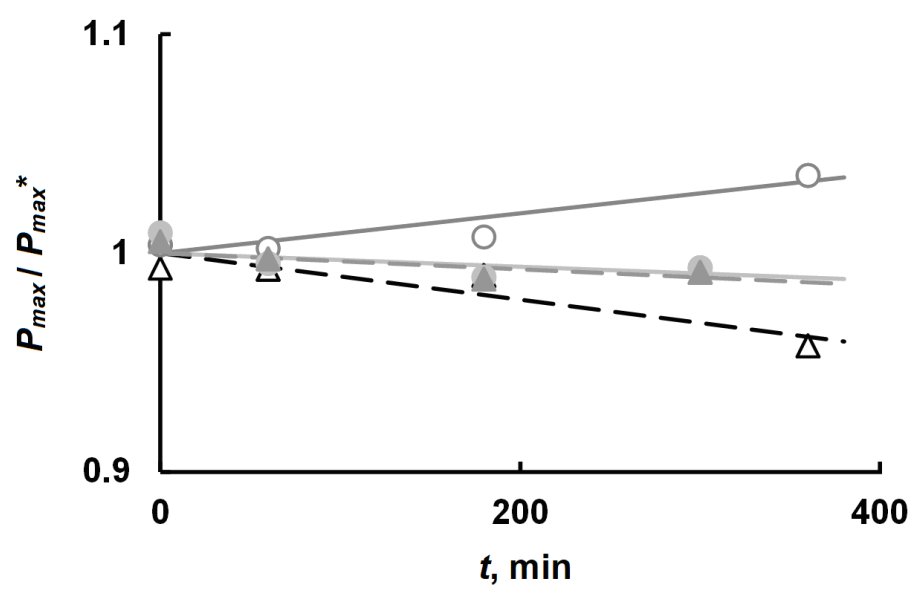

Figure 5.6. Dependence of maximum power given to the PV-cell on the duration of heat treatment $t_{H T}$ at temperature $T_{H T}=150^{\circ} \mathrm{C}$. Designations correspond to those adopted for Fig. 5.2. 
According to these data, the value of $U_{O C}$ is almost constant, and the parameters $I_{S C}$ and $P_{M}$ have a random scatter after the HT effects with a temperature of $150{ }^{\circ} \mathrm{C}$ with intervals from 0 to $360 \mathrm{~min}$ ) in all used modes and states of the PV-cells.

Thus, in the accepted conditions (temperatures and duration of heat treatments) there are no significant changes in the main functional characteristics and parameters of the studied PV-cells based on monocrystalline silicon.

The obtained results can be considered as a substantiation of the prospect of using the developed existing resettable fuses on the basis of polymer-carbon nanocomposites as circuit elements of electrical and thermal protection of components of solar array.

\subsection{Changes in the characteristics of silicon photovoltaic cells after current overloads}

Studies of the consequences of the direct flow of large currents through the reverse biased $p$ - $n$ junction of PV-cell, which lead to its heating and failure, have so far been conducted mainly for the purpose of in-depth study of breakdown mechanisms $[112,113]$. When using modern means of protection against current overloads, in particular resettable fuses [65], there may be an abnormal situation when a large current will flow through the PV-cell diode for some short time (corresponding to the implementation of the temporary breakdown mode [15]). However, the question of the level of degradation and preservation of PV-cell after exposure to current overloads for a limited period of time is insufficiently studied [114].

This subsection presents the results of the study of the influence of temporary current overloads on the current-voltage and power-voltage characteristics of photovoltaic cells and their technical parameters. 


\subsubsection{Research methodology}

The studies used samples similar to those described in subsection 5.1.1. A special experimental automated measuring complex using the known voltmeterammeter method was used to register light CVC (see Appendix A).

The breakdown state of the PV-cell was achieved by applying a constant reverse bias voltage for several minutes, which successively increased to values at which a sharp uncontrolled increase in current began (Fig. 5.7). At this point in time, PV-cell was disconnected from the voltage source using a switch.
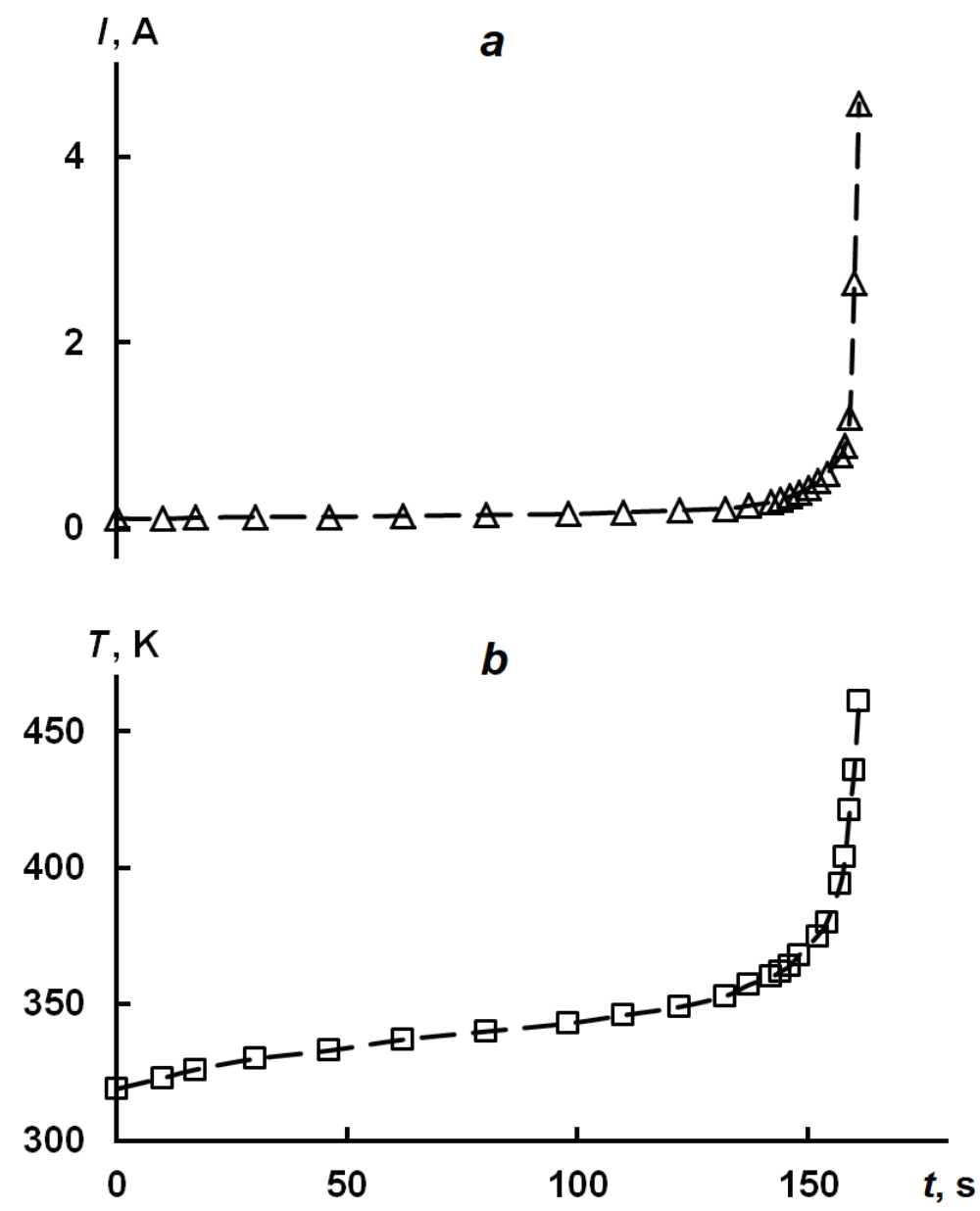

Figure 5.7. Dependences of current $I(a)$ and temperature $T(b)$ of PV-cell when applying to it the reverse bias voltage sufficient for the onset

of thermal breakdown. 
The duration of the current overload corresponding to the area of sharp increase in the dependences of Fig. 5.7 was short (did not exceed $5 \mathrm{~s}$ in the experiments).

The given dependence of temperature at realization of such breakdown testifies to its thermal character.

In order to identify the most common patterns of influence of current overloads on the properties of the considered silicon PV-cells, samples were taken with different initial CVC and PVC, which was a consequence of the prehistory of their operation or technological variation in manufacturing (Fig. 5.8).
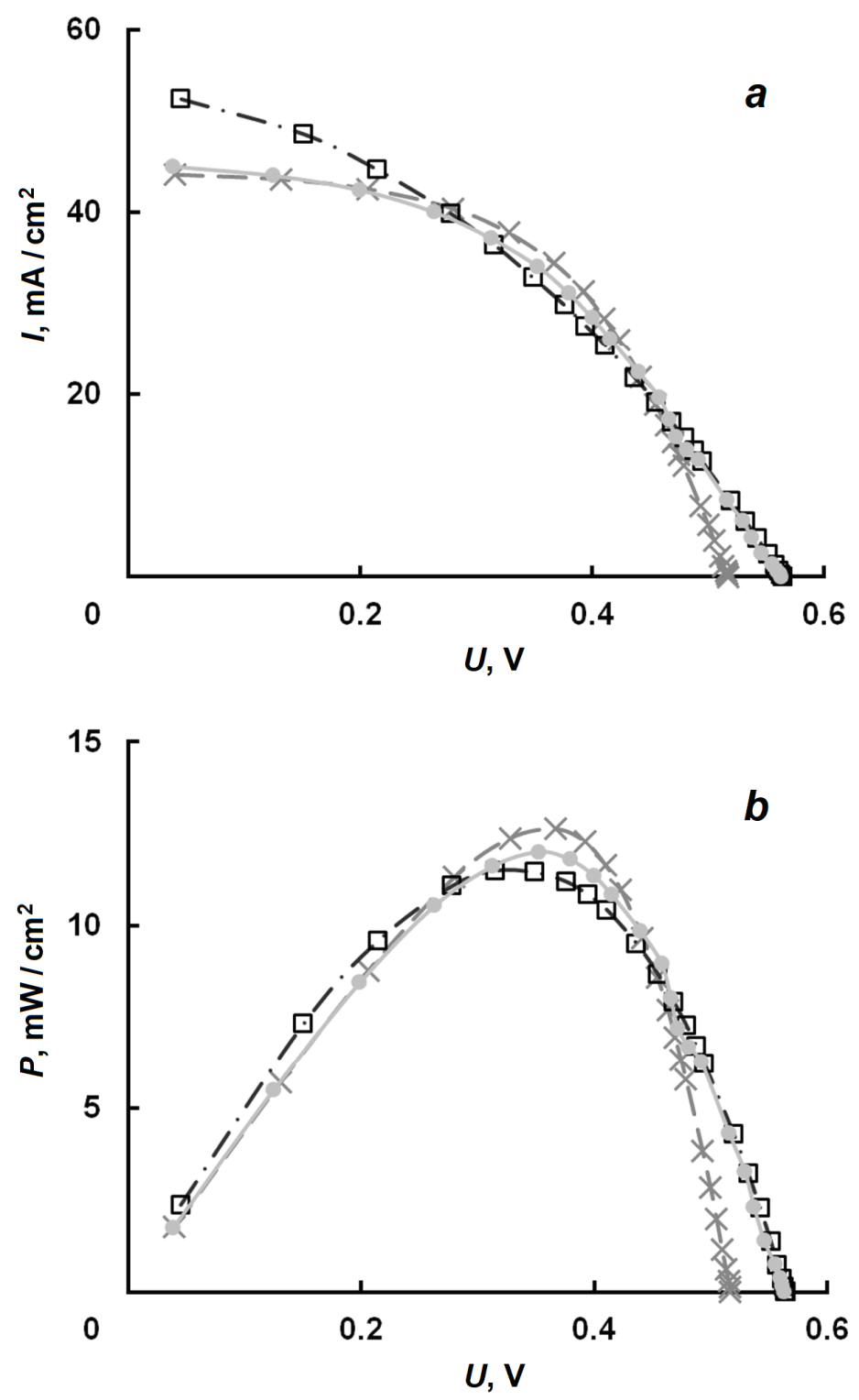

Figure 5.8. Typical light CVC $(a)$ and PVC $(b)$ of the investigated PV-cells samples. 
To determine the effect of cyclic current overloads on the efficiency of PV-cells experimental studies were conducted in the following order:

- the initial light CVC of the investigated PV-cell was measured;

- dark current was passed through the PV-cell in the direction of the reverse displacement of its diode and after the thermal breakdown, which was recorded by a critical increase in current and temperature, it was disconnected from the voltage source;

- PV-cell in the off state was cooled to room temperature, and its CVC was remeasured.

The last two points that determine the current overload cycle were repeated several times (cycles).

As a result, the following values of the main parameters of the CVC and PVC characteristics of the PV-cells sample were recorded: open-circuit voltage (with open PV-cell), short-circuit current and electric power given to the external circuit.

\subsubsection{Influence of current overloads on the characteristics of photovoltaic} cells

Fig. 5.9 shows the typical results of measurements of CVC and PVC characteristics of photovoltaic cells, which were subjected to the above-described current overloads.

As can be seen, the short-term flow of current in the breakdown state in the direction of the reverse displacement of the PV-cell diode leads to a decrease in current and power generated by the PV-cell. This effect has an additive character, i.e. with increasing number of cycles in which the PV-cell is in a state of such a breakdown, the amplitudes of the decrease in current and power increase. 

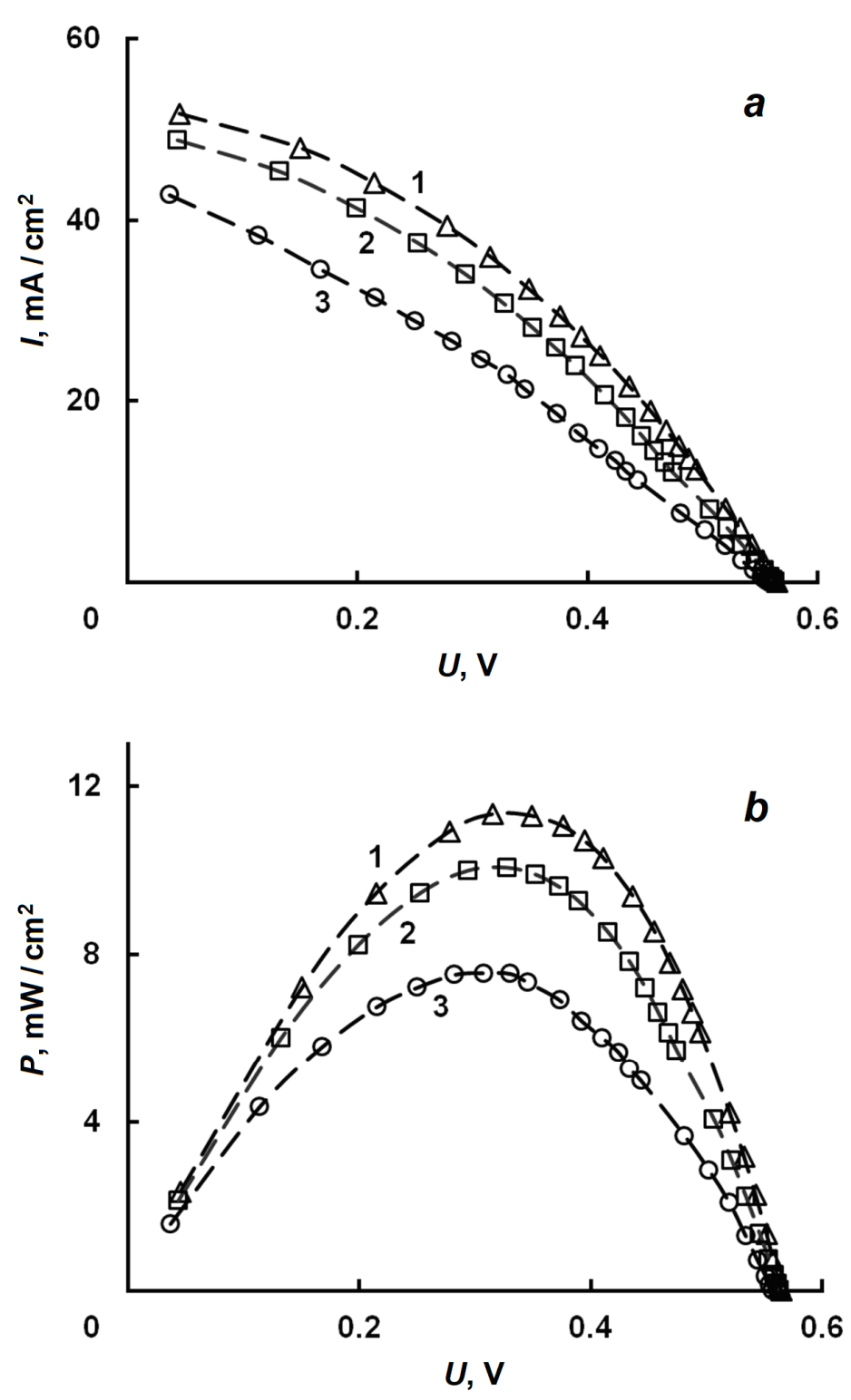

Figure 5.9. CVC ( $a$ ) and PVC (b) of the PV-cell sample before (1) and after two (2) and eight times (3) PV-cell being in the state of breakdown by the reverse electric current.

Let's analyse the dependences of CVC and PVC parameters of photovoltaic cells (open-circuit voltage $U_{O C}$, short-circuit current $I_{S C}, \mathrm{CVC}$ filling factor $f f$ and electric power given to the external circuit $P_{\max }$ ) on the number of PV-cells breakdown cycles (parameters are normalized to values that correspond to the initial state of the sample) that are given in Fig. 5.10. 


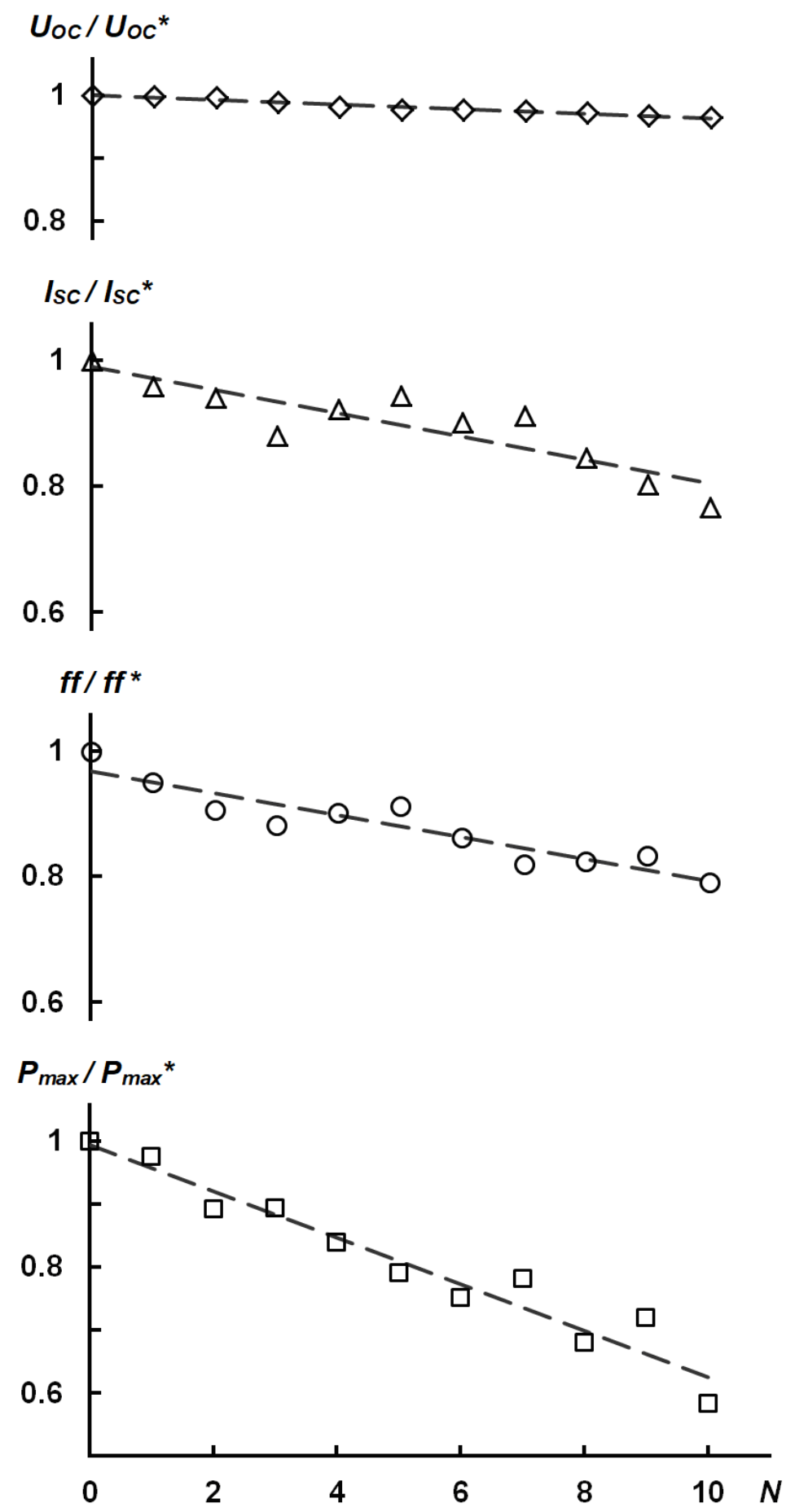

Figure 5.10. Dependences of open-circuit voltage $U_{O C}$, short-circuit current $I_{S C}$, coefficient $f f$ and maximum power $P_{\max }$ of $\mathrm{PV}$-cell on the number of current overload cycles. Values $U_{O C^{*}}, I_{S C^{*}}$, $f f^{*}$ and $P_{\max }{ }^{*}$ correspond to the initial state of the PV-cell sample before it is in a state of breakdown.

Points are experiment, dashed line is approximation. 
The $f f$ value was determined according to a known expression [45]

$$
f f=\frac{I_{\max } V_{\max }}{I_{S C} V_{O C}}
$$

where $I_{\max }$ and $U_{\max }$ - the magnitude of the current and voltage at the CVC of the PV-cell corresponding to its maximum power given to the external electrical circuit $P_{\max }$.

The obtained experimental data were represented by approximating linear dependences obtained using the least squares method.

Table 5.2 shows the average values of the controlled parameters for 10 samples. As can be seen, all the studied parameters of the PV-cell show a tendency to decrease with increasing number of cycles in which the PV-cell is in the state of breakdown by the reverse electric current. However, the open-circuit voltage $U_{O C}$ is sensitive to this to a lesser extent than the short-circuit current $I_{S C}$ and other parameters presented here (Table 5.2). This is primarily due to the fact that the values of the maximum power $P_{\max }$ and the CVC filling factor $f f$ of $\mathrm{PV}$-cell are directly related to the magnitude of its current.

Table 5.2

Estimation of influence of current overloads on parameters of silicon PV-cell

\begin{tabular}{|l|c|c|}
\hline PV-cell parameter & $\begin{array}{c}\text { The average relative } \\
\text { decrease for one } \\
\text { breakdown cycle, } \%\end{array}$ & $\begin{array}{c}\text { Relative estimation } \\
\text { error, \% }\end{array}$ \\
\hline Open-circuit voltage $U_{O C}$ & -0.5 & 1.5 \\
\hline Short-circuit current $I_{S C}$ & -1.5 & 5.0 \\
\hline CVC filling factor $f f$ & -2 & 3.0 \\
\hline Maximum power $P_{\max }$ & -3.5 & 0.8 \\
\hline
\end{tabular}

As can be seen, short-term current overloads in the opposite direction of the PV-cell diode in contrast to the PV-cell heating by external heat sources lead to a significant reduction in the power given to them in the outer circuit, and the 
degradation of other parameters. In particular, the obtained results allow predicting a decrease in maximum power by $3.5 \%$ after a single breakdown of the PV-cell in the reverse direction. Deterioration of electrical characteristics of PV-cell under the influence of current overloads has an additive (accumulative) character.

Similar results were obtained for all studied samples. Table 5.2 (third column) shows the data on the scatter of the values of the average relative reductions for one breakdown cycle of all controlled parameters associated with the differences in the initial CVC and PVC (Fig. 5.8). The given values of relative error of definition of the specified parameters $(<5 \%)$ testify to commonality of the investigated laws irrespective of a prehistory of their operation or technological scatter at manufacturing.

Regardless of the physical nature of the breakdown (thermal, avalanche or tunnel $[112,113])$, the increase in current through the PV-cell leads to local heating of its individual areas. The increase in temperature of both individual areas ("hot spots") and the entire PV-cell allows us to consider this phenomenon as a basis for the use of posistor elements such as PolySwitch, which are in contact with the PV-cells as thermal sensors $[46,88]$. As is known, the range of operation times of PolySwitch fuses is from milliseconds to several seconds $[32,33]$. The time during which the prebreakdown of the PV-cell is heated is estimated by an interval of several minutes, and the duration of the breakdown is $\sim 5 \mathrm{~s}$ (see Fig. 5.7). Thus, the obtained data suggest that in the event of abnormal situations associated with current overloads, the choice of this type of fuse can minimize degradation changes in the PV-cell parameters in the range where they do not lead to significant changes.

It should be noted that the comparison of the range of tripping times of PolySwitch fuses with the obtained duration of PV-cell breakdown suggests their prospects for use as protection against current overloads of photovoltaic systems of solar arrays in case of abnormal situations in their work. 


\subsection{Electrical properties of a photovoltaic cell with a built-in posistor layer based on a polymer nanocomposite with a carbon filler}

As already mentioned, one of the ways to solve the problem of preventing local overheating ("hot spots" [115] in photovoltaic components of solar power plants) may be the development of PV-cell with a built-in posistor layer of resettable fuse, based on the effect of its tripping when the temperature of the photovoltaic component rises and the transfer of heat from PV-cell to resettable fuse due to thermal contact between them.

Actual tasks for progress in this direction are substantiation and approbation of such physical and technological solution of prevention of local overheats in circles of photovoltaic systems of solar arrays. It should be noted that modern PV-cells belong to the elements of the distributed film type (thickness $0.1-0.2 \mathrm{~mm}$, area up to $\left.15 \times 15 \mathrm{~cm}^{2}\right)$.

At detailed research of electrothermal processes, in particular thermal breakdown, it is necessary to consider processes of distribution of heat in such structures in the plane of PV-cell that leads as a result to problems difficult in mathematical and experimental sense [116-118].

However, as a first step - to find out the effectiveness and features of the method of overload protection considered here - it will be important to study the electrical effects accompanying it, using structures with small areas, including individual photovoltaic cells, for which the heterogeneity of preheating can be neglected.

The results of experimental studies of the electrical properties of the two-layer structure are presented and analyzed in this subsection. This structure is a photovoltaic monocrystalline silicon element with an additional layer of posistor polymeric nanocomposite with a carbon filler, which are in thermal contact. The purpose is to evaluate the possibility of limiting the electrical voltage applied to the reverse connected photovoltaic cells. 


\subsubsection{Studied structure and its circuitry representation}

The structure of the samples and the equivalent electrical circuit of the photovoltaic cell samples with overvoltage protection based on two-layer structures of monocrystalline silicon PV-cell and polymer posistor nanocomposite with carbon filler (PPTC fuse) are presented in Fig. 5.11 [119].

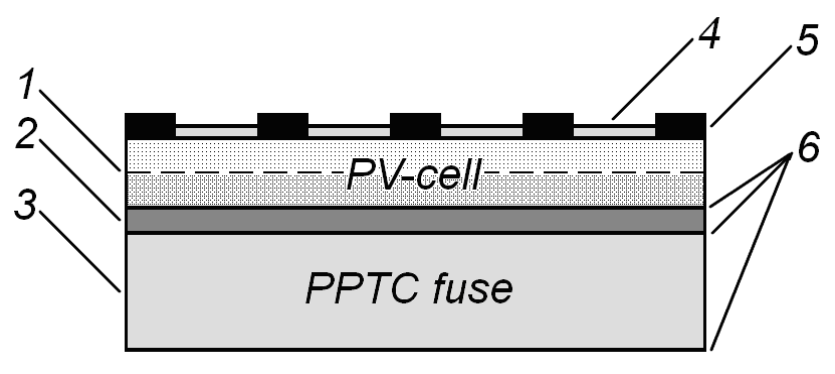

$a$

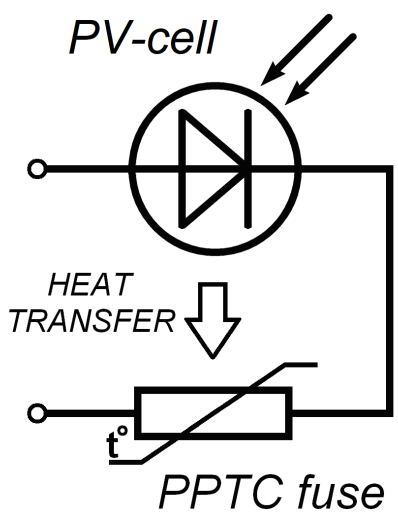

$\boldsymbol{b}$

Figure 5.11. The studied structure $(a)$ and its electrical circuit $(b)$.

$1-p-n$ junction of the photovoltaic cell; 2 - layer of heat-conducting paste; 3 - layer of posistor nanocomposite; 4 and 5 - anti-reflective coating and metal mesh (electrode) of the PV-cell layer; 6 - electrode layers.

In the experiments as a photovoltaic cell fragments of solar cells made on the basis of monocrystalline silicon SHB-10 with a coating based on ITO-film [46, 107] (thickness $0.1 \mathrm{~mm}$, area up to $4 \mathrm{~cm}^{2}$ ) were used. The second layer was the working element of the PPTC fuse of type RXEF050 (layer with a diameter of $6.8 \mathrm{~mm}$ and a thickness of $2 \mathrm{~mm}$, the resistance of the element in the conductive state is $1.17 \mathrm{Ohm}$; $T_{\text {trip }}=125^{\circ} \mathrm{C}$ ) [65]. Thermal contact between the layers was provided by using silicone heat-conducting paste KPT-8 [92]

The research was conducted using the circuit shown in Fig. 5.12. The input voltage $U$ was supplied from a standard adjustable voltage source type TEC14 (PS). 
Measurements of current $I$ and voltage values on the elements of the studied structure $\left(U_{P V}\right.$ and $\left.U_{P P T C}\right)$ were performed with commercial voltmeters and ammeters. Their temperatures $\left(T_{P V}\right.$ and $\left.T_{P P T C}\right)$ were recorded by thermocouples.

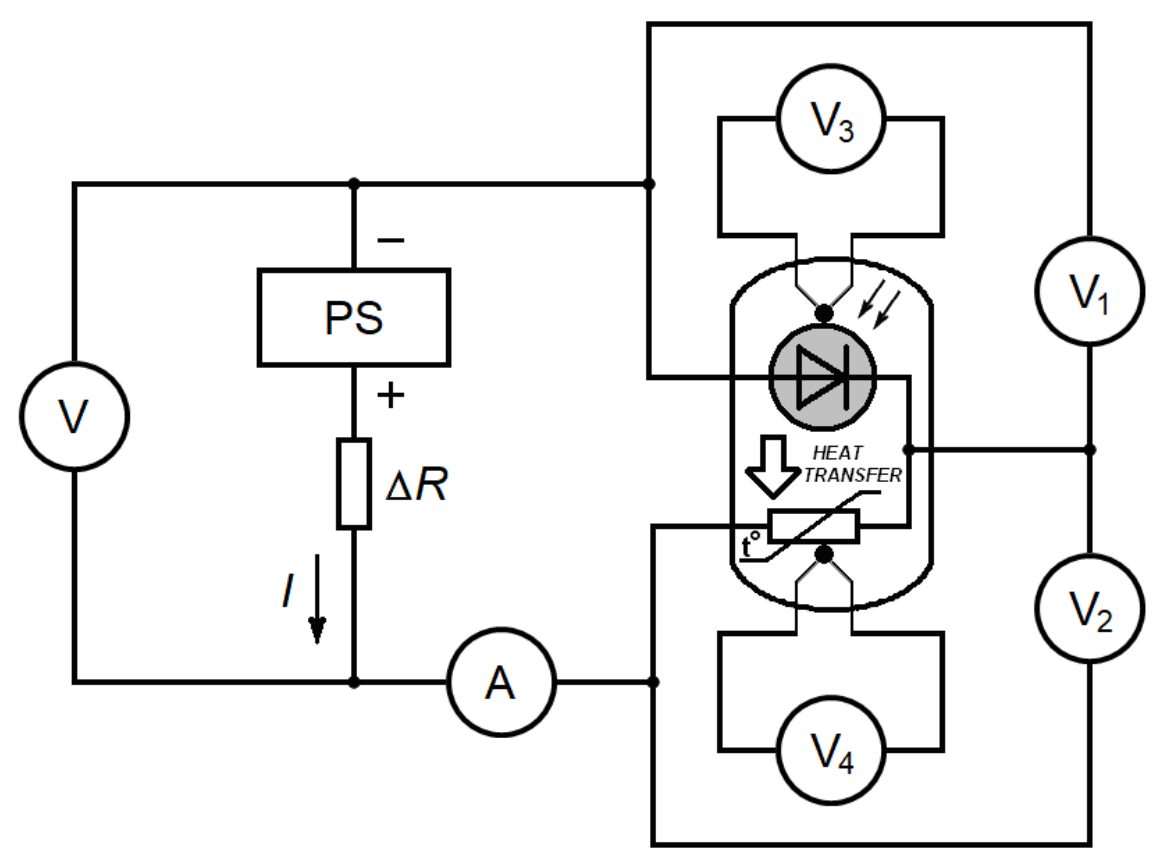

Figure 5.12. Circuit for measuring the electrical characteristics of the studied two-layer structure based on a silicon monocrystalline photovoltaic cell and a polyethylene-carbon posistor nanocomposite. $V_{1}$ and $V_{2}$-voltmeters for measured voltages on photovoltaic $\left(U_{P V}\right)$ and posistor $\left(U_{P P T C}\right)$ elements; $V_{3}$ and $V_{4}$ - voltmeters for measured temperatures on photovoltaic $\left(U_{P V}\right)$ and posistor $\left(U_{P P T C}\right)$ elements; $A-$ ammeter for measuring the current flowing through the structure $(I)$; $V$ - voltmeter for power supply voltage control; $\Delta R$ - additional internal resistance of the voltage source.

The heating state of the shaded photovoltaic cell and the entire structure under consideration was achieved by applying a constant reverse bias voltage to it [114]. The kinetics of change of these parameters was recorded in synchronous mode every second for a time interval sufficient for the relaxation of the studied structure to equilibrium state $(t \sim 10 \mathrm{~min})$. 


\subsubsection{Kinetics of the voltage limiting process of a photovoltaic cell with a posistor layer}

The kinetic dependences of current, voltage distributions and temperatures of the considered two-layer structure on the basis of a single-crystal silicon photovoltaic cell and the PPTC of the fuse are presented in Fig. 5.13.
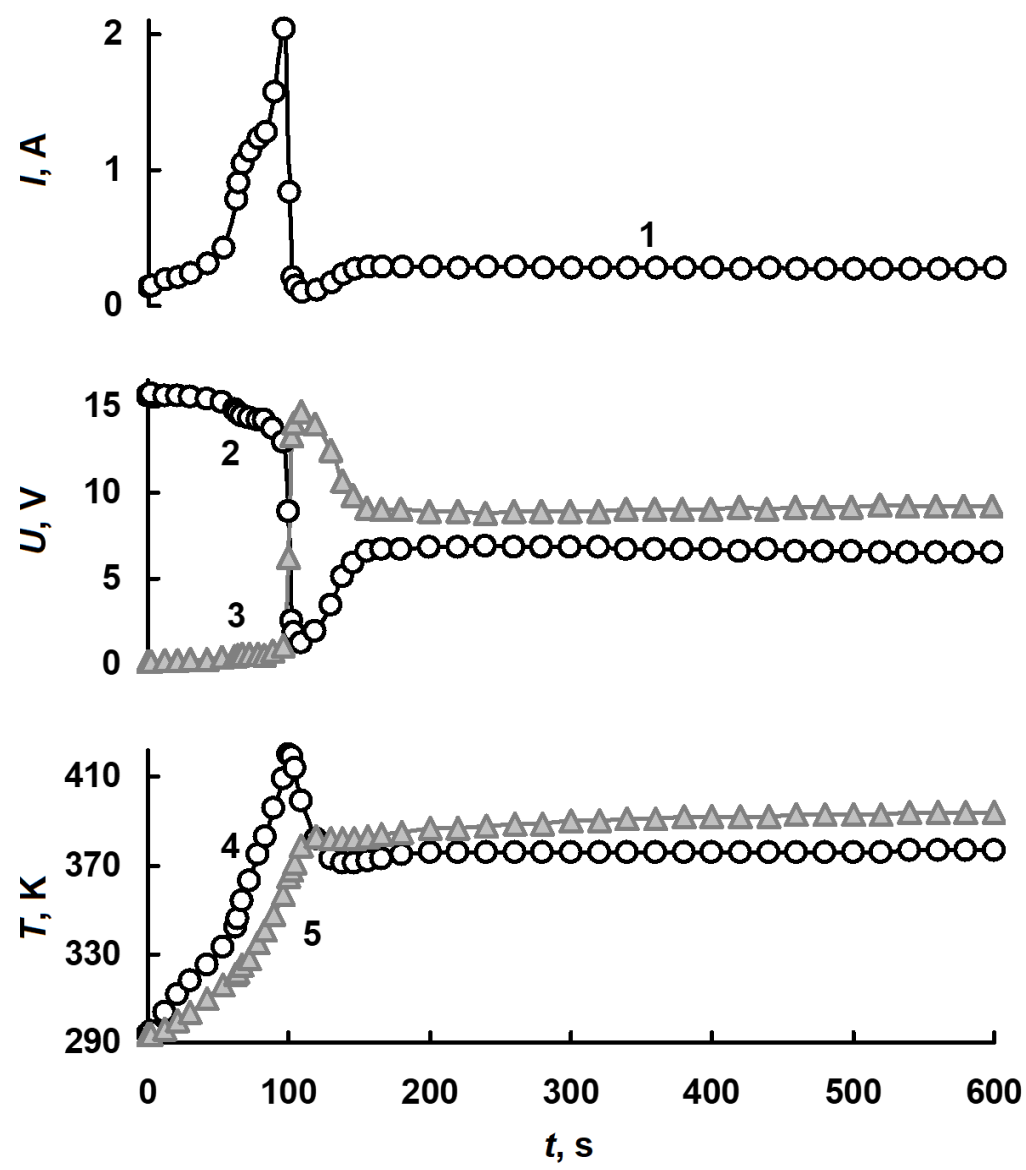

Figure 5.13. Dependence of current $I(1)$, voltage and temperature on photovoltaic $U_{P V}(2), T_{P V}(4)$ and posistor $U_{P P T C}(3), T_{P P T C}(5)$ elements of the studied structure on time when applying constant voltage of $16 \mathrm{~V}$.

The $p$ - $n$ junction of the PV-cell is included in the reverse direction, which corresponds to the most unfavourable situation when its thermal breakdown becomes possible $[4,22,115]$. As can be seen, in the initial sections $(t<100 \mathrm{~s})$ these time 
dependences are similar to those observed for photovoltaic cells in the pre-breakdown mode [114]. When the posistor element reaches the tripping temperature $T_{\text {trip }}$ (Fig. 5.13, curve 5), i.e. when it transitions to a state with high electrical resistance, there is a redistribution of the applied voltage $U$ in the direction of its significant decrease on the photovoltaic cell (curve 2) and a decrease in current (curve 1). The temperatures of both elements of the investigated structure after the tripping of the posistor element are close to $T_{\text {trip }}$ and do not change in the future.

From these data it follows that:

- the considered structures have the function of temperature limitation;

- in the range of temperature limitation (after the tripping of the thermosensitive posistor element) it is constant and almost the same for the whole structure;

- the maximum value of current through the structure is observed for a short time (about a few seconds);

- in the temperature limiting range, all the voltage (applied initially to the photovoltaic cell) is redistributed and almost completely falls on the posistor element.

\subsubsection{Influence of overvoltage amplitude and internal resistance of voltage} source

It is known that one of the most influential factors that can lead to the breakdown of the photovoltaic cell is the reverse voltage applied to it. This occurs in photovoltaic modules of the solar array, when the photovoltaic cell is shaded, faulty or degraded, and thus it acts as an active resistor and is not a source of current. Fig. 5.14 shows the results of the influence of the magnitude (amplitude) of the applied reverse DC voltage $U$ on the kinetics of the process of voltage limiting PV-cell with a posistor layer. 

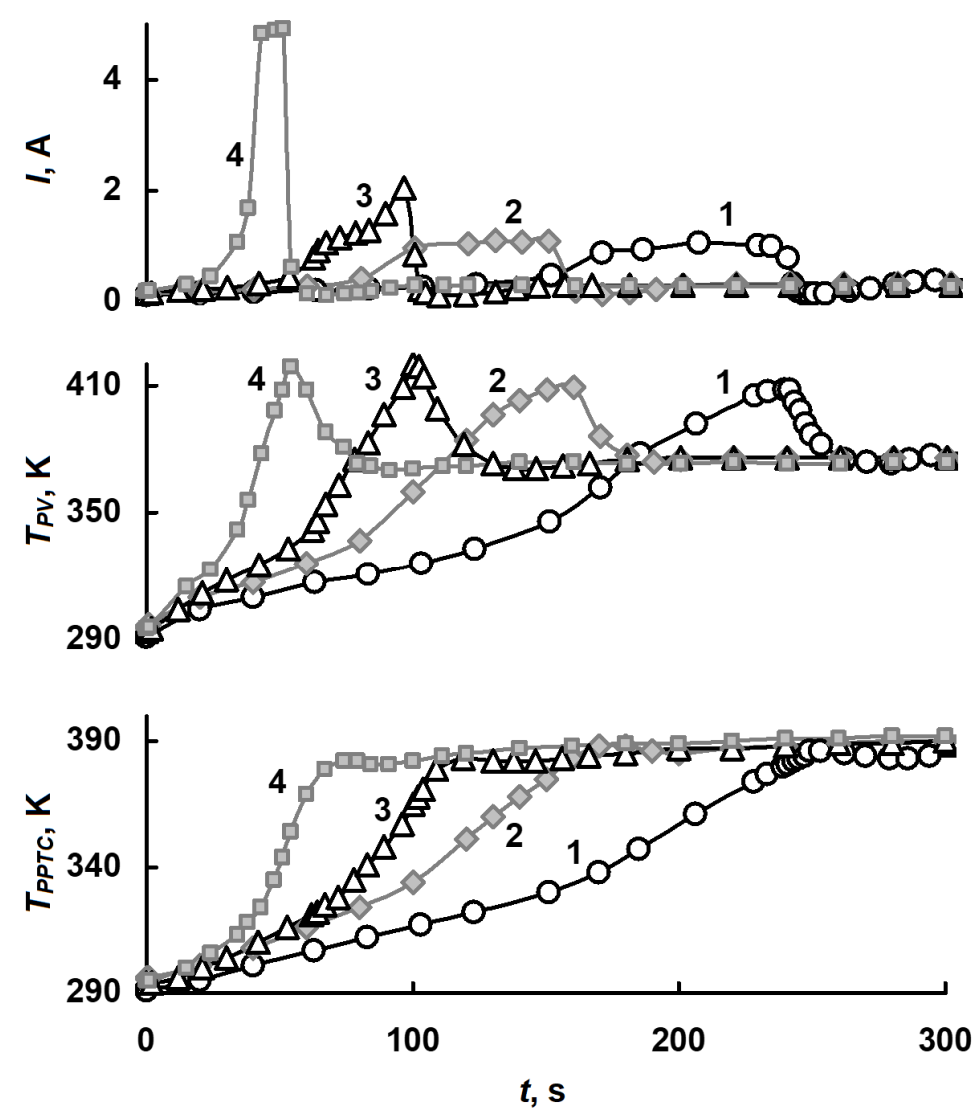

Figure 5.14. The dependence of current $(I)$ and temperature on the photovoltaic $\left(T_{P V}\right)$ and posistor $\left(T_{P P T C}\right)$ elements of the studied structure on the time when it is supplied with a constant voltage $U, \mathrm{~V}: 1-14 ; 2-15 ; 3-16 ; 4-17$.

As can be seen with increasing voltage $U$, there is a decrease in the tripping time of the considered overvoltage protection and an increase in the maximum current through the structure under study. Temperature modes thus change insignificantly. The occurrence of large maximum currents at the stage of heating the structure to the tripping temperature of the protective posistor element can lead to such an undesirable effect as the breakdown of the PV-cell until the temperature required for the tripping of the posistor element is reached.

However, it should be noted that in real conditions the current and voltage of the power supply are limited, for example, in photovoltaic modules of solar arrays, they can not be more than the short-circuit current and the open-circuit voltage of the photovoltaic cell [54]. 
In this case there may be situation where with increasing temperature, the resistance of the photgalvanic cell becomes comparable to the internal resistance of the power supply to the transition to the insulating state of the posistor element.

In the dependences presented in Fig. 5.15, the change in the level of current and voltage limitation of the power supply was achieved by the introduction of appropriate additional resistors $\Delta R$ to its internal resistance (see Fig. 5.12). These data show that the increase in the internal resistance of the power supply leads to a decrease in the peak current and to the blurring and displacement of the area, where current is significant, in the direction of large times. Thus, the energy required to heat the test structure to the tripping temperature accumulates for a longer time.
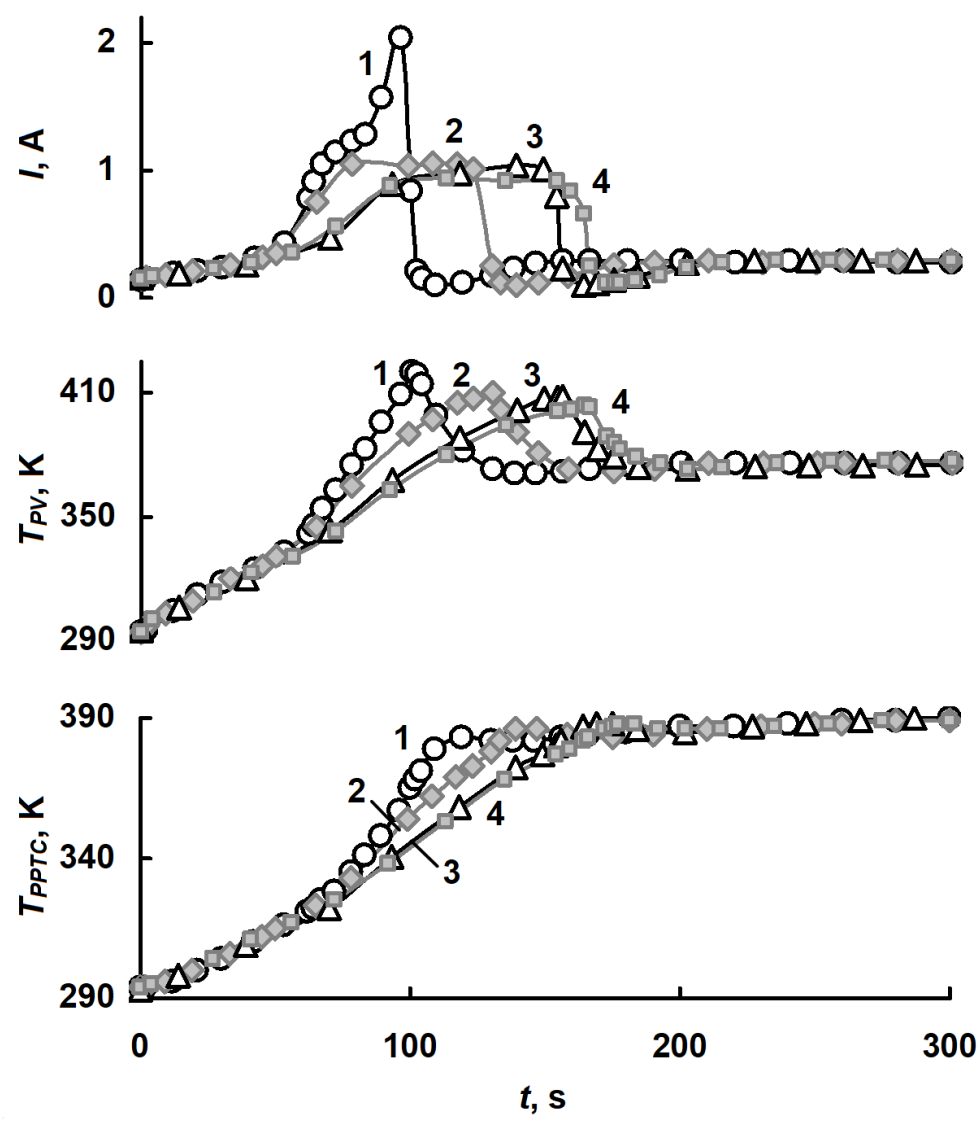

Figure 5.15. Dependences of current $(I)$ and temperature on photovoltaic $\left(T_{P V}\right)$ and posistor $\left(T_{P P T C}\right)$ elements of the studied structure on time after supply to it of constant voltage $(16 \mathrm{~V})$ and additions to internal resistance of a power supply $\Delta R, \mathrm{Ohm}$ :

$$
1-1 ; 2-1.5 ; 3-2 ; 4-3 \text {. }
$$


5.3.4 Dependence on the parameters of thermal contact between photovoltaic and posistor elements

The most important parameter is the thermal resistance of the contact between the photovoltaic and posistor elements. As can be seen from Fig. 5.16, the current value through the considered structure I most significantly depends on this parameter.
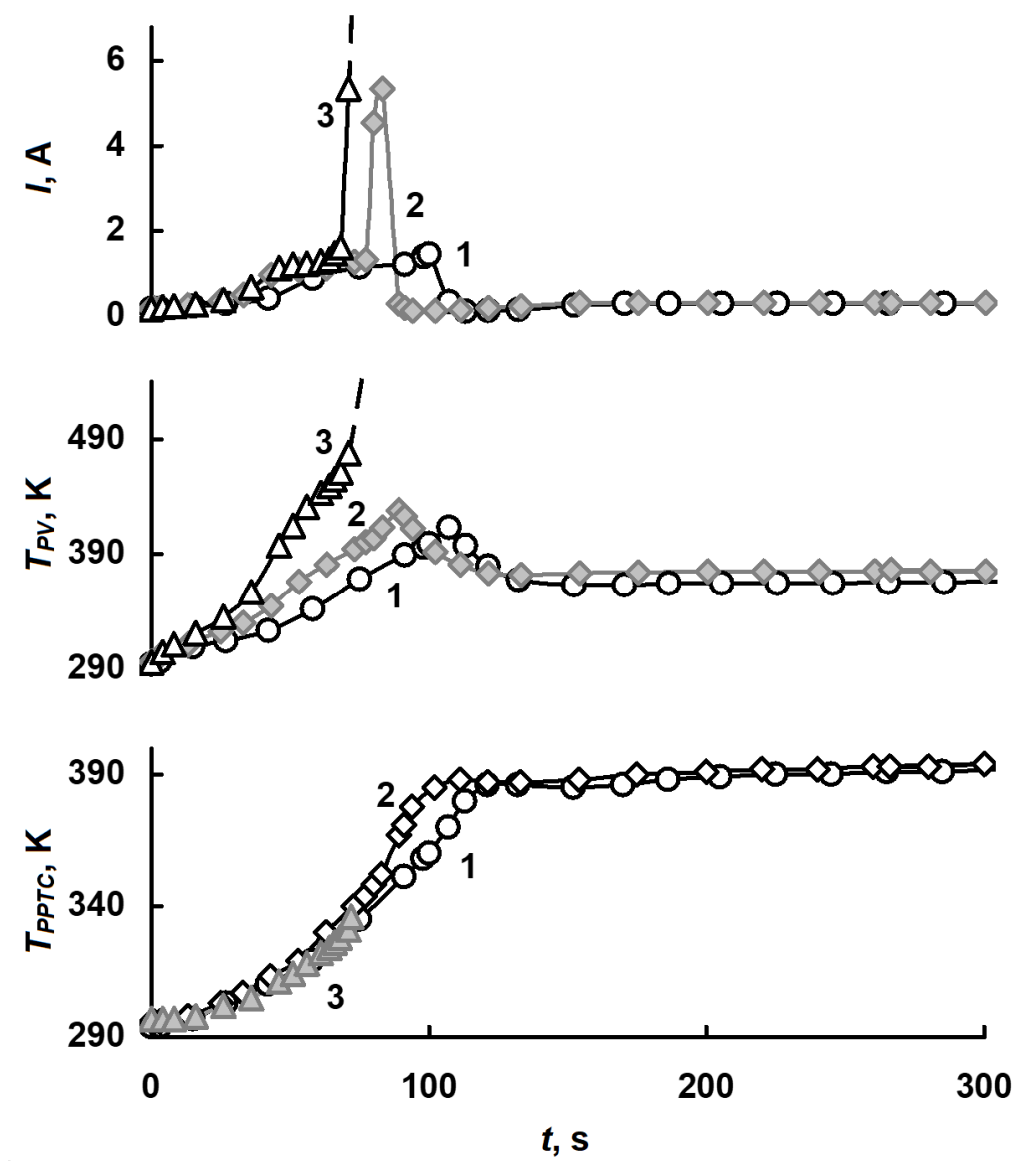

Figure 5.16. The change in time of the parameters $I, T_{P V}$ and $T_{P P T C}$ of the studied structure when applying a constant voltage $U=16 \mathrm{~V}$ at different values of the thermal resistance of the contact $R T$ between the photovoltaic and posistor elements: $1-R T_{1} ; 2-R T_{2} ; 3-R T_{3}\left(R T_{1}<R T_{2}<R T_{3}\right.$ and correspond to the overlap of the layers on 100,60 and $30 \%)$. 
With poor heat transfer between the layers of varistor ceramics and PPTC nanocomposite, the current $I$ increases significantly and can be realized thermal breakdown of the photovoltaic cell (curve 3).

In the dependences shown in Fig. 5.16, the change in the thermal resistance of the contact varied by changing its area by shifting the layers of the photovoltaic and the posistor relative to each other. The smaller overlap of the layers corresponded to the greater thermal resistance of the contact.

As can be seen, with increasing thermal resistance of the contact between the photovoltaic and posistor elements of the structure, current value required to ensure heat transfer increases. The latter is required to achieve by the posistor layer of the tripping temperature. At very high RT (curve 3), a state is realized when the photovoltaic cell is practically isolated, which leads to its thermal breakdown. 


\section{Chapter 6}

\section{PROSPECTS FOR THE CREATION OF SPECIALIZED RESETTABLE FUSES FOR SYSTEMS OF PROTECTION OF PHOTOVOLTAIC CELLS OF SOLAR ARRAYS FROM ELECTRICAL OVERLOADS}

The results of the research presented in the previous chapters allow to conclude that the considered protection elements based on polymer composites with nanocarbon fillers are able to protect in some cases the components of the solar arrays from electrical overload. They function as reusable (resettable) fuses that do not require replacement and allow to implement the solution independently or as part of combined devices (two-layer varistor-posistor structures).

The correct choice of specific products is necessary for the effective use of RFu. In this regard, it is important to analyze the suitability of the modern commercial base of such devices for the development of such circuitry for electrical protection in solar energy systems.

However, it should be noted the following. The temperature of the beginning of the phase transition (tripping) of the most common currently types of commercial $\mathrm{RFu}$ is about $80^{\circ} \mathrm{C}$, and a significant change in resistance is observed at higher temperatures. The maximum operating temperature of photovoltaic cells does not exceed $80^{\circ} \mathrm{C}$. This situation to some extent limits the widespread use of RFu such as PolySwitch as protection elements based on physical and technological principles, in particular, when using the polymeric nanocarbon composites used in them as insulation of damaged (degraded) local areas of PV-cells. In this direction, the most important is the development of tape RFu with a lower tripping temperature.

This chapter analyses the main characteristics of commercial resettable fuses and the results of the study of the possibilities of creating such devices with a lower tripping temperature. 


\subsection{Commercial resettable fuses based on polymer composites with nanocarbon fillers}

\subsubsection{Basic electrical characteristics of resettable fuses based on polymer composites with carbon fillers}

The main functional $\mathrm{RFu}$ characteristics are current-voltage characteristic and temperature dependence of resistance. To study these characteristics, a number of industrial $\mathrm{RFu}$ from different manufacturers were shown (Table 6.1), which in the ranges of electrical parameters (minimum resistance $R_{\min }$ (or $R_{1 \max }$ ) and tripping current $I_{\text {trip }}$ most meet the conditions of their use in photovoltaic systems of real solar arrays. These conditions can be formulated as the requirements of low resistance in the conductive state and low current.

Table 6.1

Typical parameters of the studied resettable fuse samples

\begin{tabular}{|c|l|c|c|}
\hline No. of sample & Resettable fuse & $R_{\min }\left(\right.$ or $\left.R_{1 \max }\right)$, Ohm & $I_{\text {trip }}, \mathrm{A}$ \\
\hline 1 & RXE160 & 0.09 & 3.2 \\
\hline 2 & FRH150-600F & 6 & 0.3 \\
\hline 3 & FRX050-60F & 0.5 & 1 \\
\hline 4 & MF-R110 & 0.10 & 2.2 \\
\hline 5 & TRF250-145-2 & 14 & 0.29 \\
\hline 6 & FRH120-250UF & 6 & 0.24 \\
\hline 7 & 1206L012 & 1.5 & 0.29 \\
\hline
\end{tabular}

When measuring the temperature dependences of the resistance, the samples were placed in an oven and connected to a digital multimeter B7-38. The rate of temperature rise, controlled by a mercury thermometer, was $40{ }^{\circ} \mathrm{C} / \mathrm{h}$. Experimental temperature dependences of resistance are shown in Fig. 6.1. 


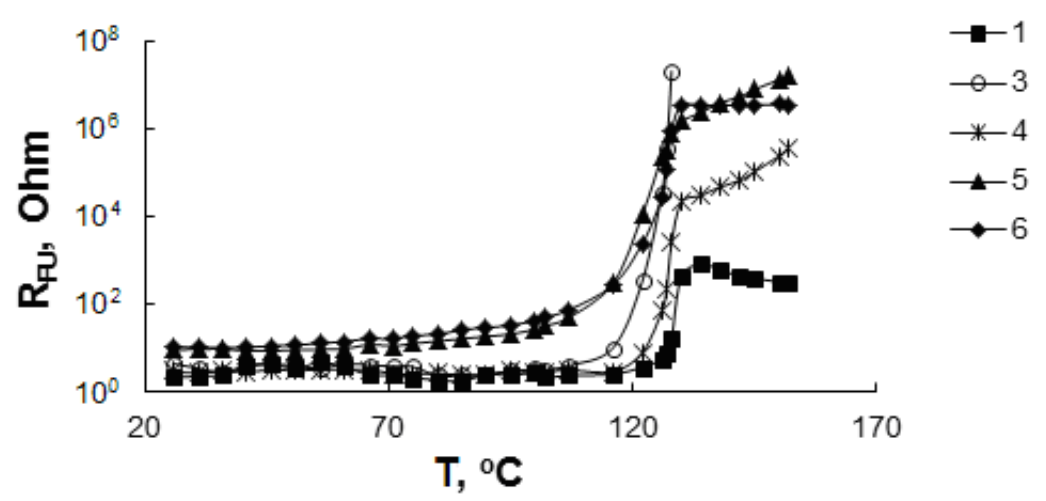

Figure 6.1. Temperature dependences of electrical resistance $R_{F U}$ of typical resettable fuse. The curves correspond to RFu, the parameters of which are given in Table 6.1.

The installation for measuring current-voltage characteristics consisted of voltmeters B7-27/A1 and adjustable power supply TEC 42. The devices were connected in a known circuit [120]. The current through the test sample was determined by the voltage drop across the current resistor.

Typical CVC of different RFu are presented in Fig. 6.2 and are similar to the corresponding characteristics of posistors [63].

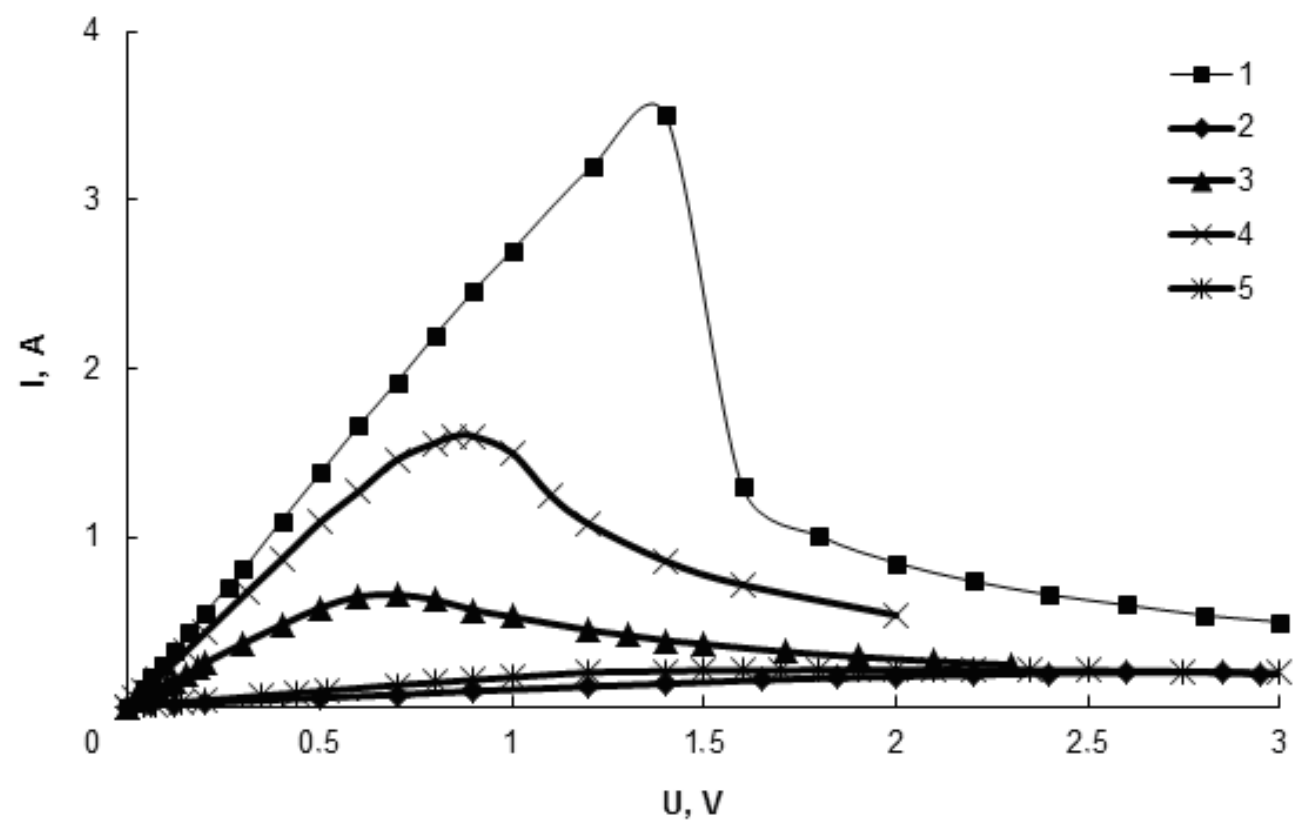

Figure 6.2. Current-voltage characteristics $I_{F U}(U)$ of low-power commercial resettable fuse. The curves correspond to $\mathrm{RFu}$, the parameters of which are given in Table 6.1. 
When the voltage increases, the current increases firstly, this area corresponds to the region 1 of the temperature dependences of the resistance (Fig. 6.1). Further increase in voltage leads to Joule heating of the composite and a sharp increase in resistance due to the melting of the crystalline phase of the polymer (region 2) while the current through the RFu drops sharply. If we continue to increase the voltage on the sample, it will lead to a relatively gradual decrease or stabilization of the current (region 3).

\subsubsection{Correlation between the resistance in the conducting state and the tripping current}

$I_{\text {trip }}$ and $R_{\min }$, which are not independent, are key parameters to determine the suitability of a particular RFu as an element of current overload protection. $R_{\min }$ determines the power dissipation, and $I_{\text {trip }}$ is determined by its specific value, which provides heating of the $\mathrm{RFu}$ material to the tripping temperature.

Fig. 6.3 shows the correlation dependence, the coordinates of which correspond to the values of the parameters $I_{\text {trip }}$ and $R_{\min }$ for commercial RFu manufactured by Bourns, Inc. [121] and Littelfuse, Inc. [122].

As can be seen, the correlation dependence shows a tendency for $I_{\text {trip }}$ to decrease with increasing $R_{\min }$. Coefficients of determination of dependences Det $=0.97-0.99$, which corresponds to the ratio between the parameters close to the functional one.

Dependence graphs are rectified in double logarithmic coordinates and approximated by the equation

$$
I_{\text {trip }}=a R_{\text {min }}{ }^{b},
$$

where coefficient $a=0.38-0.47$, and parameter $b=0.64-0.71$.

This relationship allows to assess the prospects for the use of commercial RFu to limit overloads in photovoltaic systems. According to the general conditions, $\mathrm{RFu}$ application (3.3) and (3.4) can be formulated as follows: 


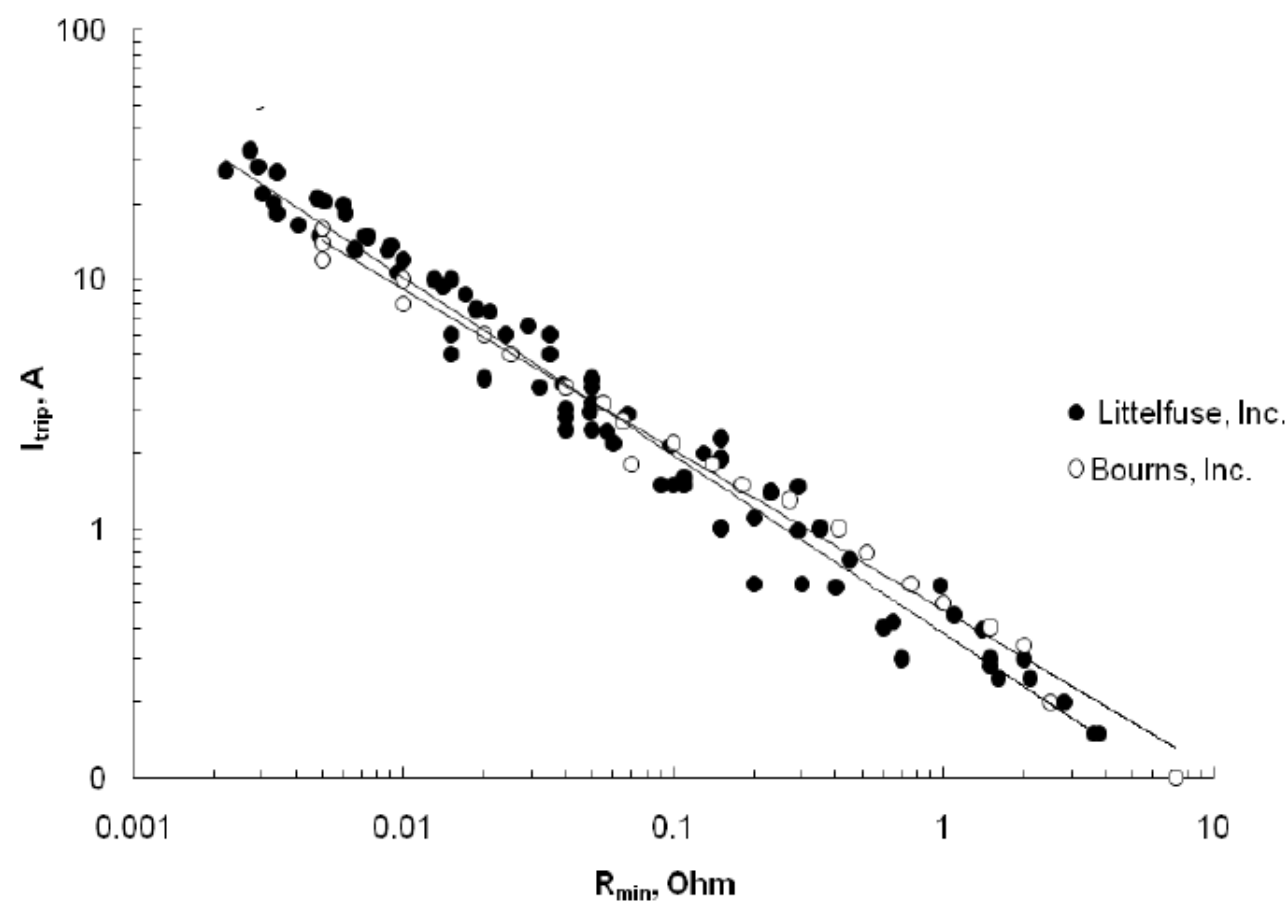

Figure 6.3. Correlation between resistance in the conductive state $R_{\min }$ and tripping current $I_{\text {trip }}$ of commercial low-power RFu.

- the presence of RFu in the electrical circuit of the photovoltaic system should not affect its normal operation;

- RFu tripping current must be greater than the short-circuit current of a single photovoltaic component and less than the current of their parallel connection in the photovoltaic system (Fig. 1.12) in the operating mode.

That is, it means that the selected value of $R_{\min }$ limits the range of current trip. For example, for $R_{\min }<0.1 \mathrm{Ohm}$, there are only RFu with tripping currents $I_{\text {trip }}>2 \mathrm{~A}$. In this case, the higher the $R_{\min }$, the lower the tripping current may be.

Based on this, we can conclude that the modern base of commercial RFu can provide protection against current overloads with parallel connections of photovoltaic modules. In the simplest case, such modules are series connections of several tens of photovoltaic modules for terms $[4,123]$ and, thus, have a sufficiently high effective resistance of such a string. For example, photovoltaic modules developed on the basis of silicon wafers SEF-4.5 have a series resistance (Fig. 3.2) up to $3 \mathrm{Ohms}$ and a short- 
circuit current of 2 A [124]. According to the dependence in Fig. 6.3, to implement protection against current overloads in the unit (parallel connection) of such photovoltaic modules, we can find RFu that meet the above conditions (for example, FRX375-60F $[69,125])$.

At the same time, for the parallel connection of typical silicon PV-cells with a series resistance of $1 \mathrm{Ohm}$ and a short-circuit current of about $0.05 \mathrm{~A}$ [56], as shown in Fig. 6.3, it is impossible to find a suitable RFu.

It should be noted that the RFu parameters $I_{\text {trip }}$ and $R_{\min }$ determine the amount of heat required for the transition of the crystal structure of the polymer matrix to amorphous. Currently nanocomposites for the RFu manufacturing are used as a matrix polyethylene with a melting point $125^{\circ} \mathrm{C}$. Replacing polyethylene with a material with a lower melting point should lead to a reduction in the power required to achieve it, and thus to the RFu creation with smaller $I_{\text {trip }}$ and $R_{\min }$.

\subsection{Posistor elements based on ceresin-nanocarbon composites}

One of the new directions of use of the considered polymeric posistor structures is development on their basis of thermosensor fuses for prevention of local overheats ("hot spots") in photovoltaic elements of the solar array [46, 50].

It is proposed to use the basic functional property of resettable fuses, namely an abrupt increase by several orders of magnitude when reaching a certain temperature limit and return to the initial high-conductivity state when the temperature decreases. However, it should be noted the following: the tripping temperature of the most common types of commercial PPTC-fuses is above $80^{\circ} \mathrm{C}$, and a significant change in resistance is observed at even higher temperatures $90-125^{\circ} \mathrm{C}[15,93,126]$. The maximum operating temperature of photovoltaic modules does not exceed $80{ }^{\circ} \mathrm{C}$ [11]. This situation to some extent limits widespread use of PPTC-fuses as elements of protection against overheating, especially if the cause of overheating is temporary. 
In this regard, it seems important to develop PPTC-fuses with low tripping temperature $[46,50,127]$, which is considered in this paper.

In this subsection, to solve the above problem, an approach is used, which is based on the use as a matrix polymer of a ceresin composite that has a lower transition temperature from the crystalline state to the amorphous state $[17,128]$. Particular attention is paid to the study of the influence of variation of technological schemes of manufacturing these posistor nanocomposites on their electrical properties.

\subsubsection{Manufacturing technology and features of research methods}

As initial components for the manufacture of the composite were used: carbon black brand N550 (according to ASTM D1765) with a particle size of 39-55 nm, ceresin 65 and polyvinylidene fluoride.

The process of synthesis of the studied composites was carried out according to the following technological schemes, similar to the general technology of manufacturing resettable fuses of PolySwitch type [41, 129].

Technological scheme No. 1 included:

- mixing ceresin with carbon black in the required proportions;

- heating the mixture to melt the ceresin and its transition to a state with low viscosity, mixing the components;

- cooling the mixture and grinding it;

- pressing the obtained charge with a hydraulic press in a mold at a pressure of $10 \mathrm{MPa}$ in the form of cylinders 3-4 $\mathrm{mm}$ high and $12 \mathrm{~mm}$ in diameter with simultaneous pressing of electrodes from a thin copper mesh in the end surface.

In accordance with the scheme No. 2:

- ceresin was dissolved in 1-methyl-2-pyrrolidone (N-methyl-2-pyrrolidinone);

- the required amount of carbon black was added to the obtained viscous solution and mixed; 
- the material synthesized in this way was applied in the form of disks with a diameter of $5 \mathrm{~mm}$ and a thickness of 1-2 $\mathrm{mm}$ between two electrodes of fine copper mesh and allowed to dry under atmospheric conditions.

Technological scheme No. 3 repeated the technology No. 2 with one difference, namely to the resulting mixture was added dissolved in 1-methyl-2-pyrrolidone polyvinylidene fluoride.

Measurements of the temperature dependence of the electrical resistivity and current-voltage characteristics were performed by standard methods [40]. To do this, the samples were placed in a protective chamber. Data were recorded after establishing the thermodynamic equilibrium of the test sample with the environment. Electrical measurements were performed using laboratory power supplies TB-2, TEC-42 and digital voltmeters B7-27/A1.

Studies of dielectric characteristics in the radio frequency range (from $50 \mathrm{kHz}$ to $10 \mathrm{MHz}$ ) were performed using a Q-meter BM-560. Studies of electrode phenomena have shown that the measured electrical values are determined by the volumetric properties of the samples.

The X-ray phase analysis (XRD) was performed on a DRON-3M device (Burevestnik Co., Russia) using $\mathrm{CuK} \alpha$ radiation $(\lambda=0.15418 \mathrm{~nm})$ in order to control the degree of ceresin crystallinity.

\subsubsection{Structure and physical properties}

Ceresin has a fine crystalline structure and is a mixture of limiting hydrocarbons with the number of carbon atoms in the molecule from 36 to 55. Its molecular weight is about 700. It consists mainly of weakly branched isoalkanes and naphthenes with a long side circuit. Carrying out X-ray phase analysis of ceresin 65 confirms its crystal structure (Fig. 6.4). 


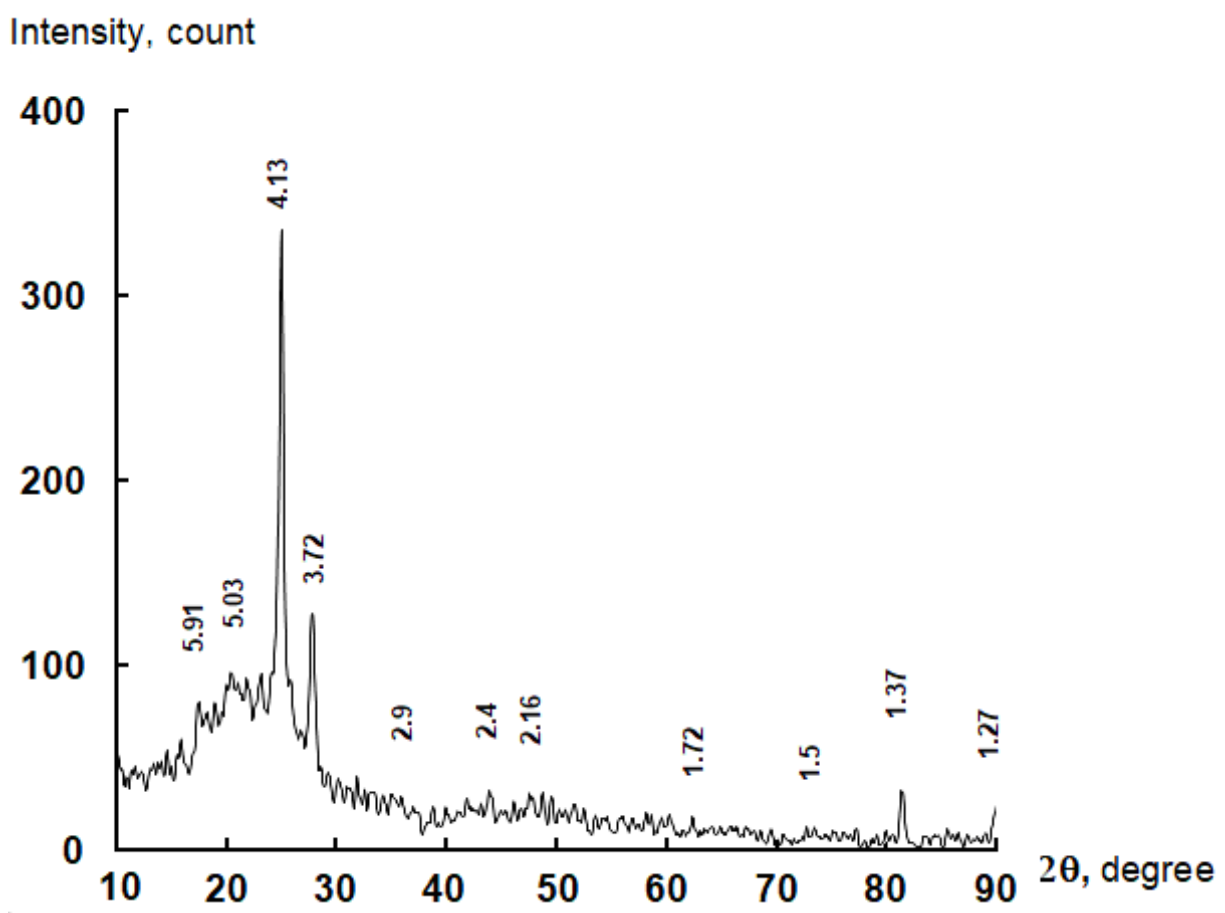

Figure 6.4. XRD ceresin 65 (radiation $\mathrm{CuK} \alpha$ ).

Samples made by technologies No. 1-3 were also subjected to X-ray phase analysis to verify the effect of technology and additives on the degree of ceresin crystallinity. It was found that a significant decrease in the degree of crystallinity is not observed. When polyvinylidene fluoride was added to the material, the lines expanded, which according to Scherer's formula [130] was interpreted as a decrease in the average size of ceresin crystals.

\subsubsection{Electrical properties}

\subsubsection{Temperature dependences of electrical conductivity}

Temperature dependences of resistivity $(\rho)$ of samples of composites with different volume particles of carbon, made by the technology No. 1, are presented in Fig. 6.5. With increasing filler content $\rho$ decreases. An increase in temperature leads 
to an increase in resistivity by more than two orders of magnitude in the temperature range $17-55^{\circ} \mathrm{C}$. However, with a further increase in temperature, softening and swelling of the composite was observed.

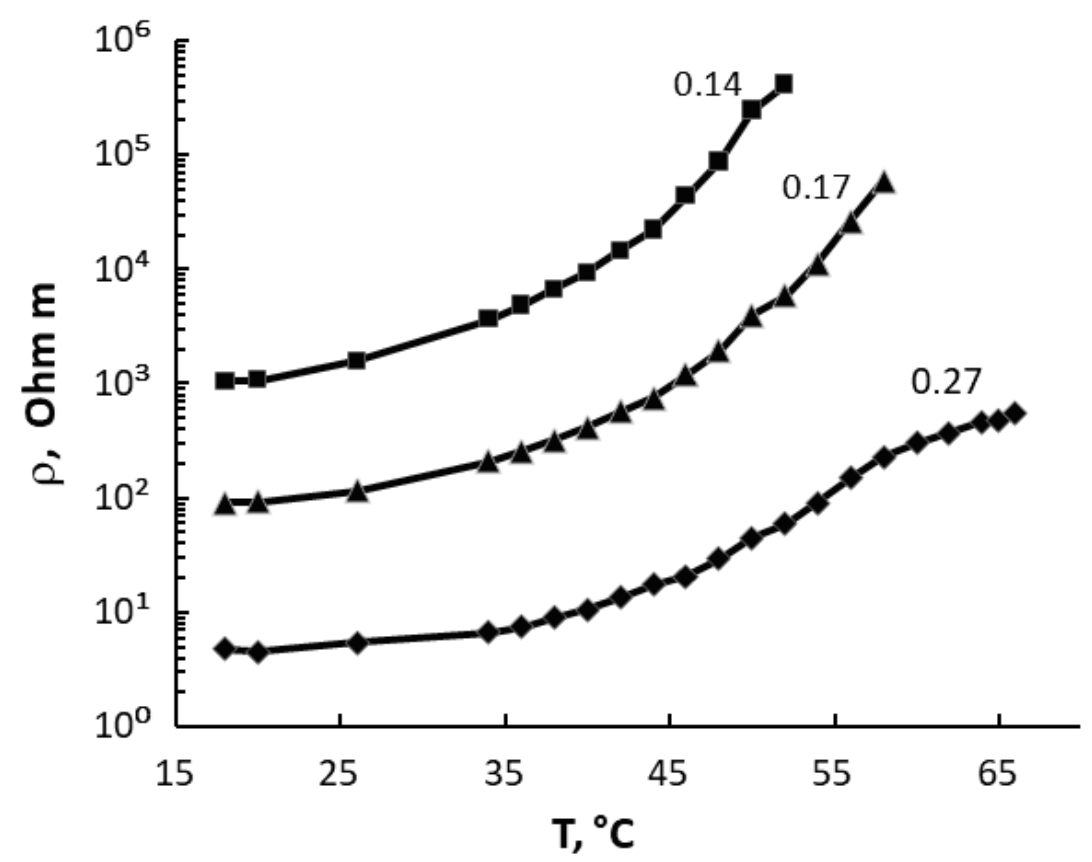

Figure 6.5. Temperature dependences of resistivity of ceresin-nanocarbon composite samples with different volume fraction of filler (nanocarbon) made by melting the source material (technological scheme No. 1).

To improve the manufacturability of the composite used the dissolution of ceresin in 1-methyl-2-pyrrolidone (scheme No.2). This precluded melting and pressing operations. The resistivity gradually increased with increasing temperature (Fig. 6.6).

As the melting point of ceresin $\left(65^{\circ} \mathrm{C}\right)$ approaches, a sharp transition is observed, apparently due to its melting and an increase in the volume of the composite matrix. A similar increase in volume occurs in polyethylene [131]. The resistance increases approximately 20 times in the temperature range $21-70{ }^{\circ} \mathrm{C}$. Then the value $\rho$ stabilizes. 


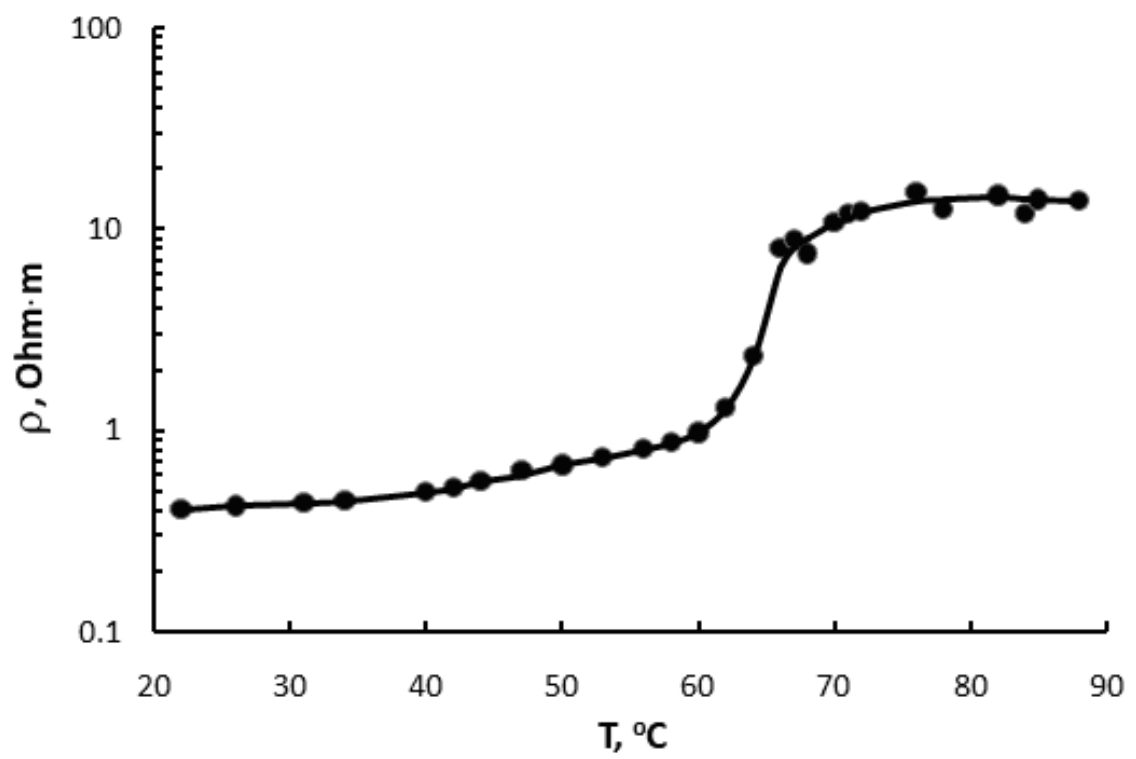

Figure 6.6. Temperature dependence of the resistivity of a sample of ceresin-nanocarbon composite made with a solvent (scheme No. 2, volume fraction of carbon $20 \%$ ).

Although the deformation with increasing temperature was not so expressed in the samples synthesized according to scheme No. 2, an attempt was made to stabilize the mechanical properties of the material by adding polyvinylidene fluoride (technological scheme No. 3).

Polyvinylidene fluoride has good mechanical strength, hardness, creep resistance and chemical resistance. The degree of its crystallinity is $45-55 \%$, melting point is $177^{\circ} \mathrm{C}$.

The resistivity of the samples obtained according to the scheme No. 3 also showed an increase with increasing temperature (Fig. 6.7).

However, the increase did not exceed one order of magnitude and was fairly monotonous. A large proportion of carbon, as well as for samples made according to the technological scheme No. 1, led to a decrease in resistivity. The experimental samples had good mechanical strength up to $90{ }^{\circ} \mathrm{C}$ and were quite stable during the thermal cyclic cycle, but their electrical resistance often changed gradually, corresponding to the general tendency to increase with increasing temperature. 


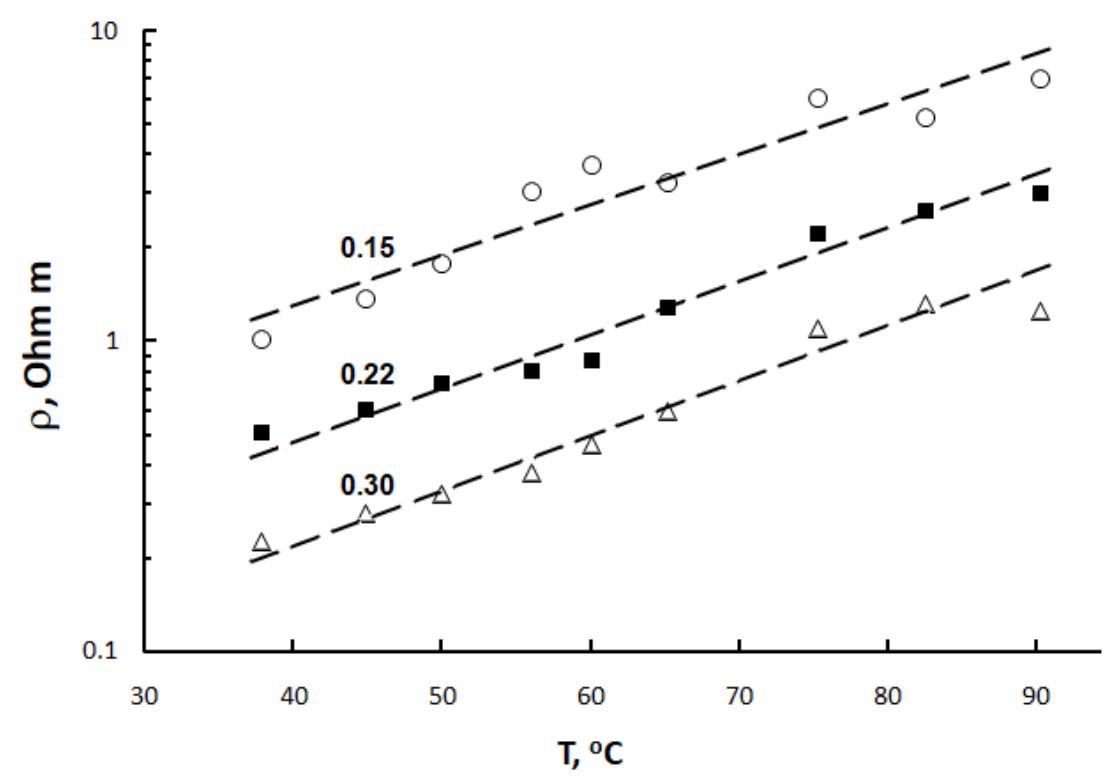

Figure 6.7. Temperature dependences of resistivity of samples of ceresin-nanocarbon composite made with the use of solvent and addition of polyvinylidene fluoride (diagram diagram No. 3) with different volume fractions of carbon.

This behaviour can be explained by the relaxation of the composite structure. As the temperature increases, there is an expansion of the ceresin, especially near the melting point, while the matrix formed by the ceresin becomes less strong. This leads to the release of mechanically stressed structures of polyvinylidene fluoride and compression of certain parts of the composite. Similar processes occur during tectonic shifts of the earth's crust, which is caused by earthquakes. This allows to explain the abrupt behaviour of temperature dependences of the parameters of ceresin-nanocarbon composite with the addition of polyvinylidene fluoride.

\subsubsection{Current-voltage characteristics}

The dependence of the current density on the electric field strength of the samples made by different methods is presented in Fig. 6.8. With increasing field strength for samples made by all three technologies, an increase in current was 
initially observed. Then, having reached a certain critical force, the value of the current begins to decrease. Presumably, this implements the same mechanism associated with the expansion of the polymer matrix, as in industrial PPTC-fuses based on polyethylene [131].
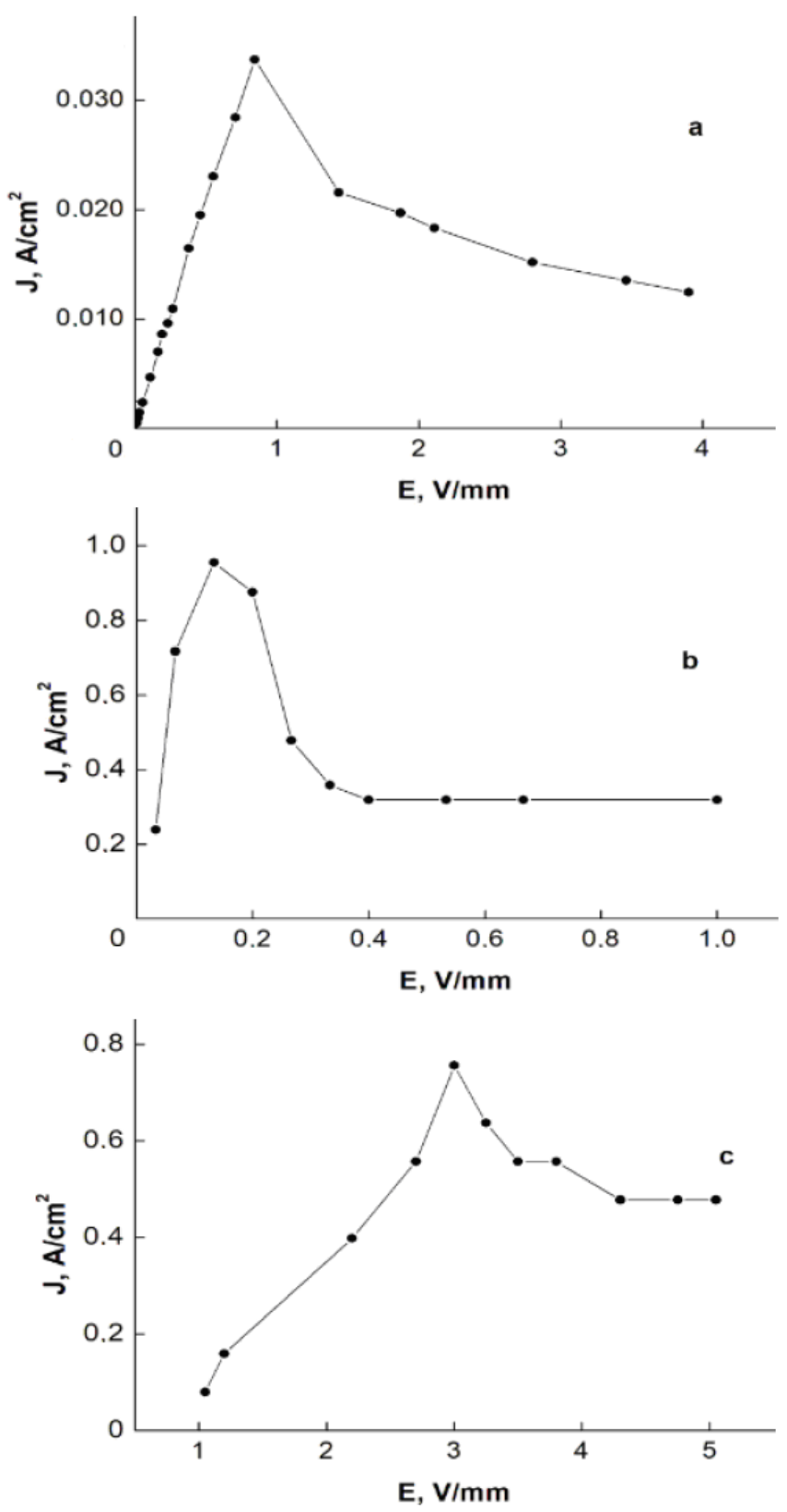

Figure 6.8. Dependence of current density on electric field strength for ceresinnanocarbon composite samples: $a$-technological scheme No. 1; the volume fraction of carbon is $9 \% ; b$-technological scheme No. 2 ; the volume fraction of carbon is $20 \%$; - technological scheme No. 3 ; the volume fraction of carbon is $15 \%$. 
Fuses made by different technologies operate at slightly different electric field strengths, as well as at different current densities through the sample. This indicates both the significant influence of technological factors on the properties of the sample and the need to optimize the technology and composition in order to reduce the anisotropy of composites.

\subsubsection{Permittivity}

Typical frequency dependences of dielectric parameters of synthesized nanocomposite structures are presented in Fig. 6.9.
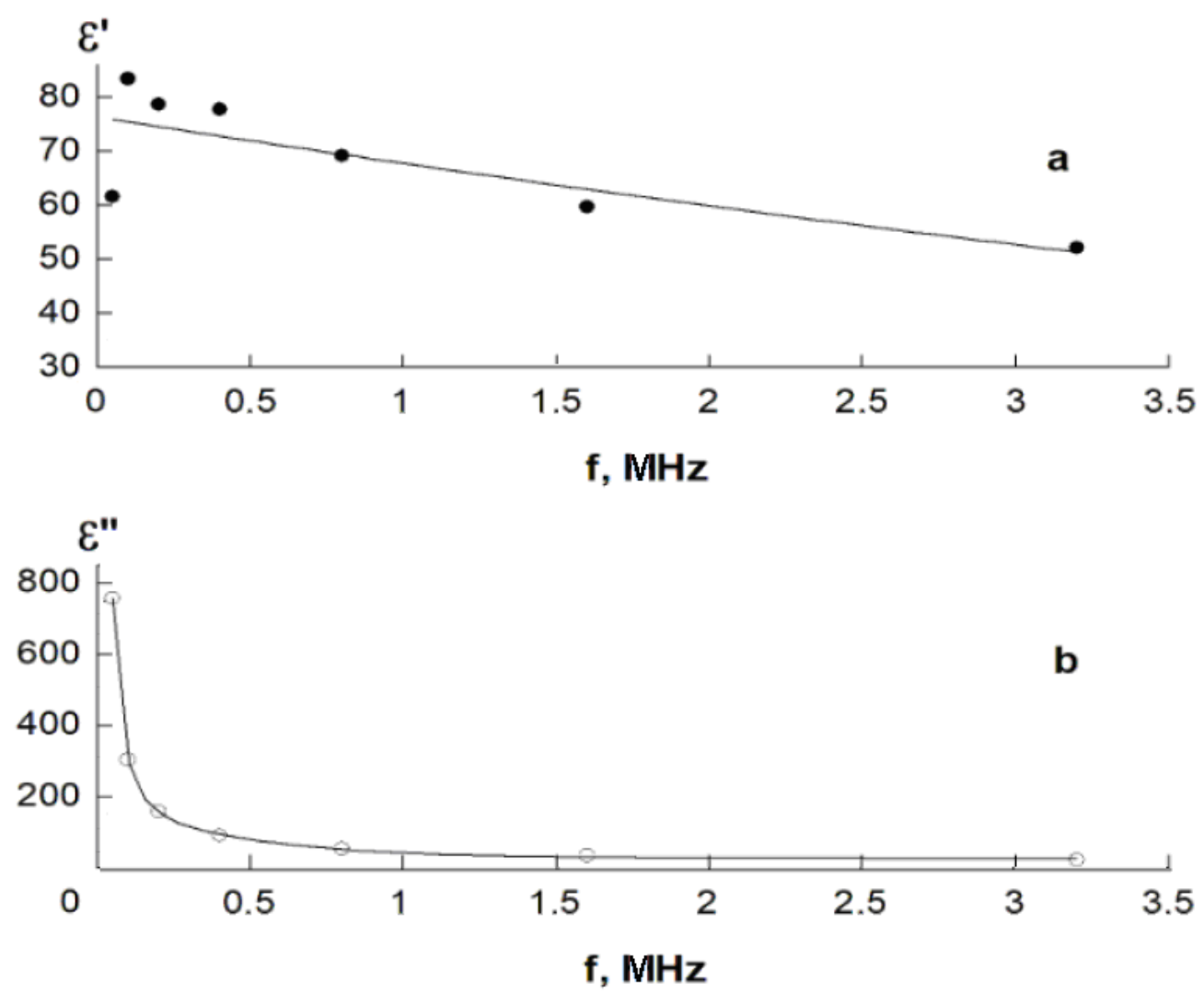

Figure 6.9. Frequency dependences of real $(a)$ and imaginary $(b)$ parts of complex dielectric constant of ceresin-nanocarbon composite made by melting of initial material (technological scheme No. 1, volume fraction of carbon $14 \%$ ). 
As can be seen, the real and imaginary parts of the complex dielectric constant decrease with increasing frequency (Fig. 6.9), which is characteristic of inhomogeneous materials [40].

Regularities in the development of physical and technological bases for the creation of posistor nanocomposites with a matrix based on ceresin were found, in particular:

- the presence of a switching mechanism in ceresin-nanocarbon composites similar to the mechanism of polyethylene-carbon composites, and associated with the rupture of the conductive channels in the process of expanding the polymer matrix during the phase transition from crystalline to amorphous state;

- low temperature of the specified phase transition, which is accompanied by a significant increase in resistance;

- the ability to regulate technologically the structure (average size of the ceresin crystal by adding a composite of polyvinylidene fluoride) and mechanical properties (their stabilization by introducing into the composition of polymers with a relatively high melting point).

They allow to consider perspective this thermosensor direction of researches in realization of protection of solar arrays against local overheating and current overloads at the level of photovoltaic cells. 


\section{CONCLUSIONS}

1. There is a growing trend to increase the efficiency and reliability of renewable energy sources such as solar arrays. There is the search and development of technologies to protect their components from electrical and thermal overload in order to increase service life and prevent abnormal (including fire hazardous) situations.

2. At the present stage, there is a focus of engineering solutions on the development of reliable, cheap, technological methods and means to prevent local overheating of electrical origin (including "hot spots") in photovoltaic systems of solar power plants.

3. One of the circuit solutions to prevent local overheating of electrical origin in photovoltaic modules with bypass diodes is the concept of opening the submodule circuit, which contains a "bad" photovoltaic cell, and the photocurrent of the whole module bypasses the submodule through its bypass diode.

4. The development of a modern base of solid-state electronics, in particular the creation and widespread use of polymer resettable fuses such as PolySwitch, allows us to consider promising to create reliable, cheap, miniature means of protection of solar energy conversion devices from electric overloads and local overheating.

5. Resettable fuses based on polymer composites with nanocarbon fillers function as reusable fuses that do not require replacement, do not affect the operation of the photovoltaic system of solar array in normal mode and tripping by performing the function of opening, in emergency situations related to overheating.

6. It is advisable to connect PolySwitch fuses in series to photovoltaic modules (or their strings) in their parallel connection, which is suitable to prevent an anomalous situation complete loss of electrical energy generated, which can occur during a short-circuit of one of its modules.

7. Circuit solution in the form of a combined structure based on layers of varistor ceramics and posistor polymer nanocomposite with carbon filler (which are 
in thermal contact) is suitable for protection of photovoltaic cells with high reverse resistance from overvoltage in case of abnormal situations, in particular the presence of photovoltaic modules with bypass diodes.

8. The problem of protection against local overheating in photovoltaic cells (or their parallel connections) can be solved by physical and technological methods of using posistor nanocomposites, in particular by creating photovoltaic cells with a built-in layer based on such a composite that is in thermal contact with it. In this case, in the presence of electric power overload, heat transfer from the plate of the photovoltaic cell leads to heating of the layer of the posistor composite. Next, the electric power (reverse voltage and current) on such a shaded, faulty or degraded photovoltaic cell is limited and reduced from the moment when the temperature of this structure reaches values close to the transition temperature of the posistor nanocomposite to a low-conductor state.

9. Important issues that arise in the development of devices for protection of photovoltaic cells from electrical overloads are the impact of their functional properties of increased temperatures and overheating due to reverse currents. Current-voltage and power-voltage characteristics of monocrystalline silicon photovoltaic cells that have undergone heat treatment at increased temperatures (up to $150^{\circ} \mathrm{C}$ ) for different times (up to 6 hours) under lighting conditions and in a shaded mode in open and short-circuited states did not show significant changes. At the same time, overloads caused by reverse currents for the mentioned cells lead to additive (accumulative) degradation of their parameters. This is especially true for shortcircuit current.

10. The results of the research allow us to consider the analysed structures on the basis of polymer composites with nanocarbon fillers as promising elements of protection against electrical overloads.

However, it should be noted the following. The temperature of the beginning of the phase transition (tripping) of the most common currently types of commercial PPTC-fuses is about $80^{\circ} \mathrm{C}$, and a significant change in resistance is observed at 
higher temperatures. The maximum operating temperature of photovoltaic cells does not exceed $80{ }^{\circ} \mathrm{C}$. This situation to some extent limits widespread use of PPTC-fuses as elements of protection against overheating, especially if the cause of overheating is temporary.

Given the wide range of parameters (values of switching current, resistance in high and low conductive states, etc.) of PPTC-fuses, the results can be considered as evidence of their actual use to protect components of solar array in cases of shortcircuit or overvoltage, which leads to overheating of various types and other abnormal situations. On the other hand, it is promising to use the polymeric nanocarbon composites as insulation to shade, damaged (degraded) photovoltaic cells or their individual parts. In this direction, the most important is the development of low-temperature PPTC-fuses. 


\section{REFERENCES}

1. Köntges, M., Kurtz, S., Packard, C., Jahn, U., Berger, K. A., Kato, K., Friesen, T., Liu, H., \& Van Iseghem, M. (2014). Review of failures of photovoltaic modules (Report IEA-PVPS T13-01:2014). International Energy Agency, Photovoltaic Power Systems Programme. https://iea-pvps.org/wp-content/uploads/ 2020/01/IEAPVPS_T13-01_2014_Review_of_Failures_of_Photovoltaic_Modules_Final.pdf

2. Honsberg, C., \& Bowden, S. (2019). PVCDROM. Retrieved from https://www.pveducation.org

3. Ramabadran, R., \& Mathur, B. (2009). Effect of shading on series and parallel connected solar PV modules. Modern Applied Science, 3(10), 32-41.

4. Daliento, S., Di Napoli, F., Guerriero, P., \& d'Alessandro, V. (2016). A modified bypass circuit for improved hot spot reliability of solar panels subject to partial shading. Solar Energy, 134, 211-218. https://doi.org/10.1016/j.solener.2016.05.001

5. Bessel, V. V., Kucherov, V.G., \& Mingaleeva, R.D. (2016). Izuchenie solnechnykh fotoelektricheskikh elementov: Uchebno-metodicheskoe posobie. Izdatelskiy tsentr RGU nefti i gaza (NIU) imeni I. M. Gubkina (in Russian). http://www.gubkin.ru/faculty/pipeline_network_design/chairs_and_departments/ther modynamics_and_thermal_engine/files/Bessel_photovoltaic_cells.pdf

6. Zezin, D. A. (2014). Degradatsionnyie protsessyi v tonkoplenochnyih solnechnyih elementah [PhD thesis, National Research Institute "MPEI"] (in Russian).

7. Gumarov, A. (Ed.). (2019). Vidyi solnechnyih batarey: sravnitelnyiy obzor konstruktsiy i sovetyi po vyiboru paneley (in Russian). Retrieved from http://sovetingenera.com/eco-energy/sun/vidy-solnechnyx-batarej.html

8. Levshov, A. V. \& Fedorov, A. Yu. (2013). Mathematical Modeling of Photovoltaic Modules. Naukovi pratsi DonNTU. Seriia: "Elektrotekhnika i enerhetyka", (1/14), 153-158 (in Russian). http://ea.donntu.org/handle/123456789/23185 
9. Kozyr, I. Ya. (1987). Kachestvo i nadezhnost integralnykh mikroshem. Vysshaya shkola (in Russian).

10. Tonkoshkur, A. S. \& Ihnatkyn, V. U. (2014). Kontrol yakosti ta nadiinosti mikroelektronnykh vyrobiv. DDTU (in Ukrainian).

11. Achkasov, V. N. \& Smerek, V. A. (2012). Generalized criterion of reliability of integrated circuits and methods for the protection of single failure in digital devices at the design stage. Scientific Journal of KubSAU, (76/2) (in Russian). http://ej.kubagro.ru/2012/02/pdf/39.pdf

12. Muñoz, J., Lorenzo, E., Martínez-Moreno, F., Marroyo, L., \& García, M. (2008). An investigation into hot-spots in two large grid-connected PV plants. Progress in Photovoltaics: Research and applications, 16(8), 693-701. https://doi.org/10.1002/pip.844

13. Salazar, A. M., \& Macabebe, E. Q. B. (2016). Hotspots detection in photovoltaic modules using infrared thermography. In MATEC Web of Conferences (70, Article 10015). EDP Sciences. https://doi.org/10.1051/matecconf/20167010015

14. Moretón, R., Lorenzo, E., \& Narvarte, L. (2015). Experimental observations on hot-spots and derived acceptance/rejection criteria. Solar energy, 118, 28-40. https://doi.org/10.1016/j.solener.2015.05.009

15. Alonso-Garcìa, M. C., Herrmann, W., Böhmer, W., \& Proisy, B. (2003). Thermal and electrical effects caused by outdoor hot-spot testing in associations of photovoltaic cells. Progress in Photovoltaics: Research and Applications, 11(5), 293-307. https://doi.org/10.1002/pip.490

16. Silvestre, S., \& Chouder, A. (2008). Effects of shadowing on photovoltaic module performance. Progress in Photovoltaics: Research and applications, 16(2), 141-149. https://doi.org/10.1002/pip.780

17. García, M., Marroyo, L., Lorenzo, E., Marcos, J., \& Pérez, M. (2014). Observed degradation in photovoltaic plants affected by hot-spots. Progress in Photovoltaics: Research and applications, 22(12), 1292-1301. https://doi.org/10.1002/pip.2393 
18. Silvestre, S., Boronat, A., \& Chouder, A. (2009). Study of bypass diodes configuration on PV modules. Applied Energy, 86(9), 1632-1640. https://doi.org/10.1016/j.apenergy.2009.01.020

19. Kim, K. A., \& Krein, P. T. (2015). Reexamination of photovoltaic hot spotting to show inadequacy of the bypass diode. IEEE Journal of Photovoltaics, 5(5), 1435-1441. https://doi.org/10.1109/JPHOTOV.2015.2444091

20. Kim, K. A., \& Krein, P. T. (2013). Photovoltaic hot spot analysis for cells with various reverse-bias characteristics through electrical and thermal simulation. In 2013 IEEE 14th Workshop on Control and Modeling for Power Electronics (COMPEL) (pp. 1-8). IEEE. https://doi.org/10.1109/COMPEL.2013.6626399

21. Acciari, G., Graci, D., \& La Scala, A. (2010). Higher PV module efficiency by a novel CBS bypass. IEEE Transactions on Power Electronics, 26(5), 1333-1336. https://doi.org/10.1109/TPEL.2010.2095469

22. d'Alessandro, V., Guerriero, P., \& Daliento, S. (2013). A simple bipolar transistor-based bypass approach for photovoltaic modules. IEEE Journal of Photovoltaics, 4(1), 405-413. https://doi.org/10.1109/JPHOTOV.2013.2282736

23. Solórzano, J., \& Egido, M. A. (2014). Hot-spot mitigation in PV arrays with distributed MPPT (DMPPT). Solar Energy, 101, 131-137. https://doi.org/10.1016/j.solener.2013.12.020

24. Kim, K. A., Krein, P. T., Seo, G. S., \& Cho, B. H. (2013). Photovoltaic ac parameter characterization for dynamic partial shading and hot spot detection. In 2013 Twenty-Eighth Annual IEEE Applied Power Electronics Conference and Exposition (APEC) (pp. 109-115). IEEE. https://doi.org/10.1109/APEC.2013.6520194

25. Sánchez Pacheco, F. J. (2015). Photovoltaic systems distributed monitoring for performance optimization [Doctoral thesis, University of Málaga]. Institutional Repository of the University of Malaga. https://riuma.uma.es/xmlui/bitstream/handle/ 10630/9922/TD_Sanchez_Pacheco.pdf?sequence $=1 \&$ isAllowed $=\mathrm{y}$ 
26. Di Napoli, F., Guerriero, P., d'Alessandro, V., \& Daliento, S. (2015). Singlepanel voltage zeroing system for safe access on PV plants. IEEE Journal of Photovoltaics, 5(5), 1428-1434. https://doi.org/10.1109/JPHOTOV.2015.2448416

27. Schmidt, H., \& Roth, W. (2012). Bypass and protection circuit for a solar module and method of controlling a solar module. (U.S. Patent No. 0194003). Washington, DC: U.S. Patent and Trademark Office.

28. Resadi, M., Costa, S., \& Cesana, M. (2010). Control and signalling device for photovoltaic modules. (U.S. Patent No. 0057266). Washington, DC: U.S. Patent and Trademark Office.

29. Sanchez-Pacheco, F. J., Sotorrío-Ruiz, P. J., Heredia-Larrubia, J. R., PérezHidalgo, F., \& de Cardona, M. S. (2014). PLC-based PV plants smart monitoring system: field measurements and uncertainty estimation. IEEE Transactions on Instrumentation and Measurement, 63(9), 2215-2222. https://doi.org/10.1109/TIM. 2014.2308972

30. Di Napoli, F., Guerriero, P., d'Alessandro, V., \& Daliento, S. (2014). A power line communication on DC bus with photovoltaic strings. In 3rd Renewable Power Generation Conference (RPG 2014) (pp. 1-6). https://oi.org/10.1049/cp. 2014.0901

31. ETI. (2020). Green protect. Protection of photovoltaic systems. Retrieved from http://www.eti.si/images/userfiles/en-GB/documents/products/Ultraquick/PV.pdf

32. Trusov, V. A., \& Gusev, A. M. (2011). Protecting elements for electrical circuits from overvoltage and overcurrent. International symposium "Realiability \& Quality", 2, 221-224 (in Russian).

33. Cheng, S., Tom, K., \& Pecht, M. (2010). Failure precursors for polymer resettable fuses. IEEE Transactions on Device and Materials Reliability, 10(3), 374-380.

34. Cheon, K. Y. (1999). Battery pack with battery protection circuit. (U.S. Patent No. 5963019). Washington, DC: U.S. Patent and Trademark Office. 
35. Oglesbee, J. W., Burns, A. G., \& More, G. (2003). Overcharge protection device and methods for lithium based rechargeable batteries. (U.S. Patent No. 6608470). Washington, DC: U.S. Patent and Trademark Office.

36. Minervini, A. D., \& Nguyen, T. K. (2001). Electrical devices having a polymer PTC array. (U.S. Patent No. 6282072). Washington, DC: U.S. Patent and Trademark Office.

37. Littelfuse, Inc. (2018). Protecting rechargeable Li-ion and Li-polymer batteries. Retrieved from http://m.littelfuse.com/ /media/electronics/application notes/littelfuse_protecting_rechargeable_li_ion_and_li_polymer_batteries_in_consu mer_portable_electronics_application_note.pdf.pdf

38. Dimpault-Darcy, E. C., \& Bragg, B. J. (1990). Thermal switch disc for short circuit protection of batteries. (U.S. Patent No. 4973936). Washington, DC: U.S. Patent and Trademark Office.

39. Kaminskaya, T., \& DomKin, K. (2008). Samovosstanavlivaiushchiesia predohraniteli dlya avtomobili elektroniki. Elektronnyye komponenty, (5), 80-82(in Russian).

40. Tonkoshkur, A. S. \& Ihnatkyn, V. U. (2010). Fizychni osnovy elektrychnoho kontroliu neodnoridnykh system: navchalnyi posibnyk. DDTU (in Ukrainian).

41. Degtyar'ov, A. V., \& Tonkoshkur, A. S. (2007). Electric conductivity of PTCR polyethylene-graphite composites. Ukrainian Journal of Physics, 52(9), 863-867.

42. Degtyar'ov, A. V., Tonkoshkur, A. S., \& Lyashkov, A. Y. (2006). Electrical properties of posistor composite materials based on polyethylene - graphite. Multidiscipline Modeling in Materials and Structures, 2(4), 435-441. https://doi.org/10.1163/157361106778554897

43. Khukhtikov, S. (2015). «Vosstanovit rabotosposobnost!» Samovosstanavlivayushchiyesya PPTC-predokhraniteli MultiFuse. Novosti elektroniki, (1), 37-41.

44. Digi-Key Electronics. (2020). PTC Resettable Fuses. Retrieved from https://www.digikey.com/en/products/filter/ptc-resettable-fuses/150 
45. Koltun, M. M. (1985). Optika i metrologiya solnechnyih elementov. Nauka (in Russian).

46. Tonkoshkur, A. S., Ivanchenko, A. V., Nakashydze, L. V., \& Mazurik, S. V. (2018). Application of resettable elements for electrical protection of solar batteries. Tekhnologiya $i$ Konstruirovanie $v$ Elektronnoi Apparature, (1), 43-49. http://dx.doi.org/10.15222/TKEA2018.1.43

47. Belykh, S. (2011). Novyi innovatsionnyiy samovosstanavlivayuschiysya komponent zaschityi dlya silovyih litiy-ionnyih akkumulyatorov. Komponenty $i$ tekhnologii, (2), 50-53 (in Russian).

48. Toth, J. (2020). PolySwitch PPTC device principals of operation. Retrieved from http://studyres.com/doc/7802565/polyswitch-pptc-device-principals-of-opera tion?page $=5$

49. Energosistemy, OOO. (2020). United Solar Technologies. Solnechnyie moduli $i$ batarei (in Russian). Retrieved from http://ust.su/solar/media/sectioninner17/

50. Tonkoshkur, A. S., \& Nakashydze, L. V. (2018). Problemy nadiinosti fotoelektrychnykh komponentiv soniachnykh batarei. Vidnovliuvana enerhetyka, (3), 21-31.

51. Tonkoshkur, A. S., Ivanchenko, A. V., Nakashydze L. V., \& Mazuryk S. V. (2018). Zakhyst soniachnykh batarei vid elektrychnykh perevantazhen: monohrafiia. (A. S. Tonkoshkur, Ed.). Aktsent PP (in Ukrainian).

52. Acciari, G., Graci, D., \& La Scala, A. (2010). Higher PV module efficiency by a novel CBS bypass. IEEE Transactions on Power Electronics, 26(5), 1333-1336. http://dx.doi.org/10.1109/TPEL.2010.2095469

53. Rahman, M. M., Selvaraj, J., Rahim, N. A., \& Hasanuzzaman, M. (2018). Global modern monitoring systems for PV based power generation: A review. Renewable and Sustainable Energy Reviews, 82(3), 4142-4158. https://doi.org/10.1016/j.rser.2017.10.111 
54. Rauschenbach, H. S. (2012). Solar cell array design handbook: the principles and technology of photovoltaic energy conversion. Springer Science \& Business Media.

55. Lorenzo, E. (1994). Solar electricity: engineering of photovoltaic systems. Earthscan/James \& James.

56. Koval, O. S., \& Tivanov, M. S. (2012). Opredelenie parametrov solnechnogo elementa iz ego svetovoj vol't-ampernoj harakteristiki. Vestnik $B G U$. Seriya 1, (2), 39-44 (in Russian).

57. Salem, F. A. (2014). Modeling and simulation issues on PhotoVoltaic systems, for mechatronics design of solar electric applications. IPASJ International Journal of Mechanical Engineering, 2(8), 24-47.

58. Alboteanu, I. L., Ivanov, S., \& Manolea, G. (2008). Modelling and simulation of a stand-alone photovoltaic system. In 8th WSEAS International Conference on POWER SYSTEMS (PS 2008) (pp. 189-194).

59. Hansen, A. D., Sorensen, P., Hansen, L. H., \& Bindner, H. (2001). Models for a stand-alone $P V$ system. Roskilde: Rio National Laboratory. http://citeseerx.ist.psu.edu/viewdoc/download?doi=10.1.1.887.2200\&rep=rep1\&type $=\mathrm{pdf}$

60. Gaevskiy, A. Yu. (2012). Opredelenie parametrov fotoelektricheskih moduley na osnove tochnogo resheniya uravneniya dlya VAH. Vidnovluvana energetika, (4), 32-39 (in Russian).

61. Tonkoshkur, A. S., \& Ivanchenko, A. V. (2020). Modeling of electrical characteristics of photovoltaic solar arrays with protection against current overloads based on PolySwitch elements. Multidiscipline Modeling in Materials and Structures, 16(3), 425-438. https://doi.org/10.1108/MMMS-01-2019-0022

62. Macklen, E. D. (1979). Thermistors. Electrochemical Publications Limited.

63. Tonkoshkur, A. S., Trystan, O. N., \& S'janov, O. M. (2004). Komponentna baza REA. DDTU (in Ukrainian). 
64. Tyco Electronics. (2005). Raychem circuit protection. PolySwitch ${ }^{\mathrm{TM}}$ resettable device short form catalog. Retrieved from https://datasheet.octopart.com/ MICROSMD010F-2-Tyco-Electronics-datasheet-45906.pdf

65. Ivanchenko, A. V., Tonkoshkur, A. S., \& Mazurik, S. V. (2018). Application of "PolySwitch" fuses for the limitation of current overloads in photovoltaic systems of solar arrays. Journal of Physics and Electronics, 26(1), 77-82. https://doi.org/10.15421/331813

66. Nakashydze, L. V., Tonkoshkur, A. S., Ivanchenko, A. V., Mazurik, S. V., Gabrinets, V. O., Tytarenko, I .V., Gnatiuk, G. L., Trofimenko, A. V., Sokol, G. I., Kotlov, V. Yu., Savchuk, T. L., Kyrychenko, S. Yu., Hilorme, T. V., Yelisyeyeva, O. K., \& Nakashydze I. S. (2019). Providing energy-saving technologies: technical, ecological and economic aspects. Collective monograph. (L. V. Nakashydze. Ed.). Yunona Publishing.

67. Tonkoshkur, A. S., \& Nakashydze, L. V. (2019). Software for calculation of parameters of equivalent electric scheme of photovoltaic cells. System technologies. Regional interuniversity compendium of scientific works, 1(120), 150-155.

68. Al-Oran Bilal Fuad. (1995). Research and development of siliceous solar elements for photoelectric stations and batteries for ground application [Abstract of $\mathrm{PhD}$ thesis, Institute of Energy and Automation of the Academy of Sciences of the Republic of Uzbekistan]. http://tekhnosfera.com/view/515380/a\#?page=1

69. Fuzetec Technology Co., LTD. (2020). Fuzetec: FRX series - radial leaded PTC. Retrieved from http://www.fuzetec.com/products_2.php?bgid=1\&gid=31

70. Gremenok, V. F., Tivanov, M. S., Zalesskiy, V. B. (2007). Solnechnyie elementyi na osnove poluprovodnikovyih materialov. Izdatelskiy tsentr BGU (in Russian).

71. Migunov, Ya. N. (2015). Modelirovanie solnechnogo elementa v graficheskoy srede Simulink. Molodezhnyiy nauchno-tehnicheskiy vestnik. Elektronnyiy zhurnal, (7) (in Russian). Retrieved from http://ainsnt.ru/doc/791154.html 
72. DeGraaff, D., Lacerda, R., \& Campeau, Z. (2011). Degradation mechanisms in Si module technologies observed in the field; their analysis and statistics. In NREL 2011 Photovoltaic Module Reliability Workshop. SunPower Corporation. https://www.irishellas.com/files/Degradation-Mechanisms-in-Si-Module.pdf

73. d'Alessandro, V., Guerriero, P., Daliento, S., \& Gargiulo, M. (2011). A straightforward method to extract the shunt resistance of photovoltaic cells from current-voltage characteristics of mounted arrays. Solid-State Electronics, 63(1), 130-136. https://doi.org/10.1016/j.sse.2011.05.018

74. Brice, C. W., Dougal, R. A., \& Hudgins, J. L. (1996). Review of technologies for current-limiting low-voltage circuit breakers. IEEE Transactions on Industry Applications, 32(5), 1005-1010. https://doi.org/10.1109/28.536858

75. Valeev, H. S., \& Kvaskov, V. B. (1983). Nelineynyie metallooksidnyie poluprovodniki. Energoizdat.

76. Gupta, T. K. (1990). Application of zinc oxide varistors. Journal of the American Ceramic Society, 73(7), 1817-1840. https://doi.org/10.1111/j.11512916.1990.tb05232.x

77. Standler, R. B. (2002). Protection of electronic circuits from overvoltages. Dover Publications, INC.

78. Golubovic, B., Becker, P. N., \& Moore, R. P. (2010). Circuit protection device having thermally coupled MOV overvoltage element and PPTC overcurrent element. (U.S. Patent No. 7660096). Washington, DC: U.S. Patent and Trademark Office.

79. Guerriero, P., Di Napoli, F., d'Alessandro, V., \& Daliento, S. (2015). Accurate maximum power tracking in photovoltaic systems affected by partial shading. International Journal of Photoenergy, 2015, Article 824832. https://doi.org/10.1155/2015/824832

80. Tonkoshkur, A. S., \& Ivanchenko, A. V. (2019). Algorithm for representations of the polyswitch fuse characteristics in the modeling problems. 
System technologies. Regional interuniversity compendium of scientific works, 1(120), 143-149. https://doi.org/10.34185/1562-9945-1-126-2020-14

81. Makarov, V. O., Tonkoshkur, A. S., \& Gomilko, I. V. (1997). Investigation of electronic processes at the grain boundaries of a multilayer varistor. Key engineering materials, 132-136, 1309-1312. https://doi.org/10.4028/www.scientific. net/KEM.132-136.1309

82. Tonkoshkur, A. S., Glot, A. B., \& Ivanchenko, A. V. (2015). Percolation effects in de degradation of $\mathrm{ZnO}$ varistors. Journal of Advanced Dielectrics, 5(1), Article 1550008. https://doi.org/10.1142/S2010135X15500083

83. Ivanchenko, A. V., Mazurik, S. V., \& Tonkoshkur, A. S. (2018). Investigation into the characteristics of silicon photovoltaic converters of solar batteries in case of overheating. Tekhnologiya $i$ Konstruirovanie $v$ Elektronnoi Apparature, (4), 14-20. http://dx.doi.org/10.15222/TKEA2018.4.14

84. Kurishev, K. (2006). Vse, chto vyi hoteli uznat o PolySwitch, no boyalis sprosit. Components \& Technologics, (3) (in Russian). Retrieved from http://www.kit-e.ru/assets/files/pdf/2006_03_30.pdf

85. Littelfuse, Inc. (2016). Fundamentals of resettable functionality in PPTC devices. Retrieved from https://m.littelfuse.com/ /media/electronics/technical_papers /resettable_ptcs/littelfuse_fundamentals_of_resettable_functionality_in_pptc_devices _technical_paper.pdf.pdf

86. El Basri, Y., Bressan, M., Seguier, L., Alawadhi, H., \& Alonso, C. (2015). A proposed graphical electrical signatures supervision method to study PV module failures. Solar Energy, 116, 247-256. https://doi.org/10.1016/j.solener.2015.02.048

87. Khaing, H. H., Liang, Y. J., Htay, N. N. M., \& Fan, J. (2014). Characteristics of different solar PV modules under partial shading. International Journal of Energy and Power Engineering, 8(9), 1418-1422.

88. Tonkoshkur A. S. (2019). Skhemotekhnichni tekhnolohii pidvyshchennia nadiinosti vidnovliuvanykh dzherel enerhii na osnovi soniachnykh batarei $\mathrm{z}$ vykorystanniam elementiv funktsionalnoi elektroniky. In Materialy VII 
Mizhnarodnoi naukovo-praktychnoi konferentsii "Rozvytok biznes-analityky, obliku ta opodatkuvannia $v$ umovakh hlobalizatsii, zahostrennia enerhetychnykh problem" (pp. 210-212) (in Ukrainian).

89. Tonkoshkur, A. S., \& Ivanchenko, A. V. (2019). Electrical properties of structures based on varistor ceramics and polymer nanocomposites with carbon filler. Journal of Advanced Dielectrics, 9(03), Article 1950023. https://doi.org/10.1142/S2010135X19500231

90. Hitano Enterprise Corp. (2020). Metal Oxide Varistors. Transient voltage surge suppressors. Retrieved from https://www.hitano.com.tw/wp-content/uploads/ doc/14D_20180620.pdf

91. Littelfuse, Inc. (2016). PolySwitch ${ }^{\circledR}$ PTC devices. Overcurrent protection device. Product: RXEF050. Retrieved from https://www.littelfuse.com/ /media/ electronics/product_specifications/resettable_ptcs/littelfuse_ptc_rxef050_product_spe cification.pdf.pdf

92. Thermalinfo.ru. (2020). Teploprovodnost termopast, sravnenie termopast po teploprovodnosti $i$ vyazkosti (in Russian). Retrieved from http:/thermalinfo.ru/ svojstva-materialov/materialy-raznye/teploprovodnost-termopast-sravnenie-termopastpo-teploprovodnosti-i-vyazkosti

93. Tyco Electronics. (2008). Application note. PolySwitch strap devices help protect rechargeable battery packs. Retrieved from http://www.digikey.jp/Web Export/Supplier Content/Tyco_8004/PDF/TE_Strap_Device.pdf

94. Ivanchenko, A. V., \& Tonkoshkur, A. S. (2018). Electrical characteristics of two-layer structure varistor ceramics-PPTC nanocomposite. Journal of Physics and Electronics, 26(2), 97-100. https://doi.org/10.15421/331832

95. Tonkoshkur, A. S., \& Ivanchenko, A. V. (2019). Modelirovanie degradatsii metalloksidnyih varistornyih elementov zaschityi elektricheskih tsepey: monografiya. Aktsent PP (in Russian).

96. Ivanchenko, A. V., Tonkoshkur, A. S., \& Mazurik, S. V. (2019). Application of varistor-posistor structure for protection from overvoltages of photovoltaic 
cells of solar arrays. Journal of Physics and Electronics, 27(1), 79-88. https://doi.org/10.15421/331913

97. Littelfuse, Inc. (2020). Metal-oxide varistors (MOVs). Surface mount multilayer varistors (MLVS). MLA series. Retrieved from https://m.littelfuse.com/ / media/electronics/datasheets/varistors/littelfuse_varistor_mla_datasheet.pdf.pdf

98. Fuzetec Technology Co., LTD. (2020). Fuzetec: Radial leaded PTC resettable fuse: FRX series. Retrieved from http://www.fuzetec.com/upload/ download/App\%20FRX\%20Series\%20[Ver.6].pdf

99. Gerasimov, V. G., Knyazkov, O. M., Krasnopolskiy, A. E., \& Suhorukov, V. V. (1986). Osnovyi promyishlennoy elektroniki: uchebnik dlya neelektrotehnicheskih spetsialnostey vuzov. (V. G. Gerasimov, Ed.). Vyisshaya shkol. (in Russian).

100. Hotuntseva, Yu. L. (Ed). (2018). Elektrotehnika. Chast 1: uchebnoe posobie dlya srednego professionalnogo obrazovaniya (3rd ed.). Yurayt (in Russian).

101. Gudkova, A. V., Gubin, S. V., \& Belokon, V. I. (2012). Thermal stabilization of solar cells for current-voltage characteristics measurement with the pulsed light source. Otkrytyye informatsionnyye $i$ komp'yuternyye integrirovannyye tekhnologii, (57), 187-196 (in Russian).

102. Bakirov, M. Ya. (1997). Photoelectric and radiation characteristics of silicon solar cells at high illumination levels and elevated temperatures. Semiconductors, 31(5).

103. Sachenko, A. V., Kryuchenko, Yu. V., Kostylyov, V. P., ., Bobyl, A. V., Terukov, E. I., Abolmasov, S. N., Abramov, A. S., Andronikov, D. A., Shvarts, M. Z., Sokolovskyi, I. O., \& Evstigneev, M. (2016). Temperature dependence of photoconversion efficiency in silicon heterojunction solar cells: Theory vs experiment. Journal of Applied Physics, 119(22), Article 225702. http://dx.doi.org/10.1063/1.4953384

104. Radziemska, E. (2006). Effect of temperature on dark current characteristics of silicon solar cells and diodes. International Journal of Energy Research, 30(2), 127-134. https://doi.org/10.1002/er.1113 
105. Flammini, M. G., Debernardi, N., Le Ster, M., Dunne, B., Bosman, J., \& Theelen, M. (2016). The influence of heating time and temperature on the properties of CIGSSe solar cells. International Journal of Photoenergy, 2016, Article 4089369. https://doi.org/10.1155/2016/4089369

106. Tonkoshkur, A. S., Nakashidze, L. V., \& Lyagushyn, S. F. (2018). Schemotechnical technologies for reliability of solar arrays. System technologies. Regional interuniversity compendium of scientific works, 4(117), 95-107.

107. Nakashydze, L. V., \& Knysh, L. I. (2008). Metodologiya opredeleniya sostava i shemnyh resheniy solnechnyh fotoelektricheskih ustanovok. Aviatsionno-kosmicheskaya tehnika $i$ tehnologiya, (10/57), 100-103. http://nbuv.gov.ua/UJRN/aktit_2008_10_20

108. Tonkoshkur, A. S., Chernenko, I. M., \& Subbota, V. L. (1995). Long-term effects of electric current on the conductivity of zinc oxide varistor ceramics. Inorganic materials, 31(6), 730-733.

109. Ivanchenko, A. V., \& Tonkoshkur, A. S. (2012). Electromigration degradation model of metal oxide varistor structures. Ukrainian Journal of Physics, 57(3), 330-338.

110. Fritz, J. M., Zuschlag, A., Skorka, D., Schmid, A., \& Hahn, G. (2017). Temperature dependent degradation and regeneration of differently doped mc-Si materials. Energy Procedia, 124, 718-725. https://doi.org/10.1016/j.egypro.2017.09.085

111. Hallam, B., Herguth, A., Hamer, P., Nampalli, N., Wilking, S., Abbott, M., Wenham, S., \& Hahn, G. (2018). Eliminating light-induced degradation in commercial p-type Czochralski silicon solar cells. Applied Sciences, 8(1), Article 10. https://doi.org/10.3390/app8010010

112. Bishop, J. W. (1989). Microplasma breakdown and hot-spots in silicon solar cells. Solar cells, 26(4), 335-349. https://doi.org/10.1016/0379-6787(89)90093-8

113. Breitenstein, O., Bauer, J., Bothe, K., Kwapil, W., Lausch, D., Rau, U., Schmidt, J., Schneemann, M., Schubert, M. C., Wagner, J.-M., \& Warta, W. (2011). 
Understanding junction breakdown in multicrystalline solar cells. Journal of Applied Physics, 109(7), Article 071101. https://doi.org/10.1063/1.3562200

114. Ivanchenko, A. V., \& Tonkoshkur, A. S. (2019). Changes in the characteristics of silicon photovoltaic cells of solar arrays after current overloads. Tekhnologiya $i$ Konstruirovanie $v$ Elektronnoi Apparature, (3-4), 19-25. http://dx.doi.org/10.15222/TKEA2019.3-4.19

115. Herrmann, W., Adrian, M., Wiesner, W., \& Rheinland, T. (1998). Operational behaviour of commercial solar cells under reverse biased conditions. In Proceedings of the Second World Conference on Photovoltaic Solar Energy Conversion (pp. 2357-2359).

116. Danikas, M. G., \& Papaschinopoulos, G. (1998). Thermal breakdown in solid dielectrics: A new approach. Journal of the Franklin Institute, 335(4), 617-621.

117. Kuffel, E., Zaengl W. S., \& Kuffel, J. (2000). High voltage engineering: Fundamentals. (2nd ed.). Newnes.

118. Virchenko, Yu. P., \& Vodyanitskii, A. A. (2001). Heat localization and formation of heat breakdown structure in semiconductor materials. I. Nonlinear model. Functional Materials, 8(3), 428-434.

119. Ivanchenko, A. V., \& Tonkoshkur, A. S. (2020). Electrical properties of photogalvanic element with built-in posistor layer based on polymer nanocomposite with carbon filler. Tekhnologiya i Konstruirovanie v Elektronnoi Apparature, (1-2), 30-36. http://dx.doi.org/10.15222/TKEA2020.1-2.30

120. Glot, A. B., Ivon, A. I., Tonkoshkur, A. S. \& Chernenko, I. M. (1998). Oksydni keramichni varystory. DDU (in Ukrainian).

121. Bourns, Inc. (2015). MF-R series - PTC resettable fuses. Retrieved from https://www.bourns.com/docs/Product-Datasheets/mfr.pdf

122. Littelfuse, Inc. (2017). Polyswitch resettable devices. Automotive devices. Retrieved from https://m.littelfuse.com/ /media/electronics/datasheets/resettable_ptcs /littelfuse_ptc_radial_leaded_catalog_datasheet.pdf.pdf 
123. Chen, K., Chen, D., Zhu, Y., \& Shen, H. (2012). Study of crystalline silicon solar cells with integrated bypass diodes. Science China Technological Sciences, 55(3), 594-599. http://dx.doi.org/10.1007/s11431-011-4712-6

124. Al'-Oran, B. F., Dadamukhamedov, S., Laieb, N., Muminov, R. A., Saidov, A. S., \& Tursunov, M.N. (1997). Silicon doped with indium: a material for photopower engineering. Applied solar energy, 33(4), 11-14.

125. Ivanchenko, A. V., \& Tonkoshkur, A. S. (2020). Application of a polymer nanocomposite with carbon filler to limit overvoltages in a photovoltaic element. Journal of Advanced Dielectrics, 10(5), Article 2050020. https://doi.org/10.1142/S2010135X20500204

126. Chen, J., \& Tsang, C. K. (2019). PPTC device having low melting temperature polymer body. (U.S. Patent No. 0096621). Washington, DC: U.S. Patent and Trademark Office.

127. Lyashkov, A. Yu., Tonkoshkur, A. S., Vasheruk, A. V., \& Makarov, V. O. (2019). Electrical properties of posistor composites based on ceresin-nanocarbon. Proceedings of 20th International Research and Practical Conference "Modern information and electronic technologies" (SIET-2019), 79-80 (in Russian).

128. Sotskov, V.A., \& Karpenko, S.V. (2003). Electrical conduction in binary macrosystems: General rules. Technical Physics, 48(1), 100-103. https://doi.org/10.1134/1.1538736

129. Degtyar'ov, A. V., Lyashkov, A. Yu., \& Tonkoshkur, A. S. (2004). Elektricheskie svoystva kompozitsionnyih pozistornyih sistem polietilen-grafit. Visnyk Dnipropetrovskoho universytetu. Fizyka. Radioelektronika, (2/2), 34-38.

130. Rembeza, S. I., Svistova, T. V., Rembeza, E. S., \& Borsyakova, O. I. (2001). The microstructure and physical properties of thin $\mathrm{SnO}_{2}$ films. Semiconductors, 35(7), 762-765.

131. Lyashkov, A. Yu., Tonkoshkur, A. S., \& Lyagushyn, S. F. (2018). Resettable fuses for overcurrent protection in photovoltaic solar array systems. Journal of Physics and Electronics, 26(2), 81-88. https://doi.org/10.15421/331829 
132. Fahrenbruch, A. L., \& Bube, R. H. (1983). Fundamentals of solar cells. Photovoltaic solar energy conversion. Academic Press.

133. Green, M. A. (1995). Silicon solar cells: advanced principles \& practice. Centre for Photovoltaic Devices and Systems.

134. Sze, S. M., \& Ng, K. K. (2006). Physics of semiconductor devices. John Wiley \& Sons.

135. Vasil'ev, A. M., \& Landsman, A. P. (1971). Poluprovodnikovye fotopreobrazovateli. Sovetskoe radio (in Russian).

136. Appelbaum, J., Chait, A., \& Thompson, D. (1993). Parameter estimation and screening of solar cells. Progress in Photovoltaics: Research and Applications, 1(2), 93-106. https://doi.org/10.1002/pip.4670010202

137. Pikus, G. E. (1965). Osnovy teorii poluprovodnikovykh priborov. Nauka (in Russian).

138. Yegorov, V. S., Zaytseva, A. K., Murkina, M. V., Polisan, A. A., Strebkov, D. S., \& Shulmeyster, L. F. (1970). Sposob opredeleniya vnutrennego soprotivleniya fotoelektricheskogo preobrazovatelya po voltampernoy harakteristike. (SU Patent No. 268541) (in Russian).

139. Gorban, A. P., Kostylev, V. P., Nikolin, I. B., \& Sachenko, A. V. (1991). O korrektnosti razlichnykh metodov opredeleniya posledovatelnogo soprotivleniya fotodiodnykh struktur. Optoelektronika i poluprovodnikovaya tehnika, (19), 85-90 (in Russian).

140. Gabrinets, V. A., Nakashydze, L. V., Zarivnyak, G. I., \& Mitrokhov, S. A. (2005). Avtomatizatsiya issledovaniy energogeneriruyushchey sposobnosti solnechnykh elementov $\mathrm{v}$ usloviyah estestvennoy insolyatsii. Aviatsionnokosmicheskaya tehnika i tehnologiya. Aerospace Engineering and Technology, (9/25), 162-167 (in Russian). http://nbuv.gov.ua/UJRN/aktit_2005_9_35

141. Nakashydze, L. V., Zarivnyak, G. I., \& Mitrokhov, S. A. (2002). Eksperimentalnaya ustanovka dlya izmereniy energeticheskih harakteristik 
solnechnykh elementov. Problemy vysokotemperaturnoy tekhniki: zbirnyk naukovykh prats, 95-99 (in Russian).

142. Tyushkevich, N. I., Dubilovich, V. M., Kostyukovskiy, A. G., \& Pylnikova, G. E. (1988). Geliostat. (SU Patent No. 1399609) (in Russian).

143. Nakashydze, L. V., Degtyarova, N. V., Zarivnyak, G. I. \& Mitrokhov, S. A. (2004). Experimental research of the power characteristics of solar cells of various types in natural illumination. Kosmichna nauka i tekhnologiya. Dodatok, 10(1), 16-18 (in Russian).

144. Degtyarova, N. V., Zarivnyak, G. I., Mitrokhov, S. A., \& Nakashydze, L. V. (2005). Eksperimentalnoye opredeleniye vliyaniya sistemy kontsentratsii na geometricheskiye parametry solnechnyh batarey. In VII Mizhnarodna molodizhna naukovo-praktychna konferentsiya „Lyudyna i kosmos” (pp. 99) (in Russian).

145. Zarivnyak, G. I., Mitrokhov, S. A., Nakashydze, L. V., \& Prolis, S. V. (2005). Programmnyye sredstva dlya obrabotki i opredeleniya energeticheskih harakteristik solnechnyh elementov. In VII Mizhnarodna molodizhna naukovopraktychna konferentsiya „Lyudyna i kosmos” (pp. 101) (in Russian).

146. Tonkoshkur, A., \& Karpenko, N. (2018). Architecture and description of the applied programs package for electrical properties simulation of heterogeneous materials. System technologies. Regional interuniversity compendium of scientific works, 1(114), 136-141.

147. Microsoft. (2020). Windows Forms documentation. Retrieved from https://docs.microsoft.com/en-us/dotnet/desktop/winforms/?view=netdesktop-5.0 


\section{Appendix A}

\section{MEASUREMENT OF THE MAIN FUNCTIONAL CHARACTERISTICS AND PARAMETERS OF PHOTOVOLTAIC CELLS AND THEIR CONNECTIONS}

The correct choice of circuit protection against electrical overloads is impossible without specific information about the electrical parameters of photovoltaic cells: series and parallel (shunt) resistances, diode saturation current density, diode coefficient and others that determine their main functional CVC property [45, $132,133]$.

\section{A.1 Methods for determining the electrical parameters of photovoltaic cells}

\section{A.1.1 Equivalent circuit of a photovoltaic cell}

At measurements of light CVC and development of algorithms of methods of definition of parameters of PV-cell the equivalent circuit similar to given in chapter 3 was used (Fig. A.1).

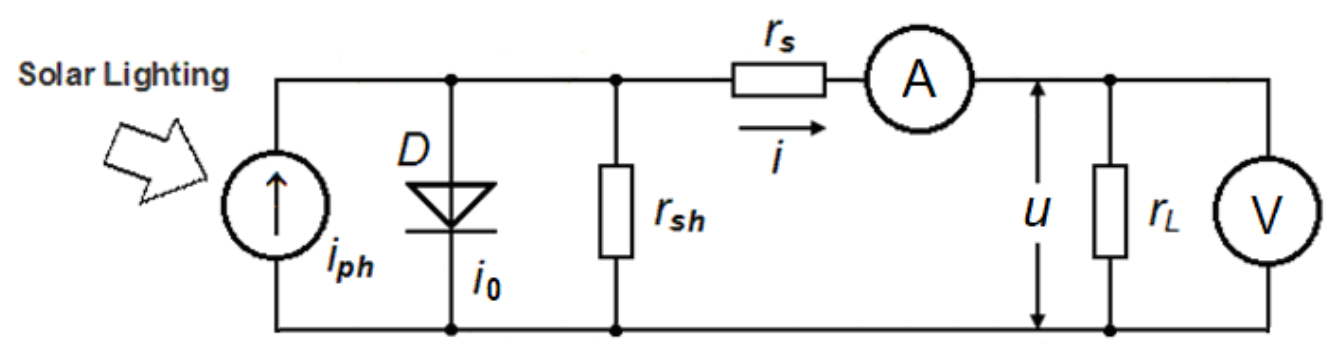

Figure A.1. Equivalent circuit for measuring the light current-voltage characteristics of the PV-cell.

The theoretical expression corresponding to this circuit was used to represent the light CVC $[45,133]$ 


$$
i=i_{p h}-i_{0}\left[\exp \left(\frac{u+i r_{s}}{m}\right)-1\right]-\frac{u+i r_{s}}{r_{s h}}
$$

where $m=A k T / e ; i_{p h}$ - value of the generated photocurrent; $i_{0}$ - value of the saturation current of the diode; $A$ - diode coefficient; $r_{s h}$ - parallel (shunt) resistance; $r_{s}$ - series resistance; $e$ - absolute value of the electron charge; $k$ - Boltzmann constant; $T$ - temperature.

\section{A.1.2 Parameters of light current-voltage and power-voltage characteristics}

Current-voltage and power-voltage characteristics are the main functional characteristics of photovoltaic cells and their connections in the form of photovoltaic modules, panels, etc.

The general view of these characteristics is presented in Fig. A.2.

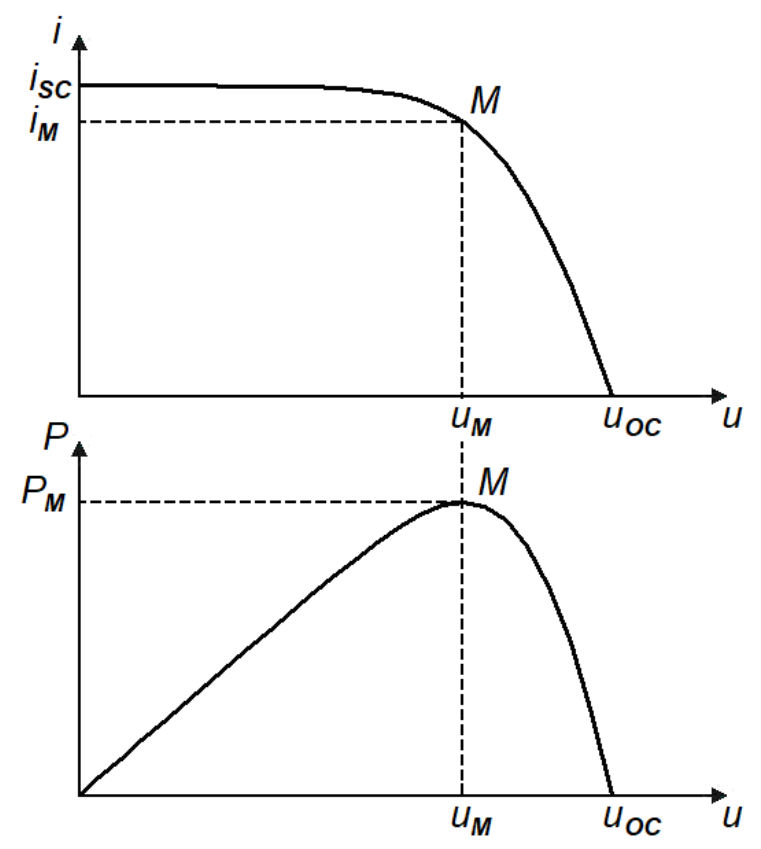

Figure A.2. Light current-voltage $i(u)$ and power-voltage $P(u)$ characteristics of the photovoltaic cell. $P_{M}$ - maximum output powe; $i_{S C}$ - short-circuit current;

$u_{O C}-$ open-circuit voltage; $i_{M}$ - current value at maximum power; $u_{M}$ - voltage at maximum power $P_{M}$. 
The main parameter of PV-cell is the coefficient of performance (efficiency) $\eta$, which because it determines the efficiency of conversion of solar radiation energy into electricity $[134,135]$

$$
\eta=\frac{P_{m}}{P}=f f \frac{i_{s c} u_{o c}}{P},
$$

where $P$ - power of the radiation falling on the PV-cell; $f f-\mathrm{CVC}$ filling factor.

The value of the filling factor of the light $\mathrm{CVC}$ is calculated according to the formula

$$
f f=\frac{i_{M} u_{M}}{i_{s c} u_{o c}},
$$

where the denominator $i_{S C} \cdot u_{O C}$ corresponds to the maximum possible CVC filling.

\section{A.1.3 Methods for determining the parameters of photovoltaic cell from its light characteristics and their comparison}

There are many ways to determine the parameters of the photovoltaic cell from its CVC [56, 70, 136-139]. The most desirable methods are those in which a single light CVC is used for the calculation, thus eliminating the dependence of the parameters of the PV-cell on the level of irradiation, temperature and current density $[45,56]$.

A comparative analysis of the main methods for determining the parameters of the PV-cell with its light CVC was performed in [56]. Its results are given in Table A.1, where the approximations used in the implementation of these methods, a list of values determined experimentally and used in the calculations, and the relative errors of estimation of the most important circuit parameter of the PV-cell is series electrical resistance. Estimates were obtained in different ways using the calculated CVC (A.1) for PV-cell with given, close to real parameters: $r_{s}=1.7 \mathrm{Ohm}$, $r_{s h}=1.2 \mathrm{kOhm}, i_{0}=0.22 \mu \mathrm{A}, A=1.9, i_{S C}=0.04 \mathrm{~A}, u_{O C}=0.595 \mathrm{~V}$.

As follows from Table A.1, the most accurate methods for determining the photovoltaic cell parameters are those based on the use of CVC angles to the 
coordinate axes $[8,70]$, and determining the parameters of the cell using the areas under its current-voltage and power-voltage characteristics $[71,139]$.

Table A. 1

Methods for determining the parameters of photovoltaic cells

\begin{tabular}{|c|c|c|c|}
\hline \multirow{2}{*}{ Method } & \multicolumn{2}{|c|}{ Used } & \multirow{2}{*}{$\begin{array}{l}\text { Relative error } \\
\text { of definition } r\end{array}$} \\
\hline & Assumption & Experimental data & \\
\hline $\begin{array}{l}\text { Determination } \\
\text { PV-cell parameters } \\
\text { using the angles of } \\
\text { inclination of its CVC } \\
\text { to the coordinate axes }\end{array}$ & $\begin{array}{c}r_{s} / r_{s h}+1 \approx 1 \\
\quad i_{p h} \approx i_{S C}\end{array}$ & $\begin{array}{c}\left.u_{i}^{\prime}\right|_{u=0} ; \\
\left.u_{i}^{\prime}\right|_{i=0} ; \\
i_{S C} ; i_{M} \\
u_{O C} ; u_{M}\end{array}$ & 12 \\
\hline $\begin{array}{l}\text { Determination of series } \\
\text { resistance using a } \\
\text { voltage-current } \\
\text { derivative }\end{array}$ & $\frac{m}{i_{S C}-i_{0} \exp }\left(\frac{i_{S C} r_{s}}{m}\right) \approx 0$ & $\left.u_{i}^{\prime}\right|_{i=0}$ & 82 \\
\hline $\begin{array}{l}\text { Determination of series } \\
\text { resistance using three } \\
\text { load resistances }\end{array}$ & - & $\begin{array}{l}i_{S C} ; i_{M} \\
u_{O C} ; u_{M}\end{array}$ & 53 \\
\hline $\begin{array}{l}\text { Determination of series } \\
\text { resistance using the } \\
\text { filling factor }\end{array}$ & $\begin{array}{c}i_{S C} r_{s}<<m \\
u_{O C}>>m\end{array}$ & $\begin{array}{l}i_{S C} ; i_{M} \\
u_{O C} ; u_{M}\end{array}$ & 70 \\
\hline $\begin{array}{l}\text { Determination of } \\
\text { PV-cell parameters } \\
\text { using areas under CVC } \\
\text { and PVC of PV-cell }\end{array}$ & $\begin{array}{c}i<<i_{p h} \\
r_{s} / r_{s h}<<1 \\
i_{p h} r_{s} / m \sim 1 \\
r_{s h}<<u_{O C} / i_{p h}\end{array}$ & $\begin{array}{c}P_{i u}=\int_{0}^{u_{O C}} i(u) d u \\
P_{P}=\int_{0}^{u_{O C}} i(u) u d u ; \\
\left.u_{i}^{\prime}\right|_{i=0} ; \quad i_{s c} ; \quad u_{o c}\end{array}$ & 17 \\
\hline
\end{tabular}

The used methods are discussed in more detail below. 


\section{A.1.4 Method using the angles of inclination of the current-voltage characteristic of the cell to the coordinate axes}

Let's write the equation of the CVC of the photovoltaic cell (A.1) for points $\left(u=0, i=i_{S C}\right)$ and $\left(u=u_{O C}, i=0\right)$. Add to this the voltage-differentiated equation (A.1) at these points. Give the variable parameter $A$ some value. The result is the following system of equations, solving which can be obtained [70]:

$$
\begin{gathered}
r_{s}=-\frac{1}{2}\left[\left(a-b^{2}+\frac{2 q}{i_{S C}} a-b+\left(\frac{u_{O C}}{i_{S C}}\right)^{2}\right)^{\frac{1}{2}}+a+b+\frac{u_{O C}}{i_{S C}}\right] ; \\
r_{s h}=\frac{u_{O C}}{\frac{A k T / e}{b+r_{s}}-\frac{A k T / e}{a+r_{s}}+i_{S C}} ; \\
i_{0}=\frac{i_{S C}}{\gamma}-\frac{u_{O C}}{\gamma r_{p}} .
\end{gathered}
$$

In (A.4) the following designations are introduced

$$
q=u_{O C} \frac{\gamma+2}{\gamma}-2 \frac{A k T}{e} ; \gamma=\exp \left(\frac{e u_{O C}}{A k T}\right)-1 ; \quad a=\left(\left.\frac{d i}{d u}\right|_{u=0}\right)^{-1} ; b=\left(\left.\frac{d i}{d u}\right|_{i=0}\right)^{-1} .
$$

Here $a$ and $b$ are the cotangents of the angles of CVC inclination to the voltage axis at the points $\left(u=0, i=i_{S C}\right)$ and $\left(u=u_{O C}, i=0\right)$, respectively (Fig. A.3). The values of $u_{O C}, i_{S C}, T$ are determined experimentally.

It is assumed that there is a condition

$$
1+\frac{r_{s}}{r_{s h}} \approx 1
$$

Such an approximation is feasible with sufficient accuracy for industrial photovoltaic cells. 


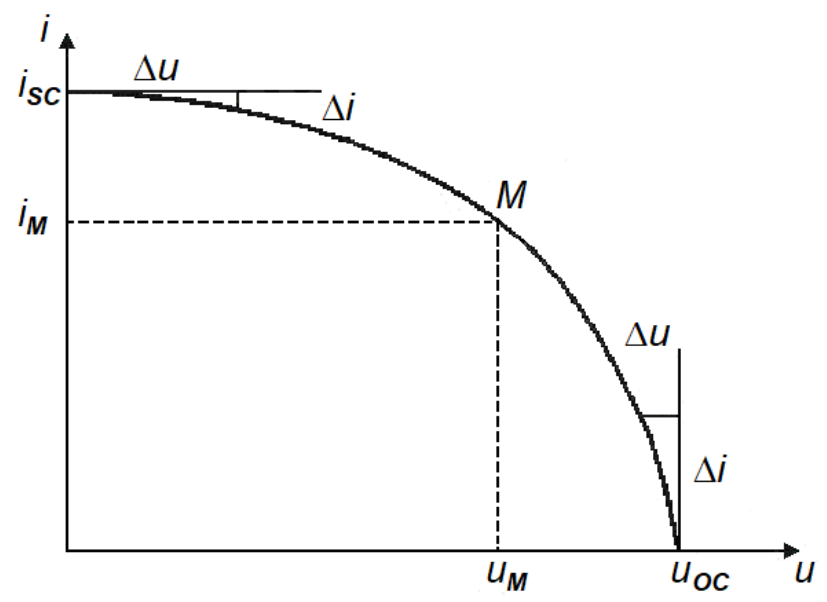

Figure A.3. Determination of PV-cell parameters using the angles of inclination of its CVC to the coordinate axes.

The value of parameter $A$ is determined from the extremum condition of the function $P=i \cdot u$ :

$$
A=\frac{e}{k T} \frac{u_{M}-i_{M} r_{s}\left(i_{S C}+i_{0}-i_{m}-u_{M} / r_{s h}\right)}{i_{m}-u_{M} / r_{s h}} .
$$

Using (A.6), specify the given parameter and according to formulas (A.4) calculate again all the parameters of photovoltaic cells. This algorithm is performed cyclically until the parameter $A$ is determined with a given accuracy.

Using expressions (A.2) and (A.3), determine the filling factor of the load characteristic and the efficiency of the photovoltaic cell.

There can be the possibility of experimental difficulties in the study of the CVC of high-efficient PV-cell to determine the value of the parameter $A$. In high-efficiency photovoltaic cells, the CVC near the point of the short-circuit current is close to a straight, parallel voltage axis.

Therefore, it is often practically impossible to determine experimentally the $\mathrm{CVC}$ angle to the voltage axis near the short-circuit current point, i.e. $\alpha \rightarrow \infty$. This circumstance creates some difficulties with the use of the first expression from (A.4) and, as a consequence, other expressions. 
In this regard, we simplify expression (A.4) according to the condition $\alpha \leftarrow \infty$, given that under normal conditions of CVC measurement of photovoltaic cells, the value of $u_{O C}$ is several times higher than $A k T / e$.

As a result, when $\alpha \rightarrow \infty$ and $u_{O C}>>A k T / e$, formulas (3.4) take the following form

$$
r_{s}=|b|-\frac{A k T / e}{i_{S C}} ; r_{s h} \rightarrow \infty ; i_{0}=\frac{i_{S C}}{\gamma} .
$$

Thus, the given theoretical analysis of light CVC of PV-cell shows the possibility of determining the parameters (series and parallel resistances, diode current density and diode coefficient), filling factor and PV-cell efficiency. The limitation of this method is its unsuitability in the study of PV-cells, which have low values of leakage resistance, as well as in the case of high radiation intensity.

\section{A.1.5 Semi-empirical method using the parameters of current-voltage and} power-voltage characteristics

The method described in [71] is one of the simplest engineering methods, which provide almost sufficient accuracy in determining the PV-cell series resistance $r_{s}$.

The basic formula of this method uses separate parameters of CVC and PVC

$$
r_{s}=\frac{u_{O C}}{i_{S C}}-\frac{P_{M}}{f f_{0} \cdot i_{S C}^{2}} .
$$

The value of $f f_{0}$ in formula (3.11) is the reference filling factor. To determine it, use the empirical formula

$$
f f_{0}=\frac{\tilde{u}_{O C}-\ln \left(\tilde{u}_{O C}+0.72\right)}{1+\tilde{u}_{O C}}
$$

where $\tilde{u}_{O C}=\frac{e u_{O C}}{A k T}-$ normalized open-circuit voltage. 


\section{A.2 Specialized equipment for measurements}

The measurement methods discussed above allow to determine the functional parameters of photovoltaic cells with sufficient accuracy. They can provide a direct measurement of the energy characteristics of photovoltaic converters in conditions of natural ground insolation and, thus, can be applied within the framework of the methodology used in Ukraine for measuring and correcting the current-voltage characteristics of crystalline silicon photovoltaic converters [140, 141].

The following section provides information on technical means, namely experimental automated measuring complexes (EAMC), given to implement the above requirements for measuring current-voltage and other characteristics of photovoltaic cells and their various connections.

EAMC $[51,142,143]$ consists of a solar tracking unit (heliostat), a panel with fixed photovoltaic cells, a measuring unit, analogue-to-digital converters, a connection module and PC (type IBM PC) (Fig. A.4).

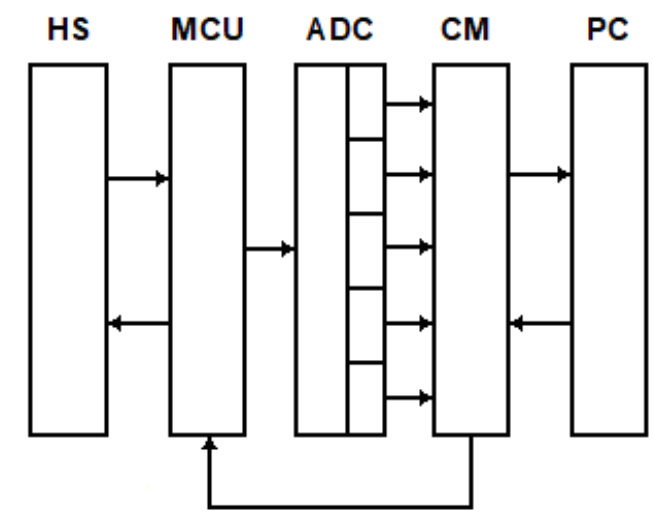

Figure A.4. Block diagram of the experimental automated measuring complex.

There are following designations on diagram: HS - heliostat; MCU - measuring and control unit; ADC - analogue-to-digital converters; CM - connection module; $\mathrm{PC}$ - personal computer.

The measuring part of EAMC functions in a following way: solar cells placed on rotating and stationary platforms are connected to the unit of variable and constant 
loads, as well as to the unit of temperature measurement, through a special connector of the measuring unit.

The operation of the measuring unit is controlled by a PC using a serial 8-byte data line $[144,145]$.

\section{A.3 Program for calculating the parameters of the equivalent electrical circuit of photovoltaic cells}

This subsection presents elements of the structure, user interface and algorithms of a specialized software application designed to process the experimental light current-voltage characteristics of photovoltaic cells of solar arrays and calculate the parameters of their equivalent circuit.

It should be noted that the processing of experimental data in order to obtain information about the studied objects, particularly to obtain information about their physical and technical parameters, is an integral part of any research or development. The solution of this problem is associated with a number of difficulties with the accuracy of calculations, the availability of their alternative algorithms and so on. It seems appropriate to computerize such work in terms of developing a specialized software application. This allows to solve these data processing problems within the concept using different, most effective software packages at each step [146], which was implemented and presented in this section.

\section{A.3.1 Block diagram of the program}

The application is designed to manage a library of application software modules, which are documents of the famous mathematical package Mathcad [67]. The general structure and list of modules is shown in Fig. A.5. 


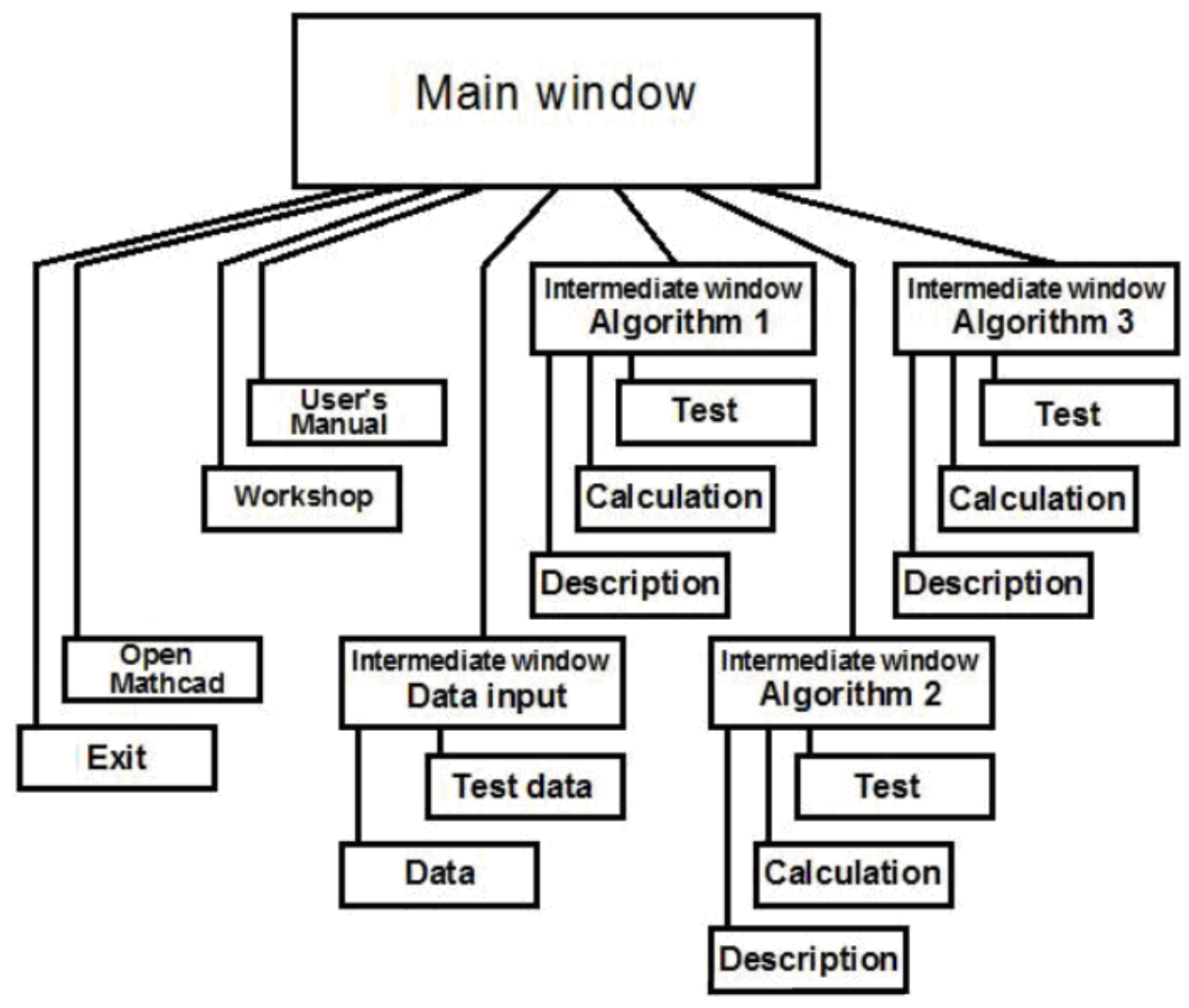

Figure A.5. Block diagram of the program for calculating the parameters of photovoltaic cells of solar arrays.

The library consists of three sections, each of which contain three subsections, corresponding to the solution of the problem of finding the parameters of the equivalent electrical circuit of photovoltaic cells of solar arrays by one of the three methods used here.

The components of the library units (Mathcad documents) are presented in two versions, test and open for changes by the user, and also contain a description file of the corresponding method.

As additional services the possibilities, input of experimental data, a call of a mathematical package of Mathcad and an exit from the program, and also acquaintance with the instruction of the user and an exit to the Internet for reception of additional literature data are provided. 
All sections are interconnected by the main menu of the package, Mathcad-documents are in the appropriate sections.

\section{A.3.2 Design of user interface windows}

The environment that ensures the operation of the described software product is the Windows operating system. Navigation between sections is done using buttons and menus of different levels (main, intermediate and working menus) [147].

The application uses the Package Monitor, which is written using the $\mathrm{C} \#$ language and the project type of the Windows Forms Application platform Visual Studio.Net. Application software modules of the library of computational algorithms, as already mentioned, are documents of the well-known mathematical package Mathcad (version 13). In addition, the application uses universal tools for working with files with extensions xls, docx and pdf.

The general view of the user interface windows of the considered application is presented in Fig. A.6.

The main elements of the main window are buttons with labels that indicate their purpose. Clicking the "Input date" button brings up an intermediate menu, which indicates the layout of the information entered, and allows you to go to the "Excel" program window, which contains data for testing ("Test") or in which to enter experimental data intended for processing ("Data").

The "Algorithm ..." buttons are used to go to the intermediate windows of the same name. Each such window contains a brief description of the algorithm and the menu of the following three items, which initialize the actions according to the block diagram of Fig. A.5:

"Test" - call the window of the Mathcad package with a test example (which does not allow any changes); 


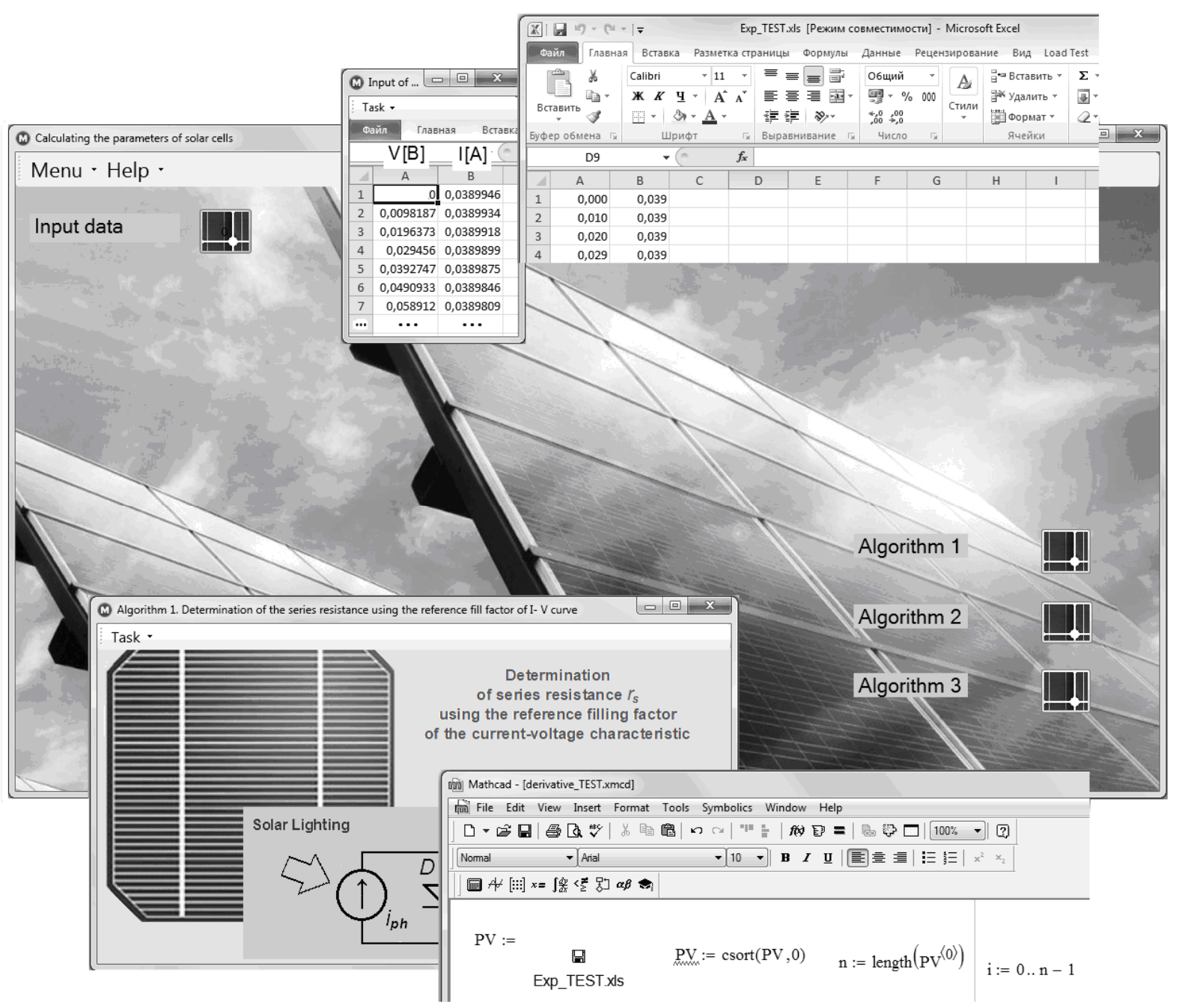

Figure A.6. The main windows of the program.

"Calculation" - call the window of the Mathcad package with a similar file used to process the experimental data downloaded for processing;

"Description" - open a PDF-file with a detailed description of the selected method.

The main window also contains a toolbar with two buttons "Menu" and "Help". The "Menu" button contains two items. When you select the first item "Open Mathcad", Mathcad will be started or you will be asked to select the Mathcad start file by yourself. If to select the second item "Exit", the application will close. The "Help" button also contains a menu of two items. The "User's Manual" item opens a 
document with user instructions. The "Workshop" launches a browser to access the Internet.

It should be noted that before using the described software product on your computer, there must be a standard mathematical package Mathcad, Excel, browser and readers for pdf files. The configuration of the product presented here is reduced to prescribing in its monitor using the Visual Studio environment the appropriate file addresses, which are specific software implementations of the calculation algorithms of its library.

\section{A.3.3 Calculation algorithms}

In the appendix the following calculation algorithms of parameters of photovoltaic cells from its light current-voltage characteristic are used, issued in the form of programs of the Mathcad package (Table A.1):

- determination of series resistance using the reference filling factor of the current-voltage characteristic (Algorithm 1);

- determination of parameters using the angles of the light current-voltage characteristic relative to the coordinate axes (Algorithm 2);

- determination of parameters using individual areas under the light currentvoltage characteristic (Algorithm 3).

Before direct calculations, the experimental light current-voltage characteristics of the photovoltaic cell are introduced, smoothing procedures undergo to eliminate random errors and are interpolated to obtain their analytical form, which is required for the implementation of calculation algorithms. 
Scientific edition

A. S. Tonkoshkur, A. V. Ivanchenko,

L. V. Nakashydze, A. Yu. Lyashkov, I. V. Gomilko

\title{
APPLICATION OF POLYMER POSISTOR NANOCOMPOSITES IN SYSTEMS FOR PROTECTING PHOTOVOLTAIC COMPONENTS OF SOLAR ARRAYS FROM ELECTRICAL OVERLOADS
}

Monograph

\author{
Edited by the authors. \\ Published by Primedia eLaunch \\ https://primediaelaunch.com/ \\ Copyright (C) 2021 by the author \\ All rights reserved.
}

\section{WARNING}

Without limitation, no part of this publication may be reproduced, stored, or introduced in any manner into any system either by mechanical, electronic, handwritten, or other means, without the prior permission of the author.

ISBN - 978-1-63972-054-5

DOI: 10.46299/978-1-63972-054-5 